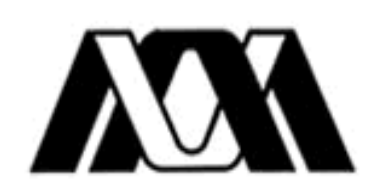

Casa abierta al tiempo

UNIVERSIDAD AUTÓNOMA METROPOLITANA UNIDAD IZTAPALAPA

\title{
Las oraciones subordinadas adverbiales propias de tiempo y lugar en el español de México
}

\author{
TESIS
}

QUE PRESENTA

\section{LAURA JIMÉNEZ NORBERTO}

\author{
PARA OBTENER EL GRADO DE \\ DOCTORA EN HUMANIDADES \\ (LÍNEA DE LINGÜÍSTICA)
}

ASESORA: DRA. MILAGROS ALFONSO VEGA

México D.F., septiembre de 2014 


\section{Índice}

Página

INTRODUCCIÓN

\section{Capítulo I \\ Antecedentes}

$\begin{array}{ll}\text { Introducción } & 11\end{array}$

1. Antecedentes $\quad 12$

1.1 La gramática tradicional 13

1.2 La gramática descriptiva y contemporánea $\quad 19$

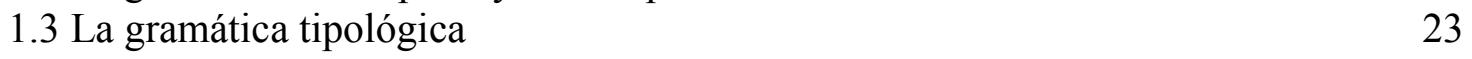

2. Oraciones subordinadas adverbiales propias 26

2.1 Relativas libres u oraciones subordinadas adverbiales $\quad 27$

$\begin{array}{ll}2.1 .1 \mathrm{El} \text { antecedente } & 32\end{array}$

2.1.1.1 Antecedente implícito o expreso 32

3. Argumentos o adjuntos 43

$\begin{array}{ll}\text { 4. Clasificación } & 47\end{array}$

5. Conclusiones $\quad 50$

\section{Capítulo II}

\section{La estructura sintáctica de las oraciones subordinadas adverbiales de tiempo}

Introducción $\quad 51$

1. Estructura sintáctica de las oraciones subordinadas adverbiales 52

1.1. Orden sintáctico $\quad 53$

1.2. Antecedente o doble complemento circunstancial de tiempo 59

$\begin{array}{ll}\text { 1.3. Nexos temporales } & 63\end{array}$

2. Análisis sintáctico de las oraciones subordinadas temporales 68

$\begin{array}{ll}\text { 2.1. Cuando } & 69\end{array}$

2.1.1 Oración principal + oración subordinada 70

2.1.2 Oración subordinada + oración principal $\quad 74$

$\begin{array}{ll}2.1 .3 \text { Oraciones interpoladas } & 77\end{array}$

2.1.4 Oraciones con doble complemento circunstancial de tiempo 78 
2.2. Mientras $\quad 83$

2.2.1 Oración principal + oración subordinada $\quad 84$

2.2.2 Oración subordinada + oración principal 86

$\begin{array}{ll}2.2 .3 \text { Mientras que } & 88\end{array}$

2.3 En tanto que $\quad 90$

2.4 Entre tanto, en cuanto, apenas 92

2.5 Luego que 93

2.6 Tan pronto como 97

2.7 Antes de que $\quad 98$

2.8 Hasta que / desde que 101

$\begin{array}{ll}\text { 3. Conclusiones } & 105\end{array}$

\section{Capítulo III}

\section{La estructura sintáctica de las oraciones subordinadas adverbiales de lugar}

Introducción 106

1. Estructura sintáctica de las oraciones subordinadas adverbiales de lugar 106

1.1. Oraciones subordinadas de relativo, sustantivas y adverbiales de lugar $\quad 107$

1.2. Oraciones subordinadas adverbiales de lugar o relativas libres 114

1.2.1. Preposición + donde 115

1.2.2. Adverbio + donde 121

1.3. Orden sintáctico de las oraciones subordinadas adverbiales de lugar 125

2. Análisis sintáctico de las oraciones subordinadas de lugar 128

2.1. Aquí, allá, acá, + donde 129

2.2. Adonde 133

2.3. En donde 136

2.4. De donde 138

2.5. Hacia donde 140

2.6. Hasta donde 144

2.7. Por donde 147

3. Conclusiones 150 


\section{Capítulo IV}

\section{La concordancia verbal en las cláusulas subordinadas adverbiales de tiempo y lugar}

Introducción

152

1. Preliminares

1.1. La consecutio temporum o concordancia verbal 155

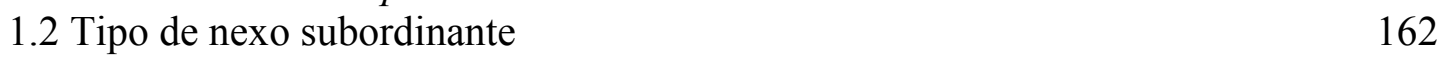

$\begin{array}{ll}1.3 \text { Modo } & 166\end{array}$

2. La concordancia de tiempos en las oraciones subordinadas adverbiales propias: tiempo y lugar

2.1. Oraciones subordinadas adverbiales de tiempo

2.1.1. Cuando

170

2.1.2. Nexos de anterioridad: antes de que

171

2.1.2.1. Hasta que

174

2.1.3. Nexos de simultaneidad: mientras, mientras que, entretanto

175

2.1.4. Nexos de posterioridad: desde que, luego que

177

2.1.4.1. Nexos de posterioridad inmediata: tan pronto como, apenas, en cuanto

185

2.2. Oraciones subordinadas adverbiales de lugar

187

2.2.1. Preposición + donde

189

3. Conclusiones

195

CONCLUSIONES

196

BIBLIOGRAFÍA

200 


\section{INTRODUCCIÓN}

El estudio de las oraciones subordinadas ha sido un tema de gran interés por parte de los lingüistas debido a que su estructura sintáctica presenta interrogantes que han suscitado controversia. Tradicionalmente, las oraciones subordinadas han sido clasificadas en tres grandes grupos: sustantivas, adjetivas y adverbiales, ya que estas desempeñan las mismas funciones que los sustantivos, los adjetivos y los adverbios cumplen dentro de la oración en la que se encuentran. En dicha clasificación predomina un enfoque funcionalista, el cual ha sido cuestionado porque algunos lingüistas consideran que no todas las oraciones subordinadas desempeñan las funciones de los sintagmas que llevan su nombre (Bosque y Rexach 2005). Asimismo, las investigaciones que se han hecho sobre las oraciones subordinadas muestran que las más estudiadas han sido las oraciones sustantivas y las adjetivas o de relativo, pero las oraciones subordinadas adverbiales han sido estudiadas en menor grado. Si bien las tres clases de oraciones subordinadas mencionadas, y que existen en el español, presentan cuestiones importantes que merecen un amplio estudio, este trabajo se centra en el análisis sintáctico las oraciones subordinadas adverbiales por las razones que se esbozan a continuación.

Primeramente, las oraciones subordinadas adverbiales han sido clasificadas en dos grupos: propias e impropias. Las oraciones subordinadas adverbiales propias son aquellas que pueden sustituirse por un adverbio, es decir, las temporales, las locativas y las modales. Las impropias son las que no tienen un adverbio correspondiente, este grupo lo constituyen las finales, causales, concesivas, adversativas, condicionales y comparativas ${ }^{1}$. Cada uno de estos grupos presenta problemas interesantes y distintos, sin embargo, esta investigación está enfocada al análisis sintáctico de las oraciones subordinadas adverbiales propias, específicamente las temporales y las locativas.

Uno de los principales problemas que las oraciones subordinadas adverbiales propias presentan, y del que se derivan otros más, es que poseen una estructura sintáctica

\footnotetext{
${ }^{1}$ Los distintos autores que se citan presentan clasificaciones y nombres diferentes de las oraciones subordinadas adverbiales impropias, mismas que mencionaremos en el Capítulo 1.
} 
que se traslapa con la organización sintáctica de las oraciones subordinadas sustantivas y adjetivas o de relativo. Nos referimos a ejemplos como los siguientes, en los que la oración subordinada está subrayada:

(1) a. Sabemos dónde trabaja (oración subordinada sustantiva).

b. Encontré el lugar donde trabaja (oración subordinada adjetiva o de relativo).

c. Trabaja donde fabrican uniformes y zapatos para militares (oración subordinada adverbial).

Las oraciones citadas en (1) muestran que los pronombres dónde y donde son los que se encargan de enlazar a las subordinadas con la oración principal, lo cual a primera vista podría generar confusiones. En (1)b y en (1)c es el mismo pronombre relativo donde el que une a las oraciones y en (1)a es el pronombre interrogativo y tónico dónde el que las enlaza, pero en los tres casos la subordinada hace alusión a un lugar. No obstante, al analizar cada oración es notable que la función que cumplen con respecto a la oración a la que se subordinan es diferente. En (1)a la subordinada dónde trabaja cumple la función de objeto directo del verbo saber; en (1)b la subordinada donde trabaja cumple la función de adjetivo, ya que está modificando al sustantivo el lugar que la precede; y (1)c la oración subordinada donde fabrican uniformes y zapatos para militares funciona como adjunto de lugar de la oración principal, es decir, desempeña los oficios de un adverbio. De modo que, aunque los pronombres que unen a las subordinadas mencionadas en (1) tienen significados parecidos o expresan ideas semejantes, puede notarse que ni funcionalmente ni estructuralmente se comportan de la misma forma.

De la estructura sintáctica de las oraciones subordinadas adverbiales propias y del traslape que tienen con las otras dos clases de oraciones subordinadas se desprenden otras interrogantes: (1) puesto que las oraciones subordinadas propias de tiempo y lugar y las oraciones de relativo están introducidas por los mismos pronombres relativos adverbiales donde y cuando ¿en qué medida pueden considerase y agruparse junto con las oraciones de relativo con un antecedente callado, es decir, dentro de las "relativas libres", como las consideran algunos lingüistas (Porto Dapena, 1997; Brucart, 1999; Real Academia 
Española, 2009; Pavón, 2012)?; (2) ¿cuál es la manera más adecuada de analizarlas, ya que el enfoque tradicional funcionalista ha sido cuestionado porque no todas las subordinadas adverbiales pueden sustituirse por un adverbio?; y (3) ¿qué problemas adicionales presentan a la estructura sintáctica los nexos o conjunciones subordinantes que las unen con la oración principal, especialmente los nexos o conjunciones de las oraciones adverbiales de tiempo? En este trabajo se dará respuesta a estas interrogantes.

Puesto que el interés principal de esta investigación se centra en el análisis sintáctico de las oraciones subordinadas adverbiales propias de tiempo y lugar, y considerando que las oraciones subordinadas adverbiales temporales se enlazan con una variedad más amplia de nexos o conjunciones que las oraciones subordinadas de lugar, primeramente hicimos una lista de los nexos o conjunciones temporales y locativos más recurrentes en el español de México, tomando como referencia las fuentes bibliográficas consultadas. Con la finalidad de delimitar aún más el tema de investigación, sólo se consideraron los nexos y conjunciones temporales que enlazaran oraciones subordinadas adverbiales con verbos finitos y dejamos de lado aquellos que unen oraciones subordinadas adverbiales con verbos no finitos. Posteriormente hicimos una búsqueda de ejemplos con cada nexo o conjunción en el Corpus en línea de la Real Academia Española y elegimos los más adecuados para ejemplificar los distintos problemas que se abordarán el presente estudio. Si bien la mayoría de los ejemplos fueron tomados del Corpus de Referencia del Español Actual (CREA), también se incluyen oraciones propias o tomadas de otras fuentes.

Cabe señalar que la presente investigación no se apega a algún modelo teórico en particular (gramática generativa, funcionalista, etc.) sino que solo se tomaron los elementos de algunos enfoques que permitieran explicar de una manera más adecuada el fenómeno que se estudiará. Se consideraron algunas propuestas de la gramática generativa, de la descriptiva, de la tipológica y de la gramática tradicional, pero no se utiliza una en especial para el desarrollo de esta investigación, sino que tratamos de presentar $\mathrm{y}$, en los casos en que fuera posible, contraponer, las discusiones teóricas relacionadas con el tema.

Ahora bien, el trabajo está organizado de la siguiente manera. En el capítulo 1 nos ocuparemos de hacer un recuento de lo que las distintas gramáticas han dicho en torno a las 
oraciones subordinadas adverbiales y tomaremos una postura con respecto al modo en que se analizarán en este trabajo. Veremos, además, si la clasificación que se hacía de las oraciones subordinadas, es decir, de acuerdo con las funciones que cumplen dentro de la oración, es la más adecuada o si se han propuesto diferentes formas de agrupar y estudiar las tres clases de subordinación que hay. Asimismo, se discutirán los problemas que han surgido en torno a la subordinación adverbial, los cuales tienen que ver con el traslape que presentan con las oraciones de relativo, particularmente con las relativas libres.

Puesto que uno de los principales problemas que surgen en torno a las oraciones subordinadas adverbiales es su estructura sintáctica, el capítulo 2 está dedicado al análisis de las oraciones subordinadas temporales. Se analizará lo siguiente, (1) el orden sintáctico que tiene la oración subordinada con respecto a la principal; (2) el corpus analizado permitió observar que algunas oraciones temporales tienen una frase prepositiva, adverbial o nominal que las precede, Porto Dapena (1994) plantea la posibilidad de que tales sintagmas se consideren un antecedente, lo cual implicaría que se trata de oraciones de relativo. No obstante, Herrero (2005) estima que las frases mencionadas, que anteceden a la oración adverbial, podrían considerarse otro complemento circunstancial de tiempo, por tanto se discutirán ambas propuestas y se tomará una postura al respecto; y (3) se estudiarán las características que tienen los nexos o conjunciones que unen a las oraciones subordinadas, ya que no todos ellos permiten diferentes órdenes sintácticos en las oraciones adverbiales temporales.

El capítulo 3 tiene como fin analizar las oraciones subordinadas adverbiales de lugar. Esta clase de oraciones es la que presenta un mayor traslape con las oraciones de relativo, ya que ambas están introducidas por el relativo adverbial donde. Otro problema importante relacionado con la estructura sintáctica de esta clase de oraciones es que el relativo adverbial donde puede estar precedido por una preposición, por ejemplo: en donde, por donde, hacia donde, etc. este tipo de estructura ha generado controversia y las gramáticas presentan diferentes análisis al respecto, de modo que en este capítulo se profundizará sobre el tema con el objetivo de tomar una postura en cuanto al modo de analizarlas y clasificarlas. 
Finalmente en el capítulo 4 se estudiará la consecutio temporum, concordancia o correlación de tiempos verbales entre la oración principal y la oración subordinada en las dos clases de oraciones adverbiales que se examinan, lugar y tiempo, y estará basado en las investigaciones de Carrasco (1999) sobre las oraciones subordinadas sustantivas y de Veiga y Mosteiro (2006) sobre las subordinadas adverbiales. Veremos que en las oraciones subordinadas adverbiales propias de lugar y tiempo la correlación de los tiempos verbales está relacionada con el tipo de nexo o conjunción que las introduce y con el modo en que están flexionados los verbos. Se considerarán ambos factores para determinar qué tiempos verbales pueden relacionarse en el español de México en las dos clases de oraciones. 


\section{Capítulo I}

\section{Antecedentes}

Introducción. La subordinación adverbial ha sido un tema controversial dadas las distintas opiniones que se encontraron en la bibliografía. En este sentido, desde la gramática tradicional hasta las más recientes se ha mostrado una discordancia con respecto a los análisis que se han hecho sobre esta clase de oraciones, en el momento de subrayar los problemas fundamentales que presenta esta clase de subordinación. Por tanto, el presente capítulo se ocupa de hacer un recuento de lo que la gramática ha dicho en torno a las oraciones subordinadas adverbiales.

Tradicionalmente se clasificaban las oraciones subordinadas en tres grandes clases: sustantivas, adjetivas y adverbiales ya que estas cumplen los mismos papeles que tales elementos desempeñan dentro de la oración en la que se encuentran, lo cual mostraba un enfoque funcional predominante. Dicha percepción ha sido cuestionada, sin embargo, cabe preguntarse si una clasificación de acuerdo con las funciones de las subordinadas es la más adecuada o si se han presentado formas de agrupar y estudiar las tres clases de subordinación distintas de la que propone la gramática tradicional o más bien aún se considera que este es el más exacto que ha habido.

En el primer apartado, partiremos de lo que ha dicho la gramática tradicional al respecto y seguiremos con lo que han dicho las gramáticas más recientes con el fin de tomar una postura respecto de la subordinación adverbial y justificar el modo en que se analizarán las construcciones en este trabajo. Puesto que el presente estudio estará enfocado en las oraciones subordinadas adverbiales propias de tiempo y lugar, en el segundo apartado, se discutirán los problemas que han surgido en torno a esta clase de subordinación, los cuales tienen que ver con el traslape que presentan con las oraciones de relativo, en particular las relativas libres. Asimismo hablaremos de un elemento que es un tanto controversial, nos referimos al antecedente, mostraremos si es posible que esta clase de oraciones pudiera tener un elemento que las anteceda y cuáles serían sus características. En el tercer apartado, veremos si las oraciones subordinadas adverbiales son argumentales 
o adjuntas y finalmente en la sección cuatro analizaremos las distintas clasificaciones de nexos que introducen a las subordinadas propias y propondremos una agrupación propia.

1. Antecedentes. Al hacer una revisión de las gramáticas tradicionales y contemporáneas, a primera vista se podría concluir que las oraciones subordinadas más estudiadas han sido las sustantivas y las relativas, porque las primeras ocupan una posición argumental y las segundas aluden a un antecedente dentro de la oración en la que se encuentran, sin embargo, la poca información que se encontraron con relación a las subordinadas adverbiales puede obedecer a dos razones: (1) porque se les considera elementos terciarios dentro de una oración (Alcina y Blecua 1980:979), es decir, son elementos adjuntos o bien (2) porque muy recientemente a algunas de estas oraciones se les ha considerado parte de las subordinadas de relativo (Porto Dapena, 1997; Brucart, 1999; Real Academia Española, 2009; Pavón, 2012). Nos referimos específicamente a las adverbiales de tiempo, lugar y modo, ya que las condicionales, concesivas, finales, causales presentan otro tipo de cuestiones que abordaremos brevemente en un apartado posterior.

Con el fin de entender las cuestiones que surgen en torno a esta clase de oraciones, es importante hacer una revisión de lo que se ha dicho sobre ellas, desde la gramática tradicional hasta ahora, y analizar cómo se ha ido modificando el lugar que dichas cláusulas ocupan dentro de la gramática del español. Bosque y Gutiérrez-Rexach (2009:731) atinadamente señalan que la gramática tradicional clasificaba las oraciones subordinadas en función del oficio que cumplieran dentro de la oración en la que se encontraran y por su equivalencia con "los sintagmas encabezados por las clases de palabras básicas". De manera que una oración subordinada sustantiva era aquella que cumplía las funciones de un sustantivo, una oración subordinada adjetiva llevaba a cabo las tareas de un adjetivo, es decir, modificar un nombre, y las subordinadas adverbiales realizaban las oficios propios de los adverbios, modificar un verbo. Bosque y Gutiérrez-Rexach advierten, sin embargo, que esta clasificación no es del todo confiable y que resulta un tanto forzada. Toman dicha postura porque encuentran que en las tres clases de subordinación existen contradicciones. Por ejemplo, subrayan que las subordinadas adjetivas pueden modificar un sustantivo pero no pueden cumplir la función de atributivo. En el caso de las oraciones subordinadas sustantivas, hay algunos verbos como creer y opinar que sólo admiten oraciones 
subordinadas sustantivas, mismas que no pueden sustituirse por un nombre, lo cual implica que no existe una correspondencia entre ellas y dicha clase de palabra.

Con respecto a las oraciones subordinadas adverbiales Bosque y Rexach muestran que también presentan cuestiones importantes. Esta clase de subordinadas se divide en dos clases, las llamadas propias, que guardan un gran parecido con las relativas sin antecedente expreso $^{2}$, y las impropias, que no tienen equivalentes adverbiales. Estos lingüistas explican que solamente las subordinadas adverbiales propias pueden sustituirse por un adverbio, pero las impropias no, lo cual contradice de cierto modo el nombre que se les ha dado: subordinadas adverbiales. Lo expuesto por Bosque y Gutiérrez-Rexach (2009) permite distinguir de manera muy general por lo menos tres cuestiones fundamentales que presentan los oraciones subordinadas adverbiales: (1) que se les consideraba adverbiales por la función que cumplen dentro de la oración en la que se encuentran; (2) no todas las clases de subordinadas adverbiales pueden sustituirse por adverbios y (3) se traslapan con las oraciones subordinadas adjetivas o relativas dado que se introducen por los mismos elementos

A continuación analizaremos las dos primeras cuestiones, veremos, además, lo que han dicho las distintas gramáticas sobre las funciones que cumplen las subordinadas adverbiales y la clasificación que cada autor propone, lo cual está relacionado con la sustitución de tales proposiciones con un sintagma adverbial.

1.1 La gramática tradicional. Atendiendo a los estudios de la gramática tradicional, Seco (1973:121, 122) muestra que los verbos toman diferentes complementos, uno de ellos es el adverbial y las palabras destinadas a esta función son los adverbios o bien un sustantivo "trasladado" que generalmente va precedido por una preposición. Sin embargo, considera que esta función también la puede llevar a cabo una proposición adverbial introducida mediante conjunciones. Distingue quince clases de proposiciones adverbiales:

1. Lugar: Este señor está siempre donde no debe.

2. Tiempo: Iremos cuando nos parezca.

\footnotetext{
${ }^{2}$ En el apartado 2.2 profundizaremos más sobre este tema.
} 
3. Paralelismo: Aprendemos según caminamos.

4. Contraste: Mientras yo no falto nunca, ella viene la mitad de los días.

5. Modo: Hacemos la tarea como podemos.

6. Intensidad: Se ha esforzado cuanto ha podido.

7. Comparación: Tan sorprendido como estás tú estoy yo.

8. Causa: Estamos contentos porque faltan tres días de las vacaciones.

9. Finalidad: Acercaos para que os vean los abuelos.

10. Consecuencia: Hizo un esfuerzo tan grande que cayó agotado.

11. Condición: Si el tiempo no lo impide, habrá corrida de toros.

12. Restricción: Aquí, que yo sepa, no ha pasado nada.

13. Concesión: El resultado es bastante dudoso, por mucho que nos esforcemos.

14. Excepción: No hay ninguna novedad, salvo que (o sino que, aparte de que) ha llamado un señor.

15. Adición: Les pagan bien, aparte de que no tienen mejor horario.

A diferencia de otros autores, Seco (1973) añade seis clases más a su agrupación: paralelismo, contraste, intensidad, restricción, excepción y adición. Se puede observar que este autor clasifica las oraciones subordinadas de acuerdo con la función que cumplen dentro de la oración en la que se encuentran, pero también considera que esta función la puede llevar a cabo un sustantivo precedido de una preposición, una idea semejante a la que Alarcos Llorach (1999) propone posteriormente.

La definición que Seco (1982) proporciona de las oraciones subordinadas adverbiales es aquella que sustituye a un adverbio de la oración principal o modifica al verbo de la oración principal del mismo modo en que lo haría un adverbio. Divide esta clase de oraciones en tres grupos, el primero incluye las oraciones de naturaleza circunstancial, es decir "las que expresan las tres relaciones fundamentales de espacio, tiempo y modo en la oración principal" (Seco 1982). Otro grupo engloba las oraciones que expresan relaciones cuantitativas y abarca las oraciones comparativas y consecutivas. El tercer grupo lo componen las oraciones condicionales y las concesivas. 
Con relación a las oraciones adverbiales que expresan el lugar, el tiempo y el espacio de la oración principal, Seco (1982) subraya dos aspectos importantes, (1) cuando tales relaciones son tan complicadas que no pueden emitirse por un adverbio morfológico, se utiliza una oración subordinada adverbial para expresarlas y (2) estructuralmente las subordinadas adverbiales de tiempo, modo y espacio poseen una ordenación uniforme, generalmente están introducidas por los adverbios relativos cuando, como y donde respectivamente, sin embargo, aclara que las oraciones no siempre se ajustan a los modelos esquemáticos propuestos estrictamente. Este autor también considera que las oraciones subordinadas adverbiales cumplen la función de un adverbio pero a diferencia de Seco (1973), separa las oraciones subordinadas por clases. Propone, además, que la estructura de las subordinadas adverbiales es diversa, lo cual es fundamental ya que los datos que se han analizado hasta ahora comprueban que la estructura de las subordinadas adverbiales es diversa y que no es invariable como se esperaría.

De igual forma Roca Pons (1970:389-392) señala que la clasificación de las oraciones subordinadas en general es problemática. Este autor dice que tradicionalmente hay tres tipos de proposiciones subordinadas: las sustantivas, las adjetivas y las adverbiales, a continuación, citamos ejemplos de Roca Pons marcados con cursivas:

1) El que tú lo digas no es suficiente. (sustantiva con función de sujeto)

2) Los alumnos que estaban atentos entendieron la explicación. (adjetiva)

3) Viviré donde tú quieras. (adverbial)

Considera que las oraciones sustantivas cumplen la función de sustantivo dentro de la oración, ya sea de sujeto o complemento directo, pero también pueden cumplir la función de complemento circunstancial, por lo que las ha clasificado como adverbiales. Las adjetivas suelen identificarse con las oraciones de relativo. La idea que da Roca Pons en relación con las oraciones subordinadas sustantivas que pueden cumplir las funciones de complemento circunstancial, muestra que la frontera que divide a unas oraciones de otras era, y quizás sigue siendo, muy imprecisa por lo cual consideraban que las oraciones subordinadas podían pasar de una clase a otra de acuerdo con las funciones que cumplían dentro de la oración. Porto Dapena (1997) explica que este tipo de análisis generaba 
confusión y de allí surgen los problemas de traslape que tienen las subordinadas, lo cual destaca la importancia que tenía hacer un estudio más adecuado sobre el comportamiento de cada clase de oración subordinada.

Asimismo, Roca Pons (1970:389-392) vislumbraba que el paralelismo que existe entre las oraciones adverbiales y los adverbios es incompleto, en el sentido de que no siempre es posible compararlas con las diferentes clases de adverbios, es decir, una oración subordinada no puede sustituirse por un adverbio en todos los casos. Por tanto, la posibilidad de sustitución sólo es factible con las oraciones adverbiales de tiempo, modo y lugar, pero no lo es para las oraciones concesivas, condicionales, finales y causales. Para Roca Pons las proposiciones adverbiales presentan otros problemas importantes, cita el siguiente ejemplo: Me quedaré allí donde pueda trabajar, en la que se presenta un adverbio como palabra individual, pero también hay una oración subordinada. O bien muestra que hay oraciones en las que el mismo adverbio necesita de un complemento: Trabajó tanto como pudo. Se advierte que este autor percibe dos de los problemas que tanto se han debatido sobre las oraciones subordinadas adverbiales, que ya se mencionaron antes: no todas las subordinadas adverbiales pueden sustituirse por un adverbio y su estructura sintáctica está en función del papel que cumple dentro de la oración principal. A este respecto se ha planteado si la oración adyacente a un adverbio puede considerarse adverbial o es más bien una sustantiva adverbializada (Porto Dapena, 1997) o quizás pudiera considerársele como una oración adverbial que puede modificar a otro adverbio, atendiendo a que dichas proposiciones cumplen las funciones de cualquier adverbio, sin embargo, dejaremos esta cuestión por el momento, puesto que se ahondará más al respecto en los capítulos siguientes.

Siguiendo con lo que propone Roca Pons, este lingüista distingue dos grupos de oraciones adverbiales:

a) las proposiciones que pueden compararse con adverbios porque expresan las mismas ideas.

b) las proposiciones que no se hallan en esta circunstancia. 
De acuerdo con la clasificación que proporciona, considera que la denominación de oraciones adverbiales aplica más al primer grupo que al segundo, dadas sus características. Roca Pons divide las oraciones del primer grupo en tres clases, a saber, local, temporal, modal; y separa a las del segundo grupo en seis clases: comparativas, finales, causales, consecutivas, concesivas y condicionales.

Por su parte Gili Gaya (1961) menciona que las oraciones subordinadas adverbiales cumplen el mismo papel que corresponde a un adverbio, por lo tanto pueden modificar cualitativa o cuantitativamente a la principal. Indica, además, que la función modificadora del verbo puede expresarse por medio de un adverbio, una frase adverbial, por un complemento circunstancial o bien por una oración subordinada si la modificación es muy compleja. Advierte este autor que las oraciones subordinadas adverbiales a menudo se confunden con las oraciones subordinadas sustantivas que cumplen la función de complemento circunstancial del verbo tal como indica Roca Pons (1970). Sin embargo, la diferencia que Gili Gaya (1961) expone es que las oraciones subordinadas adverbiales no afectan sólo al verbo, sino a toda la oración principal.

La clasificación que este autor presenta está basada en la que Seco (1982) elaboró en su Manual de gramática española:

a) Oraciones de carácter circunstancial: las que expresan las tres relaciones fundamentales de espacio, tiempo y modo.

b) Oraciones subordinadas que expresan relaciones cuantitativas y corresponden a los adverbios de cantidad y de comparación.

c) Oraciones de relación causativa. Van unidas a la principal por medio de conjunciones y frases conjuntivas.

Por otro lado, Alcina y Blecua (1980:979) también hacen alusión a las tres clases de oraciones subordinadas en español, señalan que "las oraciones subordinadas, siguiendo el criterio formal adoptado en su definición, eran clasificadas en sustantivas, adjetivas, y adverbiales, nombres tomados de la Morfología, pero hay que entender funcionalmente como recubriendo elemento en función primaria (sustantiva), secundaria (adjetivas) o terciaria (adverbiales)". Estos autores distinguen tres clases de oraciones subordinadas 
adverbiales (Alcina y Blecua 1980:1058, 1128): modales introducidas por como, comparativas, condicionales introducidas por si.

Como se muestra, la clasificación que Alcina y Blecua hacen de esta clase de oraciones es somera, quizás por la razón que ellos mismos exponen en el sentido de que las oraciones adverbiales son elementos terciarios o adjuntos, sin embargo, dedican una gran parte de su análisis de oraciones subordinadas a las sustantivas y relativas introducidas por diversos conectores por ser elementos primarios y secundarios. Al igual que Alcina y Blecua, Bello (1870) no hace una clasificación amplia de esta clase de oraciones.

Alarcos Llorach (1999: 354, 355) concuerda con la definición que los autores antes mencionados han expuesto, las oraciones adverbiales cumplen las funciones propias de un adverbio, es decir, las de complemento circunstancial, modificador o adyacente oracional. Este lingüista clasifica las oraciones subordinadas adverbiales junto con las sustantivas que cumplen las funciones de circunstancial considerando esencialmente las características sintácticas internas de estas últimas, idea que comparte con Roca Pons (1970), Gili Gaya (1961) y Seco (1982). Desde este punto de vista distingue seis clases. No obstante, atendiendo sus rasgos semánticos, las agrupa en oraciones temporales, locativas, modales, causales, finales, concesivas y condicionales. Señala que las oraciones comparativas y consecutivas no deben incluirse dentro de esta clasificación, de modo que las coloca en una clase diferente.

Ahora bien, considerando las características semánticas de estas cláusulas, Alarcos Llorach (1999: 357-364) distingue dos clases dentro de esta agrupación, las propias y las impropias. Las propias son las que pueden sustituirse por un adverbio. En este grupo se encuentran las temporales, locativas y las modales. Los siguientes ejemplos tomados de Alarcos Llorach (1999) ilustran esta clase de oraciones y la forma en que se sustituyen por un adverbio:

1)
a. Yo lo hice cuando me avisaste.
a'. Yo lo hice entonces.
b. Puso el cuadro donde había más luz.
b'. Puso el cuadro allí.
c. Tratadlo como se merece.
c'. Tratadlo así. 
Las impropias son las que no tienen sustituto adverbial y en esta agrupación se encuentran las oraciones causales, finales, concesivas, y condicionales. Sin embargo, Alarcos Llorach (1999) encuentra una solución a la falta de sustitutos adverbiales para las oraciones con sentido causal, final, concesivo y condicional. Menciona que hay grupos nominales en función adverbial que pueden sustituirlas. He aquí algunos ejemplos que proporciona:

2)
a. Lo haré porque me conviene.
a'. Lo haré por mi conveniencia.
b. Me voy para que se tranquilicen.
b'. Me voy para su tranquilidad.
c. Si tuviera éxito, me alegraría.
c'. En caso de éxito, me alegraría.
d. Aunque esté cansado, no debe cejar.
d'. Con todo su cansancio, no debe
cejar.

Dicha sustitución corrobora que no todas las oraciones adverbiales tienen un adverbio que pueda suplirlas.

La clasificación y descripción que los autores citados hicieron sobre las oraciones subordinadas adverbiales muestran que como indicaron Bosque y Gutiérrez-Rexach (2009:731) la gramática tradicional clasificaba las oraciones subordinadas adverbiales en función del papel que cumplieran dentro de la oración, se pudo notar, además, que los autores citados distinguían los problemas que presentaba la subordinación adverbial y señalaban además, las posibles soluciones a dichas dificultades. Algunas de estos puntos se han ido resolviendo, pero a pesar de que ello, aún prevalecen algunas cuestiones en las gramáticas más recientes como se verá en el apartado siguiente.

1.2 La gramática contemporánea o descriptiva. Tomando como punto de partida lo que expone la gramática tradicional en relación a las oraciones subordinadas adverbiales Munguía y Rocha (1999) definen la subordinación adverbial como oraciones que cumplen las funciones propias de un adverbio, por lo cual, también las llaman circunstanciales. Establecen que tales construcciones expresan los diferentes tipos de condiciones o circunstancias en las que se realiza la acción principal del verbo. Su clasificación parte del tipo de circunstancia que expresan. Estas autoras distinguen nueve clases: locativas 
temporales, modales, comparativas, consecutivas, causales, finales, condicionales y concesivas. Citamos ejemplos de estas autoras en (3):

3)

a. Te espero donde ya sabes. (Locativa)

b. Apenas amaneció, don Pablo fue a revisar las caballerizas. (Temporal)

c. Lloraba como si lo fueran a matar. (Modal)

d. Mi ración es menor que la tuya. (Comparativa)

e. La propuesta de la empresa le provocó desconfianza, por lo tanto, a última hora no firmó el contrato. (Consecutiva)

f. Si no tiene dinero, no podrá pagar la multa. (Condicional)

g. No juegues conmigo porque yo siempre gano. (Causal)

h. Fue a Canadá para participar en el congreso sobre teoría literaria. (Final)

i. Aunque se lo juré varias veces, no me lo creyó. (Concesiva)

Ahora bien, Di Tullio (2005:231) advierte que así como los adverbios constituyen uno de los "flancos más débiles de la gramática tradicional” por su carácter diverso en el aspecto semántico, las cláusulas adverbiales también presentan algunas cuestiones por su estructura y por las categorías semánticas que están involucradas. Indica que a diferencia de las oraciones sustantivas y relativas, las adverbiales tienen una relación más laxa con la "superordinada". Al igual que los autores citados anteriormente han mencionado, Di Tullio establece que las oraciones sustantivas son argumentales y las relativas modifican a un antecedente. Esta autora indica que algunas adverbiales son requeridas por los propios verbos, por ejemplo, las locativas. Además, recalca que por lo general se caracterizan negativamente, es decir, no son argumentales ni están todas incluidas como modificadores de un antecedente, funcionan como adjuntos en alguno de los niveles (del verbo, del predicado o de toda la cláusula). La clasificación que ella hace es de tres clases:

1. adverbiales propias: son las que pueden sustituirse por un adverbio de la misma clase semántica. 
2. adverbiales impropias: funcionan como adjuntos de un verbo, aunque es más frecuente que modifiquen a toda la cláusula, ya sea a nivel de adjunto extraclausular ya como disyunto o modificador de modalidad.

3. las comparativas y consecutivas: estas cláusulas funcionan como complemento de un elemento cuantificativo, es decir de una categoría léxica.

Al igual que la gramática tradicional, el panorama de las oraciones subordinadas sigue siendo el mismo, cumplen las funciones de un adverbio y no todas las clases pueden sustituirse por dicha clase de palabra. Se aprecia que estos autores distinguen dos clases de subordinadas principalmente: las propias y las impropias.

Rodríguez Ramalle (2005) sitúa las cláusulas adverbiales dentro de los complementos y modificadores del verbo. Refiere que tradicionalmente se consideraba que los adverbios y las construcciones vinculadas con ellos modificaban al verbo, no obstante, muestra que hay adverbios y oraciones adverbiales que modifican a toda la oración. Distingue dos clases de oraciones adverbiales, las que modifican al verbo solamente y las que modifican a toda la oración. A diferencia de las gramáticas que se han comentado hasta ahora, esta autora sólo se refiere a las oraciones subordinadas adverbiales condicionales, causales, concesivas y modales, que según señala se consideran adverbiales a pesar de que no equivalen a ningún tipo de adverbio o SSPP puesto que no pueden conmutarse por estas categorías. Esta autora deja fuera de su estudio las subordinadas de tiempo y lugar, es decir las denominadas oraciones subordinadas adverbiales propias porque considera que son oraciones de relativo tal como Brucart (1999) y Pavón (2012) señalan en sus investigaciones, no obstante, esta lingüista no proporciona ningún ejemplo del comportamiento de tales oraciones como relativas libres. Su análisis se centra en las adverbiales impropias antes mencionadas, condicionales, finales y causales, exceptuando a las modales que otros lingüistas han agrupado dentro de las propias.

Si bien esta autora no considera en su análisis las oraciones subordinadas que estudiaremos en este trabajo, los aportes que proporciona al estudio de las oraciones compuestas que examina pueden aplicarse a todas las clases de oraciones adverbiales puesto que, como reconoce, las oraciones compuestas "han sido objeto de diversos 
estudios, aunque por lo general no se les ha prestado la atención que merecen hasta hace muy poco tiempo" (Rodríguez Ramalle 2005: 285). Hace alusión en particular a las subordinadas que afectan a la cláusula en su totalidad "debido a que son externas a la relación predicativa nuclear, se las ha denominado normalmente adverbiales periféricas o de la enunciación frente a las modificadoras del SV o nucleares" (Rodríguez Ramalle 2005:285).

Para la RAE (2009) la clasificación de las oraciones subordinadas está basada en un criterio funcional, lo cual contrasta con la clasificación categorial de los grupos sintácticos, nominal, adjetival, adverbial. La clasificación de las oraciones subordinadas que la RAE (2009) menciona está basada en la tradición gramatical, es decir en tres clases: sustantivas, adjetivas o de relativo y adverbiales o circunstanciales.

Dicha gramática denomina las oraciones subordinadas sustantivas como argumentales ya que constituyen argumentos de algún predicado. Señala, además, que puede haber algunas excepciones con respecto a las oraciones de relativo. Considera esta gramática que el grupo más polémico lo componen las oraciones subordinadas adverbiales, hasta el punto de que son raras las gramáticas que las consideran como unidades de análisis sintáctico. Incluso en dicha obra se usa el término oración subordinada adverbial de manera muy restringida (RAE 2009: 76, 1.13p). Asimismo distingue los principales problemas que tradicionalmente la subordinación adverbial presenta:

1. El paralelismo con los adverbios en los que se basa es inexacto y puede estar forzado.

2. La clase de las adverbiales da lugar a cruces, solapamientos o traslapes con otras clases de oraciones.

3. Está relacionado con la estructura de este tipo de oraciones

Con respecto al punto uno, la RAE (2007:3293) señala que no todas las subordinadas adverbiales pueden sustituirse por un adverbio, únicamente las subordinadas de tiempo, lugar y modo tienen un adverbio correspondiente, pero las causales, finales, concesivas y finales no lo tienen. El segundo punto tiene que ver con el traslape que las oraciones subordinadas adverbiales propias, tiempo, lugar y modo, tienen con las oraciones 
subordinadas relativas, ya que se introducen por los mismos pronombres relativos adverbiales, cuando, donde y como. Considera esta gramática que las oraciones subordinadas adverbiales propias tradicionalmente se agruparon como subordinadas adverbiales, lo cual mostraba el problema de delimitación que había entre estas dos clases. Pero considera que las subordinadas adverbiales propias deben clasificarse como relativas libres y no como parte de las oraciones subordinadas adverbiales (RAE 2010:418) porque sostiene que al igual que las oraciones de relativo, las oraciones subordinadas propias tienen un antecedente que las precede, pero a diferencia de las relativas, el antecedente de esta clase de subordinadas es callado. Y finalmente, el punto tres está relacionado con la estructura sintáctica de las oraciones subordinadas adverbiales, la cual, como veremos en los capítulos dos y tres, es diversa.

A continuación veremos lo que la gramática tipológica ha dicho sobre la subordinación adverbial.

1.3 La gramática tipológica. Desde el panorama de la gramática tipológica Thompson y Longacre (2007) muestran que así como un adverbio, que es una palabra individual, puede modificar un verbo, las oraciones adverbiales pueden etiquetarse y categorizarse del mismo modo para cumplir las mismas funciones de un adverbio. Las lenguas tienen mecanismos para que una oración modifique a la otra, igual que un adverbio modifica una proposición.

Para Thompson y Longacre (2007) la relación de la oración subordinada y la principal es un continuo, y dentro de este continuo, las subordinadas son cláusulas que dependen de otra cláusula o de algún elemento de la misma. Consideran tres clases de subordinadas:

i. Las que funcionan como una frase nominal. A estas se les llama complementantes.

ii. Las que funcionan como modificadores de sustantivos, llamadas cláusulas relativas.

iii. Las que modifican una frase verbal o a la cláusula completa, estas son las cláusulas adverbiales.

Thompson y Longacre (2007) señalan que las cláusulas complementantes y las relativas tienen una estructura incrustada a la subordinada, ya sea porque están dentro de 
otra o porque están dentro de una frase nominal. Pero las adverbiales están en combinación con la cláusula principal, es decir están relacionadas con la cláusula principal en su totalidad. Incluso considera que las adverbiales son menos dependientes que las otras dos clases de oraciones subordinadas. Estos lingüistas muestran que las lenguas emplean distintos instrumentos para formar una oración subordinada:

1) Mediante morfemas subordinantes:

a. morfemas gramaticales sin significado léxico

b. morfemas gramaticales con contenido léxico

2) Por medio de formas verbales especiales

3) Por orden de palabras

Asimismo distinguen dos clases de cláusulas adverbiales al igual que la gramática tradicional:

A. Las que pueden sustituirse por un adverbio. Aquí se encuentran las de tiempo, lugar y modo.

B. Las que no tienen un adverbio que las sustituya. Aquí incluyen las de propósito, razón, circunstancia, simultaneidad, condicionales, concesivas, sustitutivas, aditivas y absolutivas.

Estos autores hacen una exploración somera de la primera clase y al igual que la gramática tradicional le dedican mayor parte de su análisis a las cláusulas que no tienen adverbio como sustituto.

Si bien consideran que una cláusula puede sustituirse por un adverbio, no sugieren que las cláusulas adverbiales ocurran en el mismo lugar que un adverbio y viceversa. Más bien indican que la relación semántica que existe entre una cláusula adverbial y la cláusula principal es la misma que hay entre un adverbio y la cláusula principal. Esto implica que una cláusula completa o un solo adverbio pueden expresar la relación de tiempo, lugar y modo. Al igual que la gramática tradicional señala, indican que las cláusulas adverbiales tienden a traslaparse con las cláusulas relativas ya que poseen características similares. Sin embargo, tales semejanzas sólo ocurren con las subordinadas adverbiales que se pueden 
sustituir por un adverbio, a saber, tiempo, lugar y modo, pero con las que indican causa, razón o condición no existe dicho traslape.

Diessel (2001) define las cláusulas adverbiales como aquellas que comprenden una amplia variedad de construcciones. Distingue dos grandes clases: (1) las finitas y (2) las no finitas (por ejemplo, los participios e infinitivos; y algunos tipos de cláusulas nominalizadas). Señala, además, que las cláusulas adverbiales deben diferenciarse de los otros dos grupos de subordinadas, y también de las coordinadas, puesto que las características de las oraciones complejas adverbiales son distintas de las subordinadas sustantivas y las adjetivas. Considera que las cláusulas subordinadas adverbiales son adjuntos ya que funcionan como adverbios o modificadores oracionales, por tanto, se trata de elementos no obligatorios que pueden omitirse siempre, no obstante, siguiendo a Bosque y Gutiérrez-Rexach (2009) al igual que ocurre con los complementos circunstanciales, no en todos los casos puede haber dicha omisión, por tanto puede haber casos en los que aun las oraciones subordinadas no puedan omitirse. Otra diferencia que las distingue de las otras dos clases es que las adverbiales se introducen por nexos adverbiales los cuales indican la relación semántica entre la cláusula principal y la subordinada, además que pueden modificar a la cláusula asociada o sólo a la frase verbal.

Atendiendo a lo que se ha dicho con relación a las oraciones subordinadas adverbiales, todos los autores que se mencionaron coinciden en que las oraciones subordinadas cumplen las funciones propias de un adverbio, sin embargo, la idea que transmite una oración subordinada no siempre es comparable con la que comunica un adverbio. Concuerdan en que se dividen en dos clases a saber, las que se pueden sustituir por un adverbio y las que no se pueden sustituir por este elemento. Coinciden en que presentan problemas importantes de estructura sintáctica (Roca Pons 1970), de traslape con otra oraciones (Alarcos Llorach, 1999; RAE 2009), y que son elementos adjuntos no argumentales (Alcina y Blecua, 1980; Di Tullio, 2005; Dissel, 2001).

El interés por estudiar esta clase de oraciones, particularmente las subordinadas adverbiales propias, se basa en todas estas notables aportaciones. Consideramos que el análisis tradicional, es decir, desde una perspectiva funcional, ha sido el que más 
predomina. Si bien reconozco que presenta algunos problemas, creo que es el más adecuado ya que consideramos que las funciones de las oraciones subordinadas, no sólo en las adverbiales, sino en los tres tipos, determinan a qué clase pertenecen.

2. Oraciones subordinadas adverbiales propias Al estudiar la subordinación adverbial se encontraron distintas interrogantes que requieren de estudio. Si bien todas las oraciones subordinadas adverbiales son merecedoras de análisis, este trabajo se centra en la primera clase en la que se dividen, a saber, oraciones subordinadas propias; que a su vez se agrupan en tres clases: tiempo, lugar y modo, y que además, pueden sustituirse por una frase adverbial. No obstante, solamente estudiaremos dos clases, las temporales y locativas.

Se mencionó en los apartados anteriores que no todas las oraciones subordinadas pueden sustituirse por un adverbio, lo cual contradice de cierto modo el nombre que llevan, específicamente la clase de las impropias que como vimos no tienen una correspondencia con un sintagma adverbial, ya que el español no cuenta con adverbios que cubran los aspectos semánticos de tales oraciones, es decir, no existen adverbios causales, concesivos, finales, condicionales, etc., a pesar de ello cumplen la función de subordinación adverbial o circunstancial como su nombre lo indica ${ }^{3}$. Por otro lado, las oraciones que pueden suplirse por sintagmas adverbiales, es decir las subordinadas propias, presentan cuestiones interesantes en que queremos abordar, si bien cumplen la función de ser adverbiales de tiempo, lugar y modo, también presentan un problema que ha sido controversial durante varios años. Nos referimos al traslape que tienen con las oraciones subordinadas adjetivas o de relativo, incluso dicho problema ha llevado a que varios lingüistas (Pavón, 2012; Porto Dapena, 1997; RAE, 2009) ya no las analicen como subordinadas adverbiales, más bien, las colocan dentro de las relativas ya que están introducidas por adverbios relativos, incluso se les ha etiquetado con el nombre de "relativas libres", calificativo que designa a las oraciones de relativo sin antecedente.

\footnotetext{
${ }^{3}$ La clase de las oraciones subordinadas impropias también presentan interrogantes importantes que merecen atención. El problema principal que presentan es que no pueden sustituirse por un adverbio. También se ha dicho que esta clase de oraciones no está meramente subordinada a la oración principal, por ejemplo algunos consideran que no son subordinadas sino que son aposiciones (Herrero, 2005). Otros autores consideran que hay dos clases de subordinadas impropias, las que son nucleares y modifican al sintagma verbal y las que son periféricas o de la enunciación (Rodríguez Ramalle 2005:285)
} 
Aunque aparentemente las oraciones subordinadas de tiempo, modo y lugar poseen rasgos en común con las relativas libres, como explicaremos a lo largo de esta sección, es claro que en el aspecto funcional y semántico son diferentes, de manera que en los apartados siguientes explicaremos por qué las oraciones subordinadas adverbiales han sido clasificadas dentro de las oraciones subordinadas de relativo, o más específicamente como relativas libres; se discutirá lo que han dicho diferentes autores al respecto y se justificará la postura que se tomará durante todo el trabajo. También se discutirá que se les considere elementos adjuntos aunque dicha postura también presenta pequeñas dificultades, dado que hay algunos circunstanciales que pueden considerarse argumentales en la medida que los verbos lo requieran, según lo plantean Bosque y Gutiérrez-Rexach (2009). Finalmente, analizaremos las distintas clasificaciones que se han hecho y propondremos una agrupación propia.

2.1 Relativas libres u oraciones subordinadas adverbiales. La principal razón por la que las oraciones subordinadas adverbiales de tiempo, lugar y modo son consideradas parte de las relativas es porque están introducidas por los adverbios relativos cuando, donde y como, mismos que introducen a las oraciones subordinadas de relativo o adjetivas. No obstante, la estructura sintáctica de ambas clases de oraciones es distinta, por tal motivo, consideramos que no pueden agruparse dentro de una misma clase ya que sus funciones sintácticas y semánticas son diferentes. Para empezar daremos una breve descripción de las oraciones subordinadas de relativo, mencionaremos por qué algunos autores han propuesto que estas dos clases de oraciones deben agruparse juntas y posteriormente explicaré por qué consideramos que las oraciones subordinadas adverbiales deben clasificarse como un tipo distinto de las oraciones de relativo.

La definición que las diferentes gramáticas proporcionan sobre las oraciones de relativo es aquellas que están introducidas por un pronombre, un adjetivo, un determinante o un adverbio relativo (Porto Dapena, 1997; Brucart, 1999; RAE, 2009). Entre las funciones que cumplen es que modifican a "un elemento llamado 'antecedente' que puede ser un nombre, un grupo nominal o un sintagma nominal” (Brucart, 1999:397; RAE, 2009:3292). Respecto de su estructura, la principal característica que poseen es que siempre 
están encabezadas por un nexo subordinante, mismo que según Porto Dapena (1997:11) tiene la doble misión de ser, por un lado, integrante de la oración en la que se encuentra y por otro lado, sirve de unión o vínculo con la oración principal. Menciona Brucart (1999:397) que el nexo está ligado anafóricamente al antecedente, de modo, que puede actuar como argumento o adjunto dentro de la oración subordinada. Señala la RAE (2009) que los pronombres que encabezan a esta clase de oraciones son los relativos: que, quien, cuanto; las formas del relativo cual como el cual, la cual, los cuales, las cuales; cuantas, cuantos; o bien cuyo, cuya, cuyos, cuyas; y los adverbios relativos cuando, donde y como. Así pues, considerando los rasgos que las oraciones relativas poseen es notable que comparten con las oraciones subordinadas adverbiales el nexo que las une, sin embargo, la función que cumplen es distinta.

Veamos las siguientes oraciones que ejemplifican el traslape de la subordinación de relativo y la adverbial:

(7) a. Acabo de enviar la carta donde escribí mi desacuerdo.

b. El 19 de septiembre cuando ocurrió el sismo estaba desayunando tranquilamente en casa.

(8) a. Te espero donde quedamos.

b. Llegaron cuando te marchaste

Estas oraciones muestran que los adverbios relativos donde y cuando introducen a las subordinadas relativas de (7) escribí mi desacuerdo, ocurrió el sismo, las cuales están modificando al sintagma nominal que las antecede, la carta y el 19 de septiembre respectivamente ${ }^{4}$. Pero en (8) introducen las oraciones quedamos y te marchaste. En los cuatro casos las oraciones están introducidas por un adverbio relativo, la RAE (2009) advierte que tradicionalmente los relativos donde, cuando y como han planteado problemas de delimitación entre la subordinación adjetiva y la adverbial dado que se introducen por los mismo elementos. Herrero (2005: 178) coincide con esta idea y señala que los nexos básicos de las oraciones adverbiales son los ya mencionados y además los comparten no

\footnotetext{
${ }^{4}$ No es muy común que el relativo adverbial cuando tenga un antecedente, incluso Porto Dapena (1997) menciona que la frase nominal que lo antecede puede ser otro complemento circunstancial y la subordinada sólo está matizando la idea de este.
} 
solo con las subordinadas de relativo sino también con una clase de subordinadas sustantivas. Asimismo, Porto Dapena (1997:14) indica que cuando se habla de oraciones de relativo se suele considerar como tales a aquellas cuyo nexo introductor pertenece al grupo pronominal, "clasificando entonces como subordinadas adverbiales (de lugar, de tiempo o de modo) las que, por el contrario, son introducidas por un adverbio relativo del tipo donde, cuando, como".

La $\operatorname{RAE}(2009: 418 \& 22.5 .1,22.5 .1 \mathrm{a})$ indica que en un momento se pensó que oraciones como las citadas en (8), tradicionalmente eran consideradas subordinadas adverbiales, sobre todo si precedían a la oración principal o si aparecían separadas de ella por una inflexión entonativa, por ejemplo; sin embargo, dicha gramática indica que el análisis mencionado no se considera actualmente así, ya que al examinarlas con más atención se llegó a la conclusión de que se trataba de oraciones de relativo o bien sustantivas. Pavón (2012:23) comparte esta propuesta ya que considera que la oración "La Rotunda tragó completa la ración de presos y los cautivos se quedaron donde estaban” (CREA) es una oración de relativo sin antecedente expreso encabezado por el adverbio donde. Indica esta autora que dadas las diversas estructuras que presentan las subordinadas algunos trabajos gramaticales recientes han abandonado el concepto de subordinación adverbial como denominación de un tipo de construcción sintáctica específica.

Atendiendo a lo que señalan estas fuentes, las oraciones mencionadas en (7) y (8) cumplirían con los requerimientos, por así decirlo, de las subordinadas de relativo, puesto que las cuatro están introducidas por los adverbios relativos donde y cuando respectivamente, y por tanto, se les podría clasificar como oraciones de relativo sin ningún problema. No obstante, las estructuras sintácticas de las oraciones no es idéntica, las oraciones de (7) tienen una frase nominal que las antecede y las oraciones de (8) no la tienen como se ilustra en las oraciones mismas oraciones ahora citadas en (9) y (10). Asimismo las funciones que desempeñan no son las mismas, las oraciones de (9) modifican a la frase nominal que la antecede, es decir su función es de modificador de un nombre y las oraciones de (10) funcionan como modificador del verbo que las rige.

(9) a. Acabo de enviar SN [la carta OSREL [donde escribí mi desacuerdo]]. 
b. SN [El 19 de septiembre osReL [cuando ocurrió el sismo]] estaba desayunando tranquilamente en casa.
a. Te espero OSADV [donde quedamos].
b. Llegaron OSADV [cuando te marchaste].

Otras razones, por las que los límites que dividen a una clase de oraciones con las otras no son claras, son que muchas veces las gramáticas crean confusión al momento de agruparlas, ya que suelen clasificar como subordinadas adverbiales a aquellas oraciones que no lo son en realidad (Porto Dapena 1997:15), por ejemplo la RAE (1973: 537) dice que la oración "Esta es la casa en que nací" expresa el pensamiento por medio de una relativa, pero si la frase "en que" se sustituye por el adverbio relativo donde y se dice "Esta es la casa donde nací" se expresa una oración circunstancial, sin embargo, es notable que la estructura de la oración que se acaba de citar es la correspondiente a una relativa o adjetiva, ya que la subordinada hace alusión al sintagma nominal que es su antecedente. Porto Dapena (1997:15) muestra que el criterio que se seguía para considerar a las oraciones como adverbiales o de relativo no era la función sintáctica que cumplían dentro de la oración, lo cual sería lo esperado, más bien se consideraba el hecho de "que el relativo que se utilizaba perteneciera a la clase de los adverbios, lo que suponía una mezcla de criterios inadmisible". Por tanto, el hecho de que una oración adverbial sea considerada como tal debe basarse principalmente en las funciones sintácticas y semánticas que desempeña dentro de la oración y no en el criterio de qué elemento es el que las une a la oración principal.

Asimismo, Porto Dapena advierte que al igual que ocurre con las oraciones subordinadas adjetivas, el estar introducidas por un relativo no impide bajo un criterio semántico-sintáctico que oraciones como las que se citan en (8) puedan ser clasificables al mismo tiempo como adverbiales de lugar, de tiempo y de modo, "que si bien se trata de oraciones claramente adverbiales pertenecen también, desde otro punto de vista, a la clase de las de relativo" (Porto Dapena 1997:14). Siguendo el planteamiento de este autor, las oraciones subordinadas adverbiales pueden considerarse oraciones de relativo en la medida en que están introducidas por adverbios relativos, pero no porque cumplan las mismas funciones de una oración subordinada adjetiva o de relativo, lo cual marca una clara 
diferencia entre ambas clases. Precisa este autor que decir que una oración adverbial puede ser a la vez adjetiva sugiere una contradicción, pero señala que decir que una oración adverbial puede ser al mismo tiempo relativa es distinto, ya que se diría que se trata de oraciones de relativo adverbial frente a oraciones de relativo adjetivas, pero nunca habrá oraciones adjetivas adverbiales ni adverbiales adjetivas. Esta afirmación aclara y determina que las funciones que ambas clases de oraciones desempeñan es diferente y que las oraciones subordinadas adverbiales pudieran considerarse oraciones de relativo únicamente porque comparten el pronombre relativo adverbial que las une.

Considerando las opiniones que hemos mencionado, las oraciones de (7) y (8) comparten el relativo adverbial introductorio, no obstante, es notable que haya diferencias entre un tipo y otro de oraciones. Las proposiciones de (7) son un claro ejemplo de subordinación de relativo o adjetivas ya que proporcionan información sobre el sintagma nominal que las antecede, pero las oraciones que se muestran en (8) no tienen un elemento que las anteceda y al estar directamente después del verbo rector su función es adverbial o circunstancial.

Pudiera pensarse que a pesar de que ambas clases de oraciones comparten los mismos nexos si una clase tiene un antecedente al cual se refiere y la otra no, esto debería ser una característica más que las distinga y, en consecuencia, se resolvería el problema de manera muy simple, pero no es así. Por un lado, porque se ha planteado que las oraciones subordinadas adverbiales también tienen un antecedente (Gili Gaya 1961; Seco 1983; Porto Dapena 1997; Munguía 1999) y por otro lado, porque algunos lingüistas consideran oraciones como las de (8) son ejemplos de oraciones de relativo libres cuyo antecedente está omitido. Estos últimos sostienen que ambas clases de oraciones tienen un antecedente al cual se refieren (Brucart, 1999; Pavón 2012; RAE, 2009), argumentan que en algunos casos el antecedente no está expresado fónicamente y se trata de una categoría vacía, lo cual, por supuesto, refuerza la idea de que se trata de oraciones de relativo o mejor dicho de una subclase de estas, conocidas como relativas libres, conocidas también como relativas con antecedente implícito (RAE 2009: 3293). Brucart indica que estas proposiciones "se caracterizan por ser el único representante fónico del sintagma nominal en el que se insertan" (Brucart 1999:448, 499). Asimismo Pavón (2012:43) dice que las relativas sin 
antecedente expreso o relativas libres aluden a un antecedente que no está realizado fonéticamente, además, considera que, "estructuralmente, esta clase de oraciones, así como las características de los adverbios relativos que las introducen no son distintas de las que tienen las secuencias en que el relativo tiene un antecedente expreso", sin embargo, consideramos que funcionalmente sí existen notables diferencias.

Siguiendo el concepto de las realtivas libres, las oraciones subordinadas adverbiales mencionadas en (8) deberían tener una categoría vacía antes del adverbio relativo como se muestra a continuación en (11):

a. Te espero ø donde quedamos.

b. Llegaron ø cuando te marchaste.

Dicha categoría ilustra muy bien lo que los autores antes mencionados consideran es la estructura de las relativas libres. Sin embargo, no concordamos con la existencia de dicho elemento, ya que la función que desempeña la subordinada que se encuentra adyacente al verbo en esta clase de contextos sigue siendo distinta de la que cumplen las oraciones de relativo.

Por tal motivo, en el apartado siguiente hablaremos sobre el antecedente, el cual presenta algunas interrogantes como: es necesario que las oraciones subordinadas adverbiales deban tener un antecedente o no, en qué medida el antecedente convierte a esta clase de oraciones en relativas libres, qué función tiene este en la oraciones subordinadas adverbiales, es posible que las oraciones subordinadas no estén modificando precisamente al antecedente.

2.1.1 El antecedente. El principal argumento que se propone para fundamentar que hay un antecedente callado en las oraciones relativas libres es que hay una especie de frase nominal omitida o categoría vacía antes del relativo como se ilustra en las oraciones de (11), sin embargo, hemos recalcado que no concordamos con esta postura. Primeramente explicaremos las propuestas sobre un antecedente callado y posteriomente intentaremos probar que no existe un antecedente y que las frases adverbiales o prepositivas que 
preceden a una oración encabezada por los relativos donde y cuando pueden analizarse como otro complemento circunstancial de lugar o tiempo.

2.1.1.1 Antecedente implícito o expreso. Existen variadas opiniones en relación al antecedente. Para Herrero $(2005: 179,180)$ el antecedente, en las subordinadas que funcionan como adverbiales, es más frecuente en las de lugar que en las de tiempo y modo porque 1) no hay lexemas adecuados que puedan funcionar como antecedente para las oraciones temporales y modales, es decir, aquellos cuyo significado incorpore las notas de tiempo y manera; y 2) cuando aparece el antecedente en estas dos clases de oraciones, se prefiere la modificación a través de oraciones relativas encabezadas por que, por lo que es más frecuente encontrar oraciones con frases como el momento en que que el momento cuando. Sin embargo, al parecer Herrero se refiere al antecedente de las oraciones de relativo, porque cuando aparecen las contrucciones mencionadas la función que tienen las subordinadas no es adverbial sino de relativo o adjetiva, ya que la modificación que hace la subordinada es hacia un sustantivo. A este respecto la RAE (2009:418\&22.5.1, 22.5.1a) explica que el contenido del conector cuando corresponde a la frase "en el momento en que", es decir el relativo adverbial puede ser sustituido por dicha frase y suponemos que según el análisis de dicha grámatica el relativo donde podría sustituirse por la frase "en el lugar en que" como se muestra en las oraciones de (12) en donde hemos puesto ambas oraciones:

a. Te espero en el lugar en que quedamos. /Te espero donde quedamos

b. Llegaron en el momento en que te marchaste. /Llegaron cuando te marchaste

Indica esta gramática que ambas construcciones son equivalentes, lo cual hace suponer que se trata de una especie de distribución complementaria, es decir cuando aparece la frase preposicional que propone la RAE no aparece el adverbio relativo, ya que ambas contienen el mismo significado o quizás uno muy parecido.

Osuna (2005:55) menciona que las interrogantes que surgen en torno al antecedente son muy variadas, sin embargo, expone tres razones fundamentales que se tienen para 
justificar la existencia de un antecedente en las relativas libres, y que consideramos podrían ayudar a esclarecer la creencia de que las subordinadas adverbiales también lo tienen. Señala Osuna que la necesidad de tener un antecedente está motivada por la función propia de la subordinación adjetiva o de relativo, es decir son modificadoras de un sustantivo, por lo que tales oraciones deben tener un sintagma nominal al cual referirse; no obstante, si dicho elemento se omite, la oración ya no tiene a quien modificar y, en consecuencia, ya no son oraciones de relativo sino que se convierten en oraciones subordinadas sustantivas. Lo señalado por Osuna (2005) concuerda con lo que plantea Brucart (1999:449), ya que este último sostiene que oraciones como las que cita en (13), y que hemos marcado con cursivas, son relativas libres:

a. Quien dice eso miente.

b. Decido ignorar a quienes lo insultaban.

c. Donde vive tu hermano es demasiado lejos para ir de vacaciones.

d. Como lo dijo me pareció demasiado brusco.

Si bien las oraciones de (13) están introducidas por un relativo y no tienen un antecedente expreso, la posición que ocupan no es la que atendería el modificador de un sustantivo, más bien es el sitio propio de un nombre. Incluso Brucart (1999:449) plantea dos posibilidades de análisis, la primera es que las oraciones de (13) sean consideradas de relativo y la segunda si deben analizarse en un nivel superior, es decir, como un sintagma nominal, ya que las subordinadas de (13)a, (13)c y (13)d cumplen la función de sujeto de la cláusula completa y la de (13)b de objeto directo del verbo ignorar, es decir ninguna de ellas desempeña el oficio de complemento modificador de un sustantivo sino que están en función de sustantivo.

Ahora bien, Osuna (2005:58) acertadamente señala que "cuando no hay antecedente son los elementos de la construcción verbal que siguen al relativo los que determinan su referencia. En definitiva, entendemos que la función semántica de las construcciones de relativo no dependen del antecedente sino del elemento que sigue al relativo". Si bien Brucart (1999:450) no reconoce esta afirmación abiertamente, considera que las oraciones como las que cita, y que hemos puesto en (14), tienen función circunstancial: 

a. Encontraron pretóleo donde menos lo esperaban.
b. Lo harán cuando puedan.
c. Lo harán como puedan.

Brucart admite que las oficios que las oraciones de (13) y (14) son distintas, no obstante, insiste en que deben analizarse como relativas libres, ya que opina que algunos investigadores las consideran como oraciones de naturaleza adverbial, pero señala que tal análisis no es apropiado dado que las oraciones que repasamos en (13) no cumplen la misma función que las de (14). Considera que las oraciones de (13), al estar introducidas por un relativo adverbial son relativas libres, pero desempeñan el oficio de sujeto de la oración principal en la que se encuentran, lo cual toma como prueba de que tanto las oraciones de (13) como las de (14) son oraciones con antecedente implícito, pero al mismo tiempo recalca que no debe confundirse la función que cumplen dentro de la cláusula en que se encuentran, es decir, son relativas libres pero con funciones distintas. Osuna (2005: 59) opina que en una oración como la de (14)a “el relativo donde no necesita ningún elemento que identifique la entidad mencionada, sino son los mismos elementos de la contrucción verbal que le siguen” los que realizan dicha tarea, y recalca que es la función semántica lo que determina qué clase de función cumple dentro de la oración.

En el corpus que analicé se encontraron variados ejemplos en los que hay una frase que antecede a las oraciones que están introducidas por los relativos adverbiales cuando y donde, como se muestra en los ejemplos siguientes:

a. Comenzó a eliminar los subsidios a mediados de los años 90, cuando vendió 19 ingenios en 142 millones. (CREA)

b. No es mi culpa, yo miro lo que me recuerda a mi amiga, miro allí donde descubro a la Frida que yo conocí. (CREA)

En (15)a la frase subrayada que antecede a la subordinada es prepositiva y en (15)b es una frase adverbial, en ambos casos podrían considerarse el antecedente de las subordinadas, no obstante, al omitir la frase que precede a ambas oraciones, se muestra que no se generan oraciones agramaticales. La omisión de la frase que antecede a la 
subordinada permite que sea esta última la que modifique al verbo directamente como señala Osuna (2005).

a. Comenzó a eliminar los subsidios, cuando vendió 19 ingenios en 142 millones. (CREA)

b. No es mi culpa, yo miro lo que me recuerda a mi amiga, miro donde descubro a la Frida que yo conocí. (CREA)

Si bien en las oraciones de relativo la omisión de la frase que las antecede tampoco genera oraciones agramaticales como se ilustra en los ejemplos (17)b y (17)d, también muestra que sintácticamente ya no podrían considerarse de relativo sino adverbiales.

a. Demolieron SN [el edificio osRel [donde antes estaba la Comisión de agua]].

b. ?Demolieron OSADV [donde antes estaba la Comisión de agua].

c. Regresó SN [el día OSREL [cuando me entregaron la casa]].

d. Regresó OSADV [cuando me entregaron la casa].

Los ejemplos de (17) muestran que la omisión de la frase que antecede a la subordinada permite que los relativos adverbiales cuando y donde estén adyacentes al verbo de la oración principal y lo modifiquen directamente.

Ahora bien, Osuna (2005) expone una segunda cuestión que tiene que ver con el antecedente de las oraciones de relativo, y que es pertinente mencionar para elanálisis de las subordinadas adverbiales. Dicha cuestión está relacionada con la delimitación del segmento al que se refieren las relativas, es decir qué clase de elementos pueden funcionar como antecedentes. Creemos importante señalar esta cuestión porque, indudablemente, las funciones sintácticas y semánticas del elemento que antecede a las oraciones subordinadas adverbiales debería tener diferentes rasgos de los que tienen los antecedentes de las oraciones de relativo, dado que los oficios de ambas clases de oraciones son diferentes.

En el caso de las oraciones subordinadas locativas Herrero $(2005: 179,180)$ indica que la frecuencia de casos en los que puede aparecer con antecedente y sin este es la 
misma, además, considera que los lexemas que pueden funcionar como tal son ilimitados, no obstante, consideramos que si la frase que antecede es una frase nominal, la oración que le sigue no puede ser adverbial sino de relativo. Y solamente en los casos en los que una frase adverbial o prepositiva es la que antecede a la oración subordinada podría considerarse que esta última es adverbial como se muestra en los ejemplos de (18):

a. Éstos aparecen allí donde la situación que se quiere investigar es externa. (CREA)

b. Vivo por donde se pone el tianguis los domingos.

En (18)a la frase que antecede a la subordinada es adverbial y en (18)b la oración está precedida por una frase prepositiva. Puesto que la función de los adverbios es modificar a un adjetivo, a un verbo o a un adverbio, en (18)a el adverbio allí podría considerarse el antecedente de la oración subordinada que lo precede ya que es posible que un adverbio modifique a otro adverbio. No obstante, en el ejemplo (18)b la preposición no podría considerarse su antecedente ya que sintácticamente la oración introducida por el relativo donde es el término de la misma. En oraciones como (18)b, en las que una preposición antecede a la oración subordinada, la preposición precisa el lugar al que se refiere la subordinada, ya que el sentido semántico que tiene la oración con y sin preposición es diferente, por ejemplo:
a. Trabajo donde arreglan licuadoras
b. Trabajo por donde arreglan licuadoras.

(19)a indica que trabajo justo en el lugar donde arreglan licuadoras, pero la segunda oración (19)b muestra que trabajo en los alrededores. Por tanto, la preposición no podría considerarse el antecedente de la subordinada, por un lado, porque semánticamente una oración subordinada no puede modificar a una preposición, y por otro lado, porque sintácticamente la oración subordinada debe ser el término de la preposición. De modo que, en los ejemplos citados en (19), solo (19)a podría considerarse que tiene un antecedente pero (19)b no. Si bien la estructura sintáctica de esta clase de subordinación es muy controversial es notable que tanto la preposición como el relativo adverbial forman una 
unidad semántica que da un matiz distinto a la oración y por tal motivo esta clase de construcciones se han agrupado dentro de las oraciones subordinadas adverbiales, ya que sus funciones semánticas son propias de una oración adverbial.

El problema que presentan las construcciones locativas incrementadas por una preposición es que esta última y el relativo donde aún no se han consolidado al grado de ser una sola unidad léxica como ha ocurrido con algunos nexos modales como sin que o bien con los temporales como hasta que o desde que, pero cuando aparecen adyacentes, preposición y relativo adverbial donde forman una unidad semántica que transmite una sentido distinto al que se percibe cuando al relativo adverbial aparece sólo. Alarcos Llorach (1999: 355-361) menciona que algunas oraciones subordinadas adverbiales impropias son la composición de una preposición más la conjunción que; por ejemplo para + que; por + que; hasta + que. O bien la unión de un adverbio más que, por ejemplo aún + que pero señala que su función es circunstancial no sustantiva ni relativa, lo cual indica que tanto las preposiciones como la conjunción se han unido para formar una conjunción distinta.

En relación con las estructuras sintácticas que pueden tener las frases que anteceden a las oraciones subordinadas propias de tiempo y lugar puede ser un sintagma prepositivo como se muestra en los ejemplos de (20)

a. Te espero sP [en [el lugar [donde quedamos]]].

b. Llegaron sp [en [el momento [cuando te marchaste]]].

Los ejemplos muestran que es posible que las oraciones encabezadas por los relativos adverbiales donde y cuando tengan un antecedente. Y la diferencia entre la frase que antecede a las subordinadas de relativo y la que precede a las adverbiales es que la primera es una frase nominal mientras que la segunda es una frase prepositiva, por tanto la modificación que hace la oración subordinada es distinta, ya que una oración adverbial no puede modificar una frase nominal sino a toda la frase prepositiva como se muestra en las oraciones de (21), en donde la omisión de la preposición es imposible:
a. *Te espero el lugar donde quedamos.
b. *Llegaron el momento cuando te marchaste. 
La agramaticalidad de los ejemplos (21) muestra que la función que cumplen las oraciones subordinadas adverbiales es distinta de la que desempeñan las relativas. Las oraciones el lugar donde quedamos y el momento cuando te marchaste ya no desempeñan la misma función sin la preposición, ahora son oraciones de relativo y en la posición en la que se encuentran no pueden modificar al verbo. Porto Dapena (1997:17) señala que cuando las oraciones introducidas por un relativo adverbial tienen como antecedente un sintagma prepositivo como se muestra en los ejemplos de (20), la función circunstancial no corresponde únicamente a la oración de relativo sino al sintagma compuesto por una preposición y al término de esta, ambos actúan en conjunto como complemento circunstancial de la oración regente. Subraya, además, que una oración subordinada adverbial no se considera como tal simplemente por el hecho de que esté introducida por un adverbio relativo. Más bien porque aún cuando llevara antecedente ${ }^{5}$, con la omisión del mismo, como lo muestran las oraciones de (8), la oración subordinada pasa a cumplir directamente la función adverbial dentro de la oración en la que aparece y además puede ser conmutable por un adverbio (Porto Dapena 1999:16) como se ilustra en las oraciones (22):
a. Te espero alli
b. Llegaron entonces.

Los ejemplos muestran que tanto la frase prepositiva como a la oración subordinada pueden sustituirse por un adverbio ya que cumplen funciones equivalentes.

Ahora bien, una propuesta interesante sobre las oraciones que están precedidas por una preposición es que tienen un carácter sustantivo ya que se considera son el término de la preposición como se muestra en (23), por lo tanto, podrían considerarse como oraciones "adverbiales sustantivadas" (Porto Dapena 1997) ya que la oración que se encuentra como término de la preposición está en la posición de un sustantivo.

$$
\text { Estudio [en [donde me recomendaste]]. }
$$

\footnotetext{
${ }^{5}$ Como ya hemos analizado este debe ser estrictamente una preposición o un adverbio para que sus funciones semánticas se conserven.
} 
Este análisis puede ser adecuado, ya que las funciones que tienen las oraciones antecedidas por una preposición tienen una estructura distinta de la que poseen las oraciones adverbiales que no están precedidas por una frase prepositiva o adverbial. Al estar antecedidas por una preposición, son el término de esta y, por lo tanto, sintácticamente están en posición de un sustantivo, pero su función sigue siendo de complemento circunstancial de lugar o tiempo. Asimismo es posible que en algunas oraciones la preposición no sólo esté regida por el verbo regente sino también por la oración subordinada.

A este respecto, Porto Dapena (1997:52) advierte que hay oraciones adverbiales que están precedidas por una frase prepositiva o adverbial y tanto el verbo regente como el verbo de las subordinadas rigen, véase el ejemplo que propone en (24):

$$
\text { Se dirigió hacia donde había huido el conejo }{ }^{6} \text {. (Porto Dapena 1997:52) }
$$

Ahora bien, otras maneras en que se ha analizado la frase prepositiva, adverbial o incluso nominal que antecede a las oraciones encabezadas por los relativos donde y cuando son las que sugieren Porto Dapena (1997) y Herrero (2005).

Porto Dapena considera que hay oraciones subordinadas introducidas por donde y cuando que tienen un antecedente, pero no lo modifican, más bien estima que dicha proposición solamente enuncia una manera distinta de expresar lo que la frase que lo antecede indica como lo ilustra (25). Advierte que la subordinada adverbial no está modificando a la frase adverbial muy temprano.

Me gusta salir muy temprano, cuando no hay tráfico en las calles (Porto Dapena 1997:52)

\footnotetext{
${ }^{6}$ La RAE (2010:698) menciona que algunos gramáticos consideran que todos los complementos encabezados por la preposición hasta son adjuntos o circunstanciales. Pero otros opinan lo contrario, afirman que pueden asimilarse a los complementos de régimen, sobre todo cuando modifican a predicados que indican dirección o destino. En esta oración, ya sea que el verbo dirigirse sea un verbo de régimen prepositivo o no, la oración subordinada que es el término de la preposición tiene una estructura semejante a la que tienen las que no están regidas por el verbo, por lo tanto, aquí la cuestión es qué clase de estructura sintáctica tienen, la de una oración subordinada sustantiva o la de una oración subordinadas de relativo.
} 
Herrero (2005:182) propone que las frases prepositivas o adverbiales que preceden a las oraciones subordinadas temporales y locativas pueden tratarse como otro complemento circunstancial, es decir, la frase adverbial muy temprano es un complemento circunstancial y la oración subordinada adverbial un segundo complemento circunstancial que especifica el sentido temporal que expresa la frase adverbial ${ }^{7}$. Ambos planteamientos son interesantes ya que aún en oraciones simples la presencia de dos complementos circunstanciales es posible, por ejemplo, Mañana vengo a las 6:30 o Arturo está jugando afuera en el patio.

Por otra parte, hemos analizado la posibilidad de que esta clase de oraciones pueda tener un antecedente, no obstante, no en todos los casos puede introducirse una frase prepositiva que funcione como antecedente, ya que el resultado a veces se torna forzado o quizás podría ser un uso marcado sobre todo en el caso de las temporales introducidas por cuando, nexo que más aparece en los ejemplos del corpus ${ }^{8}$. Véase los ejemplos de (26) en los que la oración subordinada está marcada en cursivas:

a. Señaló [que [cuando se asegura dinero en las detenciones la PGR debe depositarlo]] (CREA).

b. Dijeron que lo más importante cuando los delincuentes tienen rehenes es evitar la violencia (CREA).

En ambos ejemplos las subordinadas adverbiales encabezadas por cuando están dentro una oración subordinada sustantiva que funciona como complemento directo de los verbos señalar y decir respectivamente. En (26)a la subordinada adverbial se encuentra antes de la que es su oración regente y en (26)b la subordinada está en medio de la que es su oración regente $\mathrm{Si}$ a tales proposiciones se les introduce la frase nominal que es su antecedente antes del relativo y que hemos subrayado en (27), las oraciones se tornan repetitivas:

\footnotetext{
${ }^{7}$ Retomaremos esta cuestión en al Capítulo II apartado 2.1.4.

${ }^{8}$ La mayoría de las oraciones encontradas con el nexo cuando no tiene antecedente, por tanto se pudieran considerar puramente subordinadas adverbiales que no tienen una categoría vacía como lo proponen la RAE (2009) y Pavón (2012). En el marco de la gramática generativa, estructuralmente hablando podría justificarse dicha afirmación y se podría observar cómo se promueve el nexo cuando dentro de una estructura arbórea. El relativo adverbial cuando se ubicaría en el núcleo del SCompl por tratarse de un elemento [-Qu].
} 
a. Señaló que en el momento cuando se asegura dinero en las detenciones la PGR debe depositarlo (CREA).

b. Dijeron que lo más importante en el momento cuando los delincuentes tienen rehenes es evitar la violencia (CREA).

Alarcos (1999:102) subraya que el antecedente no aparece en algunos contextos porque es redundante. Herrero (2005:180) concuerda con la propuesta de Alarcos; considera que la escasa frecuencia del antecedente en las oraciones temporales y las modales es por una razón de economía lingüística, ya que la información semántica que proporcionan los adverbios relativos es la misma que posee el antecedente, por tanto su uso es redundante, y se omite sobre todo en las oraciones temporales y modales.

Finalmente la tercera cuestión a la que se refirió Osuna (2005:55) tiene que ver con las relaciones entre el relativo y el antecedente, este autor indica que en el caso de las relativas se plantea si en la oración "Siempre que vienes", que es relativo o es una conjunción y lo mismo puede aplicar en las oraciones de relativo adverbial como en la oración "Lo hizo como pudo": como es relativo o una conjunción. Otras propuestas (Brucart 1999: 450 cita lo que menciona Bello) se basan en que el nexo o relativo adverbial cumple varias funciones: la de ser nexo, por supuesto, la de llevar el significado del antecedente implícito y la de ser un elemento adjunto de la oración en la que se encuentran. Herrero (2005) considera que los relativos adverbiales cumplen una función transpositora, pero también contempla la posibilidad de que ocupen una función intermedia entre los adverbios y las conjunciones ${ }^{9}$. Consideramos que en las subordinadas adverbiales el relativo cumple la función de nexo o conjunción entre el verbo y la subordinada siempre y cuando no haya un antecedente de por medio, por ejemplo, Compraron el libro donde los mandó la SEP, muestra esta oración que el relativo adverbial donde cumple las funciones de nexo subordinante y también de adjunto de la oración en la que se halla.

\footnotetext{
${ }^{9}$ Herrero (2005:182) cita a Pedro Carbonero quien dice "ante la exigencia de tratarlos como adverbios o conjunciones lo más correcto es pensar que estamos ante un proceso de reconstrucción, de cambio lingüístico que, considerado en nuestra sincronía aún no ha terminado de producirse en su totalidad. Por ello es más oportuno considerarlos adverbios en algunos casos y conjunciones en otros, según su aparición en el discurso puesto que la lengua permite ambas posibilidades de uso para dichas unidades".
} 
Ahora bien, para finalizar este apartado, mipunto de vista en relación con las subordinadas adverbiales es que deben agruparse de acuerdo con las funciones semánticas que desempeñan dentro de la oración, es decir, las que son propias de un adverbio tal como lo señala la gramática tradicional. Si bien consideramos que hay oraciones que dentro de dicha gramática no eran adverbiales realmente, consideramos que agruparlas dentro de las relativas por el hecho de estar introducidas por un relativo adverbial no es el mejor criterio, aunque entendemos las razones por las que algunos investigadores han tomado dicha postura. Creemos que la función semántica que desempeñan dentro de la oración en la que se encuentran es lo que determina qué clase de subordinación es, mas no el nexo que las introduzca. Asimismo, opinamos que las oraciones subordinadas adverbiales pueden tener un antecedente y que sintácticamente cambia su estructura, pero semánticamente siguen cumpliendo las funciones de un circunstancial de tiempo o lugar. Citamos las palabras de Porto Dapena que pensamos resumen de mejor manera nuestro punto de vista:

"En resumidas cuentas, una oración de relativo no es adverbial solamente porque vaya introducida por los adverbios donde, cuando, como u otro equivalente, sino porque, además, el antecedente es a su vez un adverbio -0 un sintagma preposicional equivalente-, o, sobre todo, cuando por elisión de aquel, la oración subordinada pasa a desempeñar directamente la función adverbial dentro de la principal, siendo a su vez, por ello, conmutable por un adverbio" (Porto Dapena 1997:16)

3. Argumentos o adjuntos oracionales. Al principio de este capítulo hicimos alusión a lo que las distintas gramáticas han señalado en relación con las oraciones subordinadas adverbiales y señalamos que esta clase de oraciones es considerada por todos los autores mencionados como elemento adjuntos o terciarios según la terminología de Alcina y Blecua, (1980). De manera que en este trabajo las oraciones subordinadas adverbiales propias se estudiarán de la misma forma: como una clase de adjunto o adjunto oracional, como señalaron los autores antes citados, ya que esta es la función que cumplen dentro de la cláusula. En este apartado discutiremos brevemente por qué tomaremos dicha postura. 
En términos generales, las definiciones que se encontraron sobre los argumentos y los adjuntos concuerdan en que los primeros son elementos obligatorios y los segundos son opcionales. Para Lorenzo y Longa (1996:77) cada lengua tiene una estructura interna formada por sintagmas que tienen complementos alrededor de un núcleo. Los núcleos a su vez eligen elementos que encierran ciertas propiedades de selección categorial y aceptan a los que son compatibles con ellos lo cual se muestra desde su entrada léxica misma que indica qué tipo de elementos requieren obligatoriamente. Según muestran estos autores, lo que determina que los complementos sean obligatorios u opcionales es la relación que estos guardan con el significado de los núcleos. Es decir, un argumento obligatorio tendrá una relación semántica más estrecha con el núcleo, porque el argumento forma parte de su significado. Por el contrario, un complemento opcional no tiene esa misma correspondencia, porque no es parte del significado del núcleo. Tales diferencias se reflejan en las posiciones que ambos complementos toman en la estructura sintáctica: los argumentos obligatorios tomarán lugares muy cercanos o adyacentes al núcleo mientras que los opcionales se colocarán en lugares no tan próximos al núcleo o en posiciones de adjunto (Lorenzo y Longa 1996). Otra característica que distingue a los adjuntos es que aportan información no reclamada por la semántica del verbo tales como tiempo, espacio, modo o razón de la acción que expresa el verbo. De acuerdo con esta definición las subordinadas adverbiales tienen un comportamiento de adjunto más que argumental, ya que su presencia no es exigida por la semántica de los verbos que las rigen.

Asimismo, Farrell (2005) considera que cada elemento asume un papel dentro de la oración o frase en la que se encuentra, tales papeles se conocen como relaciones gramaticales. Siguiendo esta idea, si los adverbios cumplen la función de complementos circunstanciales dentro de la oración en la que se encuentran, las subordinadas adverbiales tendrían que efectuar las mismas tareas que tales elementos, ya que se les considera equivalentes y en consecuencia deben estudiarse como tales pues gramaticalmente cumplen las mismas funciones. Además, considerando que cada elemento desempeña no sólo funciones sintácticas sino también semánticas, las oraciones subordinadas adverbiales se considerarían elementos oracionales adjuntos al igual que un adverbio, ya que cumplen los mismos papeles temáticos: tiempo, lugar y modo. 
Pavón (2012: 23) citando a Brucart y Gallego (2009) menciona que "lo único que parecen tener en común las estructuras que tradicionalmente se han clasificado como oraciones adverbiales o circunstanciales es, por una parte, el desempeñar una función no argumental con respecto a la oración principal (...)”. Herrero (2005: 183) concuerda al respecto porque indica que a esta clase de oraciones se les ha considerado opcionales o no necesarias. Subraya, además, que en el caso de las temporales y modales se percibe más la función circunstancial, pero en las locativas no es tan claro dicho oficio, pues hay verbos que exigen la precisión de un lugar, se refiere a los verbos de movimiento particularmente en los ejemplos que transcribimos en (28) y (29):
a. Fui a Alemania.
b. Vino de Salamanca.
c. Se quedó en su casa.

a. Lo seguiremos adonde vaya.

b. Lo trajo de donde vino.

c. No lo encontré donde se había quedado.

En muchos ejemplos que se analizan en el corpus se encontraron que el verbo regente requiere de la preposición por tratarse de verbos de movimiento como los que se acaban de citar en los ejemplos de (28) y (29), venir, ir, salir, caminar, emerger, emanar, surgir, entre otros ${ }^{10}$. Con esta clase de verbos es imposible la omisión de la preposición, ya que está regida por el verbo, de modo que su omisión genera una oración agramatical: *Salí donde fui, *Vengo donde nací. Con algunos verbos de movimiento la omisión de la preposición es posible, por ejemplo, Voy donde María, pero Pavón (2012) indica que esto puede tratarse de una variante dialectal, en donde incluso no sólo se omite la preposición sino también el verbo de la subordinada. Mencionamos anteriormente que los verbos de movimiento subcategorizan a las preposiciones que rigen, y es importante observar que estas a su vez necesitan que su término sea un sustantivo que indique lugar, o bien un

\footnotetext{
${ }^{10}$ Los verbos de movimientos generan dudas en cuanto a si la preposición que eligen está subcategorizada o no. Algunos gramáticos opinan que la preposición de estos verbos es argumental, pero otros consideran que es un adjunto. Consideramos que algunas de las preposiciones son argumentales pero otras no lo son, sin embargo, no nos centraremos en el análisis de las preposiciones de esta clase de verbos, ya que nos enfocaremos en analizar la estructura sintáctica de la oración que es término de la preposición, que como señalamos anteriormente puede ser una oración subordinada sustantiva o de relativo o bien adverbial.
} 
adverbio locativo, por ejemplo, Salieron del cine a las 10 y Emerge de alli, de manera que también requerirán oraciones subordinadas que tengan rasgos locativos. En este sentido, las oraciones subordinadas adverbiales de lugar cumplen con tales características, por lo tanto, también parecen ser requeridas por la semántica de los verbos de movimiento.

Herrero indica que los verbos de las oraciones de (28) exigen una preposición de lugar y cumplen una función circunstancial; y en las oraciones de (29) las subordinadas funcionan como circunstancial "rellenando una función exigida por los verbos de la misma subordinada, y si esto es así, nada más lógico que suponer que en cualquier otra subordinada de lugar, el adverbio donde también desempeña esta función" (2005: 182,183). De modo que en tales ejemplos se muestra que las oraciones subordinadas adverbiales de lugar pueden considerarse como argumentales más que como adjuntos, ya que la semántica del verbo las requiere. Sin embargo, su función es la de un complemento circunstancial lo cual resulta contradictorio, ya que tales complementos no se consideran argumentos del verbo sino adjuntos.

En relación con el carácter opcional de los circunstanciales Bosque y GutiérrezRexach (2009:) señalan que considerarlos circunstanciales también representa un problema, puesto que muchas de estas oraciones no expresan la circunstancia en la que se produce la acción de la oración principal, sino en la subordinada se indica sólo un estado de cosas que debe cumplirse o satisfacerse para que determinada situación ocurra o se produzca, sobre todo en el caso de las condicionales y las finales. Bosque y Gutiérrez-Rexach (2009:289) mencionan que no todos son opcionales, en el sentido de que hay algunos circunstanciales que parecen ser exigidos por los verbos, por ejemplo: "Juan pesa mucho" o "Juan se porta mal", con ambos verbos la supresión de la frase que indica medida hace agramaticales a ambas oraciones: *Juan pesa y *Juan se porta. Las oraciones subordinadas adverbiales temporales no están dentro de los adjuntos que requiera el verbo, pero las locativas sí se considerarían como tales, específicamente con los verbos que indican movimiento por lo tanto, a lo largo del análisis que haremos en los siguientes capítulos las trataremos como adjuntos o adjuntos oracionales a las oraciones temporales pero como argumentales a las oraciones subordiandas adverbiales de lugar. 
Ahora bien, hasta el momento sólo nos hemos referido a las oraciones que están introducidas por un relativo adverbial, ya que las cuestiones que consideramos sólo les atañe a ellas, sin embargo, hay otros nexos que introducen a esta clase de oraciones, de manera que en la siguiente sección nos enfocaremos en dichos conectores y en las distintas clasificaciones que se encontraron y propondremos una clasificación.

4. Clasificación de nexos. Para finalizar este capítulo hablaremos de cómo se ha agrupado a las subordinadas adverbiales y propondremos una clasificación propia.

Se ha clasificado a las oraciones subordinadas adverbiales de distintas maneras, ya sea por sus funciones o por sus rasgos semánticos, o bien por sus rasgos sintácticos, Alarcos (1999:537) por ejemplo, hace ambas clasificaciones. Como hemos visto las subordinadas adverbiales se introducen principalmente por los adverbios relativos cuando, donde y como los cuales, pueden estar precedidos por una frase prepositiva o por una frase adverbial, por ejemplo, Me senté [[alli] [donde está el árbol de ciruelas]], en donde el adverbio allí precede a la oración encabezada por el relativo donde, o bien Pasaron [[por $]$ [donde vive Rosa]], en donde la oración introducida por el relativo donde está precedida por la preposición por, en ambos ejemplos se muestra que no hay una frase nominal de por medio. Seco (1982) propone un esquema de estructura en el que muestra que las oraciones subordinadas adverbiales pueden referirse a un antecedente dentro de la oración principal.

\begin{tabular}{|l|l|l|}
\cline { 2 - 3 } \multicolumn{1}{l|}{} & Oración principal & Oración subordinada \\
\hline De lugar & Aquí es & donde yo trabajo \\
\hline De tiempo & Entonces fue & cuando llegó mi padre \\
\hline De modo & El negocio salió así & como yo suponía \\
\hline
\end{tabular}

Tabla 1 Seco (1982)

Esta clasificación es cuestionable, porque las oraciones de lugar y tiempo tienen un verbo copulativo como se muestran en la Tabla 1, no obstante, las oraciones de lugar y tiempo son oraciones copulativas identificativas (RAE 2010:709). Algunos consideran (Brucart 1999) que se trata de subordinadas de relativo mas no adverbiales. No obstante, 
Seco (1982) aclara que las oraciones adverbiales no se ajustan exactamente a los tipos esquemáticos arriba citados, ya que el antecedente puede omitirse y quedar sobreentendido adecuadamente, como lo muestran los ejemplos que cita: Voy donde me llaman; Le veré cuando venga; El joven se condujo como correspondía a su talento.

Si bien los conectores más comunes que relacionan a las oraciones subordinadas adverbiales propias con la principal son donde, cuando y como, estos pueden variar. Munguía (1999) indica que para enlazarse pueden valerse de distintos tipos de nexos tales como "conjunciones, locuciones conjuntivas, adverbios, locuciones adverbiales, preposiciones, así como la combinación de ellas". En el caso de las locativas, para indicar relaciones de movimiento, el adverbio donde puede incrementarse por algunas preposiciones, por ejemplo adonde, por donde, para donde, hasta donde y hacia donde (Seco 1983; Munguía 1999). Con relación a las temporales la lista de conectores es más amplia; Seco (1983) registra los elementos que tienen antecedente: apenas... cuando; aún no... cuando; no bien... cuando; luego... cuando. Y entre los que no tiene antecedente o sin antecedente fijo: ya que, luego que, antes que, después que, como, en tanto que, en cuanto, mientras, mientras que. Respecto de las de modo los nexos más comunes son: como, como sí, según, según como.

La siguiente tabla muestra los nexos más comunes que introducen a las oraciones subordinadas adverbiales propias de tiempo y lugar.

CLASIFICACIÓN DE NEXOS

\begin{tabular}{|c|c|c|c|}
\hline AUTOR & TIEMPO & LUGAR & MODO \\
\hline Gili Gaya (1961) & $\begin{array}{l}\text { Cuando, mientras, mientras } \\
\text { que, mientras tanto, en tanto } \\
\text { que, tanto...cuanto, cuanto, } \\
\text { entretanto que; en cuanto, } \\
\text { apenas, apenas...cuando, aún } \\
\text { apenas, aún no, no, no bien, } \\
\text { ya que, luego que, asi que, tan } \\
\text { pronto como; primero que, } \\
\text { después que, antes (de) que, } \\
\text { después de que, hasta que }\end{array}$ & Donde & $\begin{array}{l}\text { Así... como, bien así...como, } \\
\text { tal...como; tal...cual, así...cual }\end{array}$ \\
\hline Seco, Rafael (1982) & $\begin{array}{l}\text { Cuando; apenas...cuando, aún } \\
\text { no... cuando, no } \\
\text { bien...cuando, luego... } \\
\text { cuando; sin antecedente o al }\end{array}$ & $\begin{array}{l}\text { Donde; o bien puede estar } \\
\text { afectado por preposiciones: } \\
\text { adonde, de donde, por donde, }\end{array}$ & Como, según, según que \\
\hline
\end{tabular}




\begin{tabular}{|c|c|c|c|}
\hline & $\begin{array}{l}\text { menos sin antecedente fijo ya } \\
\text { que, luego que, antes que, } \\
\text { después que, como, en tanto } \\
\text { que, en cuanto, mientras, } \\
\text { mientras que }\end{array}$ & hacia donde, hasta donde & \\
\hline Munguía, Irma (1999) & $\begin{array}{l}\text { Cuando; mientras, mientras } \\
\text { que, en cuanto, antes de que, } \\
\text { después de que, desde que, } \\
\text { apenas, tan pronto como, } \\
\text { luego que }\end{array}$ & $\begin{array}{l}\text { Donde; al cual se le puede } \\
\text { agregar una preposición }\end{array}$ & $\begin{array}{l}\text { Como; como si, igual que según, } \\
\text { sin, sin que, conforme. Carecen } \\
\text { de nexo o palabra de enlace } \\
\text { cuando su verbo es un gerundio } \\
\text { (Juan salió dando un portazo); a } \\
\text { menudo estas oraciones pueden } \\
\text { omitir el verbo cuando es el } \\
\text { mismo de la principal; al adverbio } \\
\text { comparativo como se le puede } \\
\text { agregar la preposición para con } \\
\text { lo cual se le añade un matiz de } \\
\text { finalidad, sin que por ello se } \\
\text { pierda su significado modal. }\end{array}$ \\
\hline $\begin{array}{l}\text { Herrera Lima, Ma. Eugenia } \\
\text { (1988) }\end{array}$ & $\begin{array}{l}\text { Cuando; mientras (que), que, } \\
\text { ya que, después (de) (que), } \\
\text { ora, al, antes (de) (que); desde } \\
\text { que, hasta que }\end{array}$ & $\begin{array}{l}\text { Donde; adonde, por donde, } \\
\text { hasta donde, de dónde, } \\
\text { dondequiera. Locativas } \\
\text { referidas a los adverbios: allí, } \\
\text { ahí, aquí, acá, allá, arriba, } \\
\text { enfrente. }\end{array}$ & $\begin{array}{l}\text { Como; sin y según. Modales- } \\
\text { comparativas introducidas por } \\
\text { como o igual que; modales } \\
\text { comparativas hipotéticas: como } \\
\text { que como si. }\end{array}$ \\
\hline Atlas lingüístico de México & $\begin{array}{l}\text { Cuando; a que, ahora que, al } \\
\text { poco de + inf, cada que, } \\
\text { cuando que, cuando recién } \\
\text { que, de ahí a que, de que, } \\
\text { dende que, desde cuando, el } \\
\text { dia, cada dia que, donde, en } \\
\text { eso que, en lo que, en de que, } \\
\text { al fin de, hasta cuando, hasta } \\
\text { el dia que, hora, hoy que, lo } \\
\text { que, momento, nada más, no } \\
\text { más que, primero que, tiempo, } \\
\text { temporada, vez, ya que }\end{array}$ & No tiene registro & No tiene registro \\
\hline
\end{tabular}

Tabla 2

La tabla 2 muestra que hay una variedad de nexos que introducen a las OSADV sobre todo en las de tiempo, sin embargo en esta investigación se considerarán los conectores que tuvieron mayor incidencia dentro del corpus analizado, basado además en los nexos contemplados por los autores arriba citados, como se muestra en la Tabla 2.

\begin{tabular}{|l|l|l|}
\hline \multicolumn{1}{|c|}{ TIEMPO } & \multicolumn{1}{|c|}{ LUGAR } & \multicolumn{1}{|c|}{ MODO } \\
\hline $\begin{array}{l}\text { Cuando, mientras, mientras que; en } \\
\text { cuanto, apenas, luego que, tan } \\
\text { pronto como; antes (de) que, } \\
\begin{array}{l}\text { después de que, hasta que, desde } \\
\text { que }\end{array}\end{array}$ & $\begin{array}{l}\text { les agrega una preposición: en } \\
\text { donde, por donde para donde, } \\
\text { hacia donde, hasta donde, } \\
\text { adonde. }\end{array}$ & $\begin{array}{l}\text { Como; como si, igual que, según, } \\
\text { sin que, conforme (Munguía } \\
1999)\end{array}$ \\
\hline
\end{tabular}


Tabla 3

Asimismo las oraciones subordinadas adverbiales propias que se estudiarán son las que no tienen antecedente dentro de la oración principal, o bien en las que queda sobreentendido dentro de la principal.

5. Conclusiones. A lo largo de este capítulo se analizaron los problemas que surgen en torno a las oraciones subordinadas adverbiales. Exploramos lo que las diferentes gramáticas han dicho respecto de esta clase de oraciones lo cual mostró que todos los lingüistas que citamos concuerdan en que se les debe estudiar a partir de las funciones que cumplen dentro de la oración en la que se encuentran. Consideramos que dicho enfoque es el más adecuado, por lo que el análisis que haremos en los capítulos posteriores estará basado en las funciones que estas oraciones cumplen. Asimismo, señalamos que algunos lingüistas consideran que las subordinadas adverbiales pudieran estudiarse como relativas libres y formar parte de esa agrupación, sin embargo, explicamos que no concordamos con este planteamiento. Mostramos que estas dos clases de subordinadas no tienen la misma estructura sintáctica y que son diferentes en el aspecto semántico, ya que desempeñan funciones distintas porque no modifican a las mismas categorías gramaticales, por tanto, esa sería una razón fundamental que apoya el hecho de que se les debe considerar distintas y que deben clasificarse dentro de las subordinadas adverbiales como se ha hecho tradicionalmente y no llevarlas al grupo de las relativas sólo por el hecho de que comparten los relativos que las introducen. Finalmente, las subordinadas adverbiales propias de tiempo serán tratadas como adjuntos puesto que no son exigidas por los verbos, pero a las oraciones subordinadas adverbiales de lugar las consideraremos como argumentales ya que son requeridas como término de las preposiciones regidas por los verbos. 


\section{Capítulo II}

\section{Estructura sintáctica de las oraciones subordinadas adverbiales}

Introducción. Uno de los problemas principales que presenta la clase de las oraciones subordinadas adverbiales propias es su estructura sintáctica. En el corpus analizado se encontró que las oraciones subordinadas adverbiales de tiempo pueden ubicarse, después de la oración principal, antes de esta o con algunos nexos puede interrumpir la secuencia de la oración principal. También se analizó la estructura de los nexos subordinantes con la finalidad de ver si los tres órdenes contemplados son posibles con todas las subordinadas de tiempo. Asimismo las características semánticas que poseen produce traslapes con las otras dos clases de oraciones subordinadas, como explicamos en el Capítulo 1. De manera que en el presente capítulo discutiremos la estructura de las oraciones subordinadas adverbiales temporales atendiendo a los problemas que surgen en torno a ellas, haremos alusión a las dos cuestiones: sintaxis y semántica, que como es sabido, tienen relación muy estrecha en cuanto a la clasificación de las oraciones que nos interesan.

En este capítulo consideraremos tres aspectos importantes en torno a la estructura sintáctica de las oraciones subordinadas adverbiales de tiempo, tales como el orden sintáctico que siguen, la posibilidad de que la frase prepositiva, adverbial o nominal que las precede sea un antecedente como plantea Porto Dapena (1994) o pueda considerarse otro complemento circunstancial de tiempo como propone Herrero (2005) y discutiremos sobre las características que tienen los nexos o conjunciones que unen a las oraciones subordinadas ya que tales unidades han sido en gran medida causantes de que la estructura de las oraciones subordinadas adverbiales sea cambiante. Finalmente, y atendiendo a los tres aspectos señalados, en el apartado presentaremos el análisis sintáctico de las oraciones subordinadas adverbiales de tiempo analizando cada uno de los nexos que incluimos en el presente capítulo. 
1. Estructura sintáctica de las oraciones subordinadas adverbiales. Desde la gramática tradicional se ha observado que la ordenación sintáctica de las subordinadas adverbiales es variada, asimismo se ha considerado que los rasgos semánticos de tales oraciones también han influido de manera importante en la forma en que se les ha agrupado, como señalamos en el capítulo anterior. La RAE (1973:536), por ejemplo, no habla de las estructuras sintácticas de las oraciones subordinadas adverbiales, no obstante, basa su estudio en una clasificación semántica principalmente, y las agrupa distinguiendo unas de otras según la clase de relación que por su significado guardan con la oración principal. Seco (1982) señala que estructuralmente las subordinadas adverbiales de tiempo, lugar y modo poseen una ordenación uniforme, en el sentido de que generalmente están introducidas por los adverbios relativos cuando, como y donde respectivamente, sin embargo, explica que las oraciones adverbiales no siempre se ajustan a los modelos esquemáticos propuestos estrictamente.

Siguiendo la idea de Seco, el hecho de que las subordinadas adverbiales de tiempo, por ejemplo, estén introducidas por distintos conectores y no simplemente por el relativo adverbial cuando pone de manifiesto que su estructura no es idéntica en todas las ocasiones. En el caso de las locativas podría decirse que tienen un orden más semejante entre sí porque el único nexo que las une es el relativo donde, aunque en algunos ejemplos este está incrementado por una preposición, un adverbio o bien un locución adverbial. En las subordinadas modales sucede algo parecido, sus únicos conectores son como, como si o bien así como, de modo que su estructura podría considerarse menos variada que en las temporales, en lo que a nexos se refiere. En el capítulo 1 mostramos el esquema que Seco propone en relación con las subordinadas de tiempo, modo y lugar; señalamos, además, que dichas estructura presentaban algunas cuestiones que explicamos en dicha sección ${ }^{11}$, por ejemplo, la cuestión del antecedente o bien qué clase de palabras o frases se pueden usar como nexos subordinantes.

Señala Pavón (2012:23), además, que la problemática que surge de la diversidad estructural de esta clase de oraciones en "algunos trabajos gramaticales recientes han

\footnotetext{
${ }^{11}$ Véase Cap. 1 apartado 4 pág. 47
} 
abandonado el concepto de subordinación adverbial como denominación de un tipo de construcción sintáctica específica”. Esta autora muestra incluso que la RAE (2007) ya no dedica ninguna sección al estudio de las oraciones subordinadas adverbiales por las razones antes señaladas. Lo cual consideramos inadecuado porque estas construcciones tienen estructuras particulares que merecen estudio más profundo, además, la estructura de estas oraciones plantea cuestiones importantes. Si bien las oraciones subordinadas adverbiales se presentan en estructuras variadas, también es importante observar si dicha variación corresponde exclusivamente a las oraciones adverbiales o es más bien un fenómeno que se deriva de las construcciones en las que se encuentran, por ejemplo, cuál es el orden sintáctico que presentan y el más frecuente que pueden tener. Además de las cuestiones que los nexos o conjunciones que las introducen plantean, es posible que el orden sintáctico sea el mismo con cada uno de ellos o hay alguna variación dependiendo de las conjunciones que las introducen. En este estudio se encontró que las oraciones subordinadas adverbiales pueden encontrarse en estructuras sintácticas muy complejas, y presentan movilidad dentro de las construcciones en las que se encuentran. Veamos a continuación qué es lo que las hace invariables pero al mismo tiempo variables.

1.1 Orden sintáctico. Diesel (2001) realizó un estudio tipológico de las subordinadas adverbiales el cual se basa en una muestra de 40 lenguas, en el que analiza las lenguas con órdenes SVO, VOS para comprobar si se anteponen o se posponen a la subordinada. Diesel (2001) examina la posición o el patrón posicional de las cláusulas adverbiales y muestra que hay dos patrones de orden desde la perspectiva tipológica: 1) cualquier lengua usa cláusulas adverbiales tanto antes como después de la cláusula principal o predicado (ambos órdenes son comunes) o 2) la cláusula adverbial precede a la principal o predicado. Este autor explica que al parecer lo que no ocurre es el uso rígido de la cláusula adverbial después de la principal: si una lengua usa una cláusula adverbial en posición final, también hace común el uso de cláusulas adverbiales antes de la principal. Señala que cuando ambos órdenes son comunes, la posición de la cláusula variará con el significado o la función: las condicionales generalmente preceden a la principal, las temporales preceden o siguen a la principal; las causales tienden a ocurrir en posición final, pero ocasionalmente están 
antepuestas, las de resultado y propósito casi siempre siguen o están pospuestas al elemento asociado.

Dryer (2007) señala que los órdenes sintácticos que las lenguas siguen están de acuerdo con la clase de lengua que sea, VSO, SOV o SVO. El español se considera una lengua SVO, y según Dryer los rasgos de este tipo de lenguas son muy semejantes a los de las lenguas VOS. Ambas clases de lenguas tienen el subordinante antes de la clausula subordinada, es decir, Sub + cláusula. Asimismo en esta clase de lenguas el orden sintáctico de las clausulas pueden ser dos: oración subordinada + oración principal o bien oración principal + oración subordinada. Ambos órdenes se encontraron en el corpus y la mayoría de los nexos o subordinantes siguen ambos, no obstante, notamos que con algunos nexos predomina uno de los dos órdenes en las cláusulas. Los ejemplos de (1) muestran oraciones adverbiales de tiempo que se hallan en las posiciones antes mencionadas.

(1) a. Los problemas se agravan [cuando no se aplica el Estado de derecho]. (CREA)

b. [Mientras lo llevaban cargando] otros les pegaban en el abdomen. (CREA)

c. Comenzaron una amistad que [tan pronto como se hizo], se deshizo. (CREA)

En (1)a la oración principal los problemas se agravan se encuentra al principio de la cláusula, la subordinada está introducida por el relativo adverbial cuando y se encuentra después de la oración principal. En (1)b la subordinada está introducida por mientras, en este ejemplo se ubica al principio de la cláusula, es decir antes de la oración principal: otros les pegaban en el abdomen. En (1)c hay dos oraciones subordinadas una de relativo y una adverbial. El verbo de la oración principal es comenzaron, el objeto directo es una amistad, a esta frase nominal se subordina una oración adjetiva introducida por el relativo que, sin embargo, la subordinada adverbial introducida por la locución adverbial tan pronto como se antepone a la oración principal que es se deshizo, de modo que, tanto la subordinada como la principal se encuentran dentro de una subordinada de relativo introducida por que que a su vez depende de otra oración.

En (1) se muestran tres estructuras $\mathrm{u}$ órdenes sintácticos diferentes que las subordinadas adverbiales de tiempo presentan, y como señala Rodríguez Ramalle (2009), 
dichas estructuras muestran un rasgo importante que poseen las oraciones subordinadas adverbiales, tienen una mayor movilidad dentro de la cláusula en la que se encuentran, pueden aparecer al principio o al final de la cláusula, lo cual no se observa en las oraciones subordinadas de relativo ni en las sustantivas. Las oraciones de relativo siempre se encuentran después de una frase nominal y las sustantivas, por cumplir las funciones de un nombre dentro de la oración en la que se encuentran, pueden tomar distintas posiciones, dependiendo del sitio en el que se encuentren pueden ser sujetos, objetos directos, objetos indirectos o bien términos de una preposición. No obstante, las subordinadas adverbiales pueden tener la misma movilidad conservando en todas las posiciones en las que se hallan la misma función, ser adverbios o complementos circunstanciales, lo cual es un argumento más para que sean consideradas dentro de la clase de las oraciones subordinadas adverbiales y no en las de relativo. Si bien Rodríguez Ramalle (2009) se refiere específicamente a la movilidad de las subordinadas adverbiales concesivas, adversativas y condicionales $^{12}$, los ejemplos de (1) muestran que dicho cambio de posición también lo poseen las oraciones temporales, ya que en las locativas el orden que predomina es oración principal + oración subordinada locativa y se encontraron escasos ejemplos en los que la oración subordinada de lugar se encontrara antes de la principal.

Otro orden sintáctico que se encontró en elanálisis son oraciones que interrumpen el orden de la oración principal. Conti (2012), en su estudio sobre la subordinación periférica y la subordinación central en español, alude a la clase de oraciones interpoladas, explica que esta clase de oraciones es un subtipo de las oraciones pospuestas y antepuestas a las que les antecede o sigue un elemento de la oración principal. Indica está autora que entre las oraciones subordinadas que presentan este fenómeno se encuentran las adverbiales locativas con el conector cuando. Asimismo muestra que cuando ocurre la interpolación se presenta una pausa melódica que está representada en la escritura mediante comas. En el corpus que se analizó, se encontraron oraciones de este tipo sobre todo en las temporales como indica Conti (2012) y que ilustramos en (2).

(2) [El alumno [cuando sale al mercado] ya conoce de esto]. (CREA)

\footnotetext{
${ }^{12}$ Indicamos en el capítulo 1 que Rodríguez Ramalle no considera a las subordinadas temporales, modales y locativas como parte de las oraciones adverbiales sino que las ubica dentro de las relativas libres.
} 
En (2) la oración subordinada adverbial cuando sale al mercado rompe la secuencia de la oración principal el alumno ya conoce esto. Tal como señala Conti (2012), un elemento de la oración principal, en este caso el sujeto el alumno, se antepone a la subordinada y posterior a ella se encuentra el resto de la oración principal. Veremos a lo largo de este capítulo si este fenómeno se presenta en todas las subordinadas adverbiales temporales o únicamente ocurre en las subordinadas de tiempo introducidas por el conector cuando y en el capítulo posterior veremos si puede ocurrir en las subordinadas de lugar.

Ahora bien, no sólo la estructura sintáctica de las oraciones subordinadas plantea cuestiones relacionadas con el aspecto sintáctico sino que también está involucrado el carácter semántico de las oraciones incluso la clasificación de las subordinadas adverbiales está basada en esta propiedad. Respecto a la naturaleza semántica de las subordinadas adverbiales, Gili Gaya (1961:311) indica que los límites que dividen a las oraciones subordinadas sustantivas, que cumplen las funciones de complementos circunstanciales, se confunden con los de las subordinadas adverbiales. Asimismo Alarcos Llorach (1999:554, 557) opina que si se considera la estructura sintáctica interna de las subordinadas adverbiales, estas deberían clasificarse junto con las sustantivas con funciones circunstanciales, pero si se atienden sus funciones semánticas deben clasificarse como temporales, modales, locativas, concesivas, causales, finales y condicionales ${ }^{13}$. Di Tullio (2005:231) plantea una idea semejante a la de Alarcos Llorach ya que advierte que las cláusulas adverbiales presentan dificultades por su estructura sintáctica y también por las categorías semánticas que están involucradas. Gili Gaya (1961:295) propone ejemplos de oraciones sustantivas con funciones circunstanciales en las que la semántica promueve un traslape con las subordinadas adverbiales dados los oficios que cumplen, específicamente con las sustantivas que están introducidas por una preposición más la conjunción que como se muestra en los ejemplos de (3).

(3) a. Entró sin que nadie lo viese. (Gili Gaya 1961:295)

b. Se contentará con que le paguéis la mitad de la deuda. (Gili Gaya 1961:295)

\footnotetext{
${ }^{13}$ Si bien Alarcos Llorach (1999) destaca que el análisis de las oraciones subordinadas adverbiales apunta hacia dos direcciones sintáctica y semántica, considero que la estructura de las oraciones sustantivas y las adverbiales es diferente en lo que se refiere a los nexos que las unen. 
Para Gili Gaya (1961) las oraciones de (3) pueden analizarse como complementos circunstanciales, ya que en ambos ejemplos se trata de oraciones sustantivas que son el término de la preposición que las antecede, sin embargo, no concordamos del todo con su propuesta. En (3)a se muestra que la oración subordinada encabezada por la preposición sin seguida de una oración introducida por la conjunción que es considerada un circunstancial de modo, para Gili Gaya se trata de una oración sustantiva con función adverbial. Pero consideramos que no se trata de una oración sustantiva que es término de la preposición sin, más bien tanto la preposición como la conjunción que se han consolidado y han formado la conjunción sin que, la cual introduce una oración subordinada de modo. Veremos en un apartado posterior ${ }^{14}$ que los nexos o locuciones que introducen a las adverbiales han tomado formas tan variadas que es posible que la unión de una preposición más la conjunción que ya esté tan lexicalizada ${ }^{15}$ que no sea posible separarla. Por lo tanto, se les considera locuciones conjuntivas que sirven de nexo o enlace entre las oraciones subordinadas adverbiales y la oración principal.

Por otro lado, en el ejemplo (3)b la oración sustantiva que según Gili Gaya cumple la función de complemento circunstancial está introducida por la preposición con, no obstante, a diferencia de (3)a dicha oración es el término de la preposición de un verbo de régimen: contentarse con, por lo tanto, no podría considerarse que cumple el oficio de circunstancial, ya que la preposición de esta clase de verbos no desempeña las funciones de complemento circunstancial propiamente. Si se analiza semánticamente a la preposición con más la oración subordinada, su significado no corresponde a ninguna clase de circunstancial, por lo tanto, se trata más bien de una preposición regida por el verbo contentarse, lo cual pone de manifiesto que en dicho ejemplo no existe un traslape de funciones entre una oración sustantiva y una adverbial, se trata de una oración subordinada que cumple la función de término de una preposición, al igual que lo haría un sintagma nominal. Cabe señalar, además, que este traslape sólo podría compararse con las locativas introducidas por donde e incrementadas por una preposición.

\footnotetext{
${ }^{14}$ En 1.3 discutiremos la estructura de las conjunciones que se han formado de una preposición + la conjunción que, propuesta por Pavón (1999 y 2003).

${ }^{15}$ Véase Pavón (2003).
} 
(4) a. El me dejaba jugar en donde yo me sentía bien. (CREA)

b. Marcos se paseaba a caballo por donde los fotógrafos pudieran retratarlo. (CREA)

Ambos ejemplos muestran que cumplen la función de complemento circunstancial de lugar, pero a diferencia de la oración (3)a el incremento de la preposición sigue conservando los rasgos de lugar que posee el relativo donde y en el caso de las sustantivas que son el término de la preposición, el carácter circunstancial lo aporta la unión de ambos, la preposición y la conjunción $q u e^{16}$. Si bien tanto (3)a como las oraciones de (4) tienen una estructura sintáctica semejante, semánticamente existen diferencias entre el relativo donde y la conjunción que los cuales son el término de la preposición. La principal diferencia es que el adverbio relativo donde tiene un valor anafórico y desempeña una función determinada dentro de la oración en la que se encuentra, pero la conjunción que carece de estas características (Pavón 1999:625). Los ejemplos muestran que las cuestiones que surgen de las oraciones subordinadas adverbiales apuntan hacia dos direcciones la sintáctica y la semántica. Veremos en el presente capítulo cuáles son las estructuras que se encontraron en el estudio.

Por otro lado, Porto Dapena (1997:48) advierte que la estructura sintáctica de esta clase de oraciones plantea un problema adicional, el cual también está relacionado con la semántica de las adverbiales. Señala que por tratarse de complementos circunstanciales pueden afectar a toda la oración o bien sólo a una parte de ella, en particular al verbo. Pavón (2012:17) hace alusión a esta clase de oraciones y muestra que cuando "aparecen separadas por una coma que representa una pausa [...] indica que las oraciones subordinadas están en posición externa al predicado verbal". Esta pausa muestra que la subordinada está modificando a la oración completa y no sólo al sintagma verbal como se muestra en el ejemplo (5).

(5) [América empezó a bajar de nivel, en todo, [cuando salió Beenhakker]]. (CREA)

\footnotetext{
${ }^{16}$ Ahondaremos más sobre la estructura de las oraciones temporales incrementada por una preposición en el capítulo siguiente.
} 
Se muestra en (5) que la oración principal se encuentra al principio de la cláusula, el verbo principal es la perífrasis empezar a bajar. La oración subordinada adverbial de tiempo se halla después de la principal, y puede notarse que modifica a la cláusula completa, siguiendo, la pausa mediante comas es una muestra que la modificación es hacia toda la oración completa y no sólo hacia el verbo regente.

Hasta ahora, hemos considerado dos problemas importantes relacionados con las subordinadas adverbiales propias y que consideraremos en el análisis del corpus. Respecto al orden sintáctico que presentan veremos si con todos los nexos que contemplamos en este estudio se presentan los tres diferentes órdenes: el primero en el que la oración principal aparece antes de la subordinada, el segundo en el que la subordinada aparece antes de la principal y el tercero en donde la subordinada interrumpe la secuencia de la principal, es decir, oraciones interpoladas. Asimismo, consideraremos las cuestiones semánticas involucradas con las características propias de un complemento circunstancial, a saber, si la oración subordinada adverbial modifica a toda la oración o solamente al verbo regente. Otra cuestión importante que tiene que ver con lo que se ha considerado el antecedente de las oraciones adverbiales propias será abordado en el apartado siguiente.

1.2 Antecedente o doble complemento circunstancial. En este apartado retomaremos lo mencionado en el Capítulo 1 apartado 2.1, donde hablamos del antecedente callado que las oraciones subordinadas adverbiales propias pudieran tener. Discutimos que la posibilidad de que algunas de ellas tengan un antecedente es viable, sin embargo, dicho elemento no es tácito sino que está expreso en algunas ocasiones. Lo consideramos de este modo porque en el corpus que se analizó se encontraron numerosas oraciones que tienen un antecedente, específicamente en las oraciones locativas ${ }^{17}$. No obstante, también se encontró que en las oraciones subordinadas temporales la posibilidad de que tengan un antecedente es menos probable que en las locativas. Herrero (2005:182) indica que la existencia de antecedente callado no puede sostenerse históricamente en las construcciones de tiempo y modo, ya que el antecedente nunca ha sido un uso frecuente en estas dos clases de oraciones, no obstante,

\footnotetext{
${ }^{17} \mathrm{Si}$ bien, se considera que en las oraciones adverbiales de lugar puede haber un antecedente en forma de adverbio como en: Te veo alli donde quedamos, Roca Pons considera que la oración subordinada adverbial puede ser un complemento del adverbio. Sin embargo, retomaremos esta cuestión en el capítulo siguiente.
} 
subraya que algunos autores proponen la posibilidad de que las subordinadas temporales pudieran tener un antecedente expreso.

Porto Dapena (1997:49) considera que las subordinadas temporales pudieran tener un antecedente expreso, mismo que puede estar representado por un adverbio o bien por una frase prepositiva equivalente como se muestra en (6) (Ejemplos tomados de Porto Dapena 1997:49).

(6) a. Me gusta salir muy temprano, cuando no hay tráfico en las calles.

b. Me gusta salir muy temprano, es decir, cuando no hay tráfico en las calles.

c. Me gusta salir cuando no hay tráfico en las calles.

Indica este lingüista que en estos ejemplos, la oración adverbial no modifica propiamente al antecedente sino a toda la oración, por tanto, estima que el antecedente y la oración adverbial tienen una referencia idéntica y de cierta manera la oración amplía o concreta semánticamente al antecedente. Este autor explica que "lo único que hace la oración de relativo es identificar desde otra perspectiva el momento a que se alude mediante al adverbio; pero este no resulta en absoluto modificado por ella”. Incluso este autor muestra que la simetría que hay entre ambos elementos se evidencia si se introduce una frase de equivalencia como: esto es, o sea o es decir, como se muestra en (6)b. Asimismo, destaca que la omisión del antecedente sólo implica que la subordinada modifique directamente al verbo como se muestra en (6)c, pero la oración no sufre ninguna transformación, ya que, tanto el antecedente como la subordinada son equivalentes. Si bien en algunas oraciones la aparición una frase adverbial que anteceda a la oración subordinada adverbial de tiempo, opinamos que la información que proporcionan no es idéntica, cada uno de ellos aporta información distinta que amplía más el sentido temporal dentro de la oración en la que se encuentran.

Por otro lado, es posible que la frase adverbial que se encuentra en el ejemplo que proporciona Porto Dapena (1997) no sea precisamente el antecedente de la subordinada adverbial, sino que se trate de otro complemento circunstancial de tiempo como puede ocurrir en oraciones simples como: Ayer salí a las doce de la noche o bien Todos llegaron muy temprano en la mañana. En ambos ejemplos hay dos complementos circunstanciales 
temporales juntos compuestos de una frase adverbial y una frase prepositiva. Herrero (2005:183) considera que en oraciones como las de (6), la frase adverbial no es un antecedente, sino que puede tratarse de otro complemento circunstancial. Indica que, aunque no es muy usual que una oración lleve dos complementos temporales, si ese es el caso, el segundo circunstancial de tiempo sólo precisa el alcance del primero de manera similar como Porto Dapena (1997) considera lo hace el antecedente de la subordinada en los ejemplos citados en (6).

Ambas posturas son relevantes, pero apuntan a direcciones diferentes. Herrero (2005) opina que en oraciones como las que se presentaron en (6) se trata de una oración con dos complementos circunstanciales de tiempo, a diferencia de lo que plantea Porto Dapena (1997), quien considera que una frase adverbial o prepositiva que se halla antes de la subordinada adverbial es su antecedente. Ambos subrayan que cuando una oración subordinada adverbial tiene una frase adverbial o prepositiva que la precede, la oración subordinada temporal especifica o amplía el sentido temporal de la frase adverbial o prepositiva. Siguiendo con la idea de Herrero, se encontraron casos en oraciones simples en los que hay dos complementos circunstanciales, mediante la combinación de una frase prepositiva, una frase nominal o una frase adverbial como se ilustra en (7).

(7) a Llegamos el jueves a las diez.

b. Regresaron el martes temprano.

c. Los vimos ayer en la noche.

d. Salimos mañana muy temprano.

En las oraciones de (7) se muestra que cada oración tiene dos complementos circunstanciales compuestos de una frase nominal + una frase prepositiva como se observa en (7)a; una frase nominal + una frase adverbial como se ilustra en (7)b; una frase adverbial + una frase prepositiva como se muestra en (7)c; o bien dos frases adverbiales como se observa en (7)d. En todas las oraciones ambas frases cumplen la función de complemento circunstancial y se muestra que el segundo complemento especifica al primero. Puesto que, a lo largo de este escrito hemos considerado que las oraciones subordinadas adverbiales cumplen las funciones propias de un adverbio, la posibilidad de que puedan aparecer en 
oraciones que tengan dos complementos circunstanciales de tiempo como lo ilustran las oraciones de (7) es altamente admisible, siendo el primer complemento circunstancial una frase adverbial, prepositiva o bien nominal, al igual que ocurre en los ejemplos de (7) con oraciones simples, tal como se observa en las oraciones propuestas por Porto Dapena (1997) y que citamos en (6).

Por lo tanto, atendiendo a ambas posturas, coincidimos en que las oraciones temporales generalmente no tienen un antecedente y en que en caso de que aparezca una frase adverbial o una frase prepositiva, además de la subordinada de tiempo, se trata de dos complementos circunstanciales que coexisten en una sola oración tal como lo muestra Herrero (2005). Asimismo, concordamos en que el segundo complemento circunstancial de tiempo da información más detallada sobre el primero. Sin embargo, en algunos casos observamos que existe ambigüedad en cuanto a qué elemento está modificando la subordinada, si efectivamente la subordinada precisa el sentido de temporalidad que el primer circunstancial aporta o se trata de otra circunstancia. En este caso hablaríamos de la posibilidad de que haya dos complementos circunstanciales de tiempo en una sólo oración y que cada uno de ellos proporciona información temporal sobre la oración, lo cual implica que el segundo circunstancial no necesariamente hace alusión al primero, o bien existe también la posibilidad de que en algunas oraciones la subordinada adverbial no sea un segundo complemento circunstancial sino una aposición. No obstante, por el momento dejaremos de lado esa cuestión, ya que ahondaremos más al respecto en el análisis que haremos de las subordinadas temporales en los siguientes apartados ${ }^{18}$.

Hasta este momento hemos analizado de manera general los problemas que surgen en torno a la estructura sintáctica de las oraciones subordinadas propias de tiempo, lugar y modo. Consideramos que su estructura es variable y que en el aspecto semántico podrían existir traslapes con las subordinadas sustantivas, sin embargo, en el presente capítulo enfocaremos nuestra atención en las subordinadas temporales, ya que en los dos capítulos

\footnotetext{
${ }^{18}$ La posibilidad de que las oraciones subordinadas locativas tengan doble complemento circunstancial podría ser viable si se considera que en construcciones como Comimos allí donde nos dijeron, el adverbio allí no sea un antecedente de la oración subordinada locativa sino otro complemento circunstancial de lugar, y tal como sucede con las oraciones temporales, la subordinada estaría ampliando el sentido locativo que aporta el adverbio. Se discutirá esta cuestión en el capítulo dedicado al análisis de las oraciones subordinadas adverbiales de lugar.
} 
posteriores analizaremos las subordinadas locativas y modales. En el apartado siguiente hablaremos de los nexos que se encontraron en el corpus y los problemas que plantean.

1.3. Nexos o conjunciones temporales. Puesto que los nexos o conjunciones que unen a las oraciones subordinadas con la oración principal han sido, en gran parte, motivo de que se considere variable la estructura sintáctica de las subordinadas adverbiales propias, en este apartado discutiremos cuáles son sus principales características y cómo las trataremos a lo largo de este trabajo. Nos enfocaremos específicamente en los nexos o conjunciones temporales, ya que en el capítulo siguiente discutiremos sobre las oraciones subordinadas adverbiales de lugar.

En relación con las conjunciones o nexos que unen a las oraciones subordinadas adverbiales, la RAE (1973:500) señala que en las oraciones compuestas las palabras de enlace pueden ser pronombres, relativos, adverbios, preposiciones o conjunciones. No obstante, advierte que existen zonas borrosas entre las preposiciones y las conjunciones, ya que ambas sirven de enlace, las primeras relacionan elementos de la oración simple mientras que las segundas sirven de vínculo de oraciones dentro de un periodo. Asimismo, esta gramática subraya que la mayor parte de las conjunciones que se usan se han formado de preposiciones, adverbios y otras palabras, las cuales han tenido que pasar por distintas fases intermedias que hacen que su función gramatical sea inexacta. Para Martínez (1994:46) la unidad que se ocupa de hacer posible la subordinación se llama "transpositor", el cual puede ser un relativo (átono y tónico o interrogativo) o bien alguna conjunción subordinativa. Subraya este autor que los transpositores pueden ser simples como la conjunción que o el condicional si o los históricamente compuestos de varios signos que actualmente se consideran transpositores simples como ya que, si bien, mientras que, etc., o bien pueden ser complejos o múltiples. La RAE (2009\$31.6) indica que la mayor parte de las conjunciones que unen a las oraciones temporales son locuciones conjuntivas, por tanto, constan de más de una palabra. Observamos en el corpus que se analizó que las conjunciones que unen a las subordinadas adverbiales cumplen con las características antes mencionadas, sobre todo las que unen a las oraciones temporales, porque en el caso de la locativas el adverbio relativo donde es el único elemento que funciona como enlace entre la oración principal y la subordinada. 
No obstante, nos interesa mencionar la propuesta de Pavón (2003:201) porque plantea una forma distinta de nombrar a las conjunciones que unen a las oraciones subordinadas adverbiales con la oración principal. Considera esta autora que las conjunciones se clasifican en dos principalmente: conjunciones coordinantes y conjunciones subordinantes. Dentro las conjunciones subordinantes incluye las que introducen a las oraciones subordinadas adverbiales o circunstanciales, las cuales denomina “conjunciones subordinantes léxicas". Utiliza este término porque a diferencia de las conjunciones coordinantes, las conjunciones subordinantes léxicas poseen contenido léxico y además “especifican el tipo de relación semántica que establecen entre la oración subordinada y la principal (causal, condicional, temporal, etc.)”. De modo que, para Pavón las conjunciones subordinantes léxicas son aquellas "que subordinan una oración a otra, de tal manera que la oración subordinada resultante no es sustantiva ni adjetiva" ${ }^{19}$ (2003:211).

Concordamos con la definición que Pavón hace sobre las clases de conjunciones, ya que en el análisis se encontró que la estructura de las conjunciones temporales que unen a las oraciones subordinadas adverbiales con la oración principal tiene distintas formas, desde los relativos adverbiales hasta las que se han formado por medio de adverbios o preposiciones. Asimismo Pavón $(2003: 211,212)$ indica que elaborar una lista de las partículas que corresponden a las "conjunciones subordinantes léxicas" es casi imposible porque 1) existen muy pocos elementos léxicos simples que puedan ser caracterizados como "conjunciones subordinantes léxicas"; 2) porque algunas de estas partículas tienen diferentes funciones dentro de otros contextos; y 3) hay muy pocas "conjunciones subordinantes léxicas" simples y una gran cantidad de locuciones conjuntivas.

En el capítulo 1 (Tabla 1) expusimos las agrupaciones que se han hecho sobre los nexos o conjunciones de las subordinadas temporales y mostramos (Tabla 2) la clasificación que adoptaremos a lo largo de este trabajo. Las agrupaciones mostradas en la Tabla 1 exponen que todas las locuciones conjuntivas o adverbiales que los diferentes

\footnotetext{
${ }^{19}$ Señala Pavón (2003:211) que con el término conjunciones subordinantes léxicas evita "por una parte, mezclar un concepto funcional, como lo es el de circunstancial, con uno categorial, como es el de conjunción, y, por otra, atribuir a este tipo de conjunciones una categoría, la de adverbio, que no les corresponde. La denominación léxica, por otra parte, nos permite diferenciar de la conjunción que, que carece de contenido semántico".
} 
autores recopilaron se comportan de la misma forma, es decir, si bien algunas de ellas están compuestas de dos o más palabras, todas ellas ya se consideran locuciones conjuntivas o adverbiales que cumplen la función de transpositores o unidades subordinativas o conjunciones subordinantes léxicas, usando la terminología que los autores mencionados emplean o bien locuciones conjuntivas o adverbiales como las denominaremos a lo largo del este trabajo.

Por otro lado, señalamos al principio de este apartado que la RAE (1973), y otros autores (Pavón 1999; Roca Pons 1974) muestran que hay una zona borrosa entre las preposiciones y las conjunciones puesto que ambas sirven de enlace entre la oración principal y la oración subordinada. En el corpus estudiado consideraremos oraciones temporales encabezadas por las preposiciones hasta y desde, lo cual nos pone ante una cuestión importante, si se trata de conjunciones o de preposiciones cuyo término es una oración subordinada sustantiva como se ha planteado ${ }^{20}$. Nos inclinamos por considerarlas locuciones formadas de una preposición + la conjunción que por las razones que presentamos a continuación. Pavón (1999:630) muestra que las oraciones subordinadas encabezadas por una preposición + la conjunción que, como en el caso de desde que o hasta que, las cuales incluimos en elanálisis, presentan dos tipos de construcciones: a) [sP P $[q u e . .].] \mathrm{y} \mathrm{b})[\mathrm{sx}[\mathrm{P}+$ que...]]. En relación con la estructura $\mathrm{b})$, explica que la preposición y la conjunción parecen estar cohesionadas porque no pueden separarse si se quiere hacer una coordinación de dos oraciones como se muestra en (8)a; pero cuando la oración con que es el complemento de otras categorías gramaticales es posible la separación, como se muestra en (8)b (ejemplos tomados de Pavón 1999:631):

(8) a. *No he vuelto a verle desde que nos encontramos en Valencia y que me dijo que iba a casarse.

b. Creo que me voy a quedar en casa y que voy a estudiar un poco más.

\footnotetext{
${ }^{20}$ Porto Dapena (1994) considera que las oraciones a las que antecede una frase prepositiva como "Se marchó de donde estábamos", "Dejemos este asunto para cuando volvamos a reunirnos" e "Iré contigo a donde tú vayas" tienen un carácter sustantivo por lo que propone que deben considerarse oraciones adverbiales sustantivadas.
} 
Esta autora muestra, además, que "en el término de la preposición no se pueden coordinar una frase nominal, adverbio o pronombre con una oración encabezada por que", lo cual no sucede en el complemento del verbo como lo ilustra en los ejemplos (9) (tomados de Pavón 1999:631):

(9) a. *Suspendió el examen por su inseguridad y que no se había esforzado demasiado.

b. Quiero un crédito y que me lo den ahora mismo.

Por otro lado, el argumento a favor de la estructura a), es que existe una alternancia entre la oración encabezada por que y otros elementos, como un sintagma nominal, un pronombre, un adverbio, o una oración en infinitivo sin que haya un cambio de significado o de función como se muestra en los ejemplos citados por Pavón (1999: 631):

a. No puedo hacerlo sin \{su consentimiento/que me dé su consentimiento/tener su consentimiento\}.

b. Te esperaré hasta \{entonces/que llegues\}.

Igualmente, Pavón (2012:27) considera que por cumplir las funciones temporales el término de la preposición, en el caso de las preposiciones hasta y desde, no puede sustituirse por un nombre, por ejemplo: *hasta eso o *desde eso. Dadas las funciones que cumplen, la única sustitución que aceptan es con un adverbio de tiempo como: hasta entonces o desde entonces. Por lo tanto, sugiere que ambas construcciones en lugar de compararse con otras oraciones sustantivas introducidas por que, deberían ponerse en paralelo con las oraciones adverbiales encabezadas por el adverbio cuando en construcciones como desde cuando ${ }^{21}$.

Pavón (2003:257) propone en una investigación más reciente que la conjunción que ha sufrido un proceso de incorporación a la preposición hasta ${ }^{22}$, de manera que considera que puede haber una preposición hasta y una conjunción hasta que, que cumple las funciones de conjunción subordinante léxica. Por lo tanto, atendiendo las propuestas de Pavón (1999 y 2003) estimamos que las construcciones hasta que y desde que pueden

${ }^{21}$ Pavón (2012:28) indica que desde cuando sólo se registran de manera esporádica en el español de Colombia, Venezuela y en algunos países de Centroamérica, y también en el español andino y chileno.

${ }^{22}$ Véase Pavón, 2003, capítulo IV. 
considerarse como una conjunción o "conjunción subordinante léxica” cuyos elementos están cohesionados, al grado de que no pueden descomponerse y cuyo valor semántico indica tiempo. Tomaremos la postura de Pavón a este respecto y a lo largo del análisis y consideraremos hasta que y desde que como locuciones conjuntivas formadas de una preposición + la conjunción que.

Ahora bien, en términos generales, las conjunciones que sirven de enlace entre las oraciones subordinadas adverbiales de tiempo con la oración principal, se encontró que el principal nexo o conjunción que las une es el relativo adverbial cuando y es dicho elemento el que tuvo mayor incidencia en el corpus que recopilamos. Es importante señalar que el adverbio relativo cuando presenta un problema importante, es decir, si se considera un adverbio o puede considerarse una conjunción. Herrero $(2005: 185)$ considera que no es una mera conjunción, sino que sigue cumpliendo la función sintáctica de adverbio puesto que desempeña el oficio de complemento circunstancial y además une a la oración subordinada con la principal. En los ejemplos analizados, el relativo cuando, a diferencia del relativo donde, se comporta más como una conjunción, ya que puede aparecer sólo, es decir, no necesita estar incrementado por una preposición como ocurre con el relativo donde. Además, si hay una frase que lo anteceda, la construcción se torna redundante, por ejemplo, el día cuando te vi o el mes cuando llegaste. El relativo cuando puede aparecer adyacente al verbo y funciona como enlace entre la oración principal y la oración que subordina, y al mismo tiempo conserva sus rasgos semánticos de tiempo.

Se consideraron los nexos que otros autores han incluido en sus investigaciones ${ }^{23} \mathrm{y}$ al hacer la recopilación del corpus observamos que los que presentaron más recurrencia fueron mientras, mientras que, en tanto que, en cuanto, apenas, luego que, tan pronto como, antes de que, hasta que y desde que. Asimismo nos inclinamos por analizar solamente este grupo de conjunciones porque son las que presentaban verbos flexionados, dejando de lado aquellas preposiciones + artículo que tienen verbos no flexionados como al en Lo encontramos al caer la tarde, o bien antes de en Antes de salir, cerciórate de no olvidar nada. A lo largo de este capítulo explicaremos los significados que cada una de las

\footnotetext{
${ }^{23}$ Véase Tabla 2.
} 
conjunciones tiene y los diferentes órdenes sintácticos que presentan con respecto a la oración principal.

De manera que, haciendo alusión a las oraciones temporales y considerando las aportaciones que los autores antes mencionados han propuesto, en nuestro análisis se considerarán las oraciones que estén introducidas por el relativo adverbial cuando y por otros nexos que se encontraron en el corpus. Asimismo, analizaremos aquellas oraciones temporales que tienen dos complementos circunstanciales y mostraremos si es posible encontrarlos con todos los nexos o sólo algunos lo permiten. Del mismo modo, analizaremos todos los órdenes sintácticos que se encontraron en el corpus que estudiamos, atendiendo los diferentes nexos que se encontraron y veremos si existe alguna estructura que caracterice a toda la clase de las subordinadas temporales o si presentan una variación muy notable entre ellas. En el apartado siguiente definiremos a las oraciones subordinadas adverbiales y presentaremos el análisis sintáctico de las mismas.

2. Análisis sintáctico de las oraciones adverbiales temporales. Este apartado está dedicado al análisis sintáctico de las subordinadas temporales. Tal como hemos indicado, las oraciones subordinadas adverbiales se pueden clasificar por su estructura sintáctica, sin embargo, la característica principal por la que se les agrupa es según la relación semántica que guardan con respecto a la oración principal. Las subordinadas adverbiales temporales refieren al tiempo en que acontece la acción expresada por el verbo de la oración principal a la que se subordinan, además, son equivalentes a un complemento circunstancial de tiempo (Munguía 1999:187). Asimismo la relación temporal que cumplen con respecto a la principal puede ser de anterioridad, posterioridad o bien de simultaneidad (Pavón 2012:20), lo cual en algunos casos depende del nexo que introduce a la subordinada así como de la clase de verbo que esté involucrado, incluso depende del tiempo verbal que cada oración tenga, como se muestra en el ejemplo (11).

(11) [No obstante, dicha normatividad quedó en el olvido [cuando llegó la elección de consejeros ciudadanos]]. (CREA)

En el ejemplo (11) la oración subordinada: cuando llegó la elección de consejeros ciudadanos muestra simultaneidad con respecto a la oración principal. Puesto que los 
verbos de ambas oraciones son puntuales, y además están en pretérito, indica que ocurrieron al mismo tiempo, un evento terminó y el otro empezó en el mismo momento. Si bien es un tema relevante, en el presente capítulo sólo trataremos de la estructura sintáctica de las oraciones temporales y dejaremos para un capítulo posterior el tema de los tiempos verbales.

Por otro lado, y como hemos explicado en el apartado anterior, los nexos o locuciones conjuntivas o adverbiales son diversos, no obstante, los órdenes sintácticos que siguen las oraciones subordinadas adverbiales son dos principalmente, antes o después de la oración regente, o bien pueden interrumpir la secuencia de la principal, introduciéndose entre alguno de los elementos de la misma. De manera que en el análisis que presentamos atenderemos ambos aspectos, estudiaremos los diferentes órdenes que se encontraron con cada uno de los nexos o conjunciones que incluimos en la presente investigación. Asimismo, examinaremos si todos los nexos o conjunciones permiten que haya dos complementos circunstanciales de tiempo. Empezaremos nuestra descripción con el relativo adverbial cuando, que es vínculo más frecuente de las oraciones subordinadas adverbiales de tiempo, y después seguiremos con los demás nexos, en el siguiente orden: mientras, mientras que, en tanto que, en cuanto, apenas, luego que, tan pronto como, antes de que, hasta que y desde que.

2.1. Cuando. El relativo adverbial cuando es el principal nexo que une a las subordinadas temporales. Significa en el punto, en el tiempo, en la ocasión en que (Diccionario Enciclopédico, 2007). Los órdenes sintácticos que se encontraron con cuando fueron dos principalmente: después de la oración principal, y antes de la oración regente, como se muestra en los ejemplos (12)a y (12)b respectivamente. Un tercer orden que se encontró es el que se ilustra en (2), ahora en (12)c es decir, oraciones interpoladas que rompen la secuencia de la oración regente.

(12) a. [El momento estelar de este trabajo pseudo-periodístico se dio [cuando Paulina Castañón fue invitada al estudio]] (CREA)

b. [[Cuando él hablaba] quería que todo mundo riera]. (CREA)

c. [El alumno [cuando sale al mercado] ya conoce de esto]. (CREA) 
En (12) la oración principal El momento estelar de este trabajo pseudo-periodístico se dio se encuentra al principio de la cláusula y la subordinada temporal cuando Paulina Castañón fue invitada está pospuesta a ella. En (12)b la subordinada de tiempo Cuando él hablaba está al principio de la cláusula y la oración principal: quería que todo mundo riera se ubica al final de la misma. Si bien ambos órdenes son los que sobresalen en el corpus que se analizó, ambos pueden aparecer en distintas estructuras sintácticas más complejas, ya sea dentro de una cadena de tres o cuatro oraciones subordinadas encadenadas en las que las subordinadas temporales con cuando se encuentran.

En el corpus que estudiamos, el orden oración subordinada + oración principal aparece con mayor frecuencia, más de la mitad de las oraciones que se analizaron siguen este patrón sintáctico. El orden sintáctico oración subordinada + oración principal tuvo menor recurrencia, y en ambos casos incluimos las estructuras más complejas en las que se hallan, ya sea que estuvieran dentro de una oración sustantiva o de relativo o bien una adverbial. El tercer orden que consideramos comprende las oraciones interpoladas, las cuales fueron escasas y los elementos pertenecientes a la oración principal que más aparecieron fueron complementos circunstanciales de tiempo o bien el sujeto de la principal. Empezaremos nuestro análisis con el orden oración principal + oración subordinada.

2.1.1. Oración principal + oración subordinada. Como hemos señalado antes, el orden más frecuente que hayamos es oración principal + oración subordinada como se ilustra en (12)a y en las oraciones de (13). En ambos ejemplos se muestra que la subordinada adverbial de tiempo se encuentra después de la principal.

a. [No obstante, dicha normatividad quedó en el olvido [cuando llegó la elección de consejeros ciudadanos]]. (CREA)

b. [La fibrilación cardiaca ocurre [cuando las células del corazón pierden su sincronía natural]]. (CREA)

Asimismo las oraciones adverbiales pueden encontrarse en estructuras más complejas como mencionamos antes, en (14) se muestra que pueden encontrarse dentro de 
oraciones sustantivas y el orden oración principal + oración subordinada adverbial no se altera.

a. Algunas disqueras han alegado [que deberían recibir ambos pagos [cuando los usuarios de Internet eligen las canciones que escuchan en línea]]. (CREA)

b. De otro lado, la experta ha observado [que los insectos manifiestan un mejor mecanismo de defensa [cuando son sometidos por poco tiempo a una mayor exposición tóxica], fenómeno que no ocurre al invertir las variables. (CREA)

c. ¡[Ojalá, una actitud semejante logre [disciplinar a los congresistas estadunidenses [cuando se discuta el acuerdo en viernes]]! (CREA)

En (14)a el verbo de la oración regente es alegar y en (14)b es observar, en ambos ejemplos la oración sustantiva está encabezada por el relativo que, en las dos oraciones la subordinada sustantiva cumple la función de complemento directo del verbo principal. En la oración sustantiva de (14)a el verbo principal es recibir y la subordinada adverbial lo modifica como complemento circunstancial de tiempo. Asimismo se observa que en la subordinada adverbial hay una subordinada de relativo que depende de la frase nominal canciones, la cual cumple la función de complemento directo del verbo elegir. En (14)b el verbo principal de la oración sustantiva es manifestar y al igual que en el ejemplo anterior la subordinada modifica al verbo que la rige. Se muestra en ambos ejemplos que el orden sintáctico oración principal + oración subordinada no cambia a pesar de que se encuentran dentro de otra estructura. Por otro lado, en (14)c el verbo de la oración regente es lograr, pero en esta oración, y a diferencia de los ejemplos (14)a y (14)b, la subordinada sustantiva no está encabezada por el relativo que ni por ningún nexo, se trata del verbo disciplinar el cual es el verbo al que se subordina la oración adverbial; y al igual que en los dos ejemplos anteriores se halla pospuesta a principal.

Igualmente se encontró que el orden: oración principal + oración subordinada puede hallarse dentro de oraciones de relativo como se ilustra en los siguientes ejemplos. 
a. Comprueban lo fácil [que resulta trabajar [cuando se aplican las más elementales normas de administración de negocios]]. (CREA)

b. Como los autos, televisores y otros aparatos domésticos, las PC pueden estar evolucionando hacia un tipo de producto [que los usuarios conservan por un largo tiempo y reemplazan sólo [cuando las máquinas no son compatibles con un nuevo uso popular, como archivos de música digital]]. (CREA)

Ambas oraciones muestran que la subordinada temporal se encuentra en una oración de relativo encabezada por que. En (15) el verbo de la oración principal es comprobar cuyo objeto directo es lo fácil. A esta frase nominal se subordina una oración de relativo cuyo verbo principal es trabajar y la oración subordinada adverbial se encuentra pospuesta. El ejemplo muestra, además, que la función que cumple la subordinada adverbial es de complemento circunstancial, ya que modifica al verbo trabajar, no obstante, se percibe que el alcance de esta llega hasta la frase nominal lo fácil, quizás sea porque en este ejemplo la subordinada temporal tiene un matiz de condición, ya que se puede interpretar como "es fácil trabajar si se aplican las normas elementales". En (15)b el verbo principal es evolucionar, el cual tienen una frase prepositiva hacia un tipo de producto que cumple la función de complemento circunstancial de lugar, dentro de dicha frase se encuentra la frase nominal producto a la que subordina la oración de relativo. El verbo principal de esta oración es conservar el cual está en coordinación con el verbo reemplazar, y es a este último al que se subordina la adverbial. Se muestra en las dos oraciones de (15) que el orden oración principal + oración subordinada no cambia, aunque se encuentren dentro de otra construcción o tengan un sentido diferente del temporal.

Ahora bien, el orden oración principal + oración subordinada también se halla en estructuras más complejas como dentro de una oración de relativo o sustantiva que a su vez se encuentra dentro de otra sustantiva como se ilustra en los ejemplos que siguen.

a. Pero creemos [que no es el mejor uso [que se les pueda dar ahora, [cuando no hay una verdadera crisis de petróleo]]]. (CREA) 
b. [Se espera [que el microcrédito reciba un gran impulso [cuando Fox, ex ejecutivo de Coca-Cola y fabricante de botas vaqueras], asuma la presidencia el $1^{\circ}$ de diciembre]]]. (CREA)

c. Olea reconoce [que las empresas tienen el derecho de [suspender actividades [cuando sus costos se vean afectados por el incremento en los hidrocarburos]]. (CREA)

En las oraciones de (16) se muestra que tanto la subordinada adverbial como la oración de la que depende están dentro de una OSA: (16)a y (16)b o en una sustantiva: (16)c, que a su vez se encuentran dentro de otra oración sustantiva. En (16)a el verbo principal de la oración de relativo en la que se encuentra la oración adverbial es dar. Dicha oración modifica a la frase nominal el mejor uso, el cual funciona como predicativo de la oración sustantiva en la que se encuentra. A su vez la oración sustantiva funciona como CD del verbo creer, que es el verbo principal de toda la cláusula. En (16)b la subordinada adverbial y la oración que es su principal el microcrédito reciba un gran impulso están dentro de una oración subordinada sustantiva que funciona como complemento directo del verbo regente esperar. El verbo regente de la oración sustantiva en la que se encuentra la subordinada adverbial es recibir, al que le sigue el complemento directo un gran impulso, y posterior a este se ubica la subordinada adverbial, la cual se encuentra después de la oración principal.

Por otro lado, en (16)c la subordinada adverbial está dentro de una oración sustantiva que funciona como término de la preposición de, de la frase nominal el derecho. El verbo regente de esta oración, a la cual se subordina la oración adverbial, es suspender. Ambas oraciones se localizan dentro de otra oración sustantiva que funciona como CD del verbo reconocer que es el verbo principal de toda la cláusula. Ambos ejemplos muestran que las subordinadas adverbiales de tiempo pueden localizarse dentro de estructuras más complejas, pero el orden que nos interesa, a saber oración principal + oración subordinada no cambia, sin importar la complejidad de la oración principal en la que se encuentren.

Asimismo, podemos encontrar oraciones adverbiales de las que dependen otras oraciones subordinadas como lo ilustran los ejemplos (17). 
a. Al respecto, [contraatacó Dulce María [cuando pidió que se investigue a Rosario Robles y Andrés Manuel López Obrador sobre los recursos que manejan en apoyo de César Raúl Ojeda]]. (CREA)

b. Más de $99 \%$ del ozono desaparece; [con el tiempo se regenera, [cuando la masa de aire que contiene el agujero de la capa de ozono se mezcla con aire que tiene cantidades más normales del gas]]. (CREA)

En ambas oraciones se muestra que a las subordinadas adverbiales se posponen otras oraciones. En la oración subordinada adverbial de (17)a hay una oración sustantiva que depende del verbo pedir y dentro de dicha oración se encuentra una oración de relativo que depende de la frase nominal recursos. En la subordinada adverbial (17)b también hay dos oraciones subordinadas de relativo, la primera se encuentra en el sujeto de la oración, específicamente en la frase nominal aire y la segunda en el predicado, la cual depende de la frase nominal aire. Al igual que en las demás construcciones que hemos analizado, el orden que no interesa oración principal + oración subordinada se conserva, lo cual por supuesto, no impide que haya otra clase de construcciones que se subordinen, ya sea a la oración principal o a la misma oración adverbial, lo cual no es propio de la subordinación adverbial sino que más bien es un rasgo natural de la subordinación en general. Los ejemplos muestran que el orden sintáctico oración principal + oración subordinada puede encontrarse dentro de otras estructuras sintácticas más complejas, sin embargo, dicha ordenación no cambia, es invariable en cierto sentido, porque, a pesar de que las subordinada adverbial y la oración principal se encuentren dentro de oraciones sustantivas o de relativo el orden oración principal + oración subordinada no cambia. Esto muestra que el considerar variable la estructura de las subordinadas adverbiales no es del todo incuestionable, ya que puede considerarse uniforme en cierto sentido.

2.1.2 Oración subordinada + oración principal. En el corpus que se analizó el orden sintáctico oración subordinada + oración principal tuvo menor frecuencia que el anterior, sin embargo, este orden también puede aparecer dentro de estructuras más complejas, es decir, dentro de oraciones sustantivas o de relativo. En (18) mostramos ejemplos en los que la subordinada se encuentra antes de la principal. 
a. [[Cuando trato de querer] me rechazan tajantemente], y [[cuando sencillamente no me importa] me reclaman mi desdén]. (CREA)

b. [[Además, cuando las compañías de Internet vendan descargas de música], no deberían pagar una cuota de ejecución]. (CREA)

Con respecto a este orden sintáctico Pavón (2012) señala que cuando la oración subordinada adverbial se encuentra al principio de la oración es porque se proporciona información nueva lo cual no ocurre con el orden sintáctico anterior.

Por otro lado, como señalamos antes las oraciones subordinadas adverbiales cuyo orden empieza con las subordinadas se encuentran dentro de estructuras más complejas como se ilustra en los ejemplos de (19).

a. [Advertimos [que [cuando sale otra vez el Sol en la Antártida, después de la larga noche polar], el ozono tiende a desaparecer rápidamente]]]. (CREA)

b. [Y cuenta [que [cuando tenía menos de seis años], su abuela lo llevaba a una esquina [donde un tipo vendía barquillos]]] y, ahí mismo, otro vendía cancioneros. (CREA)

La oración (19)a muestra que la subordinada adverbial está dentro de una oración subordinada sustantiva la cual funciona como complemento directo del verbo principal advertimos. El verbo regente de la oración principal a la que se subordina la oración adverbial es desaparecer y como se muestra, esta se encuentra antes de la oración principal. El ejemplo muestra, además, que la subordinada adverbial modifica al verbo desaparecer y no a toda la cláusula. En (19)b el verbo de la oración regente es contar al cual se subordina una oración sustantiva encabezada por que y que funciona como su objeto directo. En dicha oración se encuentra la subordinada adverbial la cual se encuentra antes de la principal $s u$ abuela lo llevaba a una esquina donde un tipo vendía barquillos. Dentro de esta última oración se encuentra una oración de relativo encabezada por donde y se halla en el complemento circunstancial de lugar a una esquina. 
Los dos ejemplos muestran que las estructuras en las que se encuentran son más complejas, y que el orden oración subordinada + oración principal no se altera. Asimismo los ejemplos muestran que tanto la oración principal como la subordinada pueden tener otras construcciones que dependen de ellas. En (20) se muestran otras estructuras que se subordinan a la oración principal o bien a la adverbial.

a. Claro que [[cuando se enteró de [que el par [que tan alegremente voló a la tribuna del "Stadium Australia"] cuesta 100.000 dólares estadounidenses]]], Greene recordó [que su cuenta bancaria no tiene las dimensiones de las de Woods o Agassi]]. (CREA)

b. [Pero [cuando le pregunté [que de quién era]], me respondió asertivamente [que era anónima]]]. (CREA)

En (20)a el verbo de la oración principal es recordó y tiene una oración subordinada sustantiva que cumple el oficio de objeto directo. La subordinada adverbial se encuentra antepuesta a la principal y funciona como complemento circunstancial de tiempo, por tanto está modificando al verbo de la oración principal. Asimismo, se observa que dentro de la subordinada adverbial hay dos oraciones dependientes, una sustantiva y otra adjetiva. La oración sustantiva es el término de la preposición de que está regida por el verbo enterarse y la oración de relativo está subordinada al sujeto de la oración sustantiva el par.

En (20)b se muestra una estructura semejante, la oración subordinada adverbial se ubica antes de la principal y tanto la principal como la subordinada tienen una oración subordinada sustantiva. El verbo de la oración regente es respondió y la subordinada sustantiva funciona como complemento directo de dicho verbo, la subordinada adverbial funciona como complemento circunstancial de tiempo y se muestra que está modificando al verbo regente. En la oración adverbial también se encuentra una oración sustantiva que depende del verbo preguntar, dicha oración funciona como complemento directo del verbo citado. Las oraciones de (20) muestran que las subordinadas adverbiales de tiempo pueden aparecer en distintas estructuras sintácticas desde las que sólo involucran a la oración principal y a la subordinada adverbial, hasta las que incluyen oraciones subordinadas tanto en la principal como en la subordinada adverbial. 
Hemos visto que el orden sintáctico oración subordinada +oración adverbial puede presentarse dentro de otras estructuras más complejas ya sea dentro de oraciones sustantivas, de relativo, adverbiales incluso, pero el orden en el que se presentan no varía. Por tanto, podría considerarse que, de cierto modo, existe un orden estructural fijo que las oraciones subordinadas adverbiales siguen, por supuesto, el hecho de que haya otras estructuras que se subordinen a ellas no implica que sintácticamente siempre se hallen antes o después de la oración que las rige.

2.1.3 Oraciones interpoladas. Respecto del tercer orden sintáctico que se encontró en el corpus, hay oraciones interpoladas como lo muestra el estudio de Conti (2012). Tales oraciones interrumpen la secuencia de la oración principal y algún elemento de la misma queda antes de la oración subordinada adverbial de tiempo. En (2), ahora en (21)a, mostramos que la adverbial se encuentra entre el sujeto y el predicado de la oración principal. Cabe señalar que se encontraron muy pocas oraciones de este tipo, y sobresalen las adverbiales que interrumpen la secuencia, dejando un complemento circunstancial de tiempo o lugar antes de ella. Veamos en los siguientes ejemplos de oraciones interpoladas en las que el elemento que queda antes de la subordinada adverbial es el sujeto de la oración principal.

a. [El alumno [cuando sale al mercado] ya conoce de esto]. (CREA)

b. Dijeron [que lo más importante [cuando los delincuentes tienen rehenes] es evitar la violencia, el uso de la fuerza, el derramamiento de sangre], y por eso tiene que agotarse el diálogo, la negociación. (CREA)

En las dos oraciones la subordinada adverbial se introduce entre el sujeto y el verbo de la oración regente, rompiendo la secuencia de la oración principal. En (21)b tanto la oración subordinada como la principal se encuentran dentro de una oración sustantiva que funciona como complemento directo del verbo decir. El verbo regente de la oración en la que se encuentra la subordinada adverbial es ser. Los ejemplos de (22) muestran que la oración interpolada interrumpe la secuencia entre un complemento circunstancial y el verbo de oración regente. 
a. Desde luego, [en la Argentina, en especial en la Tierra del Fuego, [cuando se produce el agujero de la capa de ozono] se reciben intensidades de radiación ultravioleta mayores que las naturales, con las consiguientes repercusiones sobre los seres vivos, incluida la población humana]. (CREA) b. En el entrenamiento, [cuando yo hacía una cosa], me decía que no estaba bien, que por qué no corría. (CREA)

En (22)a se muestra que la oración subordinada adverbial encabezada por el relativo cuando aparece antes de la oración principal, sin embargo, el elemento o elementos que nos interesan son las frases prepositivas que se encuentran antes de la subordinada adverbial: en la Argentina, en especial en la Tierra de fuego. Tales elementos pertenecen a la oración regente ya que funcionan como complementos circunstanciales de lugar, pero la subordinada interrumpe la continuidad que hay entre ellos y la oración principal. En (22)b la subordinada adverbial interrumpe la secuencia entre el complemento circunstancial de tiempo: en el entrenamiento y el verbo de la oración principal. Asimismo se muestra que la oración tiene dos complementos circunstanciales: la frase prepositiva y la subordinada adverbial que la precede. Cabe señalar la existencia de dos complementos circunstanciales en una sola oración no es muy común como ya dijimos, sin embargo, abordaremos dicha cuestión en el apartado siguiente ya que se encontraron varios ejemplos en los que hay dos complementos circunstanciales.

Finalizamos este apartado, subrayando que con el nexo cuando puede haber oraciones interpoladas que interrumpen la secuencia de la principal. Como señalamos antes se encontraron pocas oraciones que presentan dicho orden sintáctico, y los elementos que más aparecieron antes de la subordinada adverbial fueron los sujetos y los complementos circunstanciales de lugar o de tiempo. No obstante, no descartamos la posibilidad de que la subordinada adverbial pueda romper la secuencia entre otros elementos distintos a los que se encontraron en el análisis.

2.1.4 Oraciones con dos complementos circunstanciales temporales. En el corpus que se analizó, se encontraron ejemplos en los que las oraciones subordinadas adverbiales se encuentran junto con otro complemento circunstancial, el cual puede ser una frase adverbial 
o una frase prepositiva. Asimismo, obtuvimos ejemplos en los que el primer complemento circunstancial puede ser una frase nominal pero estos casos se confunden con las oraciones de relativo introducidas por el adverbio cuando. No obstante, intentaremos mostrar que en algunos casos no se trata de oraciones de relativo sino de un complemento circunstancial de tiempo en forma de frase nominal. Del mismo modo es importante señalar que la oración subordinada adverbial generalmente es el segundo complemento circunstancial de tiempo dentro de la oración y por tanto, especifica la temporalidad del primero.

Las oraciones con doble complemento circunstancial se encontraron principalmente en el orden oración principal + oración subordinada puesto que en el orden oración subordinada + oración principal no podría ocurrir este fenómeno porque se consideraría que se trata de oraciones interpoladas en las que la adverbial se introduce entre uno de los elementos de la oración principal y el resto de la misma. Véase los ejemplos de (23) cuyo orden sintáctico es oración principal + oración subordinada, asimismo se observa que el primer complemento circunstancial es una frase prepositiva

(23) a. Anticipamos más recompras en el cuarto trimestre, especialmente cuando las compañías se preparan para pre-anunciar sus ganancias. (CREA)

b. La experiencia de Minjárez se inició hace apenas cuatro años, cuando en representación de la Procuraduría de Justicia de Chihuahua acudió a la Ciudad de México a una reunión convocada por las procuradurías General de la República y General del Distrito Federal para intercambiar experiencias sobre secuestros con sus similares del país. (CREA)

c. Pero creemos que no es el mejor uso [que se les pueda dar ahora, cuando no hay una verdadera crisis de petróleo]. (CREA)

En (23)a se muestra que hay dos complementos circunstanciales de tiempo: uno es la frase prepositiva: en el cuarto trimestre y el otro es la oración subordinada adverbial. Siguiendo las propuestas de Conti (2012), Pavón (2012), Porto Dapena (1997) y Herrero (2005) la oración subordinada adverbial modifica a la oración completa y no solamente al verbo anticipar, lo cual se observa por la separación mediante comas que hay entre la frase prepositiva y la subordinada. No obstante, aunque se ha dicho que cuando aparecen dos 
complementos circunstanciales en una misma oración, el segundo, en este caso la subordinada, precisa al primer complemento circunstancial, en la oración observamos cierta ambigüedad en cuanto a dicha modificación. Podría considerase que la subordinada no está ampliando el sentido de la frase prepositiva, más bien al referirse a toda la oración cabe la posibilidad de que no se trate de una ampliación del sentido del primer complemento circunstancial sino que ambos pueden ser independientes y cada uno de ellos esté aportando información temporal sobre la oración principal, sin que ello conlleve que uno tenga que referirse al otro o ampliar su significado temporal.

Asimismo en la oración (23)b, el primer complemento circunstancial es la frase prepositiva hace apenas cuatro años, y la oración subordinada adverbial amplía el sentido temporal de la misma ya que especifica más el momento en que ocurrió la acción del verbo iniciar. Se observó, además, que el primer circunstancial puede ser una frase adverbial como se observa el ejemplo (16)a ahora en (23)c. La oración principal en la que se ubica la subordinada adverbial es se les pueda dar ahora, y es el adverbio ahora el primer circunstancial de la misma. Se observa que la subordinada adverbial especifica el momento al que se refiere el adverbio, y además de que está proporcionando más información al respecto, se muestra que tiene alcance hasta la oración principal a la que ambas se subordinan, es decir, a la oración no es el mejor uso.

Como se muestra en los ejemplos antes mencionados, el primer complemento circunstancial puede ser una frase prepositiva o bien una frase adverbial, sin embargo, hay oraciones en las que una frase nominal podría considerarse como otro complemento circunstancial de tiempo. Los ejemplos de (24) muestran la coexistencia de dos posibles complementos circunstanciales, el primero como frase nominal y el segundo como subordinada adverbial.

a. Él recibió el aviso un día soleado cuando vio una cruz mal colocada en el campo y decidió ponerla en pie, al moverla escuchó un tronido en el cielo. (CREA)

b. La situación será dirimida el miércoles 20, cuando Chile enfrente a Corea y España a Marruecos. (CREA) 
En ambas oraciones hay una frase nominal que antecede a la oración subordinada adverbial un día soleado y el miércoles 20 respectivamente; en ambos casos la subordinada adverbial proporciona más información sobre la temporalidad que expresa la frase nominal. En relación a estos ejemplos la cuestión es si se podría considerar a la frase nominal como el antecedente de la oración subordinada adverbial tal como ocurre en las oraciones de relativo. Los ejemplos indican que no es posible porque en las oraciones de relativo, la subordinada modifica a la frase nominal, pero en los ejemplos de (24) se observa que la subordinada no está modificando a la frase nominal sino a toda la oración y además está especificando el momento en que ocurre la acción del verbo de la oración principal que ya está expreso la frase nominal. De manera que sea una frase adverbial, prepositiva o nominal la que preceda a la oración subordinada adverbial, no implica que sean el antecedente de la subordinada sino que puede tratarse de dos complementos circunstanciales que coexisten en una misma oración.

Por otro lado, mencionamos antes que en el orden sintáctico oración principal + oración subordinada es donde se presenta principalmente la aparición de dos complementos circunstanciales, ya que en el orden oración subordinada + oración principal, generalmente el primer circunstancial se ubica al principio de la cláusula como se ilustra en las oraciones de (25), pero en este caso podría considerarse una oración interpolada puesto que la subordinada se introduce entre el complemento circunstancial y el resto de la oración a que pertenece.

a. En 1994, cuando México se vio obligado a devaluar su moneda, pocos se hubieran imaginado que superaría a Brasil tan rápido en términos del tamaño de su economía. (CREA)

b. Desde el 11 de septiembre, cuando el derrumbe de las Torres Gemelas sacudió todo el país del norte, todos los controles se endurecieron. (CREA)

En (25)a la frase prepositiva en 1994 se encuentra al principio de toda la cláusula, incluso se halla antes de la subordinada adverbial cuando México se vio obligado a devaluar su moneda, al parecer ambos funcionan como complementos circunstanciales de tiempo de la oración principal. Se observa que en este ejemplo la subordina adverbial 
precisa el sentido temporal que encierra la frase prepositiva, ya que especifica que durante ese año ocurrió la devaluación de la moneda, sin embargo, esta oración puede tener dos interpretaciones. Por un lado, cabe la posibilidad de que la frase prepositiva pertenezca a la oración subordinada y no a la principal ya que puede parafrasearse como Cuando México se vio obligado a devaluar su moneda en 1994 pocos se hubieran imaginado que superaría a Brasil tan rápido en términos del tamaño de su economía. Y por otro lado, es posible que la frase prepositiva pertenezca a la oración principal y se topicalice colocándose al principio de la cláusula. Así la oración subordinada rompe la secuencia de la oración regente, y por tanto, se consideraría una oración interpolada en la que un complemento circunstancial aparece antes de la oración subordinada.

No ocurre lo mismo en el ejemplo (25)b, ya que la frase prepositiva desde el 11 de septiembre corresponde a la oración regente porque puede parafrasearse como sigue: Cuando el derrumbe de las Torre Gemelas sacudió todo el país del norte, todos los controles se endurecieron desde el 11 de septiembre. No obstante, dicho orden suena un tanto marcado por la separación de los complementos circunstanciales, lo cual indica que deben estar juntos para que la oración subordinada logre especificar la temporalidad que aporta el primer complemento circunstancial.

Si bien en el orden oración subordinada + oración principal no se encontraron ejemplos en los que el primer complemento circunstancial se quede dentro de la oración principal, consideramos que pudiera haber oraciones en las que se encuentre dicho orden sintáctico, tal como sucede en una oración simple por ejemplo: Ayer se fueron a dormir hasta las doce. Sin embargo, al parecer con las oraciones subordinadas adverbiales no es tan frecuente dicha ordenación ya que se torna marcada como lo señalamos en el párrafo anterior.

Ahora bien, puesto que las oraciones subordinadas adverbiales cumplen las funciones de un adverbio, se encontraron ejemplos en los que otro adverbio modifica a la oración subordinada adverbial como se ilustra en los siguientes ejemplos. 
Justo cuando nos marchábamos de Juárez la compañía Scientific-Atlanta, el segundo fabricante estadunidense de armazones de televisores, anunció que había eliminado 1300 empleos en México debido a la disminución de la demanda. (CREA)

El ejemplo (26) el adverbio es el que precisa o modifica a la subordinada. Dado que el adverbio justo es de cantidad, suele intensificar el significado que tiene otro adverbio que esté adyacente a él, por ejemplo, justo aquí, justo ahora, justo ayer, justo entonces, por lo tanto, se trata de un adverbio que intensifica a otro adverbio que en este caso tiene forma de oración subordinada adverbial. Otro ejemplo de un adverbio que modifica a la oración subordinada adverbial es la oración (23)a, en la que el adverbio especialmente se refiere a la subordinada.

A lo largo de este apartado, describimos las tres estructuras sintácticas que las oraciones subordinadas adverbiales introducidas por el adverbio relativo cuando presentan. Las oraciones subordinadas de tiempo se presentan en estructuras variadas, es decir dentro de oraciones sustantivas o de relativo, pero los órdenes sintácticos que presentan son los que hemos señalado, antes de la principal, después de ella o bien interpoladas, rompiendo la secuencia de la principal.

2.2 Mientras. El nexo que analizaremos en este apartado es mientras, el cual transmite distintos sentidos. De acuerdo con la definición que el Diccionario panhispánico de dudas de la RAE proporciona, mientras "puede funcionar como adverbio de tiempo o como conjunción, expresando simultaneidad entre dos acciones"; o bien puede significar "durante el tiempo en que", según el diccionario en línea Word Reference, por ejemplo: Alicia barría las escaleras mientras Rosa descansaba tranquilamente en el sillón. Otro significado que tiene mientras es de condición, por ejemplo, en la siguiente oración: Mientras no hagas la tarea, no pasaras el curso, muestra el citado ejemplo que se requiere que el verbo de la subordinada esté en subjuntivo. No obstante, centraremos nuestra atención en el significado que se que refiere a dos acciones que ocurren simultáneamente en el tiempo. Si bien el uso de mientras en el que nos enfocaremos indica coincidencia en la temporalidad de la acción de la oración principal y la acción de la subordinada, la simultaneidad de algunas de las 
oraciones que se encontraron en el corpus es que una de ellas dura más que la otra, pero en algún momento del tiempo ocurren simultáneamente.

Ahora bien, respecto al orden sintáctico al igual que con el nexo cuando, se encontraron dos órdenes que predominan: oración principal + oración subordinada y oración subordinada + oración principal, pero a diferencia de las oraciones encabezadas por cuando, con el nexo mientras no se encontraron oraciones interpoladas. Al igual que con el relativo adverbial cuando, con el nexo mientras el orden que apareció con más asiduidad fue oración principal + oración subordinada a diferencia del orden oración subordinada + oración principal que se encontró con menor regularidad.

Asimismo se encontraron oraciones que se hallan dentro de otras estructuras más complejas, como oraciones sustantivas o adverbiales, si bien en el corpus que se analizó se encontraron subordinadas adverbiales con el nexo mientras dentro de oraciones adjetivas es posible que puedan hallarse en dichas contrucciones, por ejemplo en la oración: La película que vimos mientras contestabas el examen se trataba de un adolescente con problemas familiares. Cabe señalar, además, que con el nexo mientras tampoco se encontraron casos en los que coexistieran dos complementos circunstanciales como ocurre con el relativo cuando. Sin más preámbulo, empezaremos nuestro análisis con el orden que tuvo mayor frecuencia: oración principal + oración subordinada.

2.2.1 Oración principal + oración subordinada. Como hemos mencionado, el orden que más apareció en el corpus que se analizó es oración principal + oración subordinada como lo muestran las oraciones que presentamos en (27). Asimismo con el nexo mientras hay mayor variación semántica a diferencia de otros nexos.

a. [Todo esto se preguntaba un cenizo Beto [mientras, cabizbajo y sentado sobre un costal de café, viajaba rumbo a Temazcal]]. (CREA)

b. ["El gobierno está dejando morir la agricultura", dijo [mientras señalaba la corriente]]. (CREA)

Los ejemplos de (27) indican la simultaneidad que transmite el nexo mientras. En (27)a se muestra la simultaneidad en la flexión de los verbos, ambos están en copretérito, el 
sujeto se preguntaba algo mientras viajaba. Del mismo modo, en (27)b la coincidencia temporal lo indica la acción de decir y señalar que ocurren al mismo tiempo.

Por otro lado, con el orden oración principal + oración subordinada, mientras también puede significar "en cambio", en dicha construcción las acciones de las oraciones son simultáneas, pero el significado del nexo las contrapone como se observa en el ejemplo (28).

[El S60 recibió 12.5 puntos, [mientras el S40 obtuvo 11.5 puntos]]. (CREA)

Muestra la oración de (28) que las oraciones suceden al mismo tiempo pero se comparan en que una recibió un mayor número de puntos que la otra. Por otro lado, el orden sintáctico oración principal + oración subordinada también puede encontrarse en construcciones más complejas como se ilustra en

a. Pero lo más común es [que el GEA se repliegue en la investigación [mientras dura el evento]]. (CREA)

b. Tanto la CE como el Parlamento están conscientes de [que la presencia europea en América Latina decayó en los años recientes, [mientras crecía la de Estados Unidos]]. (CREA)

c. Añade, por el contrario, [que el crecimiento de la mancha urbana y la especulación inmobiliaria continuarán [mientras las autoridades mantengan “intereses contradictorios y políticas de fomento ambiguas".]] (CREA)

Se muestra que las oraciones de (29) tienen el orden sintáctico oración principal + oración subordinada, además, se encuentran dentro de una oración sustantiva encabezada por que, no obstante, el sentido que tienen no es el mismo. En (29)a la oración sustantiva, en la que se encuentra la subordinada, está en la posición de atributivo ${ }^{24}$, se muestra, además, que las acciones son simultaneas, aunque el sentido que transmite el subjuntivo puede indicar la posibilidad de que ambas acciones ocurran al mismo tiempo. Por otro lado, la oración (29)b también indica simultaneidad, pero demuestra que las acciones se

\footnotetext{
${ }^{24}$ Esta clase de oraciones se conoce como copulativas identificativas, especificativas o inversas, las cuales pueden formarse de «un grupo nominal + ser+ oración subordinada sustantiva», por ejemplo, El problema es que no nos entendemos (RAE 2010: 709).
} 
contraponen, en la principal el sujeto decayó y en la subordinada creció. Asimismo se encontraron oraciones cuyo significado es condicional como se muestra en (29)c. Al igual que en las oraciones de (29)a y (29)b, en (29)c la subordinada se encuentra dentro de una oración sustantiva que funciona como complemento directo del verbo añadir, pero en este ejemplo mientras no indica simultaneidad sino condición.

Otras construcciones en las que el orden sintáctico oración principal + oración subordinada también se encontró son dentro una oración adverbial como lo ilustra (30):

[El hígado libera una gran cantidad de glucógeno [que se transforma en glucosa], para [que el organismo no resulte dañado severamente [mientras la persona no se alimente]]]. (CREA)

Se muestra en (30) que la subordinada introducida por mientras se encuentra dentro de una oración adverbial de finalidad encabezada por para que. Ambas oraciones se hallan dentro de una oración de relativo introducida por el relativo que, la cual se subordina a la frase nominal glucógeno, misma que funciona como objeto directo del verbo liberar. En el aspecto semántico, la oración muestra que la adverbial introducida por mientras indica que la acción de la oración a la que se subordina y la que encabeza son simultaneas. Señalamos en la parte introductoria de este apartado, es decir en 2.1.2, que no se encontraron oraciones que tengan dos complementos circunstanciales como ocurre con el relativo adverbial cuando. En el apartado siguiente veremos el orden sintáctico oración subordinada + oración principal.

2.2.2 Oración subordinada + oración principal. Mencionamos que este orden tuvo menor frecuencia, pero al igual que con el orden anterior, se muestra que mientras tiene sentidos distintos y que puede hallarse en otras construcciones más complejas.

(31) a. Mientras comíamos, dejábamos que nuestros parlamentos articularan esa conversación ritual. (CREA)

b. [Mientras lo llevaban cargando] otros les pegaban en el abdomen. (CREA) c. [Mientras la tecnología vaya creciendo más y más], más y más satélites necesitarán ser lanzados para remplazar a los viejos aparatos]. (CREA) 
Las oraciones de (31) muestran el orden sintáctico oración subordinada + oración principal, en (31)a y (31)b las acciones son simultáneas, lo cual se muestra porque en ambas los verbos tanto de la principal como de la subordinada están en copretérito, lo cual muestra que las acciones ocurren en un mismo momento. No obstante, en (31)c las acciones de la principal y la subordinada son simultáneas pero no se muestra la misma simultaneidad que en las oraciones de (31)a y (31)b, en este caso mientras significa en tanto o conforme, lo cual podría parafrasearse como: En tanto la tecnología vaya creciendo más satélites serán lanzados. En las oraciones de (32) se muestra que el orden sintáctico oración subordinadas + oración principal se halla en construcciones más complejas.

a. [Por ello compartimos con Bacallao la recomendación de que [mientras el pensamiento bayesiano va desplazando al clásico], conviene utilizar las pruebas estadísticas habituales únicamente [cuando se pueda garantizar un alto grado de plausibilidad de la hipótesis nula a contrastar]]. (CREA) b. [Tuvieron que pasar otros 24 años [para que, [mientras realizaba la investigación para el guión de La tumba sin sosiego], pudiera obtener ese documento clave de la historia argentina reciente]]] (CREA)

En (32)a se muestra que la subordinada adverbial encabezada por mientras se encuentra dentro de una oración sustantiva introducida por que, la cual depende de la frase prepositiva de. En el aspecto semántico la oración indica simultaneidad, pero el significado de mientras, como en el ejemplo (31)c, puede ser "en tanto" o "conforme", por tanto las acciones de la principal como de la subordinada ocurren al mismo tiempo y se pueden parafrasear como sigue: Conforme el pensamiento bayesiano va desplazando al clásico, conviene utilizar las pruebas estadísticas habituales. Por otro lado, en (32)b el orden sintáctico oración subordinada + oración principal se encuentra dentro de una oración adverbial de finalidad. En esta construcción las acciones de la oración principal y la subordinada son simultáneas, no obstante, se muestra que una de ellas dura más que la otra, es decir, la acción de la subordinada estaba en progreso, dado que el verbo realizar está en copretérito, y la de la principal ocurrió y terminó en algún momento de la acción de la subordinada, ya que la acción de la oración principal está en pretérito del subjuntivo. Es 
interesante ver que la combinación de tiempos verbales que se presentan con este conector difieren de los que se observan con otros nexos, no obstante, hablaremos más sobre esta cuestión en un capítulo posterior.

2.2.3 Mientras que. Hemos señalado que las oraciones subordinadas adverbiales de tiempo también se introducen por medio de locuciones conjuntivas, mientras que es una locución conjuntiva que a diferencia del adverbio o conjunción mientras, se usa para contraponer dos acciones simultáneas, con sentido equivalente a 'en cambio' según el DRAE. Dicho significado también lo puede tener mientras como vimos en algunos ejemplos del apartado anterior, pero en el caso de la locución conjuntiva mientras que dicho significado es el único que tiene. Con esta locución conjuntiva apareció principalmente el orden sintáctico oración principal + oración subordinada y se apreció menor número de ejemplos con el orden oración subordinada + oración principal, y como se mencionó al principio en 2.1.2 no se encontraron oraciones interpoladas con esta conjunción.

Las oraciones de (33) muestran el orden sintáctico más recurrente con la locución conjuntiva mientras que: oración principal + oración subordinada.

a. En los últimos cuatro años, la demanda se ha disparado casi al triple, mientras que la oferta se mantiene estancada. (CREA)

b. De hecho, sólo Televisión Azteca y Multivisión han recurrido a estas opciones, mientras que Televisa se conforma con explotar sus fórmulas más conocidas e importar programas extranjeros, básicamente de Estados Unidos. (CREA)

c. El Centro de Investigación en Matemáticas impartió dentro de las instalaciones de Mabe una especialidad en Ingeniería de Calidad, mientras que el Centro de Investigación Científica de Yucatán aceptó modificar el esquema bajo el cual había cotizado un proyecto para la recuperación de plásticos de extrusión. (CREA)

En las tres oraciones se distingue el significado que tiene mientras que, es decir, la simultaneidad de las acciones que se contraponen. En (33)a se encuentra la oración principal seguida de la oración subordinada, pero en (33)b y (33)c se observan 
construcciones más complejas dentro de la subordinada adverbial. Si bien en el corpus que se analizó no se encontraron oraciones subordinadas introducidas por mientras que dentro de otras construcciones complejas como ocurre con cuando y mientras, lo cual por supuesto no implica que no pueda haber, hay estructuras complejas dentro de la subordinada adverbial. En (33)b hay una oración sustantiva que es el término de la preposición con regida por el verbo conformarse y cuyo verbo no está flexionado. En (33)c se muestra que en la subordinada encabezada por mientras que hay una oración sustantiva que depende del verbo aceptar, la cual cumple la función de objeto directo y cuyo verbo no está flexionado. Dentro de dicha oración sustantiva hay otra oración sustantiva que depende de la preposición bajo.

Ahora bien, como mencionamos anteriormente, el orden oración subordinada + oración principal se encontró con escasa frecuencia, en (34) se muestra dicho orden. Además, se observa la contraposición de las acciones de ambas oraciones.

$$
\begin{aligned}
& \text { Sin embargo, mientras que la infección con el virus Variola ocurre } \\
& \text { únicamente en humanos, los otros tres pueden infectar tanto a humanos } \\
& \text { como a otros animales vertebrados. (CREA) }
\end{aligned}
$$

Las oraciones que presentamos con el nexo mientras presentan sólo dos órdenes como hemos señalado antes, sin embargo, lo relevante de este nexo es el aspecto semántico, ya que tiene diferentes matices en cada una de las oraciones en las que se encontró. Presentamos las que indican simultaneidad estricta, es decir en la que los verbos están en el mismo tiempo verbal, que generalmente es el copretérito: Juan nadaba mientras Elsa se asoleaba, Yo reñía mientras él me miraba. Sin embargo, mientras tiene otros sentidos en los que también existe la simultaneidad de las acciones, en las que las flexiones verbales indican que una de las acciones está en proceso mientras la otra ocurre y termina. Cuando los dos verbos están flexionados en el mismo tiempo verbal indica que ambas acciones están ocurriendo simultáneamente sin que eso indique que una termina antes que la otra. Por otro lado, con el nexo mientras no se encontraron casos en los que haya dos complementos circunstanciales juntos, ni oraciones interpoladas, Conti señala que este 
fenómeno sólo ocurre con las oraciones encabezadas por cuando y con algunas de las oraciones subordinadas adverbiales propias.

Respecto de la locución conjuntiva mientras que se encontraron dos órdenes sintácticos principalmente, pero el orden oración subordinada + oración adverbial se presentó con muy poca regularidad. Asimismo a diferencia de los otros dos nexos, cuando y mientras, no se encontró dentro de oraciones complejas como sustantivas, de relativo o bien adverbiales, pero se observó que había oraciones que dependen de ella.

2.3 En tanto que. Las oraciones subordinadas adverbiales de tiempo también pueden introducirse por locuciones adverbiales como entretanto o en tanto. Este apartado está dedicado a la locución adverbial en tanto que de la cual se encontraron muy pocas oraciones. Esta locución adverbial tiene un sentido parecido al que comunica mientras que se contraponen dos acciones pero al parecer no expresan simultaneidad sino que indica que una de las acciones ocurrió antes que la otra aunque ambas hayan sucedido en el pretérito, por ejemplo. Según el DRAE, esta locución también significa "durante algún tiempo intermedio". De acuerdo con los órdenes sintácticos que hemos estado analizando: oración principal + oración subordinada $\mathrm{u}$ oración subordinada + oración principal, con esta locución adverbial predomina oración principal + oración subordinada. Si bien pueden encontrarse dentro de otras estructuras más complejas el orden sintáctico que más se halló con más frecuencia es el ya mencionado. A diferencia de las oraciones introducidas por cuando y mientras que: las oraciones introducidas por en tanto que se ubican después de la principal, como se muestra en los ejemplos de(35).

a. El plusmarquista Butch Reynolds se posesionó del tercer sitio con 45.21, en tanto que Stefan Balosak, de Eslovaquia, alcanzó el cuarto lugar con 45.33. (CREA)

b. El Grupo México acreditó ampliamente su capacidad jurídica, financiera y administrativa, en tanto que la capacidad técnica fue acreditada a través de una carta compromiso con la empresa ferroviaria South Orient Railroad Company LTD. (CREA) 
c. El martes fueron suspendidos 58 vuelos hacia Estados Unidos o procedentes de esa nación, en tanto que el miércoles fueron 56 y el jueves hasta el mediodía, 56. (CREA)

Las tres oraciones muestran el mismo orden sintáctico, en el que la oración principal aparece antes de la subordinada, no obstante, la temporalidad que expresan es diferente. En (35)a y (35)b se muestra que hay cierta simultaneidad en el momento en que ocurrieron las acciones de la principal y la subordinada. En (35)a ambas oraciones, principal y subordinada, están en pretérito y ocurrieron casi al mismo tiempo, por lo que se puede parafrasear como sigue: El plusmarquista Butch Reynolds se posesionó del tercer sitio con 45.21 mientras que Stefan Balosak, de Eslovaquia, alcanzó el cuarto lugar. En (35)b ocurre lo mismo, los eventos de la principal y la subordinada están en pretérito por lo que se interpreta que ocurrieron en un mismo momento, por lo que se puede parafrasear: Acreditó ampliamente su capacidad jurídica mientras que la capacidad técnica fue acreditada a través de una carta compromiso. No obstante, en (35)c, aunque las oraciones principal y subordinada están en pretérito, se entiende que no ocurrieron en el mismo momento, ya que en ambas oraciones el complemento circunstancial indica que la oración de la principal ocurrió antes que la subordinada, una tuvo lugar el martes y la otra el miércoles. De modo que, la conjunción adverbial en tanto que en este ejemplo sólo contrapone dos acciones que ocurrieron en el pasado pero que sucedieron en distintos momentos.

Asimismo la locución conjuntiva en tanto que se encontró en construcciones más complejas como se ilustra en la oración (36).

Fernández Vega había publicado un texto en el que afirmaba que la PGR investigaba a Salinas Pliego por presuntas transferencias financieras irregulares, en tanto que Ciro Pérez Silva y Juan Manuel Venegas se habían referido "a la investigación que realiza la PGR en torno del supuesto enriquecimiento ilícito de Raúl Salinas que incluye el préstamo de 29.8 millones de dólares a Ricardo Salinas". Estructura diferente de las anteriores

En (36) se muestra que la oración subordinada introducida por en tanto se encuentra en una subordinada sustantiva introducida por la conjunción que, a su vez esta oración 
sustantiva se encuentra dentro de otra subordinada sustantiva que es término de la preposición en. Asimismo la subordinada adverbial encabezada por en tanto tiene dos oraciones subordinadas relativas, la primera depende de la frase nominal investigación y la segunda se subordina a la frase nominal enriquecimiento.

2.4 Entre tanto, en cuanto, apenas. Las locuciones que analizaremos en este apartado son entre tanto, en cuanto y la conjunción temporal apenas. Dado que se encontraron muy pocos ejemplos con dichos nexos, consideramos conveniente estudiarlos en un solo apartado.

Según el Diccionario panhispánico de dudas de la RAE entre tanto es una locución adverbial que significa "mientras" o "mientras tanto". En cuanto es una locución conjuntiva temporal cuyo significado es "tan pronto como", esta locución conjuntiva tiene distintos significados y el significado que más sobresale es "por lo que se refiere" o "en lo que respecta a", no obstante, nos centraremos únicamente en el significado que tiene un valor temporal. Por otro lado, apenas es un adverbio que puede funcionar como conjunción temporal que significa "en cuanto, en el momento en que”. Cabe señalar que el corpus en línea de la RAE: CREA, no se encontraron concordancias con la citada conjunción, por lo tanto, se incluirán ejemplos propios.

En lo que se refiere al orden sintáctico, dado que en los tres casos obtuvimos muy pocas concordancias, se encontró lo siguiente: con las tres hallamos el orden sintáctico oración principal + oración subordinada como se muestra en los ejemplos de (37).

a. Compatriotas como los indígenas y Laura viven en la realidad real, entretanto los gobernantes existen y proceden en la realidad virtual. (CREA) b. Asimismo, Nash advierte a los turistas acerca del precio por el "banderazo" y de fijarse en que el chofer encienda el taxímetro en cuanto aborden el taxi. (CREA)

c. Abrió el regalo apenas se lo dimos. (CREA)

Se muestra en los ejemplo de (37) que el orden sintáctico oración principal + oración subordinada. En (37)a se presenta la locución adverbial entretanto y se distingue el 
significado que transmite el cual es similar al de mientras. En cuanto a (37)b se observa que la subordinada adverbial se ubica dentro de una oración sustantiva que es el término de la preposición de regida por el verbo fijarse. Y en (37)c se muestra la ordenación sintáctica en la que la oración principal se ubica al principio de la cláusula, se observa, además que el significado que dicha locución conjuntiva tiene es igual al que presenta en cuanto, ambos indican que una acción ocurre inmediatamente después que la otra.

Con respecto al orden oración subordinada + oración principal, solamente con la locución conjuntiva temporal en cuanto y con apenas se encontró dicha ordenación como se muestra en las oraciones de (38).

a. En cuanto oí silbar las primeras balas sentí que me había equivocado. (CREA)

b. Ellos no quieren regresar todo ya que en unos meses, en cuanto terminen Titanic, lo tendrían que regresar de nuevo. (CREA)

c. Apenas llame, vienes por mí.

d. Apenas leyeron la carta, nos dieron las buenas noticias.

Las oraciones muestran que el orden sintáctico es oración subordinada + oración principal. Puesto que se encontraron muy pocos ejemplos con estas tres locuciones, no se hallaron ejemplos de oraciones interpoladas o en las que las oraciones adverbiales, introducidas por las locuciones analizadas, estuvieran en construcciones más complejas, no obstante, consideramos que puede haber ejemplos en los que puedan encontrarse, como lo ilustra la oración (37)b, la cual se halla dentro de una oración sustantiva, como ya habíamos señalado, o bien como en (38)b en la que se halla una oración sustantiva que depende del verbo principal: sentir. Por tanto, pudiéramos encontrar oraciones como las siguientes: $\mathrm{Me}$ dijo que apenas recibieras el recado fueras a verla, Quiere que en cuanto suene el teléfono conteste, Pídele a la maestra que te revise la tarea en cuanto llegues a clase.

2.5 Luego que. Entre las locuciones conjuntivas que unen a las oraciones adverbiales temporales se encuentra luego que la cual significa "tan pronto como" o "al punto que" según el DRAE. Esta locución indica sucesión de acciones. Con respecto al orden sintáctico que presenta esta locución apreciamos que ambos órdenes son posibles, en el que la oración 
principal se ubica antes de la subordinada y en el que la subordinada aparece antes de la principal. No obstante, al igual que con los demás nexos o conjunciones que hemos analizado, con la locución luego que predomina el orden en que la principal está al principio de la cláusula y la subordinada o bien subordinadas están posteriores a ella. Se encontraron muy pocos ejemplos en los que la subordinada introducida por el conector luego que está al principio de la oración. Al igual que con las conjunciones que se analizaron en los apartados anteriores, no se encontraron oraciones interpoladas.

En los ejemplos de (39) se muestran los dos órdenes sintácticos que se encontraron con luego que.

a. La jugada se produjo luego que Luis González recuperó un balón en medio campo. (CREA)

b. Y luego que murió Diego y murió Frida, la hija de Nita volvió a México para vender aquellos lienzos. (CREA)

Se muestra en (39)a que la oración principal se encuentra antes de la subordinada y en (39)b la subordinada se localiza al principio de la cláusula. En ambos casos se distingue la sucesión de las acciones de las oraciones, una ocurre inmediatamente después de la otra. Se observó, además que puede haber otras oraciones subordinadas que dependan de la oración adverbial o de la principal como se muestra en los ejemplos de

a. Según el análisis de la FTSE, la caída fue consecuencia de los fuertes desequilibrios que registraron la semana pasada todos los mercados financieros, luego que se diera a conocer que Estados Unidos mantiene un débil crecimiento económico que está lejos del repunte. (CREA)

b. Dicen los de inteligencia que se están organizando grupos de resistencia civil, que van a insistir en que se convoque a elecciones luego que se acepte al doctor De Villoux para que sean civiles los que gobiernen de nuevo. (CREA)

En las oraciones de (40) el orden sintáctico en el que se observan las diferentes subordinadas es oración principal + oración subordinada, lo cual como hemos mencionado 
anteriormente no cambia, aunque ambas se hallen dentro de otras construcciones más complejas o bien otras oraciones se subordinen a ellas. La oración (40)a muestra que la subordinada adverbial se encuentra dentro de una oración de relativo encabezada por que, que depende de la frase nominal desequilibrios, asimismo la subordinada adverbial tiene una oración subordinada sustantiva que depende del verbo conocer. En (40)b la subordinada adverbial se encuentra en una construcción más compleja. Se halla dentro de una oración sustantiva que es el término de la preposición en, la cual está regida por el verbo insistir. Dicha oración se encuentra dentro de una oración de relativo encabezada por el relativo que y que depende de la frase nominal resistencia. Esta segunda oración subordinada se encuentra dentro de una oración sustantiva introducida por que, misma que funciona como complemento directo del verbo decir, el cual es verbo principal de toda la cláusula. Asimismo se muestra que en la oración subordinada adverbial hay una oración subordinada adverbial de finalidad la cual tiene otra subordinada sustantiva que funciona como sujeto de la misma.

En lo que respecta a las oraciones cuyo orden es oración principal + oración subordinada, no se encontraron ejemplos de construcciones más complejas en las que dicho orden se hallara. Puesto que luego que también puede funcionar como conjunción discursiva se apreciaron ejemplos de construcciones coordinadas como se muestra en las oraciones de (41).

a. Les pagó a los empresarios y luego que supuestamente saneó las finanzas, les volvió a vender, pero léalo bien, les prestó dinero para que compraran. (CREA)

b. Le otorgamos toda la responsabilidad a un hombre para que nos gobierne y luego que termina su gestión lo satanizamos por sus errores. (CREA)

c. Si bien, el poder desgasta a los presidentes cuando ejercen el poder, luego que terminan su mandato, la mayoría, han quedado revitalizados en forma inusitada. (CREA)

Se muestra en los ejemplos de (41)a y (41)b que las oraciones adverbiales introducidas por luego que, cuyo orden es oración subordinada + oración principal, están en 
coordinación con otras oraciones. En el caso de (41)a con una oración simple y en (41)b con una oración compleja. En (41)c la subordinada adverbial no está en coordinación con la oración que la precede, pero la separación por las comas indica que no está subordinada a ella. En los tres ejemplos se aprecia que el significado que aporta la locución es de sucesión de dos acciones.

Señalamos al principio de este apartado que no se encontraron oraciones interpoladas con la locución conjuntiva luego que. No obstante, se encontraron oraciones con dos complementos circunstanciales temporales como sucede con el relativo adverbial cuando. Al igual que ocurre con las oraciones adverbiales introducidas por cuando, las oraciones con luego que que tienen otro complemento circunstancial temporal, muestran que la oración subordinada esté especificando el sentido temporal del otro complemento circunstancial como se muestra en los siguientes ejemplos (42).

a. Lo ves en la tarde, luego que regresemos de trabajar. (CREA)

b. El empate llegó cinco minutos después luego que Daniel Alcántar buscó despejar con la cabeza un largo servicio en lugar de dejarlo a su portero Carlos Briones. (CREA)

En ambos ejemplos hay un complemento circunstancial temporal que se encuentra en la oración principal: en (42)a la frase prepositiva en la tarde y en (42)b la frase nominal cinco minutos después. En ambas oraciones la subordinada adverbial detalla el sentido temporal que aporta el primer complemento circunstancial de tiempo. En (42)a especifica el momento en que lo verá durante la tarde, es decir luego que regresen de trabajar; de la misma forma, en (42)b la subordinada adverbial precisa el momento en que ocurrió el empate, cinco minutos después cuando Daniel Alcántar buscó despejar.

La locución conjuntiva luego que muestra que puede presentarse en dos órdenes principalmente, siendo el orden más frecuente oración principal + oración subordinada. Al igual que con las adverbiales introducidas por cuando pueden tener dos complementos circunstanciales de tiempo. 
2.6 Tan pronto como. Otra locución adverbial que se usa como subordinante de las oraciones adverbiales es tan pronto como, su significado es igual al que tienen las locuciones luego que, apenas y en cuanto. Con relación al orden sintáctico que tienen las subordinadas adverbiales con esta locución, al igual que con las conjunciones anteriores el orden que predomina es aquel en el que la principal se ubica al principio de la cláusula y la subordinada o subordinadas se encuentran después de ella. Se halló menor cantidad de concordancias con las subordinadas al inicio de la cláusula. Al igual que con las locuciones anteriores no se encontraron ejemplos de oraciones interpoladas, tampoco casos en los que hubiera dos complementos circunstanciales como ocurre con las adverbiales introducidas por el relativo cuando o la locución adverbial luego que analizada en el apartado anterior.

Las oraciones de muestran los dos órdenes sintácticos que se encontraron en el corpus.

a. Prometió inyectar recursos tan pronto como se consolidara la democracia. (CREA)

b. Las semillas del arce plateado (Acer saccharinum) germinan tan pronto como son liberadas. (CREA)

c. Tan pronto como llegó al hotel, se comunicó con Philipe Morris. (CREA)

d. Tan pronto como se sienta cocido, se retira del fuego y se deja enfriar. (CREA)

Las oraciones (43)a y (43)b muestran el orden sintáctico: oración principal + oración subordinada y los ejemplos (43)c y (43)d el orden oración subordinada + oración principal. Se observa, además, que en las cuatro oraciones la subordinada adverbial está modificando a la oración principal y que dicho nexo se refiere a la sucesión de dos acciones. Asimismo hay oraciones adverbiales encabezadas por tan pronto como que se encuentran en otras construcciones complejas como se ilustra en los ejemplos de (44).

a. Stein describe el funcionamiento interno del padre negativo, que surge tan pronto como el niño interior empieza a reclamar sus derechos y sus necesidades básicas de amor, compasión y comprensión. (CREA) 
b. Como un beneficio extra, el proceso iterativo evita que los servidores TLD se entretengan demasiado para así poder atender tan pronto como sea posible otras peticiones. (CREA)

c. Días antes del cambio Jacqueline le dijo a Elena, la cocinera, que tan pronto como se instalaran en la nueva casa podría tomar sus vacaciones. (CREA)

Los ejemplos de (44) muestran que las oraciones introducidas con tan pronto como pueden localizarse dentro de construcciones complejas, es decir, dentro de oraciones sustantivas, de relativo o adverbiales. En (44)a y (44)b el orden sintáctico es oración principal + oración subordinada, y ambas se encuentra en otras construcciones. En (44)a la subordinada adverbial está dentro de una oración de relativo encabezada por que, misma que depende la frase nominal padre. En (44)b la subordinada adverbial se localiza en una oración adverbial de finalidad introducida por para y que a su vez está dentro de una subordinada sustantiva encabezada por que y que cumple la función de complemento directo del verbo evitar. En (44)c la oración adverbial se encuentra antes de la principal y ambas se encuentran en una oración sustantiva introducida por que, misma que funciona como complemento directo del verbo decir. En los tres ejemplos se observa que la subordinada adverbial modifica al verbo de la oración principal.

2.7 Antes de que. Es una locución conjuntiva que según el Diccionario Panhispánico de dudas de la RAE surgió del cruce de antes que y antes de, señala dicha obra que esta variante fue censurada por algunos gramáticos al principio por considerarla dequeísta, no obstante, actualmente es aceptada como válida. Tanto antes que como antes de que tienen un significado temporal en el que una de las acciones precede a la otra. En relación con el orden sintáctico que estamos analizando, la mayoría de las oraciones que se encontraron presenta a la principal al inicio de la cláusula y la subordinada se encuentra en una posición posterior. A pesar de que no se encontraron tantas oraciones en las que la subordinada esté al principio de la cláusula, se observa que no es un orden tan usual como el anterior.

Veamos en los siguientes ejemplos los dos órdenes que más aparecieron en el corpus. 
a. Un moderador revisa el contenido del mensaje antes de que pueda ser leído por los integrantes del grupo de discusión. (CREA)

b. Se ofreció como mediador antes de que las policías actuaran. (CREA)

c. Aun antes de que ese órgano partidista conociera la convocatoria, su equipo había enviado su currículum a los medios de comunicación. (CREA)

d. Antes de que se congelaran los depósitos bancarios, las películas brasileñas ocupaban $23 \%$ del mercado. (CREA)

Muestran las oraciones de (45) los dos órdenes sintácticos que se encontraron con esta locución conjuntiva. En (45)a y (45)b la oración principal se ubica antes de la subordinada; en (45)c y (45)d la subordinada está al principio de la cláusula. Asimismo se encontraron oraciones en las que las oraciones adverbiales pueden estar dentro de otras construcciones más complejas como se ilustra en (46).

a. El y Dianne Solís, de The Wall Street Journal, fueron los únicos periodistas que tuvieron acceso a Salinas antes de que el expresidente diera fin a su ayuno. (CREA)

b. El asunto se solucionó cuando "verificaron las autoridades que se purificaba el agua no sólo antes de que entrara a los tanques, sino que también antes de que saliera". (CREA)

c. Nos indica que aún no resolvemos nuestro mestizaje ni nuestra admiración o respeto por las culturas que florecieron aquí antes de que incluso la lengua española existiera en el mundo. (CREA)

d. Dijo que antes de que esto ocurriera, yo tendría mi cambio de adscripción. (CREA)

Los cuatro ejemplos de (46) muestran que las oraciones adverbiales se encuentran en otras estructuras, en (46)a la subordinada adverbial se halla dentro de una oración de relativo encabezada por que, la cual depende de la frase nominal periodistas. En (46)b la subordinada adverbial introducida por antes de que se encuentra en una oración sustantiva que cumple la función de complemento directo del verbo verificar. Esta oración a su vez está dentro de una oración adverbial encabezada por el relativo cuando que cumple el oficio 
de complemento circunstancial de solucionar que es el verbo principal de toda la cláusula. En (46)c la subordinada adverbial se encuentra dentro de una oración de relativo que depende de la frase nominal culturas, la citada oración a su vez se halla dentro de una subordinada sustantiva que tiene la función de complemento directo del verbo regente indicar. Finalmente en (46)d el orden sintáctico de la oración subordinada adverbial es oración subordinada + oración principal, a diferencia de los ejemplos de (46)a, (46)b y (46)c cuyo orden es oración principal + oración subordinada, dicha oración se encuentra en una oración sustantiva que funciona como complemento directo del verbo decir. De modo, que los ejemplos citados muestran que las oraciones subordinadas adverbiales encabezadas por la locución conjuntiva antes de que puede encontrarse en diferentes construcciones sintácticas y el orden sintáctico se conserva tal como ocurre con los demás nexos o conjunciones.

Asimismo, se encontraron oraciones adverbiales introducidas por antes de que, que tienen otro complemento circunstancial de tiempo como se muestra en los ejemplos de (47).

a. En 1980, ella fue examinada por la Junta, antes de que la nombrara directora del Instituto de Investigaciones Estéticas. (CREA)

b. Primero televisan a todo el país antes de que la nacionalicen. (CREA)

Se distingue en ambas oraciones de (47) que hay otro complemento circunstancial además de la subordinada adverbial. En (47)a al principio de la oración principal se ubica la frase prepositiva en 1980, la cual puede considerarse como otro complemento circunstancial de tiempo que está modificando al verbo de la oración principal examinar, lo cual implica que la subordinada adverbial especifica la información temporal que aporta la frase prepositiva. Sin embargo, el hecho de la frase prepositiva esté separada por una coma pudiera interpretarse como que está fuera de la oración como una especie de aposición.

Ahora bien, en (47)b al principio de la cláusula se encuentra el adverbio primero $^{25}$ mismo que puede considerarse como otro complemento circunstancial o adjunto de tiempo.

\footnotetext{
${ }^{25}$ Según el Diccionario Panhispánico de dudas de la RAE primero es un adjetivo ordinal que significa "que ocupa el primer lugar en una serie", pero también puede funcionar como adverbio y tiene un significado semejante.
} 
A diferencia de las oraciones que hemos analizado, ya sea con el relativo cuando o con la locución conjuntiva luego que, en los que se encontraron ejemplos de doble complemento circunstancial y en los que la oración subordinada detallaba la temporalidad del primer complemento circunstancial, en la oración de (47)b la subordinada no precisa al primer complemento circunstancial. Más bien se puede interpretar que la oración subordinada adverbial modifica a toda la oración principal incluyendo al adverbio primero, lo cual no implica que la subordinada esté especificando el sentido temporal que aporta el adverbio.

2.8 Hasta que / Desde que. Mencionamos al principio de este capítulo, que las oraciones temporales tienen una amplia variedad de nexos o conjunciones que las unen a la oración principal y que las preposiciones también cumplen la función de enlace entre las oraciones subordinadas y la principal. Asimismo en el apartado 1.3 discutimos las cuestiones que surgen en torno a la estructura de las preposiciones + la conjunción que, las cuales sirven de conjunción subordinante. El problema que la composición de una frase prepositiva + la conjunción que presenta es que su estructura sintáctica es diferente de las locuciones conjuntivas y adverbiales que se analizaron en los apartados precedentes.

Porto Dapena (1997:17) considera que esta clase de oraciones pueden estudiarse como oraciones adverbiales sustantivadas, lo cual podría ser un análisis conveniente ya que cumplen las mismas funciones que las oraciones temporales introducidas con el relativo cuando o las locuciones conjuntivas o adverbiales que hemos analizado hasta ahora, pero sintácticamente tienen otra estructura. No obstante, como explicamos en el apartado 1.3, tomaremos la postura de Pavón (1999), quien considera que un grupo de preposiciones, como hasta y desde, se han cohesionado con la conjunción que o bien la conjunción que se ha incorporado a la preposición (Pavón 2003) y han formado una locución conjuntiva que funciona como vínculo de las oraciones subordinadas adverbiales temporales. Por tanto, consideraremos hasta que y desde que como locuciones conjuntivas encabezadas por una preposición que cumple las tareas de un nexo subordinante.

Ahora bien, al igual que hemos hecho con las oraciones subordinadas adverbiales de los apartados anteriores, estudiamos los órdenes sintácticos que las oraciones subordinadas introducidas por las preposiciones hasta y desde presentan, así como la semántica de las 
mismas y observamos lo siguiente. La preposición hasta se usa para expresar el límite temporal, espacial o de cantidad con respecto a alguna cosa, no obstante, para fines de este trabajo sólo nos interesa el que expresa límite de tiempo de alguna acción. Con esta preposición, todas las oraciones registradas en el corpus tienen el orden sintáctico oración principal + oración subordinada, no se encontraron oraciones en las que la subordinada estuviera localizada antes de la oración principal como se muestra en los ejemplos de (48).

a. Dejamos de vernos por una temporada hasta que, por casualidad, nos encontramos en una exposición. (CREA)

b. Allí vivió libre hasta que se incorporó a la Guerra de los Diez Años. (CREA)

Se muestra en los ejemplos de (48) el único orden sintáctico que se encontró en las oraciones temporales con la preposición hasta, lo cual muestra que, por el significado de la misma, es necesario que se ubique después de la oración principal puesto que el límite de tiempo que expresa va dirigido al verbo de la oración regente. Sin embargo, quizás sea posible hallar oraciones en las que la subordinada se ubique antes de la principal como en los siguientes ejemplos: Hasta que vengas, me voy, Hasta que comió estuvo tranquilo, Hasta que hablé con él entendí por qué no me llamó. Asimismo notamos que las oraciones en las que la subordinada está al principio de la cláusula también podrían llevar la forma negativa, por ejemplo: Hasta que no vengas no me voy, Hasta que no comió no estuvo tranquilo. De la misma forma, se encontraron oraciones con la preposición hasta dentro de construcciones complejas y el orden es el mismo oración principal + oración subordinada como se muestra en las oraciones de (49).

a. Los informantes nativos dijeron a Sahagún que una ciudad no existía hasta que se instalaba en ella la música. (CREA)

b. El universo comienza con el estallido de una bola de materia condensada que se dilata más y más hasta que empieza a enfriarse. (CREA)

En (49)a la subordinada adverbial se localiza dentro de una oración sustantiva que cumple la función de complemento directo del verbo decir y se observa que la oración subordinada adverbial se halla después de la principal. En (49)b la oración adverbial se 102 
ubica dentro de una oración subordinada de relativo encabezada por el pronombre relativo que, la cual depende de la frase nominal materia, asimismo se muestra que el orden sintáctico de la subordinada adverbial es oración principal +oración subordinada.

En lo que respecta a la preposición desde, según la Nueva gramática de la lengua española $(2007 \S 29.4 .3 \mathrm{~g})$ "introduce el tiempo de origen, de arranque o de partida de un proceso o de una situación". Señala esta gramática que cuando se construye con oraciones subordinadas, el término de la preposición desde es la que indica el punto temporal. Puesto que el término de la preposición lo constituye una oración sustantiva, de modo que la citada gramática clasifica esta construcción dentro de las relativas sin antecedente expreso es decir dentro de las relativas libres. Considera que este análisis es apropiado porque existe la alternancia de las construcciones "desde que te vi" o bien "desde cuando te vi". No obstante, consideramos que, si bien el término de la preposición es una oración sustantiva, observamos que la alternancia que propone la RAE (2007): desde con el relativo cuando no es muy usual y pudiera considerarse una construcción marcada. Por tanto, como señalamos al inicio de este apartado concordamos con la propuesta de Pavón (1999 y 2003) quien muestra que desde que es una locución conjuntiva que cumple las mismas funciones de las locuciones adverbiales y conjuntivas que hemos analizado en los apartados anteriores.

Ahora bien, en lo que se refiere a la combinación de la preposición desde + la conjunción que, se encontraron tres diferentes órdenes sintácticos como se ilustra en las oraciones de (50).

a. El trastorno inició desde que el paciente cursaba el décimo grado escolar. (CREA)

b. Total, desde que Darwin alcanzó las islas Galápagos, cerca de la costa de Ecuador, el mundo se convirtió en un lugar mucho más interesante. (CREA) c. Ninguna sociedad, desde que hay comunicación simbólica, puede abstenerse de educar. (CREA)

En (50)a se muestra que la oración principal se localiza al principio de la cláusula, en (50)b la oración subordinada se ubica antes de la oración principal y en (50)c la subordinada se encuentra dentro de la oración principal, es decir, se trata de una oración 103 
interpolada ya que rompe la secuencia de la oración principal. Se observa que el sujeto de la oración regente se encuentra al principio de la cláusula y el resto de la oración se halla después de la subordinada. Los ejemplos indican que con la combinación de la preposición desde + la conjunción que puede haber tres distintos órdenes sintácticos, incluso los tres pueden encontrarse dentro de otras construcciones más complejas como se muestra en los ejemplos de (51).

a. Queremos agradecer al pueblo de Oaxaca el trato de hermanos de lucha que hemos recibido desde que entramos al territorio de este Estado. (CREA)

b. Creo que desde que nací estuvo conmigo. (CREA)

c. Con este antecedente podemos afirmar que el hombre, desde que nace hasta que muere, es un ser social. (CREA)

Se muestra en (51)a que la oración adverbial cuyo orden sintáctico es oración principal + oración subordinada se localiza en una oración de relativo que depende de la frase nominal lucha. Esta segunda oración se encuentra a su vez dentro de una oración sustantiva encabezada por el verbo agradecer la cual actúa como complemento directo del verbo regente querer. En (51)b la oración subordinada adverbial está dentro de una oración sustantiva introducida por que, la cual tiene la función de complemento directo del verbo creer. En esta construcción el orden sintáctico difiere de (51)a en que la subordinada adverbial se encuentra antes de la oración principal. Finalmente (51)c muestra una oración adverbial interpolada que está dentro de una oración sustantiva encabezada por la conjunción que cuya función es de complemento directo del verbo afirmar. Asimismo en (51)c se muestra que las oraciones adverbiales con las preposiciones desde y hasta pueden aparecer juntas ya que una indica el origen del tiempo y la segunda el límite del tiempo desde que nace hasta que muere.

Para finalizar este apartado, señalamos que con las preposiciones desde y hasta no se encontraron oraciones con doble complemento circunstancial de tiempo. 
3. Conclusiones. El análisis sintáctico de las oraciones subordinadas adverbiales de tiempo muestra que el orden sintáctico con respecto a la oración principal es de tres tipos. Hay dos órdenes sintácticos principalmente: el primero se refiere a que la oración principal se ubica antes de la subordinada y el segundo alude a lo contrario, la subordinada se encuentra después de la principal. Un tercer orden sintáctico que se encontró, sólo con algunas locuciones conjuntivas o adverbiales, es el de oraciones interpoladas, las cuales interrumpen la secuencia de la oración principal y alguno de los elementos de la misma queda antes de la subordinada que se introduce entre los elementos de la principal. En los ejemplos que se analizaron la oración subordinada se introduce entre el sujeto y el verbo de la oración principal.

De manera que tal como Dryer (2007) y Diesel (2001) muestran en sus estudios tipológicos de orden sintáctico, el español por ser una lengua cuyo orden es SVO, tiene el subordinante antes de la oración que subordina y presenta los dos órdenes que el tipo de lenguas SVO presenta en relación a las oraciones subordinadas y que ya hemos mencionado. El corpus analizado muestra que el orden que tiene mayor recurrencia es en el que la oración principal se encuentra antes de la oración subordinada, por lo tanto, podría decirse que el orden no marcado de las oraciones subordinadas adverbiales de tiempo en el español de México es oración principal más oración subordinada y el orden marcado es oración subordinada más oración principal. El tercer orden que encontramos también puede considerarse un orden marcado, ya que solamente aparece con algunos nexos.

Asimismo, el análisis muestra que los nexos o locuciones conjuntivas o adverbiales que las unen con la oración principal son diversos, además, tales conjunciones poseen significados diferentes que logran que el sentido de las oraciones adverbiales temporales cambie absolutamente y ya no sean temporales sino condicionales o concesivas.

Por otro lado, no con todos los nexos puede haber frases prepositivas, adverbiales o nominales que puedan considerarse como otro complemento circunstancial, además de la subordinada de tiempo, pero si alguna de estas frases puede aparecer con otros nexos y no solamente con el relativo cuando, muestra que puede considerarse como otro complemento circunstancial de tiempo y no como un antecedente del relativo cuando. 


\section{Capítulo III}

\section{La estructura sintáctica de las oraciones subordinadas adverbiales de lugar}

Introducción. A lo largo de este trabajo hemos discutido las diferentes cuestiones que las oraciones adverbiales propias generan tanto en el aspecto sintáctico como en el semántico. En el capítulo II se analizó la estructura sintáctica de las oraciones subordinadas adverbiales de tiempo, y de manera muy breve, señalamos algunos problemas que las subordinadas adverbiales de lugar presentan, por lo tanto, en el presente capítulo hablaremos sobre este tipo de oraciones.

Las oraciones subordinadas de lugar presentan un traslape con las oraciones subordinadas de relativo sobre todo en los casos en los que el relativo donde está precedido por un adverbio o una preposición. Sintácticamente las oraciones que tienen esta clase de construcción pueden considerarse oraciones de relativo en la medida en que son el término de la preposición que las antecede, pero las funciones que cumplen dentro de la oración siguen siendo de complemento circunstancial o adjunto de lugar. Las gramáticas presentan diferentes posturas sobre la estructura sintáctica de esta clase de oraciones, de modo que a lo largo de este capítulo discutiremos lo que se ha dicho al respecto con el objetivo de tomar una posición. En el apartado 1 hablaremos de la estructura sintáctica de las oraciones subordinadas de lugar, de su traslape con las otras dos clases de oraciones (1.1), del relativo adverbial donde que funciona como nexo subordinante (1.2), del orden sintáctico de las oraciones subordinadas adverbiales de lugar con respecto a la oración (1.3) y finalmente en el apartado 2 haremos un análisis sintáctico de las oraciones que se encontraron en el corpus.

1. Estructura sintáctica de las oraciones subordinadas adverbiales de lugar. En el capítulo II indicamos que las lenguas cuyo orden es SVO, el subordinante se ubica antes de la clausula que subordinan, asimismo los dos órdenes que sigue este tipo de lenguas es, oración principal + oración subordinada o bien oración subordinada + oración principal. 
Observamos que los diferentes órdenes que las subordinadas temporales presentan son los siguientes: pospuestas a la oración principal, antes de la principal, o bien interrumpiendo la secuencia de la oración principal, es decir, oraciones interpoladas (Conti, 2012). No obstante, consideramos que, si bien las subordinadas de lugar pertenecen a la misma clase de oraciones adverbiales, es decir, a las propias, notamos que hay diferencias en su estructura sintáctica. Las oraciones subordinadas de tiempo tienen mayor movilidad dentro de la oración en la que se encuentran pero las oraciones locativas no. Otra diferencia importante que presentan es respecto a los nexos o conjunciones, si es que se les puede llamar de ese modo, que las encabezan. El principal enlace que une a las oraciones subordinadas de lugar con la principal es el relativo adverbial donde, el cual puede estar incrementado por otro adverbio, por ejemplo: allí donde, allá donde, aquí donde; o bien por una preposición como: en donde, de donde, hasta donde, etc. La cuestión que surge en relación a esta composición de adverbios y preposiciones es cómo considerar su estructura, si como una frase adverbial que tiene como complemento una oración subordinada adverbial o como un caso de dos complementos circunstanciales de lugar en la misma oración, o bien como una aposición para las expresiones: allí donde, allá donde, aquí donde; y para las frases: en donde, de donde, hasta donde como una preposición cuyo término es una oración subordinada de relativo y que pudiera considerarse una oración relativa adverbializada como propone Porto Dapena (1997). En este apartado presentaremos dos estructuras diferentes y señalaremos cuál de las dos adoptaremos a lo largo de este trabajo.

Por otro lado, a diferencia de las tres clases de oraciones que componen a las oraciones subordinadas adverbiales propias: temporales, locativas y modales, las subordinadas adverbiales de lugar son las que presentan un mayor traslape con las otras dos clases de oraciones subordinadas, nos referimos a las sustantivas y a las de relativo. De modo que para iniciar con este capítulo discutiremos esta cuestión y mostraremos que el traslape que presentan está relacionado con el relativo adverbial que las encabeza, ya que tanto funcionalmente como estructuralmente son distintas.

1.1. Oraciones subordinadas de relativo, sustantivas y adverbiales de lugar. En el capítulo I mencionamos que la estructura sintáctica de las oraciones adverbiales propias es 
muy semejante a la ordenación de las subordinadas de relativo. Ambas clases de oraciones presentan un traslape que ha generado que muchos lingüistas ya no consideren a las subordinadas adverbiales como una clase de subordinación diferente, sino que se les incluye dentro de las oraciones de relativo, atribuyéndoles el nombre de relativas libres, por tener un antecedente callado o elidido (Brucart 1999; Pavón 2012; RAE 2010; RAE 2007) Asimismo expusimos en el capítulo I que nuestra postura difiere de lo que señalan tales lingüistas, ya que consideramos que no hay un antecedente elidido en las oraciones subordinadas adverbiales propias. Explicamos las razones por las que se les debe considerar como una clase diferente de los otros dos tipos de subordinación que hay en el español, criterio que basamos en las funciones que esta clase de oraciones cumple dentro de la oración a la que se subordinan. Aunque una postura funcional ha sido cuestionada, reconocemos que es la más adecuada para hacer una clasificación precisa de las tres clases de oraciones subordinadas propias que hay. Si bien señalamos en el capítulo I que no aceptamos la propuesta de un antecedente elidido, también planteamos que si las oraciones subordinadas adverbiales propias pudieran tener un antecedente, este no sería tácito sino que sería explícito, y estructuralmente sería una frase adverbial, pero no una frase nominal como sucede con las oraciones de relativo. De modo que en este apartado discutiremos primeramente el traslape que las oraciones adverbiales presentan con las oraciones de relativo y las sustantivas teniendo en cuenta su estructura sintáctica y las funciones que cada una de ellas cumple dentro de la oración. Posteriormente nos referiremos al antecedente de las oraciones subordinadas adverbiales de lugar.

Hemos mencionado que las oraciones subordinadas adverbiales de lugar son las que presentan un mayor traslape con las oraciones de relativo, ya que el adverbio relativo donde introduce a ambas clases de oraciones. De igual modo, en el capítulo II se mencionó que las oraciones subordinadas de tiempo rara vez presentan un antecedente ${ }^{26}$ (Herrero 2005:179), por tanto, el traslape que muestran con las oraciones de relativo es menos evidente. A continuación, mostraremos las diferencias sintácticas que se encontraron, pero también

\footnotetext{
${ }^{26}$ En el capítulo II discutimos que históricamente es insostenible que las subordinadas adverbiales de tiempo tengan un antecedente, y las oraciones adverbiales de lugar y modo tienen más probabilidad de tener un elemento que las preceda.
} 
algunas las semejanzas funcionales que las oraciones de relativo presentan con las subordinadas adverbiales de tiempo.

Las oraciones de relativo se introducen con el adverbio relativo donde como se muestra en los ejemplos de (1):

(1) a. [La casa donde vive] tiene un portón de madera antigua.

b. [El salón donde celebraron su quinto aniversario] da a la avenida principal.

c. [La carta donde manifiesto mi desacuerdo] está sobre la mesa.

Las tres oraciones de (1) tienen un valor locativo, ya que hacen alusión a lugares como lo ilustran los ejemplos (1)a y (1)b, no obstante, hay ejemplos en los que el sustantivo que precede a la oración encabezada por donde no es un lugar, pero semánticamente actúa como tal, como se muestra en el ejemplo (1)c. Si bien por sus características semánticas se les podría clasificar como oraciones subordinadas adverbiales, dada su estructura sintáctica se les considera oraciones subordinadas adjetivas o de relativo, ya que se referieren al nombre que las antecede. Al igual que en las oraciones de relativo encabezadas por el relativo que, las oraciones introducidas por el relativo donde presentan el movimiento de un elemento de la oración subordinada, el cual alude a la frase nominal que la antecede. No obstante, las funciones que estos dos relativos, que y donde, cumplen dentro de la oración subordinada es diferente como se ilustra en los ejemplos de (2):

(2) a. La casa [que compré el año pasado]

b. La casa [que tiene dos balcones]

\section{c. La casa [donde crecí]}

En la subordinada de (2)a que cumple la función de complemento directo, por lo tanto, podría parafrasearse como compré la casa el año pasado. En (2)b que desempeña el oficio de sujeto de la oración subordinada que encabeza, por tanto, puede interpretarse como la casa tiene dos balcones. Pero en (2)c la función que el relativo donde cumple es de complemento circunstancial de lugar, ya que la oración se enunciaría como crecí en la casa 
o bien crecí allí. Nótese que en este caso la oración no puede parafrasearse con una frase nominal como en los dos ejemplos anteriores, sino que donde debe sustituirse por una frase prepositiva o bien por un adverbio de lugar dada la función que cumple dentro de la oración. El ejemplo (2)c justifica el traslape que presentan estas dos clases de oraciones, muestra que el oficio que desempeña una oración de relativo encabezada por donde es igual a las funciones que cumplen las oraciones adverbiales de lugar que se encuentran adyacentes al verbo, pero estructuralmente son distintas y la modificación que hacen no es hacia los mismos elementos dentro de la oración. Las oraciones de relativo modificarán a una frase nominal mientras que las subordinadas adverbiales modificarán al verbo como se muestra en la oración (3) o en algunos casos a toda la oración a la que se subordinan.

(3) Siempre estudio donde no hay mucho ruido.

Por otro lado, su traslape con las oraciones sustantivas también es evidente, pero puede disolverse más fácilmente. Por un lado, porque el enlace que las une es distinto, y por otro lado, porque sólo ocurre cuando el verbo regente es transitivo. En las oraciones sustantivas el nexo que las une a la oración principal es el adverbio interrogativo dónde que además, como hemos señalado, siempre va antecedido o regido por un verbo transitivo que puede subcategorizar una oración subordinada, la cual cumple la función de complemento directo como se muestra en las oraciones (4)a y (4)b:

(4) a. Sé [dónde vives].

b. Olvidé [dónde dejé las llaves].

c. Leo [donde hay buena iluminación].

Se muestra en las oraciones (4)a y (4)b que la subordinada encerrada en corchetes es el complemento directo de los verbos saber y olvidar respectivamente, por lo que la subordinada puede sustituirse por un pronombre: lo sé y lo olvidé, respectivamente. Pero a diferencia de las oraciones presentadas en (4)a y (4)b, la oración (4)c muestra que la subordinada encabezada por donde no es el complemento directo del verbo leer sino que funciona como complemento circunstancial de lugar del mismo, ya que la sustitución por un pronombre es imposible: *lo leo, la sustitución tendría que ser por leo allí. Los ejemplos 
muestran que el nexo que vincula a las adverbiales de lugar con la oración principal es el relativo donde, el cual no sólo puede aparecer con verbos transitivos como se muestra en el ejemplo (4)c, sino que puede aparecer con otras clases de verbos como los intransitivos. Por tanto, el traslape que estas dos clases de oraciones presentan puede deshacerse al analizar la naturaleza semántica de los verbos que las rigen. Habrá algunos verbos que acepten oraciones subordinadas sustantivas con valor locativo introducidas por dónde, pero que configurarán como complemento directo y no como complemento circunstancial como se muestra en las oraciones de (5).

(5) a. Recuerdo [dónde vives].

b. Olvidé [dónde vives].

c. Escuché [dónde vives].

d. Escribe [dónde vives].

En todos los ejemplos de (5), las oraciones subordinadas cumplen la función de complemento directo, por lo que pueden sustituirse por lo recuerdo, lo olvidé, lo escuché y escríbelo. No obstante, otras clases de verbos transitivos que, del mismo modo, subcategorizan oraciones sustantivas, no aceptarán oraciones subordinadas sustantivas encabezadas por dónde como se muestra en (6)a y (6)b o bien verbos transitivos que no subcategorizan oraciones sustantivas pero sí aceptan subordinadas adverbiales encabezadas por donde como lo ilustran las oraciones de (6)c y (6)d.

(6) a. Quiero [que trabajes mañana].

b. *Quiero [dónde preparan buen café].

c. *Practican [que vienen al rato].

d. Practican [donde fueron los juegos olímpicos].

Asimismo los verbos transitivos que aceptan una subordinada sustantiva encabezada por dónde, también aceptan una oración adverbial de lugar encabezada por donde como se ilustra en las oraciones de (7).

(7) a. Olvidé el libro [donde comimos].

b. Escribe el artículo [donde haya buena iluminación]. 
c. Escucho música [donde me siento tranquila].

Los tres ejemplos muestran que los verbos transitivos de los ejemplos de (7) aceptan una oración adverbial de lugar introducida por donde, las oraciones también muestran que la frase nominal que está adyacente no es su antecedente sino el complemento directo de los verbos regentes: olvidar, escribir y escuchar. Asimismo se muestra el valor semántico y funcional que cada uno de los elementos de la oración tiene, por lo que pueden parafrasearse como Lo olvidé allí, escríbelo allí y la escucho allí. La oración subordinada adverbial puede sustituirse por un adverbio de lugar porque su función es equivalente.

El traslape que las oraciones subordinadas adverbiales de lugar tienen con las oraciones sustantivas no ocurre con los verbos intransitivos o inacusativos como se muestra en las oraciones de (8).

(8) a. El cohete cayó [donde estaba reunida la gente].

b. Ayer nadamos [donde el mar se junta con el río].

En la oración (8)a el verbo es inacusativo y en la de (8)b es intransitivo, y en ambas la oración subordinada puede sustituirse por un adverbio de lugar: el cohete cayó allí y ayer nadamos allí. Por tanto, como señalamos anteriormente, el traslape que existe entre las oraciones subordinadas sustantivas y adverbiales sólo sucede cuando el verbo regente es transitivo.

Por otro lado, los verbos intransitivos de movimiento ${ }^{27}$ presentan otro problema importante, ya que estos requieren de una frase prepositiva. En lo referente a su estructura sintáctica, el adverbio relativo donde se incrementa con una preposición ${ }^{28}$ en esta clase de verbos como se muestra en los ejemplos de (9).

(9) a. Salió de [donde estaba].

\footnotetext{
${ }^{27}$ Para Morimoto (2001:43) los verbo de movimiento se dividen en tres clases: I. verbos de desplazamiento del tipo entrar, salir, ir, venir, etc.; IIa. verbos de manera de moverse como caminar, andar, arrastrarse, correr deslizarse, etc.; y IIb. verbos de manera de moverse como tambalearse, agitarse, balancearse, bambolear se, etc.

${ }^{28}$ En el caso de las oraciones temporales el relativo cuando también puede aparecer como término de una preposición, por ejemplo: Estaré lista para cuando llegues. Sin embargo, a diferencia de las temporales, las locativas se incrementan con más preposiciones, sobre todo en el caso de los verbos de movimiento.
} 

b. Llegó de [donde fue].
c. Fue a[donde quiso].
d. Vengo de [donde trabajo].

Se muestra en todos los ejemplos de (9) que hay una preposición adyacente a la subordinada adverbial, la cual es requerida por los verbos de movimiento que se encuentran en la oración principal. Morimoto (2001) señala que los verbos de movimiento toman como argumento un objeto que indica trayectoria, lo cual implica que esta clase de verbos pueden subcategorizar una frase prepositiva. La cuestión que surge en torno a esta clase de verbos es si la oración subordinada encabezada por donde y que es el término de la preposición puede seguir considerándose adverbial, o si se trata de una oración relativa libre como considera Pavón (2012) o bien adjetiva o adverbial sustantivada como sugiere Porto Dapena (1997:17). Las distintas posturas son aceptables por distinta razones.

Consideramos aceptable el criterio de Porto Dapena, porque el término de las preposiciones puede ser una frase nominal, por lo tanto, una oración que es término de la preposición debería considerarse del mismo modo, equivalente a un nombre. No obstante, la RAE (2010: 825) indica que no todas las preposiciones aceptan una oración subordinada sustantiva como termino, específicamente las temporales como hasta o desde, ya que la oración que las sigue no puede sustituirse por un pronombre, por ejemplo, *hasta qué o * desde eso, pero si pueden suplirse por un adverbio, hasta entonces o desde cuando. Sin embargo, no solo los nombres funcionan como término de una preposición, un adjetivo y un adverbio también pueden ocupar dicha posición con algunas preposiciones, por ejemplo: por inteligente, por alegre; por allí, para allá, hacia arriba y en el caso de los adverbios únicamente pueden ser deícticos y el relativo adverbial donde posee ese mismo rasgo. Considerando que las oraciones subordinadas adverbiales temporales y locativas son término de una preposición y pueden sustituirse por adverbios de lugar o tiempo, muchos gramáticos las clasifican dentro de las oraciones subordinadas adverbiales, porque cumplen las tareas de un adverbio, pero la función circunstancial no corresponde únicamente a la oración subordinada sino a la preposición y al término de la misma (Porto Dapena 1997:17). 
De acuerdo con lo mencionado por Porto Dapena, opinamos que la oración que es término de la preposición puede tratarse como adverbial, en el sentido de que hay algunas preposiciones cuyo término no es solamente una frase nominal sino que pueden aceptar una frase adverbial, como es el caso de las preposiciones de, por, para, desde, hacia, hasta, en ejemplos como de allí, de allá, por allí, por allá, para allá, para acá, desde allí, desde allá, hacia allá y hasta allá pero en el caso de estas dos últimas por sus rasgos semánticos es imposible decir *hacia allí y ?hasta allí.

En relación a la propuesta de Pavón (2012) quien sugiere que se trata de una oración relativa libre, cuyo antecedente está elidido, opinamos por un lado, que no podría considerarse como tal, puesto que las funciones que cumple son propias de una oración adverbial y, como señalamos la sustitución de la subordinada es por un adverbio y no por una frase adjetiva como se muestra en los ejemplos de (10).
a. Salí de allí.
b. Llegó de allí.
c. Fue alli.
d. Vengo de allí.

Sin embargo, la estructura sintáctica de esta clase de construcciones no es idéntica a la de las oraciones que citamos en (3), (7) y (8) en las que el nexo subordinante es el relativo adverbial donde, en contraste con las oraciones de (9) la preposición es la que cumple la función de enlace entre la oración principal y la subordinada. Por lo tanto, la oración ya no se consideraría adverbial sino de relativo cuyo antecedente es la preposición o bien no tiene antecedente explicito como plantea Pavón (2012), no obstante, una preposición no puede considerarse el antecedente de una oración.

De manera que en el apartado siguiente discutiremos estos puntos, puesto que están relacionados con la manera en que las oraciones subordinadas adverbiales de lugar se enlazan con la oración principal.

1.2 Oraciones subordinadas adverbiales propias o relativas libres. En el apartado anterior indicamos que el relativo adverbial donde cumple las tareas de un adverbio dentro 
de la oración en la que se encuentra al igual que los relativos cuando y como, pero al mismo tiempo funciona como nexo subordinante. Mencionamos además, que en el corpus que se analizó se encontraron numerosas oraciones en las que el adverbio relativo donde se incrementa por una preposición como se ilustra en (11)a o por un adverbio de lugar como se muestra en (11)b.

a. El lama señaló con una inclinación de cabeza hacia donde se encontraba Regina. (CREA)

b. Éstos aparecen allí donde la situación que se quiere investigar es externa. (CREA)

Los ejemplos muestran que la estructura sintáctica de las oraciones de (11) es distinta de las oraciones de (8), en las que el relativo adverbial donde no tiene una preposición o un adverbio que lo anteceda, sino que está adyacente el verbo de la oración principal. En relación con la estructura sintáctica de las oraciones de (11) se ha propuesto que el adverbio es el antecedente de la subordinada y que la oración subordinada se incrementa por una preposición, pero la subordinada no es adverbial sino de relativo (Pavón, 2012). Otra propuesta sobre la oración (11)b es que la subordinada adverbial es el complemento del adverbio (Roca Pons, 1974). En los siguientes apartados trataremos ambas cuestiones.

1.2.1. Preposición + donde. En lo que respecta a la composición de una preposición + donde existen dos propuestas posibles. La primera tiene que ver con lo que plantea Pavón (2012:46), para esta autora, oraciones como la que se ilustra en (11)a son de relativo, las cuales, según explica, principalmente son las que están introducidas por los relativos cuando y donde, y que aparecen como término de diversas preposiciones que aceptan complementos que expresan lugar y tiempo. Indica esta lingüista, además, que las oraciones subordinadas propias, locativas y temporales, pueden ser complemento de diversas categorías, como un verbo, adjetivo, o adverbio. Respecto de esta propuesta, opinamos que las subordinadas de lugar pueden ser término de distintas preposiciones como plantea Pavón (2012), y concordamos en que pueda tratarse de una oración de relativo, ya que su estructura sintáctica es distinta de las oraciones cuyo nexo subordinante es el relativo 
adverbial donde sin que lo anteceda una preposición. Sin embargo, también consideramos que las preposiciones le dan matices diferentes al relativo donde cuando aparecen adyacentes, por ejemplo:
a. Caminé donde está el parque.
b. Caminé por/ hasta/ desde/ donde está el parque.
c. Juan estudia donde hay buena iluminación.
d. Juan estudia en/ por donde hay buen iluminación.

En las oraciones (12)a y (12)c donde se encuentra adyacente al verbo, por lo tanto se trata de una oración subordinada adverbial, Pero en los ejemplos (12)b y (12)d el relativo está incrementado por distintas preposiciones y se muestra que el sentido que transmiten es distinto del que se tiene las oraciones (12)a y (12)c. Las preposiciones le dan un matiz distinto a las oraciones sin la necesidad de que haya una frase nominal entre la preposición y el relativo adverbial donde. Este tipo de construcciones no hace pensar que, si bien las preposiciones y el adverbio donde no se han unido al grado de formar una conjunción, como sucede con algunas preposiciones temporales y la conjunción que, es notable que las preposiciones si proporcionan más información semántica y su presencia en la oración cambia la estructura sintáctica de este tipo de construcciones, pero eso no justifica la presencia de un antecedente elidido.

Por otro lado, Pavón (2012) afirma que las preposiciones con las que pueden aparecer las oraciones subordinadas aceptan complementos que expresan lugar y tiempo, con lo cual concordamos, además, consideramos que también es necesario analizar qué clase de verbos rigen a las preposiciones o bien si en todos los casos el verbo de la oración principal es el que rige a la preposición o es el verbo de la subordinada el que lo hace o incluso ambos. Esto ayudaría a determinar si realmente se trata de una oración de relativo o de una subordinada adverbial. Asimismo, y como señalamos en el capítulo I, considerar la posibilidad de introducir al antecedente de la relativa entre la preposición y la oración subordinada comprobaría si es posible que puedan aparecer juntos sin que la oración suene redundante. 
Por otro lado, en el capítulo I señalamos que Porto Dapena (1997:16) considera que las oraciones encabezadas por los relativos adverbiales: cuando, donde y como pueden considerarse oraciones de relativo o bien oraciones subordinadas adverbiales de acuerdo con la función sintáctica que cumplan dentro de la oración en la que se hallen. Considera este autor, además, que hay dos clases de oraciones subordinadas adverbiales, las primeras son las que no tienen antecedente y desempeñan directamente la función adverbial; las segundas son las que tienen un antecedente representado por una preposición o por un adverbio equivalente, como las que se ilustran en (11). Asimismo, explica que la función que desempeñan no corresponde únicamente a la preposición sino a todo el conjunto que forman. Indica este autor, además, que las subordinadas encabezadas por donde y antecedidas por una preposición o un adverbio no actúan como modificadores ni parecen estar subordinadas al antecedente, a diferencia de las que están adyacentes al verbo, las cuales sí funcionan como modificadoras; más bien señala que toda la oración subordinada tiene idéntica referencia al antecedente (Porto Dapena 1997:49). No obstante, a pesar de la estructura de esta clase de oraciones, este autor sigue considerándolas adverbiales ${ }^{29}$.

Respecto a estas dos propuestas, nos inclinamos por la expuesta por Porto Dapena (1997), en el sentido de las funciones que cumplen las oraciones subordinadas que son el término de la preposición, pero creemos que sintácticamente no pueden considerarse adverbiales ya que el relativo adverbial donde presenta movimiento de un constituyente de la oración subordinada y en ese sentido no podría considerase que el relativo sea una simple conjunción como ocurre con el relativo adverbial cuando en algunos contextos ${ }^{30}$. Por lo tanto, en (13) presentamos las posibles estructuras que una preposición + una oración encabezada por el relativo donde pudiera tener.
a. FP [P ø [OSREL o OSADJ]]
b. FP $[\mathrm{P}[\mathrm{ADJ}]]$

\footnotetext{
${ }^{29}$ Véase Porto Dapena 1997: 51 y 52, en donde ilustra la estructura sintáctica de las oraciones subordinadas introducidas por los relativos donde y cuando incrementadas por una preposición o un adverbio para el caso de las locativas.

${ }^{30}$ Por supuesto, concordamos con la propuesta de Herrero (2005) quien considera que el relativo cuando es el que podría ser tratado una conjunción a diferencia de los relativos donde y cuando, pero esto no implica que haya perdido sus rasgos de relativo adverbial.
} 


\section{c. FP $[\mathrm{P}[\mathrm{OSADV}]]$ \\ d. FP $[\mathrm{P}[\mathrm{ADV}]]$}

Si se adopta la estructura (13)a entonces la subordinada podría sustituirse por la estructura (13)b, ya que se trata de una oración de relativo o adjetiva y un sintagma adjetivo es el que tendría que ocupar su lugar por tener una función semejante. Pero si se adopta la estructura (13)c entonces la sustitución de la subordinada debería ser como la estructura (13)d, es decir, por un adverbio, ya que se trata de elementos equivalentes. Veamos los siguientes ejemplos.

a. Pasamos [por [donde venden vestidos de fiesta]].

a'. Pasamos *[por [SADJ]] / [por [allí]] / [por [ese lugar]]/ *[por [eso]].

b. Inmediatamente corrió [hacia [donde estaba la mesa de los dulces]].

b'. Inmediatamente corrió *[hacia [SADJ]] / [hacia [allá]] / [hacia [ese

lugar] / *[hacia [eso]].

Los ejemplos (14)a' y (14)b' muestran que la sustitución por un sintagma adjetivo genera una oración agramatical, ya que las funciones que las oraciones subordinadas de (14)a y (14)b son las que corresponden a un adverbio y no a un adjetivo. Por tanto, la sustitución por un adverbio o bien por una frase nominal que tenga un valor locativo es el más adecuado. De manera que, aludiendo a lo que Pavón (2012) señala sobre las oraciones encabezadas por donde, las cuales aparecen como término de diversas preposiciones que aceptan complementos que expresan lugar, los únicos elementos que cumplen con tales rasgos semánticos son los adverbios locativos, las oraciones subordinadas adverbiales de lugar o bien los sintagmas nominales que expresen dicho valor. Pero ni los adjetivos ni los pronombres podrían sustituir a la oración encabezada por el relativo donde ya que no poseen rasgos semánticos distintos, puesto que como observamos en los ejemplos citados en (14)a' y (14)b' la sustitución por tales elementos es imposible.

Por tanto, consideramos que la estructura sintáctica de las oraciones de relativo encabezadas por el adverbio donde que se incrementan por una preposición deben tener una estructura sintáctica como la que se muestra en (13)c, porque la sustitución por otro 
elemento que tiene sus mismas características es posible y está representado en (13)c. Sin embargo, aún la estructura propuesta en (13)c genera controversia porque sólo cubre los rasgos semánticos de esta clase de oraciones pero, sintácticamente, su estructura es como la de (13)a, de allí que la estructura de estas oraciones sea diversa y genere polémica dados los traslapes que presenta con las oraciones de relativo, por tal motivo la RAE (2010:825) señala que muchos gramáticos optan por agruparlas dentro de la relativas con antecedente implícito. De modo que ante esta cuestión consideramos que el análisis más acertado es el que propone Porto Dapena quien considera que se trata de una oración de relativo adverbializada, porque sintácticamente es de relativo pero funcionalmente o bien semánticamente cumple el oficio de una oración adverbial.

Por otra parte, explicamos en el apartado anterior que el traslape que existe entre las oraciones sustantivas y las subordinadas adverbiales solamente ocurre con los verbos transitivos, por tal motivo, consideramos que analizar con qué clase de verbos la subordinada adverbial introducida por donde se incrementa por una preposición o por un adverbio permitiría observar por qué ocurre de ese modo y por qué el relativo donde no puede aparecer adyacente al verbo principal, es decir, sin que requiera de una preposición o adverbio que funcione como enlace. En el corpus que se analizó observamos que la mayoría de los verbos que aceptan una oración subordinada encabezada por el relativo adverbial donde antecedido por una preposición son de movimiento, a excepción de verbos estativos los cuales requieren de la preposición en, lo cual implica que por los rasgos semánticos y la estructura argumental de los verbos requieren de una preposición que funcione como enlace entre la oración principal y la subordinada. Es decir, se trata de verbos que tienen una preposición en su estructura argumental, como señala Morimoto (2001) en relación con los verbos de movimiento ${ }^{31}$. Asimismo, observamos que la sustitución de la oración subordinada por otro elemento sintáctico es siempre por un adverbio de lugar y no por un sintagma adjetivo como se esperaría, puesto que se considera que la oración que es el término de la preposición es de relativo o adjetiva.

\footnotetext{
${ }^{31}$ Para Alarcos (1999) la frase prepositiva de los verbos de movimiento son suplementos inherentes porque la preposición está en consonancia con la semántica de los verbos que la rigen.
} 
En nuestro análisis incluimos las estructuras: adonde, en donde, de donde, hacia donde, hasta donde, por donde y para donde que funcionan como nexos subordinantes entre la oración principal y la subordinada. Los verbos de movimiento que rigen a esta clase de estructuras y que se encontraron en el corpus son los siguientes: ir, regresar, volver, llevar, dirigirse, acudir, transportar, salir, acercarse, venir, volar, conducir, llegar, bajar, caminar, provenir, salir, trasladarse, emerger, partir, pasar, desplazarse, escurrirse, subir, surgir, proceder (con el sentido de venir), provenir, fluir, correr, avanzar, huir, ascender, proseguir, devolverse, aproximarse, moverse, descender, trepar, entrar y encaminarse ${ }^{32}$. Por supuesto, no todos los verbos aceptan las mismas preposiciones, pero hasta ahora sólo hicimos una lista de todos los verbos de movimiento que se encontraron, porque en el análisis sintáctico que haremos posteriormente mencionaremos cuáles pueden regir a cada preposición.

Por otro lado, es importante señalar el hecho de que no hay conjunciones locativas pero sí adverbios locativos (Pavón 1999:627). Es posible que ante la necesidad de un elemento que enlace a toda la clase de oraciones locativas se puedan formar locuciones conjuntivas formadas por una preposición + el relativo adverbial donde, considerando que las locuciones toman diferentes elementos para formarse. Sin embargo, en el caso de estas construcciones, donde no ha perdido su significado como le ocurre a otra clase de palabras que han formado locuciones temporales y que se analizaron en el capítulo II. Hemos señalado que a diferencia del relativo cuando $^{33}$, el cual puede considerarse como una conjunción, el relativo donde no puede considerarse como tal, ya que a pesar de que aparece con una preposición que la antecede no da lugar a una conjunción subordinante (Pavón 2002:2055).

\footnotetext{
${ }^{32}$ La RAE (2010: 694, 697, 698) indica que hay límites imprecisos entre los complementos de régimen y los circunstanciales, sobre todo con los verbos que indican movimiento no direccional tales como caminar, merodear, pasear o vagar. Señala esta gramática que los verbos de movimiento que seleccionan la preposición de como huir y salir son considerados de régimen. No obstante, los verbos de movimiento que seleccionan las preposiciones hacia y hasta son considerados como adjuntos o circunstanciales por algunos gramáticos, pero otros los consideran verbos de régimen. Si bien entendemos que los límites que hay entre los complementos prepositivos argumentales y adjuntos son imprecisos, no nos enfocaremos en esta cuestión ya que nuestro interés se centra en la naturaleza de la oración subordinada que es el término de las preposiciones que seleccionan los verbos de movimiento que analizaremos en este capítulo.

${ }^{33}$ Véase el apartado 2.1 del Capítulo II.
} 
En esta clase de oraciones el relativo adverbial donde no es una simple conjunción, porque se observa el movimiento de uno de los elementos de la oración subordinada y por esta razón se asemeja a las oraciones de relativo cuyo movimiento sintáctico también es evidente. Sin embargo, se estima que a diferencia del relativo cuando, el cual podría considerarse mayormente como una conjunción ${ }^{34}$, el relativo donde conserva las propiedades de un adverbio, porque cumple con ambas funciones dentro de las oraciones en las que se halla. Es decir, conserva su valor anafórico y lleva a cabo los oficios de nexo subordinante y de adverbio de lugar (Pavón 1999:625). De modo que el movimiento que se observa en las oraciones que subordina obedece a tales características. Consideramos que sintácticamente las oraciones encabezadas por el adverbio relativo donde que están antecedidas por una preposición son oraciones de relativo pero se les debe considerar dentro del grupo de las adverbiales porque cumplen con las funciones propias de un adverbio y no las de un adjetivo, en ese sentido se les puede considerar complementos circunstanciales o adjuntos de lugar, de manera que el criterio funcional o semántico es el que fundamenta cuál es el valor que debe tener dentro de la oración a la que se subordina.

1.2.2. Adverbio + donde. Hasta este momento sólo nos hemos referido a las oraciones adverbiales de lugar que están introducidas por una preposición, de modo que en este apartado, hablaremos de las subordinadas que están incrementadas por un adverbio como muestra el ejemplo (11)b. La estructura sintáctica que tiene esta clase de construcciones puede analizarse de dos maneras diferentes. La primera tiene que ver con lo que Roca Pons (1974) plantea sobre oraciones como la citada en (11)b. Este autor estima que la oración subordinada puede ser el complemento del adverbio que la antecede, lo cual puede considerarse aceptable, ya que un adverbio podría tomar complementos como sucede con todas las categorías léxicas. Porto Dapena (1997:50) considera que el adverbio es el antecedente de la oración subordinada, pero señala que ambos cumplen una función idéntica dentro del conjunto oracional. Ilustramos ambas estructuras en (15).

$$
\text { a. [FADV [ADV [OSADV]] }
$$

\footnotetext{
${ }^{34} \mathrm{Si}$ bien cuando es el adverbio relativo que podría haber perdido sus propiedades adverbiales, es considerado como un adverbio que cumple las funciones de dicho elemento dentro de la oración. (Herrero2005; Osuna 2005)
} 


\section{b. $\left[\mathrm{FADV}^{1}[\mathrm{ADV}]\left[\mathrm{FADV}^{2}\right.\right.$ [OSADV]]}

En (15)a se muestra que el adverbio toma como complemento una oración subordinada como lo plantea Roca Pons y la estructura de (15)b ilustra el planteamiento de Porto Dapena en la que se muestra que el adverbio es el antecedente de una oración adverbial, al cual no modifica. Consideramos que ambas posibilidades son viables, en la propuesta de Roca Pons hay ejemplos en los que la subordinada parece estar muy unida al adverbio que la antecede, por tanto, puede considerarse que pudiera tratarse del complemento del adverbio. Por otro lado, consideramos que el planteamiento de Porto Dapena es acertado, ya que la estructura (15)b implica que se trata de dos elementos independientes, que pueden modificar al verbo pero no modificarse entre ellos, lo cual podría considerarse como oraciones en las que hay dos complementos circunstanciales de lugar, tal como Herrero (2005) propone para las oraciones subordinadas temporales.

De manera que el planteamiento de Porto Dapena nos remite a lo que se mencionó en relación a las oraciones subordinadas temporales y que expliqué en el apartado 1.2 del capítulo II. Mencionamos la propuesta de Herrero (2005:183) quien señala que no es muy común que una oración tenga dos complementos circunstanciales de tiempo, pero cuando esto sucede el segundo complemento circunstancial proporciona más información sobre el primero, es decir, amplía el sentido temporal del primer complemento circunstancial y se podría considerar un "circunstancial complejo". Puesto que estamos definiendo la distribución sintáctica de las oraciones que tienen una estructura como aquí donde, allá donde, aquí donde, en el corpus analizado se encontraron oraciones subordinadas adverbiales de lugar en las que se podría interpretar como un caso de doble complemento circunstancial o adjunto de lugar, sin embargo, en oraciones simples no es muy usual que haya dos circunstanciales locativos, ya que una de ellos podría tomarse como una aposición. No obstante, en el análisis sintáctico que haremos en el apartado 2 mostraremos algunos ejemplos que podrían considerarse como dos complementos circunstanciales de lugar, sin descartar la idea de que también podrían analizarse como aposiciones.

En oraciones simples dos complementos circunstanciales de lugar podrían aparecer como se ilustra en las oraciones de (16). 

a. Caminé largo rato [en la playa] [sobre la arena tibia].
b. Grabó su último disco [en España] [en un estudio pequeño].
c. Duérmete [arriba] [en el cuarto de huéspedes].

Muestran las oraciones de (16) que es posible que dos complementos circunstanciales de lugar puedan aparecer en una sola oración, aunque, como hemos comentado, no es muy usual. En el caso de las oraciones subordinadas adverbiales, el adverbio allí, pudiera considerarse como un primer complemento circunstancial de lugar, y la subordinada adverbial como el segundo, ya que parece estar ampliando el sentido locativo del adverbio como se ilustra en las oraciones de (17).

a. Desde que llegó a la Presidencia, no había dormido un solo día allí, donde por tradición los mandatarios ecuatorianos se hospedan. (CREA)

b. Hermoso traerá 16 caballos, los que causaron sensación aquí, donde cortó ocho rabos, y varias estrellas surgidas en esta temporada española. (CREA)

Las oraciones de (17) muestran que los adverbios allí y aquí cumplen la función de complemento circunstancial de lugar de la oración principal, pero las oraciones subordinadas adverbiales especifican el sentido locativo del adverbio. Porto Dapena (1997:49) propone, para el caso de las oraciones que tienen una frase adverbial que las precede, la introducción de una frase como esto es, o sea o es decir, entre el que para él es el antecedente y la oración subordinada, lo cual prueba que el sentido de ambos elementos es equivalente como se ilustra en (18).

a. Desde que llegó a la Presidencia, no había dormido un solo día allí, es decir, donde por tradición los mandatarios ecuatorianos se hospedan. (CREA)

b. Hermoso traerá 16 caballos, los que causaron sensación aquí, es decir, donde cortó ocho rabos, y varias estrellas surgidas en esta temporada española. (CREA)

Asimismo, este autor sugiere la omisión de la frase que antecede a la subordinada temporal prueba que el oficio que cumplen es equivalente, ya que no se produce una oración agramatical y prueba además, que se trata de una oración subordinada adverbial 
puesto que puede aparecer adyacente al verbo de la oración principal y cumple las tareas de dicha clase de oraciones como se muestra en las oraciones de (19).

a. Desde que llegó a la Presidencia, no había dormido un solo día donde por tradición los mandatarios ecuatorianos se hospedan. (CREA)

b. Hermoso traerá 16 caballos, los que causaron sensación donde cortó ocho rabos, y varias estrellas surgidas en esta temporada española. (CREA)

Muestran los ejemplos (18) y (19) que la posibilidad de que haya dos complementos circunstanciales de lugar es posible, ya que las pruebas propuestas por Porto Dapena (1997) indican que el adverbio y la oración subordinada aportan información equivalente. Asimismo, se encontraron otros ejemplos en los que aparecen dos frases prepositivas adyacentes, lo cual nos hace pensar en la existencia de dos complementos circunstanciales de lugar es probable.

a. Miraba [hacia arriba], [hacia donde debería estar la luz] y todo lo que encontraba era un firmamento rosado. (CREA)

b. Además, es imposible desarrollar acciones efectivas de atención sin la presencia de personal capacitado [en todos los niveles de atención], especialmente [en donde no hay suficiente información disponible], como sucede en las regiones rurales del país. (CREA)

Las oraciones de (20) muestran que hay dos frases prepositivas que cumplen la función de complemento circunstancial de lugar del verbo mirar. En (20)a la primera está introducida por la preposición hasta cuyo término es el adverbio arriba y la segunda es la frase prepositiva formada por hasta + la subordinada adverbial encabezada por donde. Se muestra que la segunda frase prepositiva, es decir, en la que se encuentra la oración subordinada adverbial, especifica el sentido locativo de la primera frase. El ejemplo de (20)b, del mismo modo, ilustra que hay dos frases prepositivas que funcionan como complemento circunstancial o adjunto de lugar. Ambas están introducidas por la preposición en, pero la primera tiene como término de la preposición una frase nominal, mientras que en la segunda el término es una oración subordinada adverbial. Se muestra, 
además, que la segunda frase prepositiva aporta más información sobre la primera frase preposicional que actúa como complemento circunstancial. Si les aplicamos las pruebas mencionadas, obtenemos las siguientes oraciones.

a. Miraba [hacia arriba], es decir, [hacia donde debería estar la luz]...

b. Además, es imposible desarrollar acciones efectivas de atención sin la presencia de personal capacitado [en todos los niveles de atención], es decir, especialmente [en donde no hay suficiente información disponible]...

a. Miraba [hacia donde debería estar la luz]...

b. Además, es imposible desarrollar acciones efectivas de atención sin la presencia de personal capacitado especialmente [en donde no hay suficiente información disponible]...

Con los ejemplos de (17) y (20) queremos mostrar que una frase adverbial o prepositiva podría analizarse de manera distinta a la que se ha propuesto, es decir, no como el antecedente de la oración adverbial o como el complemento de un adverbio, sino como dos posibles complementos circunstanciales de lugar en una misma oración, tal como Herrero (2005) propuso en el caso de las oraciones subordinadas adverbiales de tiempo. Otro análisis posible es considerarlas como aposiciones.

Las distintas estructuras sintácticas que se encontraron en el corpus muestran la polémica que las oraciones subordinadas adverbiales propias de lugar ha suscitado, y es difícil dibujar una estructura que pudiera unificar la ordenación sintáctica de todas la oraciones subordinadas propias, por tal motivo hemos preferido analizar cada estructura que presentan y mostrar las razones por las que se les ha clasificado como oraciones subordinadas adverbiales refiriéndonos tanto a su función dentro de la oración en la que se encuentran como a sus rasgos semánticos.

1.3. Orden sintáctico de las oraciones subordinadas adverbiales de lugar. En el capítulo II mencionamos que las oraciones subordinadas adverbiales propias siguen dos órdenes sintácticos principalmente, pueden ubicarse antes de la oración principal o bien posponerse a ella. Incluso pueden encontrarse incrustadas en la oración principal, interrumpiendo la 
secuencia de la misma, las cuales son oraciones interpoladas, usando la términología de Conti (2012). En el caso de las oraciones temporales analizadas en el capítulo II, hallamos los tres órdenes mencionados, asimismo se encontraron dentro de otras oraciones subordinadas tales como adjetivas o de relativo, sustantivas o bien adverbiales. Observamos que el orden que siguen con respecto a la oración principal no cambia, a pesar de que se encuentran dentro de construcciones más complejas. En este apartado analizaremos el orden sintáctico de las oraciones subordinadas adverbiales de lugar y veremos si, al igual que en el caso de las temporales, pueden seguir los tres órdenes antes citados.

Hemos mencionado, además, que las oraciones subordinadas propias se consideran complementos circunstanciales o adjuntos de lugar o tiempo, por lo tanto, tienen mayor movilidad dentro de la oración en la que se encuentran. El análisis sintáctico que hicimos muestra que la movilidad que las oraciones subordinadas de lugar tienen es escasamente diferente a la de las temporales. En contraste con las oraciones temporales, se encontraron muy pocos ejemplos de oraciones subordinadas de lugar que se antepongan a la principal y de oraciones interpoladas.

Al igual que en las oraciones temporales, el orden que predomina en las subordinadas de lugar es oración principal + oración subordinada como lo ilustran las oraciones de (23).

a. Lo compró [donde le dijimos].

b. Leo [donde hay buena iluminación].

Se encontraron muy pocos ejemplos en los que la subordinada antecede a la oración principal como se ilustra en las oraciones de (24).

a. A donde tú vayas, yo iré y donde tú pases la noche yo pasaré la noche. [...] Donde tú mueras, yo moriré. (Rut 1:16, 17 Traducción del Nuevo Mundo de las Santas Escrituras)

b. Nada, allá donde hay gentes hay mercado, allá donde hay comida hay hambre, donde hay hambre hay hombres, donde hay hombres hay hembras, 
donde hay hombres y hembras hay sombras, donde hay sombras hay gentes, donde hay gentes estoy yo. (CREA)

c. Pero no te preocupes, estoy segura que allá donde vas, alguien te espera, como tú me esperabas a mí. (CREA)

Se muestra en los ejemplos (24)a y (24)b que el orden es, oración subordinada + oración principal. En ambos ejemplos el verbo de la oración principal se repite en la oración subordinada. Pero en (24)c el orden oración subordinada + oración principal aparece dentro de otra oración compleja, es decir, dentro de una subordinada sustantiva.

En relación con las oraciones interpoladas, se encontraron escasos ejemplos. Algunos introducidos por aquí o alli + donde o encabezadas por la preposición hasta + donde como se ilustra en los ejemplos de (25).

a. ¿Cómo la ves, Milio? Porque si ésos del tapanco son sindicalistas y gentes derechas, entonces yo aquí donde me ven soy gurú de dianética estructural. (CREA) b. Según su peso ideal, trate hasta donde sea posible de controlar el total de calorías que le corresponden por día. (CREA)

El ejemplo (25)a muestra que la oración subordinada adverbial interrumpe la secuencia de la oración principal introduciéndose entre el sujeto: yo y el predicado de la oración regente: soy gurú de dianética estructural. En (25)b la subordinada adverbial encabezada por la preposición hasta interrumpe la secuencia de la principal introduciéndose entre el verbo: tratar y el complemento de régimen: de controlar el total de calorías que le corresponden por día. Se encontraron variadas oraciones interpoladas con la preposición hasta + donde, pero la mayoría de ellas tiene el mismo sentido de la oración de (25)b, hasta donde sea posible, hasta donde pueda, hasta donde lo permitan, etc. El corpus muestra que es menos común en las oraciones subordinadas de lugar que en las temporales.

Para concluir este apartado, mencionaremos que la estructura sintáctica de las oraciones subordinadas adverbiales de lugar es, al igual que la de las temporales, variable. Si bien las oraciones subordinadas adverbiales de lugar se introducen únicamente con el 
relativo donde, a lo largo de este apartado se mostró que puede incrementarse por una preposición o por un adverbio locativo del tipo allí, allá, acá, lo cual implica plantear qué clase de oración es la que se encuentra después de tales elementos.

Para el caso de las oraciones que están incrementadas por una preposición, y como habíamos señalado anteriormente, se ha planteado que podría tratarse de una oración sustantiva, pero la RAE señala que no todas las preposiciones aceptan una oración sustantiva como término, especialmente las temporales, por ejemplo, hasta y desde, ya que la oración que se encuentra pospuesta no puede sustituirse por un pronombre, *hasta eso, sino por un adverbio de tiempo, hasta entonces (RAE 2010: 825). De manera similar, las oraciones encabezadas por el relativo adverbial donde tampoco podrían considerarse como sustantivas porque no pueden sustituirse por pronombres sino por adverbios, por ejemplo, No quiero caminar por donde está obscuro, la cual no puede sustituirse por *No quiero caminar por eso (por eso con sentido locativo y no de causa), pero sí por No quiero caminar por allí. De manera que la oración donde está obscuro puede ser de relativo o bien adverbial. Podría tratarse de una oración adverbial más que de una subordinada de relativo, puesto que, al sustituirla, el único elemento que puede cubrir las características semánticas que tiene es un adverbio y no un adjetivo. Si se trata de una relativa libre entonces asumiríamos que la oración subordinada tiene un elemento elidido, es decir, una frase nominal omitida, pero consideramos también que la preposición proporciona matices que el relativo donde no tiene cuando aparece solo. Por otro lado, si hubiera una frase nominal elidida, la oración adverbial se estaría refiriendo a la frase prepositiva en su totalidad y no al sintagma nominal únicamente, por ejemplo, No quiero caminar [por el lugar] donde está obscuro. En el ejemplo la oración subordinada encabezada por donde se refiere a toda la frase prepositiva por el lugar y no sólo a la frase nominal el lugar.

Ahora bien, atendiendo a las propuestas que hemos discutido en esta sección, en el apartado siguiente presentaremos el análisis sintáctico de las oraciones subordinadas adverbiales de lugar.

2. Análisis sintáctico de las oraciones subordinadas adverbiales de lugar. Para empezar daremos una definición de las oraciones subordinadas adverbiales de lugar. Esta clase de 
oraciones hacen alusión al lugar en que ocurre la acción expresada por el verbo, además son equivalentes a un adverbio locativo. El principal nexo que las une con la oración principal es el relativo adverbial donde, el cual, como ya hemos estudiado, puede estar antecedido por un adverbio de lugar o bien incrementado por una preposición. Cabe señalar que se encontraron muy pocos ejemplos en los que el adverbio donde esté adyacente al verbo, la mayoría de las oraciones que se encontraron y se analizaron en el corpus están introducidas por una preposición o por un adverbio de lugar. Lo cual muestra además que el uso de las oraciones relativas encabezadas por donde está más extendido que el uso de las oraciones adverbiales de lugar.

En el análisis que haremos consideraremos los distintos órdenes sintácticos que se encontraron con cada una de las oraciones subordinadas adverbiales de lugar ya sea que estén adyacentes al verbo principal o que estén precedidas por una preposición o por un adverbio. Examinaremos, además, si pueden hallarse dentro de otras estructuras más complejas tales como oraciones subordinadas sustantivas, de relativo o bien adverbiales. Asimismo pondremos especial interés en observar la clase de verbos que rige a las preposiciones y a los adverbios, si solamente el verbo de la oración principal es el que rige a la preposición o también el verbo de la oración subordinada. Empezaremos el análisis sintáctico con las oraciones encabezadas por los adverbios allí, aquí, allá, acá. Y posteriormente examinaremos las que están antecedidas por las preposiciones: $a$, de, en, hacia, hasta, para y por.

2.1. Aquí, allí, allá, acá + donde. La estructura adverbio + preposición tuvo mayor recurrencia con el adverbio allí, aquí y allá, con acá se encontraron escasos ejemplos. Muchas de las oraciones introducidas por un adverbio seguidas del relativo donde están formadas con el verbo copulativo ser, especialmente con los adverbios aquí y allí como se muestra en las oraciones de (26).

(26) a. Es allí donde se producen las bolsas de magma que se eleva por ser menos denso que las rocas vecinas, fundiendo el material cercano y arrastrándolo. (CREA)

b. Es aquí donde aparece la figura de Carlos Salinas de Gortari. (CREA) 
Pavón (2012:46) señala que oraciones como las de (26) se conocen como oraciones copulativas enfáticas o de relieve o perífrasis de relativo. Indica que en ellas se destaca algún componente de la oración. En este caso los elementos que se resaltan son los adverbios: allí y aquí respectivamente. Se encontró un mayor número de construcciones de esta clase con el adverbio aquí.

Como se comentó en el apartado anterior la estructura adverbio + donde puede interpretarse de diferentes formas lo cual depende del contexto en el que se encuentren. Por ejemplo, hay oraciones en las que el adverbio y el relativo parecen estar muy ligados como se muestra en las siguientes oraciones.

a. Éstos aparecen allí donde la situación que se quiere investigar es externa. (CREA)

b. Parece que, desde que estoy aquí, todo ocurre allá donde me creía encerrada y recluida. (CREA)

Las oraciones muestran que el adverbio y la oración subordinada forman un solo componente, especialmente (27)b. En estos casos un primer análisis indicaría que la oración subordinada es el complemento del adverbio allí y allá respectivamente. Pero para comprobar si se trata de dos elementos independientes las someteremos a las pruebas señaladas por Porto Dapena (1997:49), lo cual mostraría otra forma de analizar a esta clase de oraciones.

a. Éstos aparecen allí, es decir, donde la situación que se quiere investigar es externa. / Éstos aparecen donde la situación que se quiere investigar es externa.

b. Parece que, desde que estoy aquí, todo ocurre allá, es decir, donde me creía encerrada y recluida. / Parece que, desde que estoy aquí, todo ocurre donde me creía encerrada y recluida,

Las oraciones de (28) muestran que el adverbio y la oración subordinada adverbial tienen funciones equivalentes ya que pueden separarse sin que se produzcan oraciones agramaticales. Asimismo, la omisión del adverbio indica que la oración subordinada puede 
encontrarse adyacente al verbo sin que se pierdan los rasgos locativos que aporta el adverbio. Por otro lado, se encontraron oraciones en las que el adverbio y la oración subordinada aparecen separados por una coma, lo cual indica con más claridad que el adverbio y la subordinada son independientes como se muestra en las oraciones de (29).

a. Decidí establecerme en Los Llanos, y combatirlos allí, donde tendríamos más libertad de acción y menos riesgos. (CREA)

b. Se establece allí que la SE hará un seminario de un día allá, donde se hablará sobre las oportunidades en energéticos mexicanos. (CREA)

En las oraciones de (29) se muestra que la separación por medio de comas demuestra que el adverbio y la oración subordinada adverbial son independientes, lo cual indica que puede considerarse que se trata de dos complementos circunstanciales o adjuntos de lugar en una misma oración. No obstante, la equivalencia de los dos elementos no es la misma ya que la subordinada aporta mayor información que la que el adverbio allí proporciona. Por otro lado, la separación mediante comas también puede indicar que se trata de una aposición como habíamos señalado anteriormente. Por tanto, los dos análisis sintácticos son posibles.

En lo que respecta al orden sintáctico de las oraciones, principal y subordinada, la mayoría siguen el orden oración principal + oración subordinada como se muestra en los ejemplos citados en (27) y (29). Con el orden oración subordinada + oración principal se encontraron muy pocos ejemplos.

a. Y aquí, donde las mujeres se cargan de hijos, sin industrialización, lo único que lograríamos es ser más pobres cada vez. (CREA)

b. Mucha gente desprecia a los boleros, pero es que no tienen ni la menor idea; aquí donde me ve yo soy dueño de mí mismo, nadie me grita, nadie rezonga, nadie me viene con insultos. (CREA)

En (30) se ilustran dos oraciones cuyo orden es oración subordinada + oración principal, ambas con el adverbio aquí, ya que con los otros tres adverbios no se encontraron 
oraciones con este orden. Asimismo se encontraron oraciones que siguen el orden citado y en este caso se encuentran dentro de otra oración compleja.

a. ¿Con qué cara decirles que allí donde me transaron con dos vasos de leche ya no hay restaurante cual ninguno, ni taller, ni cantina, ni burdelito ni nada, porque ya es eje vial? (CREA)

b. Reitero a su Majestad, que allí donde él pise será el comienzo y el fin del tiempo terrestre. (CREA)

c. Pues al oír los comunicadores de todo estilo y calaña resulta que aquí donde nos hallamos, en el México de 1996 en el umbral de 1997, ya no hay remedio en nada y para nada, ¡ya no hay remedio, ya no hay remedio, ya no hay remedio! (CREA)

Las oraciones de (31) muestran que la subordinada adverbial se encuentra antes de la oración principal. En los tres ejemplos las oraciones se ubican dentro de una subordinada sustantiva introducida por que. Hemos explicado que el adverbio que antecede a la subordinada tiene una función equivalente, por lo tanto la omisión del mismo no generaría oraciones agramaticales, pero si promovería una pérdida de información. De modo que, el adverbio que se encuentra antes de la oraciones de (31), podría considerarse como otro complemento circunstancial de lugar que pertenece a la oración principal y la oración subordinada está proporcionando más información sobre él. Puesto que el adverbio pertenece a la oración principal, podría considerarse como una oración interpolada en la que la subordinada se introdujo entre el complemento circunstancial de la oración principal y el resto de la oración. Pero por otro lado, también puede ser que un elemento de la oración principal se ha topicalizado ubicándose al principio de la toda la cláusula.

En relación a esta clase de oraciones, Porto Dapena (1997:50) explica que en algunos casos el hecho de que el adverbio se encuentre tan unido a la oración principal, obedece a que el primero ha perdido su capacidad de señalar por sí mismo el lugar -o el tiempo en el caso de los temporales-, por tal motivo parece inseparable de la oración subordinada adverbial, aunque esta última sí pueda aparecer sin el adverbio. Según este autor, dicha pérdida de significado además promueve la formación de locuciones como 
siempre que, ahora que, mientras que, entre otras. Pero Pavón (2002:2055) indica que el caso del adverbio donde no se ha producido ninguna locución todavía. Sin embargo, también consideramos la posibilidad de que el adverbio y la oración subordinada se complementen y ambos refuercen el sentido locativo que se quiere expresar en la oración principal.

2.2 Adonde. En lo que respecta a adonde, se considera que ya está unida, de hecho históricamente se encuentran registros que muestran que se trata de una construcción que se formó durante el siglo XV. Con adonde se encontraron distintas clases de verbos que la rigen o incluso casos en los que tanto el verbo de la oración principal como el de la subordinada rigen a la preposición. Asimismo, obtuvimos oraciones que se encuentran en la frontera de las relativas y de las subordinadas adverbiales. En lo relacionado con el orden que siguen las oraciones, principal y subordinada adverbial, observamos que el orden que más apareció fue oración principal + oración subordinada y sólo un ejemplo en el que la oración subordinada se antepone a la principal. No se encontraron ejemplos de oraciones interpoladas.

Empezaremos el análisis de las oraciones introducidas por adonde examinando el orden sintáctico que más se encontró.

a. Concluido el suplicio, se dirigió adonde se encontraba Motecuhzoma para retirarle los grilletes. (CREA)

b. Ahora me vas a tomar de la mano y vas a ir adonde yo te diga, sin llorar y sin hablar. (CREA)

Las oraciones de (32) muestran que la oración principal aparece antes de la oración subordinada. En lo que respecta al orden oración subordinada + oración principal, se encontraron escasos ejemplos como se muestra en (33).

a. No pregunten quién soy porque no se lo digo, sólo sé que adonde voy el amor va conmigo. (CREA) 
b. Son de los que para ir de vacaciones llevan una buena provisión de botellas porque "adonde van las dan muy caras" o les "venden bebidas adulteradas". (CREA)

Los ejemplos indican que la oración subordinada adverbial y la que es su principal se encuentran de dentro de otra oración compleja. En (33)a en una oración subordinada sustantiva que cumple la función de complemento directo del verbo saber. En (33)b se muestra que la subordinada adverbial se halla dentro de una oración adverbial de causa encabezada por porque.

Mencionamos al principio de este apartado que la mayoría de los verbos que rigen a las oraciones adverbiales encabezadas por adonde son de movimiento. Se muestra en los ejemplos que hemos analizado que ocurre en casi todas las oraciones los verbos de la oración regente son de movimiento: dirigirse en (32)a, ir en (32)c y (33)a, excepto en (33)b, en cuyo caso el verbo regente es dar, el cual no es de movimiento. En el caso de los ejemplos (32)a, (32)b, el verbo de la oración principal es el que rige a la preposición que lleva adonde pero en (33)a ambos verbos rigen a la preposición, ya que ambas oraciones llevan el verbo ir. Pero en (33)b el verbo que rige a la preposición es el de la subordinada: $i r$, porque el verbo de la oración principal no es de movimiento.

Los verbos de movimiento que se encontraron con adonde son: ir, regresar, volver, llevar, dirigirse, acudir, transportar, moverse, salir, acercarse, venir, volar, conducir, correr, llegar, bajar y caminar. En la mayoría de las oraciones el verbo regente es el que rige a la preposición ya que el verbo de la subordinada es estativo como se muestra en los ejemplos de (34).

(34) a. ¡Huye! ¡Huye niño! Corre adonde estés a salvo, ciervo hermoso; vuela adonde no te alcance la flecha de mi mirada. ¡Vete! (CREA)

b. Lupita hace una reverencia al público que aplaude, simula arrojar los trofeos y vuelve adonde estaba: su casa. (CREA) 
c. Leonor bajó adonde había dicho, trajo los chocolates que esperaba Natalia, y los comieron sin hacer caso del relleno, hasta llenarse de su compañía. (CREA)

d. Regresé viejo adonde fui joven y quizás debía esperar que los signos de la historia que estoy recordando se manifestasen con espontaneidad. (CREA) e. Se acercó adonde estaba acostado Fernando.

En todas las oraciones de (34) el verbo de la oración principal es de movimiento y en todos los ejemplos es este mismo el que rige a la preposición, ya que los verbos de las oraciones subordinadas son de otra clase. Con otra clase de verbos, es decir que no fueran de movimiento, se encontraron muy pocos ejemplos, uno de ellos es despachar citado en (11)a, que ahora mencionamos en (35).

a. Desde ahí, día y noche, cuatro agentes municipales dan solución a los problemas. y, eventualmente, despachan una patrulla adonde sea necesario. (CREA)

Mencionamos al principio de este apartado que hay algunas oraciones que parecen estar en la frontera de las relativas y las adverbiales, ya que adonde está precedido por una frase prepositiva + una frase nominal, lo cual nos pone ante la interrogante de considerarlas relativas o bien adverbiales. Como hemos explicado las oraciones de relativo o adjetivas hacen alusión a una frase nominal que es su antecedente como se ilustra en los ejemplos de (36).

a. Álvaro, nada más dame el teléfono adonde se te puede localizar, por favor.

(CREA)

b. Le inventé otros lugares, también hipotéticos, adonde llevar a sus paquidermos para impresionar a la población, potencialmente rebelde, de España. (CREA)

Las oraciones de (36) son ejemplos de oraciones de relativo encabezadas por adonde, las cuales muestran que se refieren a la frase nominal que las antecede, en (36)a a el teléfono y en (36)b a otros lugares. No obstante, en el corpus analizado se encontraron 
oraciones en las que una frase prepositiva + una frase nominal anteceden a la oración introducida por adonde como lo ilustran las oraciones de (37).

a. Parecería que se encontraban [en las inmediaciones de Cabo Catoche], [adonde desembarcarían al día siguiente]. (CREA)

b. Se reconciliaron, tumbándose a dormir [en una cama], [adonde al día siguiente los encontraría un sirviente]. (CREA)

c. La estratagema de ese guerrero consistió en llegar [al sitio del desastre], [adonde dejó ocultos cuatrocientos arqueros], internándose a continuación en la ciudad. (CREA)

Las oraciones de (37) muestran que antes de la oración subordinada hay una frase prepositiva, la cual puede considerarse como el antecedente de la misma. El análisis para esta clase de oraciones puede ser de dos formas. El primero es que la oración subordinada se refiere a toda la frase prepositiva y el segundo es que solamente alude a la frase nominal que es el término de la preposición. Puesto que la oración subordinada expresa lugar, consideramos que se refiere a toda la frase prepositiva en conjunto, ya que ambas tienen un sentido locativo. La oración subordinada específica el sentido locativo de la frase que la antecede. Asimismo, otra posibilidad que consideramos adecuada es que se trate de dos complementos circunstanciales de lugar que coexisten en la misma oración en donde la oración subordinada amplía el sentido locativo de la frase prepositiva que la antecede, como se muestra en los ejemplos de (38) en los cuales hemos omitido la frase prepositiva.

a. Parecería que se encontraban, [adonde desembarcarían al día siguiente].

b. Se reconciliaron, tumbándose a dormir, [adonde al día siguiente los encontraría un sirviente].

c. La estratagema de ese guerrero consistió en llegar, [adonde dejó ocultos cuatrocientos arqueros], internándose a continuación en la ciudad.

2.3. En donde. En lo que respecta a en donde, la mayoría de la oraciones que se encontraron son de relativo ya que las precede una frase nominal que la subordinada modifica. Sin embargo, también se encontraron oraciones que están antecedidas por una 
frase prepositiva o bien una frase prepositiva que tiene como término una frase nominal como se muestra en los ejemplos de (39).

a. El me dejaba jugar en donde yo me sentía bien

b. Además, es imposible desarrollar acciones efectivas de atención sin la presencia de personal capacitado en todos los niveles de atención, especialmente en donde no hay suficiente información disponible, como sucede en las regiones rurales del país.

c. Se concentró en las regiones más pobres del país, en donde ocurrieron $70 \%$ de las muertes maternas.

En (39)a la oración subordinada encabezada por donde es el término de la preposición en. En dicho ejemplo la subordinada puede considerarse una oración de relativo que cumple la función de un complemento circunstancial de lugar junto con la preposición que la encabeza. Pero en (39)b y (39)c la preposición + la subordinada están antecedidas por una frase prepositiva cuyo término es una frase nominal. En esta clase de ejemplos pueden darse dos interpretaciones al igual que en las oraciones analizadas en (37), la frase preposicional puede interpretarse como el antecedente de la oración subordinada o bien como dos complementos circunstanciales o adjuntos de lugar si se les aplica las pruebas que Porto Dapena sugiere, se obtiene las siguientes oraciones.

(40) a. Además, es imposible desarrollar acciones efectivas de atención sin la presencia de personal capacitado [en todos los niveles de atención], es decir, especialmente [en donde no hay suficiente información disponible], como sucede en las regiones rurales del país.

b. Se concentró [en las regiones más pobres del país], es decir, [en donde ocurrieron $70 \%$ de las muertes maternas].

(41) a. Además, es imposible desarrollar acciones efectivas de atención sin la presencia de personal capacitado, especialmente [en donde no hay suficiente información disponible], como sucede en las regiones rurales del país.

b. Se concentró [en donde ocurrieron $70 \%$ de las muertes maternas]. 
Las oraciones de (40) y (41) muestran que la omisión de la frase prepositiva no genera oraciones agramaticales pero sí una pérdida de información, en ese sentido no podría considerarse que tanto la frase prepositiva como la oración encabezada por en donde son equivalentes. Si bien la información semántica de lugar se conserva con la omisión de alguna de ellas, la oración encabezada por en donde amplía la información que proporciona la frase prepositiva.

En lo que respecta al orden sintáctico de las oraciones encabezadas por la preposición en, la ordenación que sobresale es: oración principal + oración subordinada como se muestra en las ejemplos citados en (39). No se encontraron oraciones cuyo orden sea oración subordinada + oración principal ni oraciones interpoladas.

2.4. De donde. Con respecto a las oraciones de relativo encabezadas por la preposición de, se encontraron numerosos ejemplos con verbos de movimiento tales como: provenir, salir, trasladarse, emerger, arrancar, partir, venir, pasar, desplazar(se), escurrirse, caminar, subir, surgir, extraer, proceder (con el sentido de venir) como se muestra en las oraciones de (42).

a. "Tomó tanta tristeza que luego se metió en su aposento y comenzó a sollozar, y no salió de donde estaba hasta otro día por la mañana, que era sábado, y mandó que se dijesen misas de Nuestra Señora muy de mañana".(CREA)

b. Vengo de donde viene mi amigo el viento. (CREA)

En (42)a el verbo salir rige a la preposición y en (42)b el verbo venir. Asimismo se encontraron ejemplos en los que la oración de relativo es el término de una locución preposicional como lejos de, cerca de, delante de, debajo de, arriba de, enfrente de como se muestra en los ejemplos de (43).

a. Cargue otra vez la brocha y continúe cerca de donde terminó antes.

b. Siempre se para enfrente de donde yo trabajo. (CREA)

c. La colocaba en otra parte, más adelante o más atrás de donde siempre había estado. (CREA) 
d. Constancia se levantó de la banca y caminó por Factor's Walk, lejos de donde yo observaba la escena. (CREA)

Los ejemplos muestran que la función adverbial no la lleva a cabo únicamente la oración subordinada encabezada por donde sino que la desempeñan la locución preposicional + la oración subordinada en conjunto. En las oraciones de (43)c y (43)d además de la locución preposicional y la oración subordinada, hay otra frase prepositiva que también cumple con la función de complemento circunstancial de lugar, en (43)c en otra parte y en (43)d por Factor's Walk. Atendiendo a los diferentes análisis que se han propuesto para las oraciones que tienen dos elementos que expresan lugar, las oraciones citadas podrían considerarse como dos complementos circunstanciales o adjuntos de lugar, puesto que las oraciones subordinadas no muestran estar haciendo alusión a la frase nominal ni a toda la frase prepositiva + la frase nominal en conjunto. Si bien las oraciones subordinadas proporcionan más información sobre el lugar en que se lleva a cabo la acción expresada por el verbo, no muestran que estén subordinadas a las frases prepositivas que las anteceden. Por lo tanto, consideramos que en estos dos casos se trata de dos complementos circunstanciales de lugar, el primero es una frase prepositiva que tiene como término una frase nominal y el segundo una frase prepositiva cuyo término es una oración de relativo.

Por otro lado, también hay oraciones de relativo encabezadas por la preposición de cuyo verbo regente se repite en la oración subordinada como se muestra en las oraciones $\operatorname{de}(44)$.
a. Ni el patrocinio, provenga de donde provenga, es del todo desinteresado
b. La obra de imprimir a nuestra vida un sello peculiar no parte de donde lógicamente debe partir: del conocimiento del mexicano.

Se muestra en las oraciones de (44) que el verbo de la oración regente se repite en la oración subordinada y en estos casos ambos verbos rigen a la preposición que encabeza a la subordinada. Finalmente, algunas oraciones precedidas por la preposición de también pueden estar antecedidas por un verbo copulativo como ser o estar. 
$\mathrm{Al}$ observar el orden de las oraciones principal y subordinada, la mayoría tienen el orden oración principal + oración subordinada como se ha mostrado en los ejemplos analizados. No obstante, se encontraron oraciones cuyo orden empieza con la oración subordinada como lo muestran las oraciones de (45).

a. Arriba de donde se encontraban monjes y ermitaños, en la cima del Kailas, estaba por iniciarse la última y más importante de todas las ceremonias que integraban la celebración del Kumba Mela en los Himalaya.

b. Nunca creí que de donde fuera te iban a sacar, porque no sabemos mirar, como te digo, más allá de nuestras narices.

Si bien en ambas oraciones la subordinada se antepone a la principal, en (45)a la oración de relativo está introducida por el adverbio arriba de; y en (45)b la subordinada se encuentra dentro de otra oración compleja, es decir, dentro de una oración sustantiva introducida por que. Por lo tanto, consideramos que ambos órdenes sintácticos son posibles, pero el que aparece con mayor frecuencia es en el que la oración principal se encuentra antes de la subordinada.

2.5. Hacia donde. Con respecto a las oraciones introducidas por la preposición hacia que se analizaron en el corpus, observamos que el verbo de la oración principal la rige, ya que aparece adyacente a él. A diferencia de las preposiciones que se analizaron en los apartados anteriores, en las que se encontró una gran cantidad de oraciones de relativo cuyo antecedente aparece en la oración, con la preposición hacia se obtuvieron muy pocos ejemplos de oraciones de relativo o adjetivas cuyo antecedente es una frase nominal. Asimismo, el corpus muestra que los verbos de la oración principal son de movimiento como: fluir, dirigirse, ir, correr, caminar, avanzar, huir, ascender, proseguir, devolverse y aproximarse, como se muestra en las oraciones de (46).

(46) a. Así pues, cada quien corrió hacia donde pudo intentando ponerse a salvo. (CREA)

b. El mexicano y el yanqui se dirigieron hacia donde se encontraban las casas caminando por las calles que aún existían. (CREA) 
c. Y suspirando caminó hacia donde él estaba. (CREA)

d. Va hacia donde se encuentran accionando los Cargadores. (CREA)

e. Mayra se aproximó decidida hacia donde estaba la muñeca, se inclinó a recogerla y se la llevó. (CREA)

Las cinco oraciones muestran que el verbo rector es de movimiento y la frase prepositiva está adyacente al mismo, por lo tanto, puede analizarse como un complemento circunstancial o adjunto del verbo. Asimismo, se encontraron variadas oraciones en las que el verbo regente es de percepción como ver y mirar, o bien que expresan el mismo sentido como: volver la vista, volverse (voltear), volver el rostro, voltearse y volver la cara, en (47) se muestran ejemplos de tales verbos.

a. Miré hacia donde mi futura presa, Alma Curiel, despachaba sus respectivos tacos de caguama, y para mi dolor, no encontré a nadie. (CREA)

b. Volvió la vista hacia donde había visto el pie de un hombre minutos antes y notó que ahora asomaba parte del muslo y la rodilla. (CREA)

c. Los muchachos de enfrente dejaron de hablar y volvieron sus rostros hacia donde venían los pasos. (CREA)

d. Rogelio volteó hacia donde estaba Mayra, que en esos momentos le daba la espalda. (CREA)

Otros verbos que también se encontraron en el corpus e indican movimiento, pero que son transitivos son: empujar, arrojar y jalar. En (48)a, (48)b y (48)c se muestran oraciones con los verbos señalados.

a. El Miserable-parlante termina la cerveza y arroja la lata hacia donde se encuentran Jorge y Sara en el momento en que ella se ha aproximado a la ventana. (CREA)

b. La empujé hacia donde venían los gritos. (CREA)

c. Un remolino la jaló hacia donde se despeñaba una cascada. (CREA) 
d. Las ciudades de México crecen en materia habitacional hacia donde muchas veces líderes corruptos que explotan a la gente los llevan a invadir. (CREA)

Muestran los ejemplos (48)a, (48)b y (48)c que los verbos rectores son transitivos, porque en las tres oraciones se encuentra el complemento directo, pero son verbos que indican movimiento. Asimismo los verbos estativos pueden regir a la preposición hacia como se ilustra en (48)d en donde el verbo regente es crecer.

Por otro lado, se encontraron oraciones introducidas por la preposición hasta en las que el verbo de la subordinada rige a la preposición. Los ejemplos de (49) lo ilustran.

a. Si escuchas disparos, montas y huyes hacia donde vinimos. (CREA)

b. Voy hacia donde vaya. (CREA)

Las oraciones muestran que los verbos de la subordinadas venir e ir también rigen a la preposición hasta.

Por otro lado, al igual que con las oraciones encabezadas por las preposiciones que hemos estudiado hasta ahora, con la preposición hacia también hay oraciones que tienen doble frase prepositiva que podría considerarse como un caso de doble complemento circunstancial. Véase los ejemplos de (50).

a. Miraba hacia arriba, hacia donde debería estar la luz y todo lo que encontraba era un firmamento rosado. (CREA)

b. Unos colores que iban del rojo al púrpura y otros entre amarillos y azules se iban dilatando por las nubes, hacia el poniente, hacia donde todavía las persecuciones no habían terminado. (CREA)

En ambos ejemplos se muestra que hay dos frases prepositivas encabezadas por la preposición hacia. En (50)a la primera frase prepositiva tiene como término una frase adverbial: hacia arriba; la segunda frase preposicional tiene como término una oración de relativo encabezada por donde. Se muestra en la oración que ambas frases son 
independientes, es decir, la segunda frase prepositiva no modifica a la primera frase, sino que solo está ampliando la información de lugar que proporciona la primera frase prepositiva. En (50)b la oración tiene tres frases prepositivas que podrían considerarse como adjuntos de lugar. La primera es por las nubes, la segunda hacia el poniente y la tercera es la que introduce a la oración subordinada de relativo hacia donde todavía las percusiones no habian terminado. Las tres frases prepositivas cumplen la función de adjunto de lugar en la oración, puesto que cada una proporciona información sobre el lugar en que se dilataban el sujeto.

En lo que respecta al orden sintáctico de las oraciones principal y subordinada, sólo se obtuvieron oraciones cuya oración principal antecede a la oración subordinada. Asimismo hay oraciones que además de tener una subordinada encabezada por la preposición hacia que indica lugar también tienen un complemento circunstancial de modo que modifica al verbo regente, como se muestra en las oraciones de (51).

a. El muchacho se terció la carabina sobre la espalda y ascendió [a grandes zancadas] hacia donde yacía el venado. (CREA)

b. Luego, de común acuerdo, empezamos a caminar [en silencio] hacia donde estaba la fiesta. (CREA)

c. Mayra se aproximó [decidida] hacia donde estaba la muñeca, se inclinó a recogerla y se la llevó. (CREA)

d. [Con los ojos nublados] me devolví hacia donde estaba nuestro camión. (CREA)

Los complementos circunstanciales de modo que se encuentran en las oraciones de (51) son: a grandes zancadas en (51)a, en silencio en (51)b, decidida en (51)c y con los ojos nublados en (51)d. Si bien los complementos circunstanciales de distintas clases pueden aparecer dentro de cualquier oración, llamó nuestra atención que con las oraciones adverbiales encabezadas por la preposición hacia, los complementos circunstanciales de modo son los que más aparecieron, lo cual podría obedecer a la clase de verbos que tiene la oración principal. 
Asimismo, se observa que además de verbos de movimiento, algunos verbos de las oraciones subordinadas encabezadas por hacia son estativos, lo cual tiene que ver con los rasgos semánticos de la preposición, ya que esta indica trayectoria de orientación. Señala Morimoto (2001:74) que hacia "representa una Trayectoria dirigida en dirección al espacio señalado por el Objeto o el Lugar de referencia”.

2.6. Hasta donde. En lo que respecta a las oraciones adverbiales encabezadas por la preposición hasta, al igual que con las preposiciones ya analizadas, se encontraron variados ejemplos con verbos de movimiento como: llegar, huir, subir, encaminarse, caminar, acercarse y aproximarse como se muestra en las oraciones de (52).

a. Llegaron hasta donde se encontraba el navío, y allí, ocultos entre los arbustos, permanecieron largas horas al acecho. (CREA)

b. Se acercó hasta donde yo estaba y le dije que buscaba a la familia Guerra. (CREA)

c. Después caminó hasta donde se encontraba el guerrillero. (CREA)

d. Se lavaron caras, manos y pies, luego se encaminaron hasta donde se encontraba El Sargento. (CREA)

Se muestra en los cuatro ejemplos que la oración encabezada por la preposición hasta está regida por un verbo de movimiento, en (52)a el verbo llegar, en (52)b acercarse, en (52)c caminar y en (52)d encaminarse. Otros verbos que no son de movimiento que también se encontraron en el corpus son llevar, conducir, extenderse, prolongarse, estirarse, etc. como se ilustra en las oraciones de (53).

a. Con movimientos largos extienda el tinte hasta donde ya estaba entintado, sin sobreponer. (CREA)

b. Un señor que quién sabe de dónde salió, fue por mí, me tomó de la mano y me llevó hasta donde estaba el Chato. (CREA)

Puesto que la preposición hasta indica límite, en este caso de lugar, puede ser compatible con distintas clases de verbos, en (53)a el verbo extender es de estado y en (53)b llevar es transitivo. Por otro lado, se encontraron numerosas oraciones encabezadas 
por la preposición hasta + donde que no se refieren a un lugar, se trata de expresiones del tipo: hasta donde sé, hasta donde tengo entendido, hasta donde es/sea/fue posible, hasta donde recuerdo, etc. Muchas de estas oraciones aparecen antepuestas a la oración principal o bien interrumpen la secuencia de la oración principal, es decir oraciones interpoladas, como se ilustra en los ejemplos de (54).

a. Pero hasta donde nosotros sabemos, no hay policías involucrados en algún nivel del delito. (CREA)

b. El consenso se practica hasta donde es posible, y en la ley de la democracia, que es mi frase favorita, hasta donde es y cuando es necesario. (CREA)

c. Ningún grupo, hasta donde yo sé, se ha adjudicado la responsabilidad por el estallido del vuelo 800 de Nueva York a París de la TWA la semana pasada. (CREA)

En la oración (54)a la oración subordinada aparece antes de la principal; en (54)b la subordinada está pospuesta a la principal y en (54)c la subordinada interrumpe la secuencia de la oración principal ya que se introduce entre el sujeto, ningún grupo, y el verbo de la oración regente adjudicarse. No obstante, como señalamos anteriormente, esta clase de oraciones no expresan lugar precisamente, sino que se trata de frases que generalmente tienen como verbo principal el verbo copulativo ser o bien verbos de pensamiento como saber, entender, recordar, conocer, o expresiones equivalentes como hasta donde tengo entendido, hasta donde la memoria me asiste. Con esta clase de oraciones se encontraron numerosos ejemplos en los que la subordinada se encuentra al principio de la cláusula o que interrumpe la secuencia de la oración principal.

En lo que respecta a las oraciones que sí expresan lugar, como las que ilustramos en (52) y (53), se encontró únicamente el orden oración principal + oración subordinada. Igualmente, se encontraron ejemplos en los que, además de tener una oración subordinada encabezada por la preposición hasta, tienen otra frase prepositiva que puede considerarse como otro complemento circunstancial o adjunto de lugar como se muestra en los ejemplos de $(55)$. 
a. Los policías, ante la sorpresa, huyeron [hacia sus oficinas], [hasta donde fueron perseguidos por los embozados, los cuales no dejaron de dispararles]. (CREA)

b. Opera a la luz del día [en las regiones de refugio indias] [hasta donde no llega consistentemente el poder de coerción de la casta gobernante] y persiste sub-rosa en las villas y ciudades españolas al favor de la acogida que le dan las castas subalternas integradas en la sociedad colonial. (CREA)

En (55)a hay dos frases prepositivas que cumplen la función de adjunto de lugar. La primera es hacia sus oficinas y la segunda es hasta donde fueron perseguidos por los embozados. Se muestra que ambas frases son independientes, es decir la frase prepositiva que encabeza a la oración de relativo no modifica a la frase prepositiva que la antecede, sino que modifica al verbo y además amplía la información de lugar que proporciona la primera frase preposicional, por tanto, puede considerarse que hay dos adjuntos de lugar en dicha oración. En la oración (55)b también hay dos frases preposicionales que desempeñan las tareas de un adjunto de lugar, la primera frase está introducida por la preposición en y su término es una frase nominal y a la segunda la introduce la preposición hasta y su término es la relativa encabezada por donde. Al igual que la oración (55)a las frases prepositivas son independientes, es decir, la frase prepositiva encabezada por hasta no modifica a la frase prepositiva en las regiones de refugio indias, sino que modifica al verbo operar, pero también aporta más información de lugar en que ocurre la acción del verbo. Por tal motivo, ambas frases pueden considerarse adjuntos de lugar que coexisten en una misma oración.

Algunas de las oraciones encabezadas por la preposición hasta + donde no tienen un valor locativo sino que expresan tiempo como se muestra en las oraciones de (56).

a. Nosotros vamos a continuar hasta donde tope con la lucha política, social y organizada. (CREA)

b. Obedeceré hasta donde las agallas me lo permitan o hasta que el señor agarre la mano y me saque de las trencitas. (CREA) 
En ambas oraciones la subordinada muestra que el límite de la acción expresada por el verbo no sucede cuando lleguen a un lugar o sitio determinado, sino que durarán por un período de tiempo, ya que tales oraciones se pueden parafrasear como sigue: Nosotros vamos a continuar hasta que tope con la lucha política en (56)a y Obedeceré hasta que las agallas se lo permitan en (56)b, en ambos casos el sentido es temporal y no locativo.

2.7. Por/para donde. Para finalizar este apartado nos referiremos a las oraciones relativas encabezadas por las preposiciones por y para. $\mathrm{Al}$ igual que las oraciones encabezadas por las preposiciones que se analizaron en los apartados precedentes, muchos verbos que rigen a las oraciones introducidas por la preposición por son de movimiento tale como: moverse, pasearse, descender, subir, trepar, salir, entrar, llegar, venir, etc. Incluso, en los ejemplos de oraciones de relativo o adjetivas encabezadas por la preposición por, el verbo de la subordinada es de movimiento también. En (57) presentamos ejemplos de oraciones precedidas por la preposición por + donde con función adverbial.

a. Una vez decidido el regreso Evans y Bourdillon descendieron muy agotados por donde habían trepado a la subida. (CREA)

b. Acabo de pasar por donde un montón apilado de ellas afea la calle. (CREA)

c. Al igual que los demás caracoles, deja una línea brillante por donde camina; una línea que parece de plata cuando la luz del sol poniente la ilumina. (CREA)

En (57)a y (57)b los verbo de la oración principal son de movimiento descender y pasar respectivamente, pero en (57)c el verbo de la oración principal es dejar, el cual es transitivo. Si bien la mayoría de los verbo que rigen a la preposición por son de movimiento, también puede encontrarse con otras clases de verbos.

Asimismo, hay oraciones encabezadas por la preposición por en las que tanto el verbo de la oración principal como el de la subordinada rigen a la preposición como se muestra en las oraciones de (58). 
a. Al ver muerto al suboficial quedarían desorientados y sin saber qué hacer, regresarían por donde habían venido para reunirse con el grueso de la tropa. (CREA)

b. Las miró por ambos lados, montó de nuevo y se fue por donde había venido con el mismo trote que lo había traído. (CREA)

c. Controlé mi aflicción y con la presteza de un ladrón escalé el lavabo y la regadera para salir por donde había entrado. (CREA)

Las oraciones de (58) muestran que tanto el verbo regente como el de la subordinada rigen a las preposición, ya que ambos son verbos de movimiento. En (58)a los verbos son regresar y venir, en (58)b irse y venir y en (58)c salir y entrar que se encuentran en una oración de finalidad encabezada por la preposición para en donde el verbo principal está en infinitivo. En oraciones en las que ambos verbos rigen a la preposición, los verbos tienen un sentido contrario como entrar y salir, descender y subir o regresar y venir. En otras oraciones el verbo de la oración principal se repite en la subordinada que generalmente es de movimiento.

Respecto al orden sintáctico que tienen las oraciones encabezadas por la preposición por, la mayoría tienen el orden oración principal + oración subordinada como lo muestran las oraciones citadas en (57) y (58). Dicho orden puede encontrarse también cuando la oración principal y la subordinada se ubican dentro de otras construcciones más complejas como se muestra en (58)c en la cual la subordinada se localiza dentro de una oración subordinada de finalidad. Con el orden oración subordinada + oración principal u oraciones interpoladas se encontraron escasos ejemplos. En (59) se ilustra una oración interpolada.

Poco después, anocheciendo, los huaves ven aparecer por donde se fue la de motor una canoa de tronco que navega con vela y tripula un único y solitario mestizo, pescador de algún otro poblado del litoral.

La oración de (59) indica que la oración subordinada, introducida por la preposición por, se encuentra dentro de una oración sustantiva que cumple la función de complemento directo del verbo ver. Se muestra que la subordinada adverbial interrumpe la secuencia de 
la oración principal, ya que se ubica entre el verbo principal aparecer y el sujeto: una canoa de tronco [...]. El ejemplo muestra además que ambos verbos rigen a la preposición.

Ahora bien, con respecto a oraciones que tienen dos complementos circunstanciales o adjuntos de lugar, se encontraron los siguientes ejemplos.

a. Después del ataque salieron huyendo por la zona hotelera, por donde está el campo de golf, y tomaron la carretera federal rumbo a Pochutla. (CREA) b. Además, soy portadora de otras muy gratas nuevas que te diré por allí, por donde tú quieras que vayamos. (CREA)

c. Al atardecer los viejos, sentados en las bancas, sin hablarse, posan sus miradas en el crepúsculo de las montañas por donde sus hijos o nietos salieron atraídos por la fiebre del dólar, empujados por el olvido de estas comunidades bastiones de la cristiada. (CREA)

Las oraciones de (60) tienen dos frases prepositivas, en (60)a y (60)c la primera tiene como término una frase nominal y en (60)b una frase adverbial. La segunda frase prepositiva de todas las oraciones tiene como término una oración de relativo encabezada por donde. Los tres ejemplos muestran que las frases prepositivas son independientes y se observa que la segunda frase prepositiva proporciona más información sobre la primera frase. En (60)a la frases son por la zona hotelera y la segunda por donde está el campo de golf; en (60)b la primera frase es por allí y la segunda es por donde tú quieras que vayamos y en (60)c la primera frase preposicional es en el crepúsculo de las montañas y la segunda por donde sus hijos y nietos salieron atraídos por la fiebre del dólar. Tales ejemplos pueden considerarse como dos complementos circunstanciales o adjuntos de lugar en una sola oración.

Finalmente, hablaremos de las oraciones encabezadas por la preposición para + donde, de las cuales se encontraron muy pocos ejemplos.

(61) Hay que sufrir y llorar mucho para donde usted va. (CREA) 
La oración (61) muestra que tanto el verbo de la oración principal como el de la subordinada: ir rigen a la preposición para. Puesto que se encontraron escasos ejemplos de esta construcción, no se hallaron oraciones interpoladas ni con dos complementos circunstanciales o adjuntos de lugar.

3. Conclusiones. El análisis sintáctico de las oraciones adverbiales de lugar muestra que no tienen una estructura uniforme. Si bien cumplen las funciones de un adverbio de lugar, el traslape que presentan con las oraciones de relativo o las llamadas relativas libres es muy notable pero su ordenación sintáctica es distinta.

La estructura sintáctica esperada en esta clase de oraciones es la que tiene como unión o nexo subordinante al relativo donde sin que este esté incrementado o mejor dicho sea término de una preposición o lo anteceda un adverbio, por ejemplo: Lo vi donde quedamos, Trabaja donde hacen escobas, Da clases donde estudió. Tales oraciones se consideran oraciones adverbiales de lugar porque la subordinada está adyacente al verbo de la oración principal y por lo tanto, lo modifica. Sin embargo, el corpus analizado muestra que hay muy pocas oraciones con esta clase de estructura, gran parte de las oraciones que se encontraron son oraciones en las que el relativo donde tiene la función adjetiva y modifica a un sustantivo, por ejemplo: el pueblo donde llegaron, Oaxaca, donde nacieron sus abuelos, etc.

Los ejemplos en los que el relativo adverbial donde está incrementado por una preposición, la oración subordinada se podría considerar adverbial porque puede sustituirse por un adverbio, pero como las que mencionamos en unas líneas anteriores, el relativo donde no une directamente a la subordinada con la oración principal y por tal motivo su estructura sintáctica podría considerarse como una relativa libre. Sin embargo, también mencionamos que las preposiciones proporcionan matices distintos a la subordinada y al significado que transmiten dentro de la oración en la que se encuentran sin que haya una frase nominal de por medio, es decir, tanto la preposición como el relativo adverbial donde refuerzan el sentido locativo que transmite la oración subordinada y en este sentido pueden considerarse dentro del grupo de las subordinadas adverbiales y no en el grupo de las relativas. 
Es importante enfatizar, además, que si bien sintácticamente tienen una estructura distinta de las que tradicionalmente se han considerado como oraciones adverbiales de lugar, las funciones que cumplen dentro de la oración en la que se encuentran son las propias de un adverbio de lugar. Por lo tanto, atendiendo a las diferentes posturas que se analizaron al principio de este capítulo, concluimos que la estructura de las oraciones adverbiales de lugar es más polémica que la estructura de las oraciones subordinadas adverbiales temporales. Las oraciones adverbiales de lugar presentan distintas estructuras sintácticas y diferentes modos de analizarlas. Hay oraciones en las que donde actúa como nexo subordinante de la oración que depende de la principal, pero hay otra estructura en la que se trata de una oración de relativo que es término de una preposición o de un adverbio que cumple las funciones de un adverbio de lugar, sobre todo cuando el verbo de la oración principal es de movimiento, pero semánticamente cumplen las funciones de un adverbio por lo que en estos casos las oraciones subordinadas de lugar son consideradas argumentos del verbo que las rige.

Puesto que en el corpus no se encontraron muchas oraciones en las que el relativo adverbial donde uniera directamente a la oración principal con la subordinada dicha estructura nos sugiere, además, un cambio que puede estar ocurriendo en la lengua, es decir, en la que los hablantes prefieran la forma adjetiva o de relativo o sustantiva que la adverbial o bien en un intenten reforzar el sentido que transmite en relativo donde por medio de una preposición o viceversa. Finalmente, consideramos que las frases prepositivas o adverbiales que preceden a las subordinadas adverbiales de lugar pueden analizarse como otro complemento circunstancial o adjunto de lugar que precisa o amplía el sentido que la oración adverbial expresa. 


\section{Capítulo IV}

\section{La concordancia temporal en las cláusulas subordinadas adverbiales de tiempo y lugar}

Introducción. Este capítulo se ocupa de describir la consecutio temporum, concordancia o correlación de tiempos verbales entre la oración principal y la oración subordinada en las cláusulas adverbiales de lugar y tiempo, tomando como punto de partida las investigaciones que se han hecho sobre las oraciones subordinadas sustantivas realizadas por Carrasco (1999) y sobre las subordinadas adverbiales por Veiga y Mosteiro (2006). En su trabajo, Carrasco analiza la consecutio temporum de las oraciones subordinadas sustantivas en relación con la principal, muestra qué tiempos verbales pueden ser posibles en esta clase de oraciones, no obstante en las oraciones subordinadas adverbiales propias de lugar y tiempo la correlación de los tiempos verbales está relacionada con el tipo de conector introductorio y el modo de los verbos encontrados en el corpus. Por lo tanto, con el fin de determinar cuáles son los tiempos verbales que pueden correlacionarse en el español de México consideraremos ambos factores para determinar qué tiempos son posibles en esta clase de oraciones. En primer lugar presentaremos los aspectos teóricos en los que basamos el análisis, y posteriormente mostraremos ejemplos de oraciones subordinadas adverbiales que ilustren la concordancia de tiempos verbales que se encontraron y que pueden ser posibles.

1. Preliminares. En los capítulos precedentes discutimos que las oraciones subordinadas adverbiales cumplen la función propia de un adverbio. De acuerdo con Seco (1973), Seco (1982), Gili Gaya (1983), Munguía y Rocha (1996) y Alarcos Llorach (1999: 354,355) entre los diferentes complementos que toman los verbos se encuentra el adverbial, cuya función puede llevarse a cabo mediante una proposición adverbial introducida por medio de conjunciones. De manera que las OSADV pueden sustituir a un adverbio de la oración principal o modificar al verbo de la oración principal del mismo modo en que lo haría un adverbio; pueden modificar cualitativa o cuantitativamente a la subordinada por lo cual, también se les llama oraciones circunstanciales. Mostramos, además, que la estructura de 
las oraciones subordinadas adverbiales es diversa, asimismo muestran que tienen movilidad dentro de las oraciones en las que se encuentran ya que siguen tres órdenes distintos.

Señalamos que las conjunciones temporales tienen estructuras distintas, y que pueden formarse mediante preposiciones + la conjunción que como hasta que, desde que, o para que $e^{35}$ bien pueden formarse de adverbios como antes (de) que o después (de) que. Hacemos hincapié en las conjunciones porque consideramos que influyen de manera importante en la concordancia verbal de las oraciones subordinadas adverbiales propias, que es el tema que nos ocupa en este capítulo, específicamente en las oraciones temporales. Veiga y Mosteiro (2006) analizan las formas verbales de las oraciones subordinadas adverbiales propias e impropias, si bien su estudio se enfoca principalmente en el modo de los verbos de tales oraciones, hacen una clasificación de los nexos o conjunciones subordinantes temporales en función de las propiedades léxicas que poseen, es decir, si muestran anterioridad, posterioridad o simultaneidad con respecto a la oración principal. Dicha clasificación resulta muy aclaratoria, ya que los rasgos temporales y aspectuales que las citadas conjunciones poseen son un factor relevante en la concordancia de tiempos que abordaremos en este capítulo y que trataremos en un apartado posterior.

Para Carrasco (1999) la concordancia de los tiempos verbales de las oraciones subordinadas sustantivas está orientada al análisis de los tiempos verbales así como al modo en que pueden encontrarse, y muestra los tiempos canónicos de concordancia de tiempos verbales de las subordinadas sustantivas en relación con la oración principal. Carrasco (1999) señala en su estudio de las oraciones subordinadas sustantivas, que el evento de estas puede ser anterior, simultáneo o posterior al evento de la oración regente, del mismo modo, en las oraciones subordinadas adverbiales de tiempo y lugar, el evento de la oración subordinada puede ser simultáneo, posterior o anterior al de la oración principal como lo muestran los ejemplos de (1).

(1) a. Nuestra vida cambió mucho cuando llegamos aquí.

b. Terminó de preparar los bocadillos antes de que los invitados llegaran.

c. Les daremos una ayuda económica tan pronto como los veamos.

\footnotetext{
${ }^{35}$ Para el caso de las oraciones subordinadas impropias de finalidad.
} 
En (1)a la oración subordinada está introducida por el relativo adverbial cuando, se muestra además que los eventos de la oración principal y la subordinada ocurren en un mismo momento, ya que ambos verbos cambió y llegamos están en pretérito. En (1)b el nexo subordinante es antes de que, se observa, además, que tanto el verbo de la oración principal como el de la subordinada están flexionados en pretérito, no obstante, el evento de la oración principal es anterior al evento de la oración subordinada porque el nexo subordinante así lo indica. En (1)c el verbo de la oración principal está flexionado en futuro y el de la subordinada en presente del modo subjuntivo. El ejemplo citado muestra que el evento de la oración principal es posterior al evento de la oración subordinada. En los tres casos se puede observar que no solamente los tiempos verbales influyen en la concordancia de tiempos sino que los nexos subordinantes temporales también están relacionados con ella.

Hipotéticamente, un factor importante que influye en la concordancia verbal o consecutio temporum de las oraciones subordinadas adverbiales es el nexo subordinante, lo cual únicamente tiene que ver con las oraciones temporales, ya que en las locativas el relativo adverbial donde, por sus propiedades léxicas, no influye en los tiempos verbales que puedan combinarse, más bien los tiempos verbales son los que indican cuál de los dos eventos es anterior, posterior o simultáneo como se ilustra en las oraciones de (2).

(2) a. Como donde me gusta.

b. Compré el libro donde me dijiste.

c. Vive donde vivía su abuelita.

Las oraciones de (2) muestran que el relativo donde no influye en la temporalidad de las oraciones principal y subordinada. En (2)a los verbos de las oraciones principal y subordinada están flexionados en presente y muestran que son simultáneas. En (2)b ambos verbos están flexionados en pretérito, pero no se trata de eventos que ocurran de manera simultánea, la oración muestra que el evento de la oración principal es posterior al evento de la oración subordinada. En (2)c el verbo de la oración principal está flexionado en presente pero el verbo de la oración subordinada está flexionado en copretérito lo cual indica que el evento de la principal es posterior al evento de la subordinada. Los ejemplos 
muestran que con el relativo adverbial donde el evento de la oración subordinada puede ser posterior, anterior o simultáneo con respecto al de la oración principal, pero no es donde el que lo indica sino los tiempos verbales.

De manera que en el presente estudio examinaremos la consecutio temporum o concordancia verbal de las oraciones subordinadas adverbiales con respecto a la oración principal, atendiendo a los factores que intervienen en dicho fenómeno. En los apartados sucesivos veremos la definición de consecutio temporum o correlación verbal y posteriormente se describirá cada uno de los factores que están relacionados con la concordancia verbal en las OSADV.

1.1 La consecutio temporum o concordancia verbal de tiempo. Cuando hablamos del término concordancia, podríamos referirnos a la concordancia de género y número que debe haber entre un determinante y un nombre o bien entre un nombre y un adjetivo cuando aparecen juntos, es decir consideramos que un sustantivo masculino singular debe llevar un determinante con el mismo género y número, por ejemplo, diríamos el teléfono y no *la teléfono o *los teléfono. Asimismo, cuando añadimos un adjetivo este debe concordar en género y número con el determinante y el sustantivo, por tanto, diríamos el teléfono rojo pero no *el teléfono roja. Del mismo modo, ocurre con la consecutio temporum o concordancia verbal de tiempos, los tiempos verbales de las oraciones subordinadas deben tener correlación con respecto al tiempo verbal de la oración principal a la que se subordinan como explicaremos a continuación.

La concordancia o correlación de tiempos verbales es una función gramatical cuyo origen provienen de la naturaleza deíctica de los tiempos verbales (Carrasco 2000:9). Señala Carrasco que "las categorías deícticas se caracterizan porque su interpretación depende de determinadas circunstancias del tiempo del habla" (Carrasco 2000:9). Dado que los tiempos verbales son categorías deícticas, su interpretación también depende de las circunstancias en que ocurra el momento del habla, el cual se toma como el punto de referencia de los eventos denotados por los verbos. Así, un evento en presente se considerará simultáneo al momento del habla, un evento en pasado se tomará como anterior al momento del habla y una acción en futuro se considerará como posterior al momento del 
habla. De manera que en oraciones simples o independientes las formas verbales orientarán sus relaciones temporales con respecto al momento del habla, lo cual, como se ha mencionado, se tomará como el eje de la deixis temporal como se ilustra en los ejemplos de (3).

(3) a. Marysa rentó un nuevo apartamento el mes pasado.

b. Beti hace ejercicio por la mañana.

c. Saldremos a caminar en la tarde.

La oración (3)a es anterior al momento del habla, porque el verbo rentó está en pretérito, es decir, se trata de un evento que pertenece al pasado. La oración (3)b está en presente por lo tanto, coincide con el momento del habla, es decir, existe simultaneidad. (3)c está en futuro, por tanto, es un evento posterior al momento del habla. No obstante, en las oraciones subordinadas el tiempo de las formas verbales que se toma como punto de referencia, es decir, el eje de la deixis temporal, ya no es el momento del habla sino el tiempo del evento de la oración principal. Por lo tanto, la temporalidad de la oración subordinada puede ser anterior, posterior o simultánea con respecto al tiempo de la oración principal (Pavón 2012:20) como se muestra en los siguientes ejemplos.

(4) a. Muchos se levantaban a platicar o a tomar café, mientras un secretario de Estado leía de manera monótona un texto. (CREA)

b. Lo ves en la tarde, luego que regresemos de trabajar. (CREA)

En (4)a la subordinada adverbial está introducida por mientras y su punto de referencia es el evento de la oración principal: se levantaba. El ejemplo muestra que el evento de la subordinada: leía es simultáneo al de la oración principal, ya que ambos están en copretérito, por lo tanto, ocurren en un mismo momento. En (4)b se observa que la oración subordinada está encabezada por luego que. Asimismo este ejemplo ilustra que el evento de la oración subordinada adverbial toma como punto de referencia el tiempo del evento de la oración principal, lo cual muestra que el evento de la subordinada adverbial: regresemos es anterior al de la principal: ves. Si bien ambos eventos están en presente, notamos que el evento de la oración principal está en modo indicativo y el evento de la subordinada está en modo subjuntivo, lo cual en algunas ocasiones tiene que ver con el tipo 
de conjunción que introduce a la oración subordinada adverbial o bien con eventos que tendrán lugar en el futuro o que no se han realizado aún como analizaremos en los apartados posteriores.

Por otro lado, para ver con mayor claridad cómo ocurre la concordancia temporal en las oraciones simples y subordinadas, explica Carrasco que se deben atender dos cosas importantes. Primeramente, que los hablantes dividen la línea temporal en dos partes o esferas y pueden situar los eventos expresados por los verbos en cualquiera de esas dos esferas. En segundo lugar, se debe tener en cuenta que algunos tiempos verbales, denominados tiempos absolutos, ubican el evento con respecto al momento del habla directamente, pero otros tiempos verbales, llamados tiempos relativos, lo hacen de manera indirecta, es decir, a través del tiempo de otro evento (Carrasco 2000:17; RAE 2010:466). De modo que la línea temporal se puede representar como sigue:

(5) $/ / / / / / 1$ $\underline{\mathrm{H}}$

Esfera del pasado

Esfera del presente (Carrasco 2000:17)

En el diagrama se muestra que las líneas diagonales dividen las esferas, del presente y del pasado; la letra $\mathrm{H}$ indica el momento del habla, el cual está dentro de la esfera del presente y la esfera del pasado es anterior al momento del habla. Carrasco indica que la representación de la línea del tiempo en dos esferas permite que los tiempos verbales puedan clasificarse dentro de cada una de ellas ya sea que se ubiquen en la del presente o en la del pasado. Considera esta lingüista que los tiempos de la esfera del presente y del pasado son todos aquellos en los que una forma verbal se sitúe: (1) en la esfera del presente o del pasado o (2) con respecto a otro evento situado en la esfera del presente o del pasado. De modo, que la clasificación de tiempos verbales que esta autora hace es la siguiente, en la esfera del presente se encuentran el presente, el antepresente, el futuro y el ante-futuro. En la esfera del pasado ubica al pretérito, al copretérito, al ante-copretérito, al pospretérito y al ante-pospretérito (Carrasco 2000:17, 18).

Hemos visto en los ejemplos citados en (3) y (4) que los tiempos verbales deben tener un punto de referencia ya sea con respecto al momento del habla o bien con respecto a otro evento, por tanto, la definición que Carrasco da sobre la consecutio temporum o 157 
concordancia de tiempos es la siguiente: "es la relación de dependencia que se establece entre las interpretaciones temporales de dos formas verbales. Es la concordancia que hay entre el verbo de una oración subordinada y el verbo de su oración principal siempre que el primero oriente sus relaciones temporales con respecto al segundo" (Carrasco 1999:3063). Considerando la definición que acabamos de citar, podemos decir que en los ejemplos de (4) las oraciones subordinadas toman como eje temporal el tiempo verbal de las oraciones principales, por lo que la concordancia de tiempos es como sigue: en (4)a es copretérito tanto en la principal como en la subordinada, y como señalamos antes indican simultaneidad; en (4)b tenemos presente del indicativo en la principal y presente del subjuntivo en la subordinada, pero en este ejemplo la subordinada muestra anterioridad con respecto a la subordinada. (4).

Tal como señalamos al principio de este apartado en el caso de los determinantes y los nombres o los nombres y los adjetivos en los que debe haber concordancia de género y número cuando se construyen juntos, en la concordancia temporal también debe haber combinaciones de tiempos verbales que sean gramaticales. Habrá tiempos verbales que no podrán combinarse entre sí, ya sea porque los tiempos de la esfera temporal a la que pertenecen no se puedan combinar o porque el modo, indicativo o subjuntivo, no es posible en alguna de las oraciones, principal o subordinada, o porque el significado léxico del nexo subordinante no lo permite como se muestra en las siguientes oraciones.

(6) a. Mientras comíamos, mirábamos la televisión.

b. Mientras comíamos, miramos la televisión.

c. *Mientras comíamos, miraremos la televisión.

d. Primero televisan a todo el país antes de que la nacionalicen. (CREA)

e. *Primero televisan a todo el país antes de que la nacionalizan. CREA)

Las oraciones de (6) muestran que no todas las combinaciones de tiempos son posibles. En (6)a los verbos de ambas oraciones, principal y subordinada, pertenecen a la esfera del pasado, ya que ambos están flexionados en copretérito, además, el nexo subordinante es mientras cuyo significado indica simultaneidad. Por tanto, atendiendo a los tres factores mencionados, la oración subordinada adverbial es simultánea con respecto a la 
oración regente. En (6)b tenemos a la misma oración de (6)a, pero en este caso le hemos cambiado el tiempo verbal a la oración principal, el cual ya no está en copretérito sino en pretérito. Este ejemplo muestra que la combinación de tiempos pretérito en la oración principal y copretérito en la oración subordinada es aceptable, ya que ambos tiempos verbales pertenecen a la esfera temporal del pasado y el sentido de simultaneidad se conserva porque mientras aporta dicho significado. No obstante, la diferencia entre (6)a y (6)b es que en (6)a los eventos continúan, es decir, se trata de eventos imperfectivos ${ }^{36}$, pero en (6)b el evento de la subordinada continúa, o sea, es imperfectivo y en la oración principal el evento concluyó, es decir, es perfectivo. Esto implica que si bien existe simultaneidad entre los eventos de (6)b, el evento de la oración principal concluyó antes que el de la subordinada, lo cual podría considerarse una simultaneidad desfasada.

Ahora bien, (6)c es agramatical porque la combinación de tiempos verbales no es posible, porque el nexo subordinante mientras transmite un sentido de simultaneidad, por tanto, los tiempos verbales que acepta deben pertenecer a la misma esfera temporal como mostramos en los ejemplos (6)a y (6)b. Dadas las propiedades semánticas de mientras la concordancia temporal futuro en la oración principal y copretérito en la subordinada no es viable, ya que genera una oración agramatical.

En relación con las oraciones (6)d y (6)e, en (6)d se muestra que la subordinada adverbial está encabezada por la conjunción antes de que, cuyo significado indica anterioridad. Los eventos de ambas oraciones, principal y subordinada, pertenecen a la esfera del presente, presente de indicativo en la oración principal y presente de subjuntivo en la oración subordinada. El ejemplo muestra que el evento de la subordinada adverbial es posterior al evento de la oración principal, dicho en otras palabras la oración principal es anterior a la oración subordinada. Sin embargo, en (6)d transcribimos la oración (6)e, pero cambiamos el modo del verbo de la oración subordinada adverbial, la cual ya no está en

\footnotetext{
${ }^{36}$ A lo largo de este capítulo haremos alusión a los tiempos perfectivos e imperfectivos, es decir, nos referiremos únicamente al aspecto morfológico de los verbos. Según el Manual de la RAE (2010:430, 431) el aspecto morfológico se expresa a través de las desinencias verbales, el cual se usa para dividir a los tiempos perfectos e imperfectos. Los tiempos perfectos hacen alusión a los eventos en su conjunto, es decir, presentan eventos completos o acabados, por ejemplo: Apagué el radio. En contraste los tiempos imperfectos presentan el evento en su transcurso, y no aluden a su principio ni a su fin, por ejemplo: Aplaudian con entusiasmo.
} 
modo subjuntivo sino en modo indicativo y se observa que se generó una oración agramatical. Este ejemplo muestra que con la conjunción antes de que, la concordancia temporal permite que el verbo de la oración subordinada adverbial pertenezca a la misma esfera temporal, pero este debe estar flexionado en modo subjuntivo no en modo indicativo. Veremos más adelante que la imposibilidad del modo indicativo en la subordinada obedece a los rasgos semánticos de la conjunción subordinante antes de que, la cual únicamente permite que el verbo de la oración que subordina se flexione en modo subjuntivo.

Los ejemplos de (6) indican que en la concordancia temporal de las oraciones subordinadas adverbiales se tienen que tomar en cuenta diferentes factores como los rasgos semánticos de los nexos subordinantes, en el caso de las oraciones temporales principalmente, y también se deben atender las esferas temporales a las que pertenezcan los tiempos verbales, en el sentido de si es posible que los tiempos que pertenecen a cada una de ellas se puede combinar.

Ahora bien, con respecto a las oraciones subordinadas sustantivas, Carrasco (1999) muestra los casos canónicos de concordancia de tiempo como se muestra a continuación. Los tiempos de anterioridad de la subordinada sustantiva si la oración principal está en la esfera del presente son: pretérito de indicativo, antepresente de indicativo y subjuntivo, copretérito de indicativo y pretérito de subjuntivo. Si el verbo de la oración principal pertenece a la esfera del pasado o está en antepresente los tiempos de la subordinada son: ante copretérito de indicativo y subjuntivo. Igualmente en las oraciones subordinadas adverbiales podrían establecerse casos canónicos de concordancia temporal, dependiendo de la esfera de tiempo a la que pertenezca el verbo de la oración principal y del nexo subordinante; ya que, a diferencia de las oraciones subordinadas sustantivas, en las oraciones adverbiales cada nexo subordinante temporal indicará qué tiempos pueden concordar, como señalamos anteriormente. Los ejemplos de (7) muestran algunas combinaciones temporales posibles con los nexos antes de que, tan pronto como y cuando.

(7) a. Se ofreció como mediador antes de que las policías actuaran. (CREA)

b. Sin duda Rubio inició las gestiones de su publicación tan pronto como llegó a Europa. (CREA) 
c. A veces me los encuentro cuando compro el periódico y café. (CREA)

En la oración (7)a la subordinada está encabezada por la conjunción antes de que la cual indica que el evento de una de las oraciones ocurre antes que el otro. En este caso el evento de la oración principal es el que ocurre antes que el evento de la oración subordinada. Muestra este ejemplo que el tiempo de la principal pertenece a la esfera del pasado, ya que está en pretérito. Asimismo, el evento de la oración subordinada está en pretérito de subjuntivo, no obstante, aunque pertenecen a la misma esfera temporal, el evento de la principal es anterior al de la subordinada, pero es la semántica del nexo el que lo indica.

En (7)b la conjunción subordinante es tan pronto como, la cual indica posterioridad inmediata. En este caso la oración principal es posterior a la subordinada. El ejemplo muestra, además, que ambas oraciones, principal y subordinada, pertenecen a la esfera del pasado puesto que las dos están en pretérito, y al igual que señalamos en el ejemplo (7)a, los eventos pertenecen a la misma esfera temporal pero es el nexo el que indica que uno de ellos es posterior al otro. Con respecto a (7)c el adverbio relativo cuando es el que introduce a la subordinada adverbial, los eventos de ambas oraciones pertenecen a la esfera del presente puesto que una y otra están en presente. El ejemplo muestra que los eventos son simultáneos, muestra este ejemplo, además, que la semántica del relativo adverbial cuando permite que el evento de la oración principal pudiera ser anterior o posterior al evento de la oración principal, a diferencia de lo que indican las oraciones de (7)a y (7)b, en las que los nexos son los que indican cuál de los eventos dos es anterior o posterior al otro. Por lo tanto, las oraciones de (7) muestran que las conjunciones subordinantes influyen en que los eventos de las oraciones subordinadas adverbiales sean anteriores, posteriores o bien simultáneos al evento de la oración principal independientemente de que ambos eventos pertenezcan a la misma esfera temporal.

Por lo tanto, en el caso de las oraciones subordinadas adverbiales los casos canónicos de concordancia dependen del significado de las conjunciones que las encabezan. En el apartado siguiente hablaremos de las conjunciones o nexos subordinantes. 
1.2 Tipo de nexo subordinante. En el apartado anterior expusimos que la semántica de las conjunciones o nexos subordinantes de la oraciones subordinadas adverbiales desempeña un papel importante en la concordancia de tiempos verbales, por lo tanto, en este apartado hablaremos de los nexos subordinantes que hemos considerado para el análisis sintáctico de la oraciones que nos ocupan y explicaremos cómo la semántica de estos repercute en la concordancia de tiempos.

En la sección anterior se señaló que la concordancia temporal muestra las relaciones de anterioridad, posterioridad o simultaneidad de las oraciones subordinadas adverbiales con respecto a la oración rectora, no obstante, en esta clase de oraciones los tiempos verbales no son los únicos que marcan dichas relaciones de temporalidad, ya que, como señalamos anteriormente, los nexos subordinantes temporales poseen rasgos semánticos que también indican dichas relaciones. Veiga y Mosteiro (2006:346, 348) consideran que los nexos subordinantes de las oraciones subordinadas adverbiales poseen rasgos aspectotemporales que deben tomarse en cuenta para establecer las relaciones de anterioridad, posterioridad o simultaneidad con respecto a la oración principal. Estos autores señalan que los nexos subordinantes de las oraciones subordinadas de tiempo comparten con los verbos la temporalidad, pero no solamente este rasgo sino que también poseen significados gramaticales aspectuales. Citando a Eberenz (1982), quien fue el primero en abordar el tema de los rasgos semánticos de los nexos subordinantes, estos lingüistas explican que el mencionado autor estableció una primera distinción entre nexos que expresan relatividad, es decir, anterioridad, posterioridad y simultaneidad; y además distinguió nexos que expresan delimitación, a la izquierda como desde que o bien a la derecha como hasta que. Por tanto, Veiga y Mosteiro (2006:352, 353) consideran los rasgos semánticos de los nexos temporales y los clasifican de acuerdo con las características temporales y aspectuales que poseen, y por consiguiente, ya no los llaman nexos temporales sino "nexos aspectotemporales", agrupándolos en una jerarquía de tres niveles.

El primer grupo lo componen los nexos que denominan "no unidimensionales", es decir, aquellos que expresan una relación temporal única entre los eventos expresados por los verbos que forman parte de la estructura sintáctica. Es decir, se trata de nexos que pueden subordinar oraciones que indiquen anterioridad, posterioridad y simultaneidad. En 
este grupo hay otras dos clases de nexos: los que no indican iteración: cuando; y los que marcan iteración: cada vez que. No obstante, solamente se considera al adverbio relativo cuando, el cual no indica iteración.

En el segundo grupo se encuentran los nexos "unidimensionales", es decir, aquellos nexos cuyo significado gramatical incluye una relación temporal determinada, ya sea de anterioridad, posterioridad o de simultaneidad. En esta clase se encuentran las conjunciones antes de que, mientras y después de que que indican anterioridad, simultaneidad y posterioridad respectivamente. A ambos grupos los clasifican de acuerdo con los rasgos de: (1) significación temporal unidimensional o no unidimensional; (2) orientación temporal (anterioridad, simultaneidad o posterioridad); y (3) contenido aspectual (iterativos, delimitativos, progresivos).

Ahora bien, atendiendo a los rasgos aspectuales y temporales que Veiga y Mosteiro consideran con respecto a los nexos subordinantes, las conjunciones temporales que se estudian en este trabajo se pueden clasificar de la siguiente manera. Cuando es el nexo que puede subordinar oraciones anteriores, posteriores o simultáneas, es decir, se considera no unidimensional; y aspectualmente es no iterativo. En las conjunciones que Veiga y Mosteiro denominan unidimensionales, ubicamos a las que indican anterioridad: antes de que que aspectualmente es no delimitativa; las que muestran simultaneidad: mientras, mientras que, entretanto, en tanto que que no son progresivas; y las que denotan posterioridad: después de que, luego que, que no son delimitativas y desde que que es delimitativa. Dentro de este grupo se encuentran las que indican posterioridad inmediata: en cuanto, tan pronto como y apenas que no son delimitativas. En cuanto a la conjunción hasta que Veiga y Mosteiro (2006:356) la clasifican dentro de las que indican anterioridad, no obstante, en la variante del español de México la citada conjunción también puede indicar posterioridad, por ejemplo: Cené hasta que llegó Pati. Dicha oración indica que después de que el sujeto de la oración subordinada llegó, cené. De modo que en este trabajo la consideraremos en ambas posiciones como indicadora de posterioridad o de anterioridad y delimitativa como lo muestran Veiga y Mosteiro. 
Ahora bien, hemos visto que los nexos subordinantes que encabezan a las subordinadas adverbiales poseen rasgos temporales y aspectuales que influyen en la concordancia verbal de las subordinadas adverbiales, específicamente en las oraciones de tiempo, ya que en las oraciones locativas el relativo donde, si bien es un deíctico, este no comparte las propiedades semánticas de temporalidad de los verbos como las conjunciones de tiempo, por tanto, la concordancia temporal no es afectada por el relativo donde como veremos en el análisis sintáctico en el apartado 2.2. Ya habíamos advertido en el apartado anterior que las relaciones de anterioridad, posterioridad o simultaneidad no corresponden exclusivamente a la concordancia temporal de las oraciones subordinadas de tiempo sino que, como hemos explicado, los nexos subordinantes también poseen rasgos temporales y aspectuales que están implicados en dichas relaciones y por tanto, la concordancia temporal de algunos tiempos verbales está relacionada con este hecho. Véase los siguientes ejemplos que ilustran la concordancia de tiempos verbales que es posible con las conjunciones desde que, hasta que y cuando.

(8) a. Escucho Mix 106 desde que me gané dos pases dobles.

b. *Escucho Mix 106 hasta que me gané dos pases dobles.

c. Escucho Mix 106 hasta que llego al trabajo.

d. Aquí se alojó Hernán Cortés cuando llegó a la ciudad. (CREA)

e. Lo sabré después cuando mis actos tengan un resultado. (CREA)

f. Cuando llegas ya estoy dormida.

En (8)a el nexo subordinante es desde que, el cual indica posterioridad y además aspectualmente es delimitativo. El ejemplo muestra que el evento de la oración principal pertenece a la esfera del presente, ya que está flexionado en presente y el evento de la subordinada adverbial corresponde a la esfera del pasado porque está flexionado en pretérito. Atendiendo a los rasgos semánticos del nexo subordinante desde que es posible que los eventos de la oración principal y la subordinada pertenezcan a dos esferas temporales diferentes, como se muestra en (8)a, pero también pueden pertenecer a la misma, ya que el significado del nexo indica que uno de los eventos siempre será posterior al otro, en este caso el evento de la oración principal será posterior al de la subordinada. Sin 
embargo, la construcción de un evento futuro en la oración principal y un evento pasado en la subordinada no es viable, por ejemplo: *Escucharé Mix 106 desde que me gané dos pases dobles, es agramatical. Por tanto, con el nexo desde que la concordancia de tiempos verbales, si pertenecen a distintas esferas temporales, debe ser con tiempos presentes en la oración principal y pretéritos en la subordinada. Asimismo el aspecto del nexo subordinante desde que indica delimitación, lo cual se muestra en que el evento de la oración principal empieza, es decir, su principio está marcado a partir del término del evento de la oración subordinada adverbial.

En el ejemplo (8)b transcribimos la oración (8)a pero le hemos cambiado el nexo subordinante desde que por hasta que y se muestra que se generó una oración agramatical. La razón radica justo en las propiedades temporales y aspectuales de la conjunción hasta que, la cual, como hemos señalado antes, puede indicar anterioridad o bien posterioridad. El ejemplo muestra que los tiempos verbales no concuerdan, aunque indican que uno de los eventos es anterior al otro, las propiedades semánticas de hasta que no permiten que los tiempos verbales de la oración principal y la subordinada pertenezcan a distintas esferas temporales, es decir, para que haya concordancia de tiempos los eventos deben pertenecer a la misma esfera temporal, como se muestra en (8)c. Dicho ejemplo muestra que tanto el evento de la oración principal como el de la subordinada pertenecen a la esfera del presente y el sentido de posterioridad de uno de los eventos se mantiene, es decir, el evento de la oración principal es posterior al de la subordinada adverbial. Por tanto, (8)c puede parafrasearse como después de que llego al trabajo escucho Mix 106, de modo que, hasta que indica posterioridad inmediata, lo cual implica que el evento de la oración principal terminó y el de la subordinada comienza inmediatamente ${ }^{37}$.

Ahora bien, con respecto al relativo adverbial cuando, mencionamos que está clasificado dentro de los nexos no unidimensionales, según Veiga y Mosteiro, por tanto, puede indicar anterioridad, simultaneidad o bien posterioridad. Los ejemplos (8)d y (8)e indican posterioridad. En (8)d ambos eventos pertenecen a la esfera del pasado, ya que

\footnotetext{
${ }^{37}$ También puede interpretarse de manera contraria, como anterioridad, es decir, el evento de la oración principal: escucho Mix 106 sucede de manera continua antes de que el evento de la subordinada: llego a mi trabajo comience. Así la conjunción hasta que indica el límite temporal del evento de la oración principal.
} 
ambos están en pretérito, no obstante, la oración principal es posterior a la subordinada. El ejemplo (8)e muestra que los eventos pertenecen a la esfera del presente, pero los tiempos verbales muestran con más claridad que uno de ellos es posterior al otro, el evento de la oración principal está en futuro y el de la subordinada en presente del subjuntivo. (8)f indica que los eventos pertenecen a la esfera del presente y muestran simultaneidad. Asimismo, los ejemplos indican que los tiempos verbales de las oraciones que se construyen con el relativo cuando pueden pertenecer a la misma esfera temporal, pero los factores pragmáticos permitirán determinar cuál de los dos eventos ocurrió antes, después o de manera simultánea con respecto al otro.

Hasta ahora, hemos mostrado que los rasgos aspectuales y temporales de las conjunciones que introducen a las oraciones subordinadas adverbiales deben tenerse en cuenta para establecer cuáles podrían ser los tiempos canónicos de concordancia de tiempos verbales en esta clase de oraciones, no obstante, otro aspecto importante que queremos destacar es lo que se muestra en el ejemplo (8)e, la oración subordinada se construye con el modo subjuntivo y no con el modo indicativo como la oración principal. Asimismo en (8)f el verbo de la oración subordinada está en modo indicativo, pero si se usa el modo subjuntivo en la subordinada el tiempo de la principal debe estar en futuro: Cuando llegues ya estaré dormida. De manera que el modo en que se flexionen los verbos de las oraciones también es un rasgo que debe considerarse lo cual puede obedecer a diferentes razones. Por un lado, puede ser por el nexo subordinante el que lo determina y por otro lado, por el valor de verdad que el hablante le atribuye a lo que dice. En el apartado siguiente abordaremos este tema, de manera breve ya que nuestro interés no se centra en la modalidad de los verbos sino en la concordancia de tiempos verbales.

1.3. Modo. En el apartado anterior mostramos que hay oraciones subordinadas adverbiales que, aunque pertenecen a la misma esfera temporal que la oración regente a la que se subordinan, se flexionan en modo subjuntivo y no en indicativo como en el ejemplo (8)e ahora en (9)a. O en oraciones como (8)f ahora en (9)b en donde el modo subjuntivo modifica el tiempo en que el verbo de la oración principal se flexiona como se ilustra en (9)c. 
(9) a. Lo sabré después cuando mis actos tengan un resultado. (CREA)

b. Cuando llegas ya estoy dormida

c. Cuando llegues ya estaré dormida.

Puesto que el presente capítulo está enfocado a la concordancia de tiempos verbales, en esta sección no hablaremos del modo de manera amplia, sino que daremos una explicación breve del concepto y nos enfocaremos en por qué con algunos nexos subordinantes puede aparecer el modo indicativo o subjuntivo o bien en algunos casos pueden alternar.

En términos generales el modo se define como la actitud del hablante frente a lo que enuncia (Munguía 2002). Di Tullio (1997) advierte que resulta complejo definir el concepto de modo ya que está asociado a la noción semántica de modalidad. Señala que el primero corresponde a una serie de flexiones particulares del verbo, la segunda tiene varios tipos de expresión sean auxiliares o subordinadas adverbiales. Considera esta autora que la definición que se le ha dado al modo es imprecisa. Igualmente Rodríguez Ramalle (2005:470) indica que el modo está relacionado con la modalidad y señala que es la manifestación de las actitudes u opiniones del hablante ante lo que dice y comprende. La RAE (2010: 473) subraya que tradicionalmente se ha dicho que el modo revela la actitud del hablante frente a la información que suministra, es decir, el punto de vista que tiene sobre lo que presenta o describe. No obstante, advierte que el modo se caracteriza por tener una amplia gama de valores gramaticales, por tanto, no se puede definir únicamente por una actitud del hablante ante lo que dice.

Atendiendo a las características principales y generales de esta categoría gramatical, en las flexiones verbales del español se distinguen tres modos: el imperativo, el indicativo y el subjuntivo; no obstante, para fines de esta investigación sólo nos referiremos a los dos últimos. El modo indicativo y subjuntivo tienen características semánticas distintas incluso se podría decir que contrarias, ya que se les pone en oposición por ser real el primero e irreal el segundo. Di Tullio (1997) señala que al subjuntivo se le han atribuido los significados de eventualidad o de irrealidad, sin embargo, considera que tales nociones no están asociadas al subjuntivo necesariamente ya que depende del verbo rector que tales 
sentidos se expresen a veces obligatoriamente en indicativo, por ejemplo, en oraciones como "Conjeturo / supongo que Juan lo dijo con mala intención" 38 . Rodríguez Ramalle indica que algunos matices de la modalidad se expresan en español mediante la distinción entre indicativo y subjuntivo, de modo que el subjuntivo se describe como lo irreal y el indicativo como lo real o lo posible (Rodríguez 2005:470).

Siguiendo con las distinciones semánticas que los modos, indicativo y subjuntivo presentan, veamos las razones por las que las subordinadas adverbiales pueden aparecer en modo subjuntivo o en modo indicativo. Pérez Saldanya (1999:3286) muestra que "en las oraciones subordinadas adverbiales el modo aparece normalmente de manera unívoca por la conjunción o locución conjuntiva". No obstante, aclara que esta noción no es del todo general, ya que en algunos contextos la conjunción puede alternar con los dos modos sin que esto modifique el significado de las oraciones. Explica este autor que en las oraciones subordinadas sustantivas la alternancia del modo indicativo y subjuntivo depende del valor de verdad que el hablante otorga a la oración subordinada. Por lo tanto, subraya que generalmente el indicativo se usa para oraciones que denotan eventos que poseen un carácter factual; en oposición, el subjuntivo se utiliza en oraciones sustantivas no factuales.

Afirma Pérez Saldanya (1999:331) que del mismo modo ocurre con las oraciones subordinadas adverbiales, cuando el verbo se flexiona en modo indicativo, el evento tienen un carácter factual o real, es decir la oración se considera verdadera "en el mundo que se toma como referencia y remite a un hecho experimentado" ya sea pasado, presente o habitual como se muestra en los ejemplos de (10).

a. En Jericó, las detonaciones iluminaron la noche mientras los tanques entraban en la ciudad. (CREA)

b. Vivimos tranquilos hasta que vinieron los troyanos. (CREA)

\footnotetext{
${ }^{38}$ Por ejemplo, en las oraciones sustantivas los verbos de comunicación verbal como aclarar, afirmar, comentar, comunicar, los verbos de opinión: considerar, creer, imaginarse, parecer; los verbos de percepción: advertir, oír, percibir, sentir, ver; los de conocimiento: acordarse de, descubrir, saber, tomar en cuenta, seleccionan el indicativo. Los que toman subjuntivo son los volitivos: desear, optar, preferir, querer; los de influencia: ordenar, mandar, prohibir; los psicológicos y los que expresan emoción o sentimiento: agradar, asombrar, divertir, interesar, importar, lamentar sorprender; y los epistémicos de la clase de dudar, puede que, ser dudoso, ser posible (Rodríguez Ramale 2005).
} 
c. Todos los días cuando llego a mi casa me espera la incertidumbre más grande. (CREA)

Pero las oraciones que refieren a eventos posteriores al momento que se toma como referencia y, "por lo tanto, a situaciones eventuales y no experimentadas exigen el modo subjuntivo" y el valor de posterioridad pueden aludir al momento del habla o al momento del pasado (Pérez Saldanya 1999:3311, 3312) como lo ilustran el ejemplo (9)a y las oraciones (11).

a. Al parecer, no saldrá hasta que un acuerdo concertado resuelva la crisis. (CREA)

b. Prometió inyectar recursos tan pronto como se consolidara la democracia. (CREA)

En (9)a se muestra que el nexo subordinante es el relativo cuando. Puesto que la oración principal está en futuro, es decir, se refiere a un evento que aún no se ha experimentado, la oración subordinada adverbial está en subjuntivo. Asimismo (11)a muestra que la oración principal está en futuro y por tratarse de un evento que aún no sucede, el verbo de la oración subordinada está flexionado en modo subjuntivo. En (11)b el tiempo de las oraciones principal y subordinada pertenecen a la esfera del pasado, pero los eventos aluden a una situación que aún no se ha experimentado dentro del pasado. Indica que habría recursos en cuanto ocurriera el evento de la subordinada.

Por otro lado, las oraciones (9)b y (9)c muestran que el modo tiempo verbal de la oración principal modifica el tiempo en que se flexiona el verbo de la subordinada adverbial. En ambas oraciones los tiempos pertenecen a la esfera de presente, en (9)b ambos verbos están flexionados en presente de indicativo, lo cual implica que son eventos reales o factuales, asimismo los eventos indican simultaneidad. Sin embargo, en (9)c el verbo de la oración principal está flexionado en futuro y el de la subordinada está en presente del subjuntivo, es decir, los eventos muestran posterioridad, por lo tanto, como propone Pérez Saldanya, se trata de situaciones no experimentadas, de manera que la subordinada adverbial requiere del modo subjuntivo. 
Cabe señalar, además, que los rasgos temporales y aspectuales de los nexos subordinantes también están relacionados con el modo en que se flexionen los verbos de las oraciones subordinadas adverbiales, tal es el caso de la conjunción subordinante antes de que. La mencionada conjunción no indica posterioridad sino lo opuesto, indica anterioridad, sin embargo, el verbo de la subordinada siempre debe flexionarse en modo subjuntivo como lo muestran los ejemplos siguientes.

A. En 1980, ella fue examinada por la Junta, antes de que la nombrara directora del Instituto de Investigaciones Estéticas.

b. "-¿Conoció el presidente tu discurso antes de que lo pronunciaras?"

Las oraciones de (12) indican que no únicamente el sentido de posterioridad que muestren las oraciones es lo que determina si el modo de la oración subordinada debe flexionarse en modo subjuntivo, sino que las conjunciones también determinan el modo en que los verbos se pueden flexionar.

Ahora bien, ya que hemos mencionado los motivos por los que los modos, indicativo o subjuntivo, pueden utilizarse en las subordinadas temporales, en el apartado siguiente veremos cómo funciona la consecutio temporum en las oraciones subordinadas adverbiales propias de tiempo y lugar considerando los nexos subordinantes que las unen con la oración principal.

\section{La concordancia de tiempos de las oraciones subordinadas adverbiales propias:}

lugar y tiempo. En esta sección veremos la concordancia de tiempos verbales que se encontraron en el corpus que se analizó. Hemos mencionado que las oraciones subordinadas de tiempo son las que presentan mayores problemas al momento de analizarla y por el contrario las oraciones de lugar no presentan mayor conflicto al respecto. De manera que empezaremos el análisis con las oraciones de tiempo y posteriormente nos referiremos a las oraciones de lugar.

2.1. Oraciones subordinadas adverbiales de tiempo. En el capítulo II mencionamos que el principal nexo que une a las oraciones subordinadas adverbiales con la oración principal es el relativo cuando. Otras conjunciones que se consideraron para este trabajo y que 
también se encuentran con mucha frecuencia son mientras, mientras que, hasta que y desde que. Asimismo analizaremos la concordancia de tiempos verbales de las conjunciones cuyos ejemplos fueron escasos en tanto que, en cuanto, tan pronto como, apenas.

Atendiendo a la clasificación de nexos o conjunciones que Veiga y Mosteiro (2006) proponen, agruparemos las conjunciones considerando sus rasgos temporales y aspectuales. En primer lugar analizaremos los nexos que los mencionados autores denominan "no unidimensionales", es decir, los nexos que pueden subordinar oraciones que indiquen anterioridad, posterioridad y simultaneidad. El relativo cuando cumple con esta descripción por tanto será analizado en primer lugar. Posteriormente nos enfocaremos en las conjunciones que Veiga y Mosteiro denominan "unidimensionales", es decir, las que indican anterioridad: antes de que y que aspectualmente es no delimitativa. A continuación estudiaremos las que muestran simultaneidad: mientras, mientras que, entretanto, en tanto que que no son progresivas; y finalmente las que denotan posterioridad: después de que, luego que, que no son delimitativas y desde que que es delimitativa. Dentro de este grupo se encuentran las que indican posterioridad inmediata: en cuanto, tan pronto como y apenas que no son delimitativas.

2.1.1 Cuando. Mencionamos en el apartado anterior que el relativo adverbial cuando está clasificado como nexo no unidimensional, ya que la oración que subordina puede indicar anterioridad, posterioridad o bien simultaneidad con respecto a la oración principal. Ahora bien, teniendo en cuenta los rasgos semánticos del relativo adverbial cuando y haciendo referencia a los tiempos verbales, se encontraron distintas concordancias tanto en la esfera del presente como en la esfera del pasado como explicaremos a continuación.

Dentro de la esfera del presente las dos concordancias verbales que se encontraron con mayor asiduidad fueron presente en ambas oraciones, principal y subordinada, como se muestra en los ejemplos (13)a y (13)b; o bien futuro en la oración principal y presente de subjuntivo en la oración subordinada como lo ilustran los ejemplos (13)c y (13)d.

a. Los problemas se agravan cuando no se aplica el Estado de derecho. (CREA) 
b. Cuando la escucha simplemente su ánimo sube de temperatura. (CREA)

c. Capella y otros cuatro miembros del actual Consejo administrativo de Compaq se unirán al Consejo de HP cuando culmine la operación. (CREA)

d. No seremos defensores de oficio ni le aceptaremos la renuncia cuando ya sea desconocido su paradero. (CREA)

Se muestra en las oraciones (13)a y (13)b que tanto el verbo de la oración principal como el de la subordinada están en tiempo presente y en ambas oraciones los eventos son simultáneos. En ambos ejemplos (13)c y (13)d el verbo de la oración principal está en futuro, lo cual indica que es posterior al evento de la oración subordinada cuyo verbo está flexionado en presente del subjuntivo. Muestran estos dos ejemplos que por tratarse de eventos futuros o no realizados aún, el tiempo de los verbos de las subordinadas están flexionados en modo subjuntivo.

Por otro lado, en la esfera del pasado se encontraron más variedad de concordancias verbales que en la esfera del presente. La primera de ellas es la que se ilustra en las oraciones de (14). Se trata de pretérito en ambas oraciones, principal y subordinada. elección de consejeros ciudadanos. (CREA)

b. América empezó a bajar de nivel, en todo, cuando salió Beenhakker. (CREA)

En ambas oraciones los tiempos verbales pertenecen a la esfera del pasado, ya que ambos eventos están en pretérito y muestran simultaneidad. Otra concordancia verbal con el relativo adverbial cuando es pretérito en la oración principal y copretérito o antecopretérito en la oración subordinada como se muestra en los ejemplos de (15).

a. Pudimos resolverlo cuando estaba arriba, pero no lo hice. (CREA)

b. Yao Ming salió del partido por acumulación de faltas cuando apenas había comenzado la segunda mitad. (CREA) 
En ambos ejemplos, el verbo de la oración principal está flexionado en pretérito, no obstante, en (15)a el verbo de la subordinada está en copretérito lo cual indica que los eventos de las oraciones, principal y subordinada, ocurren de manera simultánea. En (15)b el verbo de la oración subordinada está flexionado en ante-copretérito, lo cual muestra que el evento de la oración principal es posterior al de la subordinada. Otra concordancia temporal es copretérito en la oración principal y pretérito o copretérito en la subordinada como se muestra en los ejemplos de (16).
A. También me tocó bajar a las fincas como tres años seguidos, le ayudaba a mis papás, apenas tenía nueve años cuando bajé la primera vez. (CREA)
b. Las proclamas en favor de la reunificación se intensificaban cuando competía en el tatami un judoca norcoreano. (CREA)

En (16)a el pretérito en el verbo principal y el copretérito en el subordinado muestran que los eventos son simultáneos, aunque uno de ellos, el de la oración principal, dura más que el de la subordinada, pero en algún momento fueron simultáneos. Puesto que en (16)b ambos verbos están flexionados en copretérito, indica que los eventos ocurren en un mismo momento, es decir son simultáneos. Otra concordancia verbal que se encontró con el relativo cuando es ante-copretérito en la oración principal y pretérito en la subordinada como lo ilustra el ejemplo (17).

Apenas habían transcurrido 44 segundos del encuentro, cuando por la banda izquierda Álvaro Ortiz tomó el balón y se fue quitando rivales dentro del área. (CREA)

Muestra el ejemplo (17) que el evento de la oración principal es anterior al de la subordinada ya que el primero habían transcurrido está en ante-copretérito y el segundo tomó en pretérito.

Las oraciones analizadas muestran que el relativo adverbial cuando puede subordinar oraciones que muestran simultaneidad, posterioridad o anterioridad con respecto a la oración principal. 
2.1.2. Nexos de anterioridad: antes de que. La conjunción antes de que pertenece a los nexos unidimensionales que indican solamente anterioridad. Las oraciones indican que el evento de la oración principal tiene lugar antes del evento de la oración subordinada adverbial. Las concordancias verbales que se encontraron son las siguientes. En la esfera del presente se hallaron presente o futuro de indicativo en la oración principal y presente de subjuntivo en la subordinada como se muestra en los ejemplos de (18).

a. Un moderador revisa el contenido del mensaje antes de que pueda ser leído por los integrantes del grupo de discusión. (CREA)

b. Tan pronto o incluso antes de que los campesinos obtengan sus títulos de propiedad, presionados por la necesidad, venderán la tierra que les queda. (CREA)

En (18)a el verbo de la oración principal está flexionado en presente de indicativo y en la oración subordinada el verbo se flexiona en presente subjuntivo. Asimismo en la oración (18)b el verbo de la oración principal está en futuro y el de la subordinada en presente del subjuntivo. En ambos casos, y como lo muestra el significado de la conjunción antes de que, el evento de la oración principal ocurre antes que el evento de la subordinada. Muestran estos ejemplos que los tiempos verbales de las oraciones, principal y subordinada, pertenecen a la misma esfera temporal.

Con respecto a los tempos que corresponden a la esfera del pasado, se encontraron las siguientes concordancias. En la oración principal pretérito, pos-pretérito o copretérito del indicativo y en la subordinada pretérito del subjuntivo como se muestra en las oraciones de (19).

a. Se ofreció como mediador antes de que las policías actuaran. (CREA)

b. Antes de que se congelaran los depósitos bancarios, las películas brasileñas ocupaban $23 \%$ del mercado. (CREA)

c. En nuestro reporte ya habíamos llegado a la conclusión antes de que los aviones rompieran el vidrio y el acero de las torres del World Trade Center, que el mercado estadunidense iba hacia el desastre. (CREA) 
d. Dijo que antes de que esto ocurriera, yo tendría mi cambio de adscripción. (CREA)

En (19)a el verbo de la oración principal está flexionado en pretérito, en (19)b en copretérito y en (19)c en ante-copretérito del indicativo. Los tres ejemplos muestran que el verbo de la oración subordinada se flexiona en pretérito del subjuntivo, incluso si el tiempo verbal de la oración principal estuviera en pos-pretérito, el verbo de la oración subordinada se flexiona en pretérito de subjuntivo como lo muestra el ejemplo de (19)d, en la que la subordinada adverbial y la que es su oración principal se encuentran dentro de una oración sustantiva encabezada por la conjunción que.

Los ejemplos muestran el sentido de anterioridad que transmite la conjunción antes de que, asimismo se observa que los tiempos verbales pertenecen a la misma esfera temporal, ya sea del presente como en los ejemplos de (18) o a la del pasado como se ilustra en las oraciones de (19). El nexo subordinante indica que el verbo de la oración que subordina siempre debe estar en modo subjuntivo, ya que el modo indicativo generaría oraciones agramaticales. Si bien hemos considerado que el modo indicativo o subjuntivo tienen un valor de realidad o irrealidad, respectivamente, en este caso es la conjunción antes de que la que determina el modo en que se flexionen los verbos, ya que el sentido que las oraciones transmiten, aún con verbos conjugados en subjuntivo es de realidad y no de irrealidad o posibilidad como se esperaría por estar flexionadas en modo subjuntivo.

2.1.2.1. Hasta que. En el apartado 1.2 de este capítulo explicamos que para Veiga y Mosteiro (2006) la conjunción hasta que indica anterioridad, no obstante señalamos que en el español de México puede interpretarse como posterioridad, es decir el evento de la oración principal ocurre después del evento de la subordinada en oraciones como: Me dormi hasta que acabó la película. Dicha oración indica que la acción de dormir ocurrió después de que la acción de la oración subordinada concluyó. No obstante, también puede interpretarse como anterioridad es decir, el evento de la oración principal tiene lugar antes del evento de la oración subordinada, por ejemplo: Vi la televisión hasta que me llamaron a comer. La citada oración puede interpretarse así: la acción de ver la televisión continuó y concluyó en el momento que me llamaron a comer. Si bien nuestra intención no es dar una 
explicación exhaustiva del uso de la conjunción hasta que ${ }^{39}$, nos interesa explicar que en algunas oraciones la interpretación de la conjunción puede ser tanto de anterioridad como de posterioridad, lo cual puede obedecer a razones pragmáticas.

Dentro de la esfera del presente se encontraron las siguientes concordancias temporales: ambas oraciones, principal y subordinada en presente; o bien presente o futuro en la principal y presente de subjuntivo en la subordinada como se muestra en los ejemplos de (20).

a. Lo intentas hasta que lo logras.

b. Pero, a diferencia de otros, Salinas se considera inocente hasta que se pruebe que los demás son culpables. (CREA)

c. Al parecer, no saldrá hasta que un acuerdo concertado resuelva la crisis. (CREA)

En las oraciones (20)a y (20)b el verbo de la oración principal está en presente, pero el verbo de la oración subordinada en (20)a está flexionado en presente de indicativo y en (20)b en presente de subjuntivo. En ambas oraciones el evento de la oración principal es anterior al de la subordinada. Las diferencias de modo indican que en (20)a por estar los verbos en indicativo se trata de eventos reales o posibles pero en (20)b el subjuntivo de la oración subordinada indica posibilidad. En la oración principal de (20)c el tiempo del verbo es futuro y en la subordinada es presente de subjuntivo, y como hemos señalado antes, esta concordancia de tiempos es frecuente cuando se trata de eventos futuros. Asimismo (20)c indica que el evento de la oración principal es posterior a la subordinada.

Ahora bien, con respecto a los tiempos de la esfera del pasado, las concordancias verbales que encontré son las siguientes: pretérito o copretérito en la oración principal y pretérito en la subordinada en la subordinada como lo ilustran las oraciones de (21).

a. Allí vivió libre hasta que se incorporó a la Guerra de los Diez Años.

b. Yo montaba mucho a caballo, hasta que tuve mi accidente en 1978.

\footnotetext{
${ }^{39}$ Para un análisis más profundo sobre la conjunción hasta que, véase Pavón (2003).
} 
En (21)a tanto el verbo de la oración principal como el de la subordinada están flexionados en pretérito y en (21)b la principal está en copretérito y la subordinada está en pretérito, no obstante, en ambas oraciones el evento de la oración principal es anterior al de la subordinada.

2.1.3. Nexos de simultaneidad: mientras, mientras que, entretanto. Las oraciones cuyos nexos indican simultaneidad deben tener verbos flexionados en la misma esfera temporal e incluso, en algunos casos, en el mismo tiempo verbal, ya que se trata de eventos que ocurren en un mismo momento.

Con el nexo mientras, el cual denota acciones simultáneas, la concordancia de tiempos en la oración principal debe ser el mismo que el de la subordinada adverbial. En la esfera del presente se encontró presente en la principal y presente en la subordinada como se muestra en las oraciones de (22).

a. Minjárez, quien inició su carrera judicial como agente del Ministerio Público, habla para Proceso en el cuartel del GEA en Chihuahua, mientras entran y salen agentes de su oficina y repiquetea a cada momento su teléfono celular. (CREA)

b. Mientras dura el estudio las consultas, revisiones, exámenes de laboratorio y el medicamento son gratuitos. (CREA)

Las oraciones muestran que tanto en la oración principal como en la subordinada el verbo está en presente, lo cual indica que son eventos que ocurren al mismo tiempo. De igual forma ocurre cuando los verbos se flexionan en los tiempos de la esfera del pasado. Puesto que el nexo mientras subordina oraciones cuyo evento es simultáneo con el de la oración principal, en la esfera del pasado el tiempo verbal que indica con mayor precisión dicha simultaneidad es el copretérito tanto en la oración principal como en la subordinada como lo muestran las oraciones de (23)a y (23)b.

(23) a. Todo esto se preguntaba un cenizo Beto mientras, cabizbajo y sentado sobre un costal de café, viajaba rumbo a Temazcal. (CREA) 
b. Mientras comíamos, dejábamos que nuestros parlamentos articularan esa conversación ritual. (CREA)

c. Laura escribió el ensayo mientras Dani planchó su cabello.

Los ejemplos (23)a y (23)b muestran que el copretérito, por tratarse de un tiempo imperfectivo, indica que los dos eventos tienen duración y además suceden en un mismo momento. No obstante, en (23)c ambos verbos están flexionados en pretérito, lo cual indica simultaneidad, pero no es una concordancia de tiempos usual en el español, cuando la conjunción mientras tiene el sentido de simultaneidad que se ilustra en (23)a y (23)b. Si ambas oraciones, principal y subordinada, están en pretérito como en las oraciones de (24), el sentido de simultaneidad se conserva, pero el significado de mientras es distinto. En tales oraciones mientras significa "en cambio", lo cual indica que se trata de dos eventos simultáneos que se contraponen.

a. El S60 recibió 12.5 puntos, mientras el S40 obtuvo 11.5 puntos. (CREA) b. Las acciones serie L del grupo financiero Bital experimentaron la mayor caída del día, retrocediendo 9.7\%, mientras las acciones serie O de BBVA Bancomer retrocedieron 6.7 por ciento. (CREA)

Sin embargo, para que la oración que citamos en (23)c tenga el mismo sentido de simultaneidad que expresan las oraciones de (23)a y (23)b la oración subordinada debe estar flexionado en copretérito: Laura escribió el ensayo mientras Dani se planchaba el cabello. En la esfera del pasado se encontró la mencionada concordancia de tiempos verbales en donde el verbo de la oración principal está flexionado en pretérito pero el de la oración adverbial está en copretérito, lo cual indica simultaneidad como lo ilustran las oraciones de (25).

a. El mercado aguantó un duro decrecimiento por 17 años mientras las acciones y valuaciones revertían al promedio. (CREA)

b. Mientras esperaba un trasplante del órgano, su riñón fue controlado mediante el proceso de diálisis. (CREA) 
Los ejemplos muestran que los eventos son simultáneos y además los eventos de la oración principal, aunque están en pretérito indican duración. En (25)a la frase prepositiva por 17 años indica que el evento duró el periodo de tiempo mencionado y en (25)b la frase nominal proceso en la oración principal indica duración. No obstante, hay oraciones cuya concordancia de tiempos es la que acabamos de mencionar: pretérito en la principal y copretérito en la subordinada y se observa que uno de los eventos concluyó antes que el otro como se muestra en los ejemplos de (26).

a. El Promedio Industrial Dow Jones se desplomó mientras los alemanes avanzaban por Europa. (CREA)

b. En Jericó, las detonaciones iluminaron la noche mientras los tanques entraban en la ciudad. (CREA)

Ambos ejemplos muestran que el verbo de la oración principal está flexionado en pretérito, es decir, es un evento perfectivo; en cambio el de la subordinada adverbial está en copretérito, o sea es un evento imperfectivo, esta concordancia de tiempos indica que los eventos son simultáneos. No obstante, el evento de la oración principal por ser perfectivo indica que ya concluyó, pero el evento de la oración subordinada, por ser imperfectivo, continúa y no se indica en qué momento concluye. Por lo tanto, se trata de dos eventos que fueron simultáneos en un momento pero uno acabó y el otro siguió.

Por otro lado, dentro de la esfera del presente también encontré la concordancia de tiempos: presente en la principal y presente del subjuntivo en la subordinada como se muestra en (27)a. En (27)b futuro en la principal y presente de subjuntivo en la subordinada. Sin embargo, en ambos ejemplos mientras no expresa simultaneidad sino condición.

a. Mientras la reciente reforma constitucional esté vigente, toda disposición legal que dimane de la misma, fortalece y refrenda su carácter retrógrada y racista. (CREA)

b. Mientras la tecnología vaya creciendo más y más, más y más satélites necesitarán ser lanzados para remplazar a los viejos aparatos. (CREA) 
Muestran los ejemplos de (27) que el sentido de mientras no es de dos eventos simultáneos sino de una oración que expresa condición.

Ahora bien, en relación con la conjunción mientras que, se usa para contraponer dos eventos simultáneos y el sentido que tiene es "en cambio", tal como las oraciones que se encuentran en (24) encabezadas por mientras. En la esfera del presente se hallaron las concordancias de tiempos que siguen: presente o antepresente en la oración principal y presente en la subordinada adverbial; y futuro en ambas oraciones, principal y subordinada, como se ilustra en las oraciones de (28).

a. Sin embargo, mientras que la infección con el virus Variola ocurre únicamente en humanos, los otros tres pueden infectar tanto a humanos como a otros animales vertebrados. (CREA)

b. En los últimos cuatro años, la demanda se ha disparado casi al triple, mientras que la oferta se mantiene estancada. (CREA)

c. La que se encuentre en manos privadas se expandirá continuamente, mientras que la mixta se desatenderá y descapitalizará, como le ha venido sucediendo a Pemex a consecuencia de la política fiscal aplicada. (CREA)

En (28)a la concordancia de tiempos es presente tanto en la principal como en la subordinada, (28)b muestra que en la principal el verbo se flexiona en antepresente y en la subordinada en presente y (28)c ilustra la correlación verbal de futuro en ambas oraciones. Los tres ejemplos muestran que los eventos de las oraciones son simultáneos pero se contraponen.

Con respecto a los tiempos de la esfera del pasado, las concordancias verbales que apreciamos son las siguientes: pretérito o copretérito en la oración principal y pretérito en la subordinada adverbial como lo muestran las oraciones de (29).

a. El Ejército redobló sus operativos de vigilancia en las carreteras que conducen a Cancún, mientras que la Armada de México y la PJF hicieron lo propio en las costas y terminales aéreas del estado. (CREA) 
b. Hacer una sociedad mexicana se tardaba semanas mientras que el fideicomiso con Bancomer demoró diez días. (CREA)

En (29)a tanto el verbo de la oración principal como el de la subordinada están flexionados en pretérito y en (29)b en la oración regente el verbo está en copretérito y el de la subordinada está en pretérito. Las oraciones muestran la simultaneidad de dos eventos que se comparan.

Finalmente con la conjunción entretanto, que también indica simultaneidad, se encontraron escasos ejemplos, no obstante la concordancia de tiempos que se halló fue: presente en ambas oraciones como se muestra en (30).

Compatriotas como los indígenas y Laura viven en la realidad real, entretanto los gobernantes existen y proceden en la realidad virtual.

2.1.4. Nexos de posterioridad: desde que, luego que. En esta sección analizaremos las conjunciones que indican posterioridad y posterioridad inmediata. Empezaré el análisis con la conjunción desde que, el cual Veiga y Mosteiro (2006) consideran en delimitativo. La conjunción desde que indica que la oración principal es posterior a la subordinada adverbial. Asimismo muestra límite, es decir, el evento de la oración principal empieza o termina a partir del evento de la oración subordinada, por ejemplo: Desperté desde que mi papá encendió el motor del camión, muestra que el evento despertar ocurrió en el momento en que el sujeto de la oración subordinada encendió el motor.

Ahora bien, la concordancia de tiempos verbales que obtuvimos con la conjunción desde que son los siguientes. En la esfera del presente se aprecian: presente o antepresente en la oración principal y presente en la subordinada adverbial o antepresente en la principal y pretérito en la subordinada como se observa en las oraciones de (31).

a. La erosión acelerada está ligada a la agricultura y al pastoreo desde que estas actividades existen, y ha alterado ya grandes extensiones del paisaje terrestre. (CREA)

b. Desde que tengo memoria ha sido así. 


\section{c. Me han llamado rara desde que nací. (CREA)}

En (31)a los verbos de ambas oraciones están flexionados en presente. Las oraciones (31)b y (31)c muestran que el verbo de la oración principal está flexionado en antepresente pero en (31)b el verbo de la subordinada está en presente y en (31)c está en pretérito. En los tres ejemplos, el evento de la oración principal empieza a partir del evento de la oración subordinada asimismo indican que el evento de la subordinada es durativo. Puesto que el evento de la oración principal es posterior al evento de la subordinada, los tiempos de la esfera del pasado en la subordinada pueden estar en concordancia con los tiempos del presente en la oración principal como se muestra en el ejemplo (31)c. De modo que el copretérito en la subordinada puede concordar con el presente en la subordinada, por ejemplo: Vivo en esta casa desde que tenía 2 años.

Con respecto a los tiempos verbales que pertenecen a la esfera del pasado se encontraron las concordancias que siguen: pretérito, copretérito o ante-copretérito en la oración principal y pretérito en la subordinada; y pretérito o copretérito en la principal y copretérito en la subordinada. Las oraciones siguientes ilustran cada una de las concordancias mencionadas.

a. Me impresionó particularmente desde que vi el primer cuadro. (CREA)

b. Serafín lo acompañaba desde que dejó la escuela. (CREA)

c. No había vuelto a saber de usted desde que nos vimos en Londres ¡hace mil años! (CREA)

d. El trastorno inició desde que el paciente cursaba el décimo grado escolar. (CREA)

e. Ella vivía en la cuadra desde que Jorge recordaba. (CREA)

En (32)a tanto el verbo de la oración principal como el de la subordinada están flexionados en pretérito: impresionó y vi respectivamente; en (32)b el tiempo del verbo principal es copretérito: acompañaba y el de la subordinada es pretérito: dejó. Con respecto a (32)c el verbo de la oración principal está en ante-copretérito: había vuelto y el de la subordinada está en pretérito: vimos. En (32)d el verbo de la oración regente es inició, el 
cual está flexionado en pretérito mientras que el de la subordinada se flexiona en copretérito: cursaba. Y finalmente (32)e muestra que la concordancia de tiempos es copretérito en ambos verbos: vivía y recordaba. Con la conjunción desde que no se encontraron concordancias de tiempo con futuro y pospretérito. Sin embargo, pueden construirse algunas concordancias que indican la posterioridad que marca la conjunción: ?Vendría a ayudarte desde que me llamaras, ?Te buscaré desde que llegue. Muestran ambos ejemplos que por tratarse de tiempos futuros en la oración principal con respecto al tiempo de la oración subordinada, el tiempo de esta última es en modo subjuntivo, ya que como señalamos anteriormente el modo subjuntivo se usa para eventos que no se han sucedido aún.

Ahora bien, en relación con la conjunción luego que, la cual también indica posterioridad, se encontraron las concordancias de tiempos que estudiaremos a continuación. Las concordancias de tiempo que más se encontraron fueron en la esfera del pasado. No obstante, en la esfera del presente, los tiempos verbales pueden ser los siguientes: presente en ambas oraciones principal y subordinada; y presente o futuro en la principal y presente de subjuntivo en la subordinada como se muestra en los ejemplos de (33).
a. Lavo los trastes luego que terminamos de comer.
b. Te cuento luego que regreses del mercado.
c. María vendrá luego que salga de la escuela.

Las oraciones de (33) muestran las concordancias de tiempos mencionados. En (33)a ambos verbos están flexionados en presente; indican, además, que el evento de la oración principal tiene lugar después del evento de la subordinada y por estar en modo indicativo muestran que se trata de eventos que ocurren de manera habitual. En cambio en (33)b el verbo de la oración subordinada está flexionado en presente de subjuntivo y el de la principal en presente de indicativo, al igual que en (33)a el evento de la oración principal es posterior al de la subordinada, pero esta diferencia de tiempos indica que los eventos de (33)b no suceden habitualmente. Ya que si a dicha oración le agregamos un adverbio que indique que el evento de la oración principal es habitual el verbo de la oración subordinada 
debe flexionarse en modo indicativo: Siempre te cuento luego que regresas del mercado. (33)c muestra que cuando el verbo de la oración principal se flexiona en futuro el verbo de la oración subordinada se flexiona en presente del subjuntivo, ya que se trata de eventos futuros aún no experimentados.

Otras concordancias que se encontraron en la esfera del presente son: presente o futuro en la oración principal y pretérito en la oración subordinada adverbial como se muestra en las oraciones de (34).

a. En Coahuila continúa la alerta entre la población, luego que los termómetros marcaron temperaturas por debajo del cero. (CREA)

b. Los tricolores llegarán al encuentro con la obligación de triunfar por amplio margen, luego que los Venados de Yucatán, de la Primera División A, doblegaron por 2-0 a los vicentinos el miércoles ppdo. (CREA)

Puesto que la conjunción luego que indica posterioridad, es decir, el evento de la oración principal ocurre después del evento de la subordinada, es posible que los tiempos de las esferas del presente y del pasado tengan concordancia. Las oraciones muestran que en (34)a el verbo de la oración principal está flexionado en presente y en (34)b está flexionado en futuro, ambos son tiempos que corresponden a la esfera del presente. No obstante, en la oración subordinada de (34)a y (34)b, el tiempo verbal pertenece a la esfera del pasado. En (34)a el verbo es marcaron y en (34)b el verbo es doblegaron.

Ahora bien, con respecto a los tiempos de la esfera del pasado, encontré las concordancias temporales siguientes: pretérito de indicativo en la principal y pretérito o ante-copretérito en la subordinada; o pretérito de indicativo en la principal y pretérito de subjuntivo en la subordinada. Los ejemplos de (35) ilustran las concordancias temporales mencionadas.

a. La jugada se produjo luego que Luis González recuperó un balón en medio campo. (CREA)

b. El caso Nandayapa removió escombros políticos anti-inmigrantes, luego que se les negara visas a los integrantes de su grupo. (CREA) 
c. El diálogo entre el Gobierno Federal y el e-zeta-ele-ene se interrumpió luego que las partes habían firmado los acuerdos de San Andrés. (CREA)

En (35)a tanto el verbo de la oración principal como el de la subordinada está flexionado en pretérito y en (35)b el verbo de la principal está en pretérito de indicativo y el de la subordinada en pretérito de subjuntivo, lo cual no muestra una diferencia semántica entre el sentido de ambas oraciones por la alternancia de modos. El ejemplo de (35)c muestra que en la oración principal el verbo está flexionado en pretérito y el de la subordinada en ante-copretérito, es decir, muestra que el evento de la subordinada ocurrió antes que el evento de la oración principal.

2.1.4.1. Nexos de posterioridad inmediata: tan pronto como, apenas, en cuanto. En este apartado analizaremos las conjunciones que indican posterioridad inmediata. Puesto que se trata de eventos que ocurren uno inmediatamente después del otro, los verbos de la oración principal y subordinada pueden flexionarse en el mismo tiempo verbal, pero también puede haber distintas concordancias temporales. Cabe señalar además que con las conjunciones que analizaremos a continuación se encontraron escasos ejemplos, pero proporcionaremos ejemplos que muestren qué concordancias son posibles con las conjunciones referidas.

Con la conjunción en cuanto, se encontraron muy pocos ejemplos, no obstante, las concordancias de tiempos que pertenecen a la esfera del presente son las siguientes: presente en ambas oraciones, o futuro en la oración principal y presente de subjuntivo en la oración subordinada como se ilustra en (36).

a. Leo el correo electrónico en cuanto llego a la oficina.

b. Rosa tomará un taxi en cuanto salga del trabajo.

Los ejemplos de (36) muestran las concordancias de tiempo de la esfera del presente. En (36)a presente en ambas oraciones y en (36)b futuro en la oración principal y presente del subjuntivo en la subordinada adverbial. Con respecto a los tiempos de la esfera del pasado encontré: pretérito en ambas oraciones; o bien pospretérito en la principal y presente de subjuntivo en la subordinada. Los ejemplos de (37) ilustran las concordancias mencionadas. 
a. En cuanto oí silbar las primeras balas sentí que me había equivocado. (CREA)

b. Ellos no quieren regresar todo ya que en unos meses, en cuanto terminen Titanic, lo tendrían que regresar de nuevo. (CREA)

Se observa que la oración (37)a tiene ambos verbos flexionados en pretérito y en (37)b el verbo de la oración principal está en pospretérito y el de la subordinada en presente del subjuntivo. En ambas oraciones la conjunción en cuanto indica que el evento de la oración principal sucede inmediatamente después del evento de la oración subordinada. (37)b los tiempos verbales también indican posibilidad.

Ahora bien, con respecto a la conjunción tan pronto como, hallamos las siguientes concordancias verbales de los tiempos que pertenecen a la esfera del presente: presente en la oración principal y presente de indicativo o subjuntivo en la subordinada adverbial. Véase los ejemplos de (38).

a. Ambos se sacan tan pronto como los tomates se suavizan. (CREA)

b. Por eso deseamos cooperar tan pronto como sepamos algo más. (CREA)

Los ejemplos muestran los tiempos verbales de la esfera del presente. En (38)a presente en ambas oraciones y en (38)b presente de indicativo en la oración principal y presente de subjuntivo en la subordinada. Si bien no encontré oraciones en futuro en el corpus, este tiempo puede aparecer en la oración principal con subjuntivo en la subordinada: Te llamaré tan pronto como llegue a casa.

Con respecto a los tiempos verbales de la esfera del pasado encontré las concordancias que citamos a continuación: pretérito en ambas oraciones; copretérito en ambas oraciones como se ilustra en (39).

a. Sin duda Rubio inició las gestiones de su publicación tan pronto como llegó a Europa. (CREA)

b. A la vez, tan pronto como un nuevo mecanismo o un nuevo material se desarrollaba para satisfacer dichas necesidades, surgían nuevas empresas y 
ampliaciones que antes parecían imposibles o ni siquiera se sospechaban. (CREA)

Los ejemplos muestran las concordancias verbales de la esfera del pasado. En (39)a ambos verbos están flexionados en pretérito; inició y llegó; y en (39)b ambos verbos están flexionados en copretérito: desarrollaba y surgían. En ambos casos se muestra que el evento de la oración principal ocurre inmediatamente después que el evento de la oración subordinada.

Finalmente, con la conjunción apenas las concordancias de tiempos que se encontraron en la esfera del presente son: presente en ambas oraciones; o futuro en la principal y presente de subjuntivo en la subordinada. Y en la esfera del pasado hallamos: pretérito en ambas oraciones como se muestra en las oraciones de (40).
a. Apenas come le duele el estómago.
b. Buscaré los datos apenas encienda la computadora.
c. Abrió el regalo apenas se lo dimos.

Advertimos anteriormente que con el adverbio apenas en su función de conjunción subordinante se encontraron escasos ejemplos. Vemos en las oraciones de (40) que los tiempos verbales que pueden relacionarse son presente en ambas oraciones como se ilustra en (40)a; futuro en la principal y presente del subjuntivo en la subordinada como se muestra en (40)b; y pretérito en ambas oraciones como se observa en (40)c.Las oraciones cuyo nexo subordinante indican posterioridad requieren que los verbos estén flexionados en la misma esfera temporal.

2.2. Oraciones subordinadas adverbiales de lugar. En al capítulo III se analizaron sintácticamente las oraciones subordinadas adverbiales de lugar, señalamos que el conector que las une es el relativo adverbial donde, el cual puede estar antecedido por los adverbios deícticos: aquí, allí, allá; o bien puede estar incrementado por las preposiciones: $a$, de, desde, en, hacia, hasta, para, por. En esta sección analizaremos las concordancias verbales que las oraciones adverbiales de lugar presentan. Queremos enfatizar que en esta subclase de oraciones propias, el relativo donde permite una concordancia de tiempos más amplia 
que en las oraciones temporales, ya que el significado del adverbio no está relacionado con la temporalidad de las oraciones subordinadas locativas, por lo tanto, el sentido de anterioridad, simultaneidad o posterioridad corresponde exclusivamente a los tiempos verbales de las oraciones principal y subordinada. Las oraciones de (41) muestran que el relativo adverbial donde permite concordancias de tiempos más variada, ya que si el verbo de la oración principal pertenece a la esfera del presente, el verbo de la oración subordinada puede pertenecer a la misma esfera o bien a puede pertenecer a la esfera del pasado.
a. Te veo donde comemos los jueves.
b. Te veo donde comimos ayer.
c. Te veo donde comeremos mañana.
d. Te veo donde comíamos diario.
e. *Te veo donde comeríamos hoy.
f. Te veo donde hemos comido siempre.
g. Te veo donde hubiéramos comido hoy.

Las oraciones muestran que el verbo de la principal corresponde a la esfera del presente, puesto que está flexionado en presente y el de la subordinada puede pertenecer a la misma esfera temporal como se observa en (41)a,(41)c y (41)f que están flexionados en presente, en futuro y en antepresente respectivamente. Asimismo las oraciones citadas muestran que el evento de la oración principal es futuro, aunque esté flexionado en presente. Por tanto, en (41)a la oración principal indica que es posterior a la subordinada, en (41)c el evento de la oración principal es anterior al evento de la oración subordinada y en (41)f el evento de la principal es posterior al evento de la subordinada. En relación con las oraciones restantes, los verbos de las oraciones subordinadas de (41)b,(41)d y (41)g pertenecen a la esfera del pasado, en (41)b el verbo de la subordinada está flexionado en pretérito, en (41)d en copretérito, y en (41)g en ante-pretérito de subjuntivo. Las tres oraciones subordinadas mencionadas (41)b,(41)d y (41)g muestran que son anteriores a la oración principal. Muestra el ejemplo (41)e que el pospretérito es el único tiempo verbal que no concuerda. 
En el apartado que sigue estudiaremos la concordancia verbal de las estructuras sintácticas que se analizarán en el capítulo III, oraciones en las que el relativo donde esté incrementado por una preposición.

2.2.1. Preposición + donde. Puesto que se encontraron muy pocas concordancias en las que el relativo adverbial donde introdujera directamente a las oraciones adverbiales de lugar, en este apartado analizaremos las oraciones introducidas por una preposición seguida del relativo adverbial donde. Explicamos anteriormente que el relativo donde permite una mayor variedad de tiempos verbales, ya sea cuando une directamente a las oraciones subordinadas con la oración principal, como señalamos en el apartado anterior, o cuando está incrementado por una preposición como mostraremos a continuación.

Las oraciones que se analizaron están introducidas por las preposiciones $a$, $d e$, en, hacia, hasta, para y por y la oración subordinada introducida por el relativo donde es el término de las preposiciones. Dentro de la esfera del presente, la concordancia verbal que se encontró en todas las oraciones subordinadas introducidas por una preposición es presente en ambas oraciones, principal y subordinada, como se muestra en lo ejemplos de (42).

a. Por eso su conocimiento penetra adonde el de otros hombres no llega. (CREA)

b. Generalmente, el puente se localiza en medio del navío en donde el capitán o el oficial de guardia llevan su dirección. (CREA)

c. La obra de imprimir a nuestra vida un sello peculiar no parte de donde lógicamente debe partir: del conocimiento del mexicano. (CREA)

d. Las ciudades de México crecen en materia habitacional hacia donde muchas veces líderes corruptos que explotan a la gente los llevan a invadir. (CREA)

e. Las grandes cuestiones económicas van por donde tienen que ir y con optimismo. (CREA)

f. Sara se aproxima hasta donde se encuentra Jorge, vigilante. (CREA)

g. Hay que sufrir y llorar mucho para donde usted va. (CREA) 
Las oraciones de (42) muestran la concordancia de tiempos de la esfera del presente, ya que en todas ellas el verbo de la oración principal y el de la subordinada están flexionados en presente. Lo cual también implica que los eventos ocurren de manera simultánea.

Otras concordancias de tiempo que se encontraron con tiempos de la esfera del presente son las siguientes: el verbo de oración la principal flexionado en antepresente y el de la subordinada en presente con la preposición $a+$ donde como se muestra en (43) a, o bien futuro perifrástico en la oración principal y presente de subjuntivo en la subordinada, como se muestra en (43)b.

a. No puedo negarlo, también me han llevado adonde estoy ahora. (CREA) b. Ahora me vas a tomar de la mano y vas a ir adonde yo te diga, sin llorar y sin hablar. (CREA)

En (43)a se muestra que los eventos de las oraciones principal y subordinada son simultáneos, en cambio en (43)b el evento de la oración principal es posterior al evento de la oración subordinada. Siguiendo con los tiempos de la esfera del presente se encontraron concordancias con verbos flexionados en presente o futuro en la oración principal y presente de subjuntivo en la oración subordinada con la preposición hacia + donde como se ilustra en (44)a y (44)b.
a. Voy hacia donde vaya. (CREA)
b. Una vez allá, destruiremos sus papeles y con documentación inglesa podrá proseguir hacia donde le plazca. (CREA)

En las oraciones de (44)a el modo subjuntivo en la subordinada indica que se trata de un evento que es posterior al evento de la oración principal. Del mismo modo en (44)b el tiempo futuro en la oración principal requiere que la subordinada esté en modo subjuntivo porque se trata de un evento que aún no se ha llevado a cabo. Además el modo indicativo en la oración subordinada genera una oración marcada: Y con documentación inglesa podrá proseguir hacia donde le place. 
Por otro lado, se encontraron oraciones cuyo verbo principal está flexionado en presente, el cual pertenece a la esfera del presente, pero el verbo de la oración subordinada está flexionado en pretérito, es decir, corresponde a la esfera del pasado como lo ilustran las oraciones de (45).

a. Va hacia donde le indicaron.

b. Te conseguimos una buena liquidación y te vas por donde viniste sin problema alguno.

En el corpus que analizado la concordancia de tiempos citada sólo se encontró con las preposiciones hacia + donde y por + donde, como se muestra en los ejemplos de (45). No obstante, dicha concordancia puede hallarse con las preposiciones $a+$ donde y en + donde como se muestra en los siguientes ejemplos: Voy adonde me recomendaron, Estoy en donde quedamos. Las citadas oraciones muestran que el evento de la oración subordinada es anterior al evento de la oración principal. Pero con las preposiciones de + donde y hasta + donde el pretérito en la oración subordinada no es posible, *Viene de donde vivió, * Diario caminan hasta donde estuvo el Walmart. Con las dos preposiciones mencionadas el copretérito es más adecuado, Viene de donde vivía, Diario caminan hasta donde estaba el Walmart.

Ahora bien, con respecto a los tiempos que pertenecen a la esfera del pasado, se encontraron más concordancias temporales que en los tiempos que corresponden a la esfera del presente. Ilustramos en (46) oraciones en las que tanto el verbo de la oración principal como el de la subordinada están en pretérito.

a. Regresé viejo adonde fui joven. (CREA)

b. Así pues, cada quien corrió hacia donde pudo intentando ponerse a salvo. (CREA)

c. La cosa es que allí se rompió la familia y cada uno fue por donde pudo. (CREA)

d. Me aguanté hasta donde pude... y terminé llorando a mares... (CREA) 
Las oraciones citadas en (46) muestran que los verbos de ambas oraciones, principal y subordinada, están flexionados en pretérito. En (46)a los verbos son regresé y fui, en (46)b corrió y pudo, en (46)c fue y pudo y en (46)d aguanté y pude. Únicamente (46)a muestra que el evento de la oración subordinada es anterior al evento de la principal. En los demás ejemplos de (46) los eventos son simultáneos. Otra concordancia verbal que se halló con casi todas las preposiciones + donde es pretérito en el verbo de la oración principal y copretérito en la subordinada tal como se muestra en las oraciones de (47).
a. Se acercó adonde estaba acostado Fernando. (CREA)
b. Y no salió de donde estaba hasta otro día por la mañana, que era sábado. (CREA)
c. El mexicano y el yanqui se dirigieron hacia donde se encontraban las casas caminando por las calles que aún existían. (CREA)
d. El remedio llegó por donde menos lo esperaban. (CREA)
e. Llegaron hasta donde se encontraba el navío. (CREA)

Se muestra en los ejemplos de (47) la concordancia temporal pretérito en la oración principal y copretérito en la subordinada. En (47)a los verbos son acercó y estaba, en (47)b salió y estaba, en (47)c se dirigieron y se encontraban, en (47)d llegó y esperaban y finalmente en (47)e llegaron y se encontraba. Muestran los ejemplos que el evento de la oración principal es perfectivo y el de la subordinada es imperfectivo, lo cual indica que fueron simultáneos en un momento pero el evento de la oración principal concluyó y el de la subordinada continuó. Otra concordancia temporal de la esfera del pasado es pretérito en la oración principal y ante-copretérito en la subordinada como lo ilustran las oraciones de (48) cuyas preposiciones son $a+$ donde, hacia + donde y por + donde.
a. Leonor bajó adonde había dicho. (CREA)
b. Volvió la vista hacia donde había visto el pie de un hombre minutos antes y notó que ahora asomaba parte del muslo y la rodilla. (CREA)
c. Las miró por ambos lados, montó de nuevo y se fue por donde había venido con el mismo trote que lo había traído. (CREA)


Muestran los ejemplos de (48) que el verbo de la oración principal está flexionado en pretérito y el verbo de la subordinada en ante-copretérito, lo cual indica que el evento de la oración subordinada es anterior al de la principal. Dicha concordancia temporal se encontró con las preposiciones citadas, a, hacia y por, no obstante, es posible que pueda encontrarse con las demás preposiciones, en, hasta y de + donde, como se muestra en las siguientes oraciones: Detuvo la camioneta en donde habiamos encontrado a Juan un día antes, Los competidores siguieron hasta donde habian puesto los señalamientos de girar a la derecha, Salimos de donde habíamos pasado la noche ${ }^{40}$. Asimismo la concordancia de tiempos pretérito en la principal y pospretérito en la subordinada se encontró con la preposición hacia + donde como se muestra en (49)a. Y en (49)b se muestra que con la preposición por + donde el verbo de la oración principal está pretérito y el de la subordinada en presente.

a. Luego, cuando los participantes entregaron el cuestionario, recibieron un folleto de información sobre violencia contra la mujer, y una lista con direcciones de los servicios disponibles en el estado de Morelos hacia donde podían canalizar a las mujeres maltratadas que atendieran posteriormente en su consulta. (CREA)

b. Después del ataque salieron huyendo por la zona hotelera, por donde está el campo de golf, y tomaron la carretera federal rumbo a Pochutla. (CREA)

Otra concordancia de tiempos que se encontró con todas la preposiciones es copretérito en ambas oraciones, principal y subordinada, como se ilustra en las oraciones de (50).
a. Unas locatarias se acercaban adonde estábamos Pablo y yo y se quejaban de que el desgraciado inspector. (CREA)
b. El me dejaba jugar en donde yo me sentía bien. (CREA)

\footnotetext{
${ }^{40} \mathrm{Si}$ bien la concordancia de tiempos pretérito en la oración principal y ante-copretérito en la subordinada es posible con las preposiciones en, hasta y de + donde, ya que las oraciones con gramaticales, el copretérito o pretérito es más frecuente en la oración subordinada como se muestra en los mismos ejemplos que citamos: Detuvo la camioneta en donde encontramos a Juan un día antes, Los competidores siguieron hasta donde estaban los señalamientos de girar a la derecha, Salimos de donde pasamos la noche.
} 
c. Me agarraba de donde podía, esperando que no respingara al siguiente paso. (CREA)

d. Luchaban cuerpo a cuerpo a cuchilladas, corrían hacia donde podían, algunos caían al agua, chapaleaban un momento y se iban al fondo por el peso de lo que llevaban encima. (CREA)

e. Por supuesto ya nadie pasaba por donde existía, prefería dar la vuelta por tierra firme aunque se caminara más. (CREA)

Los ejemplos muestran que los eventos de las oraciones, principal y subordinada, son simultáneos, puesto que ambos están en copretérito. Finalmente, otras concordancias de tiempos que se encontraron únicamente con algunas de las preposiciones más el relativo donde son las siguientes: copretérito en la oración principal y pospretérito en la subordinada con la preposición hacia como se ilustra en (51)a. En (51)b se muestra pospretérito en la oración principal y ante-copretérito en la subordinada con la preposición por. Con la preposición hasta en (51)c, el verbo de la oración principal puede estar flexionado en pospretérito o copretérito y el verbo de la subordinada en pretérito de subjuntivo. Y finalmente con la preposición $a$ la oración principal está en ante-copretérito y la subordinada de copretérito en (51)d.

(51) a. Miraba hacia arriba, hacia donde debería estar la luz. (CREA)

b. Al ver muerto al suboficial quedarían desorientados y sin saber qué hacer, regresarían por donde habían venido para reunirse con el grueso de la tropa. (CREA)

c. Mis hermanitas -no les importará que hable así de ellas- eran unas verdaderas guerreras y pelearían hasta donde pudieran... iy vaya si han podido! (CREA)

d. Iban hasta donde pudieran o les alcanzara la fuerza. (CREA)

e. Habíamos llegado adonde queríamos, aun cuando no pensé que Frank fuese a plantear la cuestión tan abruptamente. (CREA) 
3. Conclusiones. El análisis sintáctico que hicimos en este capítulo nos llevó a las siguientes conclusiones. La consecutio temporum de las oraciones subordinadas adverbiales ocurre de manera diferente a como ocurre en las oraciones subordinadas sustantivas. En el caso de las subordinadas adverbiales temporales los nexos subordinantes son los que determinan qué tiempos verbales pueden aceptar, señalamos que con algunos de ellos los tiempos de la esfera del presente no pueden combinarse con los tiempos de la esfera del pasado ya que se generan oraciones agramaticales, pero en otros casos es posible hacer dichas combinaciones. La Tabla 4 muestra la correlación de tiempos verbales que se encontraron en las oraciones temporales. Se mostró, además, que en las oraciones adverbiales de lugar el relativo adverbial donde no influye en la correlación de tiempos verbales, y permite que los tiempos de la esfera del presente y del pasado puedan combinarse entre sí, podría decirse que se trata de un nexo no unidimensional, pero a pesar de esto, mostramos que no todos los tiempos pueden combinarse entre sí.

\begin{tabular}{|c|c|c|}
\hline Nexo subordinante & Tiempos de la esfera del presente & Tiempos de la esfera del pasado \\
\hline Cuando & $\begin{array}{ll} & \text { Presente + presente } \\
\text { - } & \text { Futuro + presente del subjuntivo }\end{array}$ & $\begin{array}{ll}\text { - } & \text { Pretérito + pretérito } \\
\text { - } & \text { Pretérito + copretérito } \\
\text { - } & \text { Pretérito + ante-copretérito } \\
\text { - } & \text { Copretérito + pretérito } \\
\text { - } & \text { Copretérito + copretérito } \\
\text { - } & \text { Ante-copretérito + pretérito }\end{array}$ \\
\hline Antes de que & $\begin{array}{ll}- & \begin{array}{l}\text { Presente o futuro }+ \text { presente de } \\
\text { subjuntivo }\end{array}\end{array}$ & $\begin{array}{l}\text { - } \quad \text { Pretérito o pospretérito o copretérito } \\
+ \text { presente de subjuntivo }\end{array}$ \\
\hline Hasta que & $\begin{array}{ll}- & \begin{array}{l}\text { Presente }+ \text { presente o presente de } \\
\text { subjuntivo }\end{array} \\
\text { - } & \begin{array}{l}\text { Presente o futuro }+ \text { presente de } \\
\text { subjuntivo }\end{array}\end{array}$ & - $\quad$ Pretérito o copretérito + pretérito \\
\hline Mientras & - $\quad$ Presente + presente & $\begin{array}{ll}\text { - } & \text { Pretérito + pretérito o copretérito } \\
\text { - } & \text { Copretérito + copretérito }\end{array}$ \\
\hline Mientras que & $\begin{array}{ll}\text { - } & \text { Presente } o \text { antepresente }+ \text { presente } \\
& \text { Futuro +futuro }\end{array}$ & - Pretérito o copretérito + pretérito \\
\hline Entretanto & - $\quad$ Presente + presente & $\bullet$ \\
\hline Desde que & $\begin{array}{ll}\text { - } & \text { Presente } o \text { antepresente }+ \text { presente } \\
\text { - } & \text { Antepresente }+ \text { pretérito }\end{array}$ & $\begin{array}{ll}\text { - } & \begin{array}{l}\text { Pretérito, copretérito o ante- } \\
\text { copretérito + pretérito }\end{array} \\
\text { - } & \text { Pretérito o copretérito + copretérito }\end{array}$ \\
\hline Luego que & $\begin{array}{ll}\text { - } & \text { Presente }+ \text { presente } \\
\text { - } & \text { Presente o futuro }+ \text { presente de } \\
& \text { subjuntivo } \\
\text { - } & \text { Presente o futuro }+ \text { pretérito }\end{array}$ & $\begin{array}{ll}\text { - } & \text { Pretérito }+ \text { pretérito o ante- } \\
\text { copretérito } & \\
\text { - } & \begin{array}{l}\text { Pretérito }+ \text { pretérito de subjuntivo en } \\
\text { la subordinada }\end{array}\end{array}$ \\
\hline En cuanto & $\begin{array}{ll}\text { - } & \text { Presente + presente } \\
\text { - } & \text { Futuro }+ \text { presente de subjuntivo }\end{array}$ & $\begin{array}{ll}\text { - } & \text { Pretérito + pretérito } \\
\text { - } & \text { Pospretérito + presente de subjuntivo }\end{array}$ \\
\hline Tan pronto como & $\begin{array}{ll}\text { - } & \begin{array}{l}\text { Presente }+ \text { presente o presente de } \\
\text { subjuntivo }\end{array}\end{array}$ & $\begin{array}{ll}\text { - } & \text { Pretérito + pretérito } \\
\text { - } & \text { Copretérito + copretérito }\end{array}$ \\
\hline
\end{tabular}

\section{Tabla 4}




\section{CONCLUSIONES}

El análisis de las oraciones subordinadas adverbiales propias de tiempo y lugar nos lleva a las siguientes conclusiones.

Al principio de este escrito mencionamos que tradicionalmente las oraciones subordinadas eran estudiadas de acuerdo con las funciones que cumplían dentro de la oración en la que se encontraban. Señalamos que el enfoque funcionalista ha sido cuestionado porque no todas las oraciones subordinadas desempeñan las tareas propias de los sintagmas nominales, adjetivos o adverbiales que llevan por nombre. No obstante, las diferentes gramáticas que citamos concuerdan en que las oraciones subordinadas deben estudiarse a partir de los oficios que cumplen dentro de la oración en la que se encuentran. Mencionamos que dicho enfoque ha sido, hasta ahora, el más adecuado, ya que no se ha propuesto una manera distinta de analizarlas, únicamente se ha reagrupado a las oraciones subordinadas adverbiales propias, tiempo, lugar y modo, como parte de las oraciones de relativo, considerándolas relativas libres. Dicho de otro modo, se ha propuesto que su estructura sintáctica es semejante a la de las relativas, pero funcionalmente siguen siendo adverbiales, lo cual no implica que el enfoque funcionalista se haya modificado. Simplemente, se añadió otro tipo de oraciones a un grupo ya existente, pero el problema de su estructura sintáctica continua.

Asimismo, explicamos que no concordamos en que las oraciones subordinadas adverbiales propias sean consideradas relativas libres por las razones antes mencionadas: (1) porque no tienen la misma estructura sintáctica y (2) porque difieren en el aspecto semántico, es decir, las tareas que desempeñan son distintas, ya que no modifican a las mismas categorías gramaticales, lo cual es una razón fundamental que apoya el hecho de que se les debe considerar distintas de las oraciones relativas y por tanto, deben clasificarse dentro de las subordinadas adverbiales como se ha hecho tradicionalmente.

El análisis sintáctico de las oraciones subordinadas adverbiales de tiempo que hicimos en el segundo capítulo mostró que el orden sintáctico de las oraciones subordinadas temporales es variable y muestra que su comportamiento es semejante al de los complementos 
circunstanciales de tiempo ya que tienen movilidad dentro de la oración a la cual se subordinan. El análisis sintáctico muestra que pueden seguir tres órdenes diferentes: la oración subordinada puede aparecer antes de la principal, después de la principal y con algunos nexos o conjunciones pueden romper la secuencia de la oración regente. Asimismo, los subordinantes o nexos se ubican al principio de la oración que subordinan lo cual es propio de las lenguas cuyo orden es SVO. Mostramos además que los nexos subordinantes, se componen de diferentes estructuras. El más común es el pronombre relativo adverbial cuando, pero los nexos o conjunciones que introducen a las subordinadas adverbiales de tiempo también pueden formarse de preposiciones más la conjunción que, por ejemplo, hasta que o desde que. Esta clase de oraciones muestra que la presencia de un antecedente es menos probable que en el caso de las oraciones subordinadas de lugar, dicho elemento sólo puede aparecer con el relativo adverbial cuando, ya que con los demás nexos que estudiamos su presencia no es posible. En algunos casos la frase nominal, o prepositiva que precede a la oración encabezada por el relativo cuando puede considerase como otro complemento circunstancial, lo cual es más probable en las oraciones subordinadas de tiempo que en las de lugar.

El análisis sintáctico de las oraciones subordinadas de lugar que hicimos en el tercer capítulo muestra que su estructura sintáctica es también variable, ya que el relativo adverbial donde puede estar incrementado por una preposición o locución prepositiva o bien antecedido por una frase adverbial. Respecto del orden sintáctico, a diferencia de las oraciones subordinadas de tiempo, las subordinadas de lugar no tienen tanta movilidad dentro de la oración en la que se encuentran. Esta clase de oraciones presentan un orden más estable o menos variable porque generalmente se encuentran pospuestas a la oración principal. El corpus analizado muestra que la mayoría de las oraciones tienen el orden, oración principal + oración subordinada, y se encontraron muy pocos ejemplos en los que la oración subordinada de lugar se encuentra antepuesta a la oración principal o que interrumpe la secuencia de la misma. Cuando el relativo adverbial donde aparece solo o bien, antecedido por un adverbio como allí, aquí o allá su movilidad dentro de la oración es más probable, pero cuando está incrementado por una preposición su único orden es pospuesto a la oración principal. 
Si bien el único nexo que las enlaza es el relativo adverbial donde, el corpus que estudiamos muestra que hay muy pocas oraciones que están adyacentes al verbo, es decir, en las que el relativo adverbial donde esté solo, sin una preposición o un adverbio de lugar que lo anteceda, y que esté modificando al verbo directamente. Los datos indican que predominan las oraciones en las que el relativo adverbial donde está incrementado por una preposición o un adverbio de lugar, por ejemplo, allí donde, allá donde, en donde, para donde o hasta donde. Esta clase de construcciones muestra que las preposiciones dan matices distintos a la oración encabezada por el relativo donde, pero reconocemos que su estructura sintáctica no es idéntica a la de las oraciones que se construyen sólo con el relativo adverbial donde. De manera que las preposiciones o los adverbios que preceden al relativo donde enfatizan o especifican el lugar al que se refiere el relativo, por ejemplo en oraciones como, Juan vive donde venden flores frente a Juan vive por donde venden flores o Juan trabaja donde venden aceites frente a Juan trabaja por donde venden aceites. La primera oración indica que Juan vive o trabaja en el lugar mencionado, pero la segunda oración indica que Juan vive o trabaja en los alrededores del lugar.

Esto ejemplos muestran que las preposiciones modifican el sentido de las oraciones locativas y que, aunque tienen una estructura sintáctica diferente, las funciones que cumplen son las mismas, es decir, ambas modifican al verbo que las rige y por tanto pueden considerarse como complementos circunstanciales de lugar, ya que la oración encabezada por donde puede sustituirse por un adverbio pero no por un adjetivo ni por un sustantivo. Por otro lado, mencionamos que en algunas ocasiones son los verbos los que requieren de una preposición específicamente, como es el caso de los verbos de movimiento, pero la oración que es el término de la preposición tiene una naturaleza adverbial más que de adjetivo. Por tales motivos esta clase de oraciones ha sido clasificada como relativas libres cuyo antecedente es callado (Brucart 1999; Pavón 2012; RAE 2007 y 2010) dadas las características que poseen. Pero en este trabajo las hemos agrupado dentro de las adverbiales porque semánticamente se comportan como un adverbio. Asimismo señalamos la posibilidad de un cambio en la lengua, ya que las oraciones en las que el relativo adverbial donde se encuentra adyacente al verbo fueron muy escasas. Este hecho no sugiere 
que los hablantes prefieren la estructura de las oraciones sustantivas o bien en la que el relativo adverbial donde esté incrementado por una preposición.

Con respecto a las frases prepositivas que anteceden a las oraciones subordinadas de lugar, señalamos que estas podrían analizarse como otro complemento circunstancial de lugar. En algunos ejemplos, la omisión de la frase prepositiva mostraba que la frase prepositiva y la oración encabezada por el relativo donde no son equivalentes ya que cada una aporta información distinta. Mencionamos que este tipo de construcciones también pueden analizarse como aposiciones, si bien no profundizamos sobre este tema, creemos que es otro posible análisis que puede explicar el comportamiento de este tipo de construcciones.

Ahora bien, el análisis de los tiempos verbales o la consecutio temporum, que examinamos en el capítulo cuarto, mostró que los tiempos verbales que pueden combinarse son diferentes en las dos clases de oraciones. En las subordinadas adverbiales temporales los nexos subordinantes son los que determinan qué tiempos verbales pueden aceptar, por lo que los tiempos de la esfera del presente no pueden combinarse con los tiempos de la esfera del pasado con algunos nexos, ya que sus rasgos semánticos impiden que el evento de la subordinada sea anterior o posterior o simultaneo al evento de la oración principal. En cambio, en las oraciones adverbiales de lugar el relativo donde no influye en la correlación de tiempos verbales, y permite que los tiempos de la esfera del presente y del pasado puedan combinarse entre sí, ya que el relativo adverbial puede considerarse no unidimensional.

Finalmente, el estudio de las oraciones subordinadas adverbiales propias de tiempo y lugar muestra que su estructura sintáctica es polémica, ya que no es uniforme, no obstante, el análisis mostró que el orden sintáctico no marcado de las oraciones subordinadas adverbiales de tiempo y lugar es oración principal + oración subordinada y el orden marcado es el que indica lo contrario, oración subordinada + oración principal. Ambas clases de oraciones muestran que las funciones que cumplen dentro de la oración en que se encuentran siguen siendo las de un adverbio temporal o de lugar. 


\section{Bibliografía}

\section{a) Corpus}

REAL ACADEMIA ESPAÑOLA: Banco de datos (CREA) [en línea]. Corpus de referencia del español actual. s.f. $<<$ http://www.rae.es $>>$ (Febrero-mayo de 2013).

\section{b) Referencias bibliográficas}

Alarcos Llorach, Emilio. Gramática de la lengua española. Madrid: Espasa Calpe, 1999.

Alcina Franch, Juan y José Manuel Blecua. Gramática española. Barcelona: Ariel, 1980.

Bello, Andrés (c 1847). Gramática de la lengua castellana. Madrid: EDAE, 1984.

Bosque, Ignacio y Javier Gutiérrez- Rexach. Fundamentos de la sintaxis formal. Madrid: Ediciones Akal, S.A., 2009.

Brucart, José Ma. «Las estructuras del sintagma nominal: las oraciones de relativo.» Demonte, Ignacio Bosque y Violeta. Gramática descriptiva del español. Vol. Volumen I. Madrid: Espasa-Calpe, 199.9.

Carrasco Gutiérrez, Ángeles. «El tiempo verbal y la sintaxis oracional. La consecutio temporum» Bosque Ignacio y Violeta Demonte, eds. Gramática dscriptiva de la lengua española. Vol. I. Madrid: Espasa-Calpe, 1999.

—. La concordancia de tiempos. Madrid: Arcos Libros, S.L., 2000.

Conti Jiménez, Carmen. «Subordinación adverbial periférica y subordinación dependiente: clasificación estructural de la subordinación adverbial en español» Ricardo Marial, Lilian Guerrero, Carlos González. El funcionalismo de la teoría lingüística: la Gramática del Papel y la Referencia. Madrid: Akal, 2012.

Di Tulio, Ángela. Manual de gramática del español. Buenos Aires: La Isla de la Luna, 2005.

Diessel, Holger. «The Ordering Distribution of Main and Adverbial Clauses. A Typological Study.» Language 77.3 (2001): 433-455.

Dryer, Matthew. «Word Order.» Shopen, Timothy. Language Typology and Syntactic Description. Vol. I. New York: Cambridge University Press, 2007.

Farrell, Patrick. Grammatical Relations. Oxford: Oxford University Press, 2005. 
Gili Gaya, Samuel. Curso superior de sintaxis española. Barcelona: Bibliograf, 1961.

Herrera Lima, María Eugenia. Los nexos subordinantes adverbiales en el habla popular de la Ciudad de México . México: UNAM, 1988.

Herrero Ruiz Loizaga, F. Javier. Sintaxis histórica de la oración compuesta. Madrid: Gredos, 2005.

Lope Blanch, Juan M. (dir.). Atlas lingüistico de México. México: COLMEX, 1990.

Lorenzo, Guillermo, Víctor Manuel Longa. Introducción a la sintaxis generativa. La teoría de Principios y Parámetros en evolución. Madrid: Alianza, 1996.

Martínez, José A. La oración compuesta y compleja. Madrid: Arcos/Libros, S.L., 1994.

Morimoto, Yuko. Los verbos de movimiento. Madrid: Visor Libros, 2001.

Munguía, Irma. Gramática de la lengua española. Reglas y ejercicios. México: Larousse, 2002.

Osuna García, Francisco. Las construcciones de relativo. Córdoba: Servicio de Publicaciones Universidad de Córdoba, 2005.

Pavón Lucero, Ma. Victoria. Sintaxis de las partículas. Madrid: Visor Libros, 2003.

—. «Clases de partículas: preposición, conjunción y adverbio» (coords), Ignacio Bosque y Violeta Demonte. Gramática descriptiva de la lengua española. Vol. I. Madrid: Espasa Calpe, 1999.

—. Estructuras sintácticas en la suordinación adverbial. Madrid: Arcos Libros, S.L., 2012.

Pérez Saldanya, Manuel. «El modo en las subordinadas relativas y adverbiales.»(eds.), Ignacio Bosque y Violeta Demote. Gramática descriptiva de la lengua española. Vol. II. Madrid: Espasa Calpe, 1999.

Porto Dapena, José Álvaro. Oraciones de relativo. Madrid: Arcos/Libros, S.L., 1997.

Real Academia Española. Diccionario Panhípanico de dudas en línea. http://www.rae.es/recursos/diccionarios/dpd, s.f.

—. Esbozo de una nueva gramática de la lengua española. Madrid: Espasa-Calpe, 1973.

—. Nueva gramática de la lengua española. Madrid: Espasa-Calpe, 2007.

- Nueva gramática de la lengua española. Manual. México: Planeta Mexicana, S.A. de C.V., 2010. 
Roca Pons, José. Introducción a la gramática. Barcelona: Teide, 1970.

Rodríguez Ramalle, Ma. Teresa. Manual de sintaxis. Madrid: Castalia, 2005.

Seco, Manuel. Gramática esencial del español. Introducción al estudio de la lengua. Madrid: Aguilar, 1973.

Seco, Rafael. Manual de la gramática española. Madrid: Aguilar, 1982.

Thompson, Sandra, Robert E. Longacre y Shin Ja J. Hwang. "Adverbial Clauses.» Timothy, Shopen. Language Typology and Syntactic Description. Vol. II. Cambridge: Cambridge, 2007.

Traducción del Nuevo Mundo de las Santas Escrituras. Nueva York: Watch Tower Bible and Tract Society of Pensylvania, 1987.

Veiga, Alexandre y Manuel Mosteiro Louzao. El modo verbal en las cláusulas condicionales, causales, finales y adverbiales de lugar, tiempo y modo. Salamanca: Ediciones Universidad de Salamanca, 2006.

Wordreference.com, /Online Language Dictionaries. Diccionario de la lengua española. s.f. $<$ http://www.wordreference.com/definicion/>. 


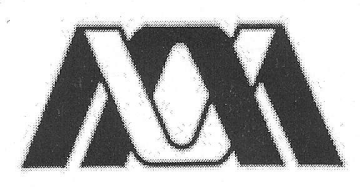

Casa abierta al tiempo

\author{
UNIVERSIDAD AUTÓNOMA METROPOLITANA \\ UNIDAD IZTAPALAPA
}

\title{
Las oraciones subordinadas adverbiales propias de tiempo y lugar en el español de México
}

\author{
TESIS \\ QUE PRESENTA \\ LAURA JIMÉNEZ NORBERTO \\ PARA OBTENER EL GRADO DE \\ DOCTORA EN HUMANIDADES \\ (LÍNEA DE LINGÜÍSTICA)

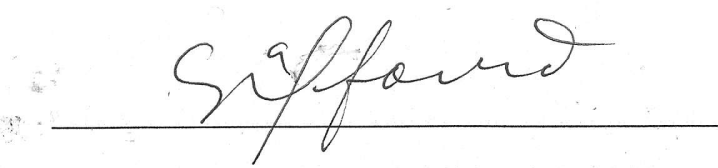

ASESORA: DRA. MILAGROS ALFONSO VEGA

México D.F., septiembre de 2014 


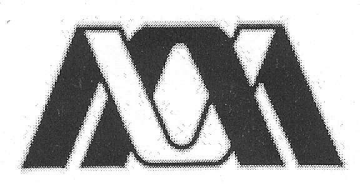

Casa abierta al tiempo

\title{
UNIVERSIDAD AUTÓNOMA METROPOLITANA UNIDAD IZTAPALAPA
}

\section{Las oraciones subordinadas adverbiales propias de tiempo y lugar en el español de México}

\author{
TESIS
}

QUE PRESENTA

LAURA JIMÉNEZ NORBERTO

PARA OBTENER EL GRADO DE

DOCTORA EN HUMANIDADES

(LÍNEA DE LINGÜÍSTICA)

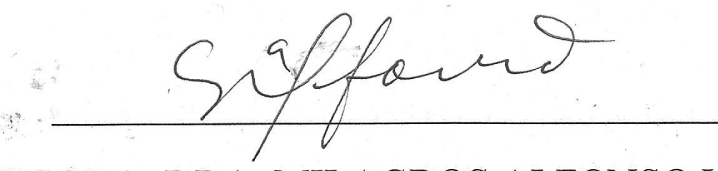

ASESORA: DRA. MILAGROS ALFONSO VEGA

México D.F., septiembre de 2014 